\title{
Regions in Industrial Transition
}

POLICIES FOR PEOPLE AND PLACES

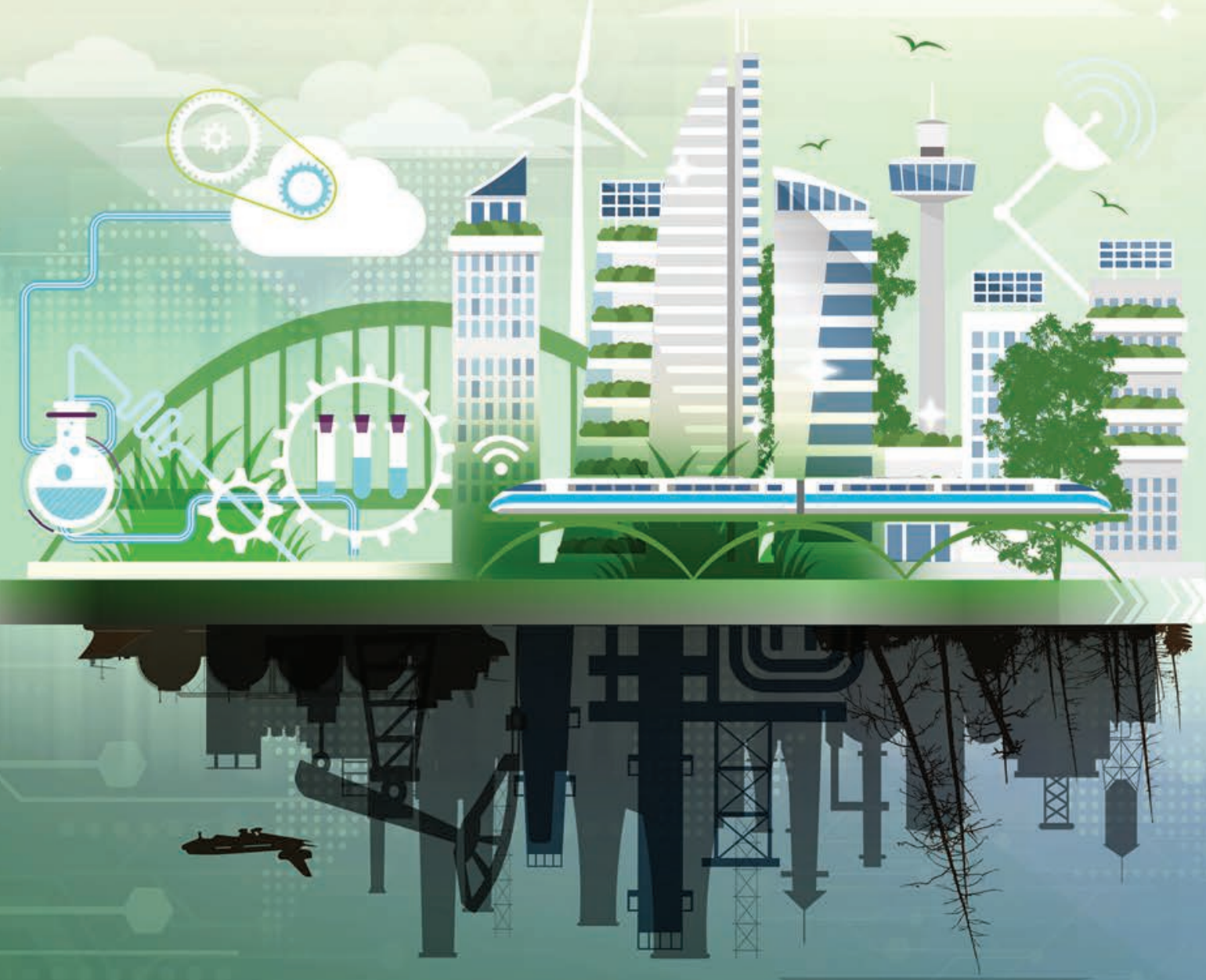





\section{Regions in Industrial Transition}

POLICIES FOR PEOPLE AND PLACES 
This document, as well as any data and any map included herein, are without prejudice to the status of or sovereignty over any territory, to the delimitation of international frontiers and boundaries and to the name of any territory, city or area.

Please cite this publication as:

OECD (2019), Regions in Industrial Transition: Policies for People and Places, OECD Publishing, Paris, https://doi.org/10.1787/c76ec2a1-en.

ISBN 978-92-64-80468-5 (print)

ISBN 978-92-64-84593-0 (pdf)

The statistical data for Israel are supplied by and under the responsibility of the relevant Israeli authorities. The use of such data by the OECD is without prejudice to the status of the Golan Heights, East Jerusalem and Israeli settlements in the West Bank under the terms of international law.

Photo credits: Cover @ Gabriella Agner.

Corrigenda to OECD publications may be found on line at: www.oecd.org/about/publishing/corrigenda.htm.

(c) OECD 2019

You can copy, download or print OECD content for your own use, and you can include excerpts from OECD publications, databases and multimedia products in your own documents, presentations, blogs, websites and teaching materials, provided that suitable acknowledgement of OECD as source and copyright owner is given. All requests for public or commercial use and translation rights should be submitted to rights@oecd.org. Requests for permission to photocopy portions of this material for public or commercial use shall be addressed directly to the Copyright Clearance Center (CCC) at info@copyright.com or the Centre français d'exploitation du droit de copie (CFC) at contact@cfcopies.com. 


\section{Foreword}

This report offers guidance on how to manage industrial transition and is directed towards all policymakers seeking to improve the "what" and "how" of policies that promote industrial change. Building on frontier OECD work and regional experiences, it identifies how regions in industrial transition can become more competitive and more resilient in the context of major shifts brought about by globalisation, decarbonisation and ongoing technological change.

Industrial transition is a transformative, yet complex process. The success of industrial transition depends inherently on the ability of regions to harness the opportunities arising from industrial modernisation while at the same time limiting the costs for affected communities and workers. Regions in industrial transition typically face challenges in modernising their industrial base, upgrading the skills of the workforce, compensating for job losses in key sectors and raising low productivity that limits income growth. Overall, regions will benefit from technological progress and related developments, yet some places and certain population groups risk being left behind.

Addressing the challenges associated with long-term transformations requires active transition management on the part of policymakers and key stakeholders in regions in industrial transition. A strong place-based dimension and a tailored approach to local conditions will be essential to raise productivity and well-being in regions. Promoting development models for successful industrial transition will require building on each region's past legacy and using policy experimentation to identify the tools that best fit the local context and assets.

The report takes stock of discussions emanating from a series of peer-learning workshops jointly organised in 2018 by the European Commission (EC) and the OECD as part of the EC Pilot Action on Regions in Industrial Transition*. The results of the pilot action will feed into the implementation of smart specialisation in the next generation of European Union Cohesion Policy programmes in the period 2012-2027. The report outlines the specific challenges confronting regions in industrial transition and offers guidance on how innovation-led regional development policies can facilitate a forward-looking approach to industrial transformation through policy design, implementation and monitoring. The report discusses targeted and place-based policy strategies and approaches to preparing for the jobs of the future, broadening innovation diffusion, stimulating innovative entrepreneurship, supporting the transition to a climate-neutral economy, and ensuring an inclusive and just transition in regions in industrial transition. The report also identifies a range of crosscutting lessons and key considerations that make industrial transition successful. The report underscores that there may often be a need for better rather than more policies.

This publication contributes to the broader work programme of the OECD Regional Development Policy Committee (RDPC). The initial findings of the peer-learning exercise were discussed at the 40th session of the RDPC on 8 November 2018. The report was approved by the Regional Development Policy Committee through written procedure on 11 October 2019 (CFE/RDPC(2019)11).

\footnotetext{
*"Regions in Industrial Transition: No Region Left Behind", European Commission (2019)

https://ec.europa.eu/regional_policy/sources/docgener/brochure/Industrial_transition_no_region_left_behind_en.pdf
} 


\section{Acknowledgements}

This report was produced by the OECD Centre for Entrepreneurship, SMEs, Regions and Cities (CFE) led by Lamia Kamal-Chaoui, Director. It is part of the Programme of Work of the OECD's Regional Development Policy Committee (RDPC).

The report is the outcome of ten one-and-a-half-day peer-learning workshops organised in 2018 by the European Commission and the OECD in the framework of the project "Pilot Action on Regions in Industrial Transition: The Peer-learning Exercise". The financial contributions and support from the DirectorateGeneral for Regional and Urban Policy (DG REGIO) are gratefully acknowledged.

The OECD Secretariat would particularly like to thank the participating regions of the peer-learning workshops, Cantabria (SP), Centre-Val de Loire (FR), East and North Finland (FI), Grand-Est (FR), Greater Manchester (UK), Hauts-de-France (FR), North Middle Sweden (SE), Piemonte (IT), Saxony (DE), Wallonia (BE), and two countries, Lithuania and Slovenia. Many of the examples and insights in this report come from the discussions, findings and conclusions derived from the peer-learning workshops.

Several experts and regional and country representatives contributed their perspectives to inform this report. The team would like to thank the following external experts for their contributions to the workshops: Ryan Glenn, Director of State-wide Initiatives, Ben Franklin Technology Partners, Pennsylvania, U.S; Johanna Lundström, Chief Analyst, Regional Development, Strategy and Analysis, Region Syddanmark, Denmark; Cristina Oyón, Head of Strategic Initiatives, GRUPO SPRI TALDEA, Bilbao, Spain; Professor William Swan, Associate Dean Enterprise, School of the Built Environment, Salford University; and Michael Theben, Director General for Climate Protection, Ministry for Economic Affairs, Innovation, Digitalization and Energy, North Rhine Westphalia, Germany. Within the OECD particular thanks goes to Jonathan Barr (CFE), David Bartolini (CFE), Enrico Botta (ENV), Mario Cervantes (STI), Enrique Garcilazo (CFE), Sylvain Giguere (CFE), Sandrine Kergroach (CFE), Lukas Kleine-Rueschkamp (CFE), Alexander Lembcke (CFE), Virginie Marchal (ENV), Alistair Nolan (STI), Jonathan Potter (CFE), Andres Sanabria (CFE), and Paolo Veneri (CFE). Inputs and comments from delegates of the Regional Development Policy Committee are also gratefully acknowledged.

The peer-learning workshops were co-ordinated in CFE by Maria Varinia Michalun and Debra Mountford and the final report was co-ordinated and drafted by Sandra Hannig, all under the supervision of Rüdiger Ahrend, Head of the Economic Analysis, Statistics and Multi-level Governance Section in CFE. Each chapter builds on in-house background papers as well as the workshop discussions. Maria Varinia Michalun provided input and edited the report. Eric Gonnard provided statistical input. The report benefited from valuable comments by Rüdiger Ahrend, Maria Varinia Michalun and Debra Mountford at the OECD, and Peter Berkowitz, Richard Deiss, Sander Haepperts, Laurent de Mercey, Denisa Perrin and Marek Przeor at the European Commission. The report was copy-edited by Eleonore Morena and prepared for publication by Francois Iglesias and Pilar Philip. 


\section{Table of contents}

Foreword

$\begin{array}{ll}\text { Acknowledgements } & 4\end{array}$

$\begin{array}{ll}\text { Executive summary } & 9\end{array}$

1 Boosting innovation-led growth in regions in industrial transition 13

Introduction 14

Setting the scene: Current and future challenges for regions in industrial transition $\quad 16$

Strategies for managing industrial transition 23

What makes industrial transition successful? Crosscutting lessons and key considerations 26

References $\quad 31$

Annex 1.A. Toolkit to assess policy responses to industrial transition 32

2 Preparing for the jobs of the future $\quad 35$

Changing skills and jobs profiles affect regions in industrial transition 37

What challenges and opportunities do regions in industrial transition face in preparing for the future of work? $\quad 40$

What can policy do (better) to support a successful transition into the future of work? 45

Key considerations and conclusions $\quad 55$

$\begin{array}{ll}\text { References } & 57\end{array}$

Annex 2.A. Overview of policy issues and responses in preparing for the future of work 59

3 Broadening and diffusing innovation $\quad 61$

What challenges and opportunities do regions in industrial transition face in broadening and diffusing innovation? $\quad 66$

How can policy (better) support broadening and diffusing of innovation?

Key considerations and conclusions $\quad 82$

References $\quad 83$

Annex 3.A. Overview of policy issues and responses in broadening and diffusing innovation $\quad 86$

4 Promoting entrepreneurship and private sector engagement 87

Innovative entrepreneurship can help renew old industrial structures 89

What challenges and opportunities do regions in industrial transition face in promoting entrepreneurship and private sector engagement? 91

How can policy (better) support entrepreneurship and private sector engagement? 93

$\begin{array}{ll}\text { Key considerations and conclusions } & 104\end{array}$

$\begin{array}{lr}\text { References } & 106\end{array}$ 
Annex 4.A. Overview of policy issues and responses in supporting entrepreneurship and private sector development

\section{Transition towards a climate-neutral economy}

The climate-neutral transition can foster sustainable investment, growth and jobs

What challenges and opportunities do regions in industrial transition face in achieving a climate-

neutral economy?

How can policy (better) support the transition to a climate-neutral economy? 120

$\begin{array}{lr}\text { Key considerations and conclusions } & 129\end{array}$

References $\quad 130$

$\begin{array}{ll}\text { Note } & 131\end{array}$

Annex 5.A. Overview of policy issues and responses in the transition to a climate-neutral economy

\section{Promoting inclusive growth}

Adopting an integrated territorial approach helps ensure an inclusive transition

What challenges and opportunities do regions in industrial transition face in promoting inclusive growth?

How can policy (better) support inclusive growth?

$\begin{array}{ll}\text { Key considerations and conclusions } & 149\end{array}$

$\begin{array}{ll}\text { References } & 150\end{array}$

Annex 6.A. Overview of policy issues and responses in promoting inclusive growth 152

\section{Annex A. Pilot Action on Regions in Industrial Transition: The peer-learning exercise 153}

\section{Tables}

Table 1.1. Types of new regional path development

Table 2.1. Supplying the right skills for new and emerging activities: Policy issues, instruments and rationales

Table 2.2. Protecting vulnerable workers in transition: Policy issues, instruments and rationales

Table 2.3. Providing investment for new sources of growth: Policy issues, instruments and rationales

Table 2.4. The benefits of better using skills

Table 2.5. Creating adequate co-ordination and financing mechanisms: Policy issues, instruments and rationales

Table 2.6. Financial incentives for individuals and employers

Table 3.1. Supporting innovation ecosystems: Policy issues, instruments and rationales

Table 3.2. Strengthening knowledge transfer: Policy issues, instruments and rationales

Table 3.3. Formal and informal mechanisms of knowledge transfer

Table 3.4. Enhancing territorial inclusiveness: Policy issues, instruments and rationales

Table 4.1. Access to finance: policy issues, instruments and rationales

Table 4.2. Policy issues, instruments and rationales in access to entrepreneurship skills and networks for start-ups and scale-ups

Table 4.3. Policy issues, instruments and rationales in improving the entrepreneurial enabling environment

Table 4.4. Six steps to heaven

Table 5.1. Supporting labour transitions: Policy Issues, instruments and rationales

Table 5.2. Encouraging green innovations: Policy issues, instruments and rationales 123

Table 5.3. Policy instruments to promote environmental compliance and green business practices 123

Table 5.4. Overcoming governance challenges: Policy issues, instruments and rationales 126

Table 6.1. Regional well-being: Policy issues, instruments and rationales 139

Table 6.2. Territorial linkages: Policy issues, instruments and rationales $\quad 143$

Table 6.3. Policy challenges addressed by rural-urban partnerships by type of urban-rural interaction $\quad 144$

Table 6.4. Inclusive growth governance: Policy issues, instruments and rationales 145

Annex Table 1.A.1. Overview of policy issues and policy responses for regions in industrial transition 32 
Annex Table 2.A.1. Overview of policy issues, implementation mechanisms and rationales in preparing for the future of work in regions in industrial transition

Annex Table 3.A.1. Overview of policy issues, implementation mechanisms and rationales in broadening and diffusing innovation in regions in industrial transition

Annex Table 4.A.1. Overview of policy issues, implementation mechanisms and rationales to support

entrepreneurship and private sector engagement in regions in industrial transition

Annex Table 5.A.1. Overview of policy issues, implementation mechanisms and rationales in the transition to a climate-neutral economy in regions in industrial transition

Annex Table 6.A.1. Policy Issues, implementation mechanisms and rationales in promoting inclusive growth in regions in industrial transition

\section{Figures}

Figure 1.1. Changes in manufacturing employment, 2000-16 21

Figure 1.2. The march of the robots 22

Figure 2.1. Risk of automation across European TL2 regions, 2016

Figure 2.2. Changes in the share of jobs by skills level 39

Figure 2.3. Combining skills supply and skills demand at the regional level in French (2012) and UK subregions (2013)

Figure 2.4. Smaller firms lack soft skills for innovation

Figure 25. Barriers to participation in training programmes in OECD countries

Figure 3.1. Productivity levels at the regional level in the EU 64

Figure 3.2. Productivity gaps between frontier firms and other firms are widening 65

Figure 3.3. Substantial differences exist in subnational R\&D expenditures 67

Figure 3.4. SMEs take up and diffuse digital technologies much slower than large firms 68

Figure 4.1. Young firms contribute disproportionally to job creation 89

Figure 4.2. Key areas for regional intervention 91

Figure 4.3. Venture capital investments by country 92

Figure 4.4. Entrepreneurship skills as a barrier to business creation for men and women, 2012-16 93

Figure 4.5. Alternative debt-financing instruments by firm profile and stage of development 94

Figure 5.1. Proportion of electricity generated from renewable energy sources at TL2 level 114

Figure 6.1. Large spatial differences in productivity persist within the same large (TL) region 136

Figure 6.2. Disparities in youth unemployment remain across regions 138

Figure 6.3. Regional well-being measurement cycle: A possible sequencing of steps 142

\section{Boxes}

Box 1.1. The growing importance of policies to address industrial transition in the EU

Box 1.2. What are the key characteristics of regions in industrial transition? 16

Box 1.3. Past and current industrial transition 18

Box 1.4. What characterises the process of industrial transition? 19

Box 1.5. What are key policy challenges for regions in industrial transition? 23

Box 2.1. Industry and skills mapping by the Public Employment Service in Wallonia 46

Box 2.2. Apprenticeships for higher education and research 47

Box 2.3. Regional foresight in East and North Finland 49

Box 2.4. Singapore's SkillsFuture Programme 50

Box 2.5. The "Decent Work for Saxony" programme 51

Box 2.6. The Skillnet programme in Ireland 53

Box 3.1. Broadening the conceptual understanding of innovation 66

Box 3.2. Innovations in East and North Finland 71

Box 3.3. Broadening innovation in Limburg, the Netherlands 72

Box 3.4. OECD Principles on Effective Public Investment across Levels of Government 73

Box 3.5. Monitoring and evaluation of innovation in the Basque region 74

Box 3.6. Mittelstand-Digital, Germany $\quad 75$

Box 3.7. Norwegian Innovation Clusters

Box 3.8. Innovation networks in Centre-Val de Loire 78

Box 3.9. Startup Sweden: Connecting digital start-ups from rural areas to Stockholm 81

Box 4.1. The TGFS venture capital fund in Saxony 95 
Box 4.2. Entrepreneurship as a pillar of regional development: Lessons from Ben Franklin Technology Partners

Box 4.3. Start:up Slovenia

Box 4.4. The "how to" of business support policy design

Box 4.5. The Cantabria Entrepreneurship Centre

Box 4.6. Supporting innovative start-ups and spin-offs resulting from public research in Piemonte, Italy

Box 4.7. HElnnovate - Higher education and entrepreneurship

Box 5.1. Keys to a successful climate-neutral transition: North-Rhine Westphalia

Box 5.2. An OECD checklist for a just transition

Box 5.3. Assessing skill needs for displaced workers: TransverS'AL

Box 5.4. The Greater Manchester Sustainable Communities Project

Box 5.5. The energy cluster in Saxony

Box 5.6. Sustainable procurement for food delivery to the elderly in North Middle Sweden

Box 5.7. Supporting energy efficiency in Piemonte's small public administrations: Together 2020

Box 5.8. Good practice in Hauts-de-France: REV3

Box 6.1. Addressing youth unemployment in Slovenia

Box 6.2. Building gender inclusiveness in North Middle Sweden

Box 6.3. Labour market policies to integrate long-term unemployed and supporting self-employment

Box 6.4. Making well-being an integral part of a region's development policy in Southern Denmark

Box 6.5. Research meets policy and practice in Greater Manchester

Box 6.6. Social Innovation in Centre-Val de Loire and Grand Est

Box 6.7. A co-ordinated approach to greater inclusiveness in Piemonte and Saxony 


\section{Executive summary}

Many regions in Europe and across OECD countries have a long experience with industrial change and the uneven impact it can have on economic development. Historically, industrial change has always given rise to new jobs, while the productivity growth from automation has been the most important driver of rising living standards. Yet, industrial transition also poses clear challenges. Changing economic patterns can cause temporary, but possibly prolonged, increases in unemployment, which are often spatially concentrated. Furthermore, the changing demand for particular skills affects wage levels and causes permanent gains or losses for certain groups of workers. Globalisation, technological progress, and the transition to a climate-neutral and circular economy raise additional challenges in these contexts, but can also offer important opportunities.

Regions in industrial transition have a comparatively strong potential to seize the chances offered by current megatrends (e.g. digitalisation and automation) to revive economic growth and productivity, and to improve resilience to future technology shocks. These regions often have a strong legacy in manufacturing and sophisticated innovation activities in local core industries. Well-trained workers, established knowledge and strong social capital long characterised them as engines of growth and prosperity. At the same time, these regions can face specific challenges, notably where deindustrialisation has been associated with a lack of an appropriate skill base for future-oriented occupations and low levels of productivity outside traditional technology fields. Across OECD countries, the share of tertiary educated differs on average by 20 percentage points between those regions with the lowest and those with the highest share in a given country. Even though regions in industrial transition do not necessarily have the lowest share in a country, they tend to be below the national average, implying a significant potential for increases. When there is a lack of skilled labour, it can become very difficult to attract the investment necessary for broad industrial modernisation or increased economic activity in higher value added services.

Successful industrial transition will depend on the ability of a region to foster "high-road competitiveness" strategies - in other words, its ability to foster innovation-led growth and ensure that the benefits from growth are widespread - spatially and, more generally, across the population. Seizing the opportunities of industrial transition while mitigating its social costs locally will require policy interventions that build on each region's existing capabilities and legacies. Concerted action is needed by both governments and the private sector to successfully move industrial transition forward.

\section{Key messages}

- Regions in industrial transition need to help workers to transition to future-oriented jobs and firms to embrace the digital economy. Regions in industrial transition are often home to a skilled and well-trained labour force in traditional industries. In addition, some regions have been relatively successful in building a labour force in future-oriented and digital occupations, but most of them are just starting to do so. In order to modernise their local industrial base, it is critical for these regions to continue upgrading the skills and production capabilities of existing industries while simultaneously promoting the diversification of the local economy towards more future-oriented economic sectors. Better anticipating skills needs, for example through industry and skills mapping or through 
regional skills foresight exercises, helps move industrial transition forward. More generally, the development of future-oriented activities, such as smart manufacturing, life sciences, e-mobility or higher value-added services, has a higher chance of success in those fields where the region already has some assets it can build on.

- Broadening and diffusing innovation supports productivity growth in regions in industrial transition. Broadening the focus of innovation policy to include both digital and non-technological innovation is essential for regions in industrial transition. Building up digital competencies in small and medium-sized enterprises (SMEs) can be enhanced through publicly supported training, including managerial training via webinars or through personal counselling. Policymakers in regions in industrial transition can better connect SMEs and start-ups with large businesses through strategic cluster management, project calls for open innovation projects, and the organisation of matching events. Building these connections can support small firm innovation capability. A broadened innovation policy should also strive to support tradable sectors, which tend to be more innovative and productive.

- Innovative entrepreneurship can support new industrial growth paths. Empowering and encouraging entrepreneurship is even more important in regions in industrial transition than elsewhere because these regions are in greater need of economic diversification and new firms in growing sectors. Public-support organisations such as incubators, science parks or cluster organisations can help promote industrial diversification. Regional policymakers should also aim to strengthen networks between industry, research, public services, and civil society. Such networks can be built around regional innovation strategies, such as smart specialisation priorities, through open project calls and through cross-cluster and cross-sector collaboration.

- Industrial transition should aim to be just and inclusive. The progressive phasing out of carbon industries will present challenges for regions where firms operating in carbonintensive sectors are large employers. Ensuring a just and inclusive transition requires achieving deep emission reductions while addressing inequalities across both social groups and local communities within the same region. This can mean providing individually targeted training not only to displaced workers, but also to certain groups with lower employment rates such as women or young people. It also means to better measure and integrate well-being indicators beyond GDP in regional development strategies, and to revive peri-urban areas, which often have been affected by a decline in local industrial activity.

- Ensuring an effective multi-level governance policy framework is key. Industrial transition takes place in a complex governance environment, requires action by multiple levels of government (local, regional, national and possibly supranational), and involves a wide variety of actors. Promoting a cross-sectoral and multi-stakeholder approach includes fostering active co-operation among all actors to clarify roles and responsibilities and to ensure that policies at all levels of government are well aligned.

- Managing policy complexity requires active policy learning and adaptation. Experimental governance that embeds learning-by-doing and trial-and-error processes into policy design can help regional policymakers develop better approaches to address industrial transition. This includes making more and better use of forecast techniques to understand future trends, including more and better data-driven forecasts (e.g. on skills needs and mismatches) as well as introducing more robust performance measurement.

\section{Looking ahead}

Regions in industrial transition use a variety of policies and implementation tools to support their transition processes. As policymakers advance on their path to industrial transition, they may need to consider that additional progress may not always come from more or new policies, but rather from improving the implementation of existing ones. More generally, taking a strong place-based approach, and ensuring that 
current governance structures and policies can better accommodate structural change will be essential to successful industrial modernisation. 



\section{Boosting innovation-led growth in regions in industrial transition}

The chapter provides insights into past, current and future challenges of industrial transition and outlines how regions in industrial transition are affected by long-term megatrends, such as globalisation and digitalisation. The chapter introduces five policy themes that contribute to industrial transformation and highlights the need for a strong regional and placebased approach. It further summarises crosscutting lessons on how to address multi-level governance challenges across policy themes. 


\section{Introduction}

Over the past two centuries, European and OECD regions have undergone extensive periods of industrial change caused by technological progress and automation. The labour-replacing element of technological progress has historically led to fears of prolonged unemployment. Despite these fears, technological innovations have always given rise to new jobs that provided employment, while the productivity growth from automation has been the most important driver of rising living standards.

Yet, it would be incorrect to argue that technological progress comes without challenges. Even though the past two centuries of automation and technological progress have not made human labour obsolete, changes in technology alter the types and remuneration of jobs available. This can be particularly problematic where such changes are concentrated among certain groups or in certain localities. In recent years, one noticeable change has been the "polarisation" of regional labour markets, wherein middleskilled jobs are hollowed-out while the top and bottom of the income and skills distribution grow.

Globalisation, ongoing technological progress and the demands of fighting climate change compound these adjustment costs, while also presenting an opportunity for industrial transformation. Some regions experiencing industrial transition were once motors of growth and prosperity. Since the outsourcing of industrial production to emerging economies, these regions have been struggling to adapt. In other regions, industrial transition has left pockets of disadvantage in close proximity with areas of relative prosperity. In some regions, the challenge of industrial transition is compounded by shrinking employment in the primary sector or demographic change.

Furthermore, technological advances, and in particular digitalisation and automation, are further transforming the industrial base of different types of regions. The transition to a climate-neutral and circular economy will radically alter economies and societies. Reaping the benefits of such changes will lead to strengthened competitiveness and resilience. At the same time, a lack of capacity and opportunity to keep pace with technological and industrial innovation can lead to declining investment, growth and income. If no action is taken, stronger economic disparities and territorial and social fragmentation within the European Union (EU) and other developed economies can result.

Declining industries in once-prosperous places are at the heart of current debates on territorial disparities and increased income inequality within countries. In principle, industrial decline is not always a cause for concern: it can enable an economy to progress and innovation to advance. However, for economies that are unable to manage the process of adjustments, it can cause structural unemployment and stagnation. Tackling these challenges calls for urgent deployment of new solutions and requires profound, systemic transformations.

Addressing current industrial transformation requires moving beyond traditional development policies towards those that maximise the potential of every region through a place-based approach. Doing so permits policymakers to consider the existing capabilities and legacies of regions in industrial transition, taking account of their specific characteristics. For these regions, substantial investment is needed in advanced manufacturing, skills and research and innovation in order to reap the benefits of industrial change.

To avoid focusing strictly on narrow supply-side innovation policies, policy measures in regions in industrial transition need to pay more attention to actions that can address demand-side characteristics, such as consumption patterns, firm strategies, new business models and regulatory aspects. Improved governance, including effective co-ordination mechanisms among levels of government and between innovation-led regional development policies and related policy domains, is also needed. 
This report outlines the specific challenges confronting regions in industrial transition and offers guidance on how innovation-led regional development policies can facilitate a forward-looking approach to industrial transformation through policy design, implementation and monitoring. The report is directed towards all policymakers seeking to improve the "what" and "how" of policies that accompany industrial change.

This report focuses on those regions most exposed to industrial change. But almost all regions face the legacy of industrial transition in certain sectors and share a common set of challenges linked to globalisation, the Fourth Industrial Revolution and the transition to a low-carbon, circular economy. The practices and policy recommendations contained in this report will, therefore, be of significant relevance to most regions in the European Union in the context of developing their smart specialisation strategies (see Box 1.1).

\section{Box 1.1. The growing importance of policies to address industrial transition in the EU}

While the benefits of globalisation are widely spread, the costs are often localised. In addition, the transformation to a climate-neutral economy can have an overall positive impact on the EU economy but could also increase social and regional disparities. This is why this deep modernisation process needs to be well managed. The European Union is committed to helping all regions prepare themselves for the challenges of globalisation and the transition to a climate-neutral economy by 2050 , ensuring a fair and socially acceptable transition for all.

The EU's Cohesion Policy has, for many years, supported the sustainable industrial transition of Europe's regions and cities and is the main EU policy instrument to address structural changes linked to energy and industrial transition. In the current 2014-20 programming period, EUR 120 billion is targeted at helping regions become more innovative and competitive. Smart specialisation strategies, that is to say strategies building on a region's competitive strengths, are at the centre of this approach. Putting in place such a strategy is a requirement for regions to receive support from the European Regional Development Fund (ERDF). These regional strategies play a key role in helping regions diversify their economies, create jobs and move up the value chain. The European Commission has proposed that, in the future, member states will be required to identify actions to facilitate industrial transition based on a thorough analysis of transition challenges and needs, including in coal and carbonintensive regions.

Sources: European Commission (2017a), Reflection Paper on Harnessing Globalisation, https://ec.europa.eu/commission/sites/betapolitical/files/reflection-paper-globalisation_en.pdf; European Commission (2017b), Reflection Paper on Towards a more sustainable Europe by 2030, https://ec.europa.eu/commission/sites/beta-political/files/rp_sustainable_europe_30-01_en_web.pdf.

This first chapter highlights contextual elements and summarises crosscutting lessons and key considerations for boosting innovation-led growth in regions in industrial transition. The subsequent chapters summarise insights and policy conclusions on five policy themes to help regional policymakers to manage industrial transition successfully, including the future of work, innovation diffusion, entrepreneurship and private sector engagement, the transition to a climate-neutral economy, and inclusive growth. Each chapter includes highlights of practices shared by the regions and countries that participated in the industrial transition peer-learning exercise (see Annex A) and concludes with a set of potential policy recommendations emanating from the related workshops (see Annex 1.A. for an overview of all policy recommendations). 


\section{Setting the scene: Current and future challenges for regions in industrial transition}

Regions undergoing industrial transition share a range of very specific, yet highly interconnected opportunities and challenges resulting from their legacy of manufacturing activity. These regions often possess strong capabilities and knowledge in important industries of today but need to re-orient these towards new and emerging activities for the industries of tomorrow. A key challenge for successful industrial transition is boosting the ability of regions and their industries to break out of locked-in paths of development by pursuing innovation, new technological pathways and industrial renewal.

\section{Regions in industrial transition have an important range of assets to build on, but face dangers of lock-in}

Regions in industrial transition often have a strong legacy in manufacturing and sophisticated innovation activities in local core industries. They tend to have a pool of well-trained workers in well-established technological and industrial fields and are often home to regional innovation centres in existing industries.

However, a key risk of this legacy is lock-in: being potentially overspecialised in mature technologies and industries in decline. Innovation activities in these regions are often very sophisticated but tend to follow mature technological trajectories of a mainly incremental nature. Even though these regions may have a highly developed and specialised knowledge-generation and diffusion system, it is usually oriented towards traditional industries and technology fields. Where regions in industrial transition have been able to develop future-oriented innovation activity, it has rarely spread beyond local innovation hubs.

Moreover, small firm innovation and entrepreneurial activity tend to be low given the dominance of larger firms, incumbent to the established and mature industrial and technological specialisation. Examples of this type of path dependency is frequently found in regions specialised in heavy industries such as the Ruhr area in Germany or North East England. These regions are also well-known for being sites that may face difficulties in dealing with environmental waste and pollution (e.g. carbon emissions) as well as dependence on energy-intensive industries (Box 1.2) provides an overview of some defining characteristics of regions in industrial transition.

\section{Box 1.2. What are the key characteristics of regions in industrial transition?}

Regions in industrial transition are regions that have undergone or are currently undergoing a major restructuring of their economies and industrial profiles. These regions have experienced or are experiencing substantial changes of growth and contraction at the sectoral and business levels, with consequences for jobs and workers.

Regions in industrial transition are often characterised by:

- a long heritage of traditional (carbon-intensive) manufacturing

- a strong skills base in traditional occupations (but a lack of future-oriented skills)

- highly developed knowledge-generation and diffusion systems in established industries

- an existing high-quality knowledge infrastructure (e.g. universities, science parks) in a range of technology fields

- productivity and investment opportunities largely derived from traditional industry fields. 
Regions in industrial transition have a strong potential to turn opportunities offered by current megatrends (e.g. digitalisation and automation) into regional growth paths. At the same time, these regions underperform on a range of socio-economic indicators, such as level and growth of productivity and gross domestic product (GDP), or shares of tertiary education. Addressing the challenge of industrial transitions means making better use of existing capabilities in order to successfully modernise and upgrade local economies.

\section{Industrial decline can lead to growing inequalities}

The decline in manufacturing jobs experienced by regions in industrial transition is often met with anxiety. People are concerned that a smaller manufacturing sector implies slower economic growth and a scarcity of well-paying jobs for workers in low- and middle-skilled jobs, contributing to a growth in inequality. A declining industry has a very visible impact on local communities and this is what people see. It is much harder to see the new firms and new jobs that are created as these take time to generate.

The consequences of industrial decline can be severe. Inequalities are rising and transfers alone will not be able to substitute endogenous growth opportunities. Across the OECD, a "geography of discontent" has emerged, expressed as growing disenchantment with globalisation, open economies and established policies. The divide goes between economically dynamic metropolitan places - home to high-skilled and highly educated workers - and those urban, peri-urban and rural areas where such skills may be lacking and which are left on the fringes of prosperity.

Regions in industrial transition are usually characterised by a long heritage of traditional industries and low levels of productivity in at least some parts of the local economy. It is, therefore, critical for these regions to increase productivity in order to catch up to more productive places within the same country and beyond. Policymakers addressing industrial transition have the responsibility to manage decline. This includes limiting the scale of problems arising from transition, such as prolonged periods of unemployment, while also tapping into the opportunities provided by new growth sectors, matching those with local resources and ensuring that the benefits of new activities are shared with local residents.

\section{Industrial transition is not a new phenomenon}

Industrial transition as such is not a new phenomenon. Since the first industrial revolution and the onset of modern industrial production, regional economies have undergone major changes. Today, they are experiencing yet another industrial revolution. The catalyst for each transition has been different, ranging from steam in the first industrial transition, to transport and electricity in the second, computers, semiconductors and the Internet in the third, and finally to artificial intelligence and machine learning in today's fourth industrial transition (Box 1.3).

Continued advancements in the development of artificial intelligence (AI) are likely to further accelerate changes in the world of work, transforming more tasks previously performed by humans. If managed well, these new technologies can be transformative, supporting higher productivity growth and improved wellbeing by complementing human capabilities rather than substituting them. For instance, they can promote the emergence of new business models and innovative ways of working, providing more flexibility for both workers and employers. 


\section{Box 1.3. Past and current industrial transition}

The industrial revolution currently unfolding blurs the boundaries between the physical, digital and biological worlds. It combines technological advancements in artificial intelligence (Al), robotics, the Internet of Things (IOT), 3D printing, genetic engineering, quantum computing and other technologies. These enabling technologies are changing how people live and how business is conducted in nearly every sector, disrupting existing industries across OECD countries and providing important opportunities to advance the transition to a climate-neutral and circular economy.

While the Fourth Industrial Revolution, sometimes called Industry 4.0, is radically changing economies and societies, it rests on foundations created by the first three industrial revolutions. The advent of the steam engine in the 18th century led to the first industrial revolution, allowing for mechanisation of production for the first time and driving social change as people became increasingly urbanised. During the second industrial revolution at the beginning of the 19th century, electricity and other scientific advancements led to mass production. The third industrial revolution, beginning in the 1970s, saw the emergence of computers and digital technology. Like its two predecessors, the third industrial transition had a large impact on virtually all aspects of society. It led to a massive shift in the occupational structure of the labour force, resulting in individual winners and losers based on occupations, and had a significant impact on the prosperity of cities and regions.

The Fourth Industrial Revolution will strongly affect the nature of future jobs and future skills requirements. As with previous industrial revolutions, changing technologies and, in particular, artificial intelligence and increased automation, will see many types of jobs disappear. At the same time, entirely new categories of jobs are emerging, such as big data processing and analytics. These effects are not only relevant to large-scale companies but also provide new opportunities for small- and medium-sized enterprises (SMEs) and entrepreneurs. These technological advances will also have the potential to significantly reduce carbon emissions and resource usage across industrial and agricultural production cycles - from manufacturing to shipment, packaging and reuse.

Source: OECD (2018b), OECD Science, Technology and Innovation Outlook 2018: Adapting to Technological and Societal Disruption, https://doi.org/10.1787/sti_in_outlook-2018-en.

\section{The past impact of industrial transition was not spread evenly across space}

In order to sustain long-term regional development, regions must constantly transform and renew their economic base. Historically, industrial transition has led to changes in economic structures at the national and regional levels. For example, the core industrial areas of Belgium, Germany and the United Kingdom lost their economic dominance and were replaced by a set of new growth regions in the southeast of England, Flanders and the south of Germany respectively (Boschma, 2009).

Industrial change can be experienced as a temporary loss of competitiveness in a certain region. However, it is often far more substantial than that. The decline of Akron, Ohio's tire manufacturing or Pittsburgh, Pennsylvania's steel industry in the United States illustrates this. Industrial decline in these places led to substantial changes in how industries and production processes are structured. These examples also show that the actual process of industrial change comes with many faces and characteristics. Box 1.4 seeks to provide a few central elements of industrial transition. 


\section{Box 1.4. What characterises the process of industrial transition?}

Industrial transition has many facets. Industrial transition is a broad term, which is often not clearly defined. Industrial transition brings with it a change in the economic structure, i.e. in relative weights of individual sectors during development processes. It can also result in shifts in the knowledge infrastructure (research organisations, intermediaries) and possibilities for the use of knowledge. From an economic geography perspective, industrial transition includes changes within a region to the spatial configuration of economic activities, the supply and demand for labour, as well as changes to the regional infrastructure, natural capital and land and housing values.

Industrial transition is closely linked to innovation. Industrial transition often involves a process by which traditional structures are replaced by modern industries. Positive industrial transition is the outcome of processes reflecting the ability of a firm, an industry, a region or a national economy to respond to new market pressures and create new opportunities for workers. On the other hand, failure to respond to a constantly changing market environment can result in economic decline, unemployment and rising inequalities, environmental externalities and falling land values. The objective of transition management is to help structurally weaker regions onto a dynamic growth path by means of innovationpromoting measures.

Industrial transition brings long-term benefits but comes with short- and medium-term costs. Industrial transition is neither automatic nor instantaneous. The most significant costs related to the adjustment process are associated with structural unemployment and environmental degradation, which in turn can generate significant adverse consequences for social welfare, especially where lasting over many decades.

Industrial transition can help some regions grow and cause others to fall behind. Industrial transition depends on many factors. Transition can be continuous or disruptive and can affect strong and weak regions and touches rural areas as much as urban areas. Industrial transition can result in different growth rates and structural adjustment pathways. Given the important role of maintaining institutional and social capital, local actors, stakeholder groups, civil society initiatives and promoters with a high level of personal commitment can play an essential role in industrial transition. In addition to firms (particularly SMEs), universities and intermediary organisations, civil society organisations that are involved in regional development projects as well as policymakers are important drivers of positive transition outcomes.

Industrial transition is place-based and time-specific. Industrial transition, ultimately, is defined on a case-by-case basis. This is due to the variations in the type and intensity of change regions experience, as well as the structures and the diverse profiles of those affected. Regionally specific approaches are important for the success of support measures, and framework conditions can differ markedly between places. Policy needs to be place-based and oriented to specific target groups since problems vary across firms, research institutions and intermediaries.

Industrial transition has unfolded differently across European and other OECD regions. Previous waves of technological breakthroughs show that technologies such as automation do not spread evenly across European and OECD regions. Rather, they affect different regions in heterogeneous ways, with a common lesson being that investment in human capital has always been a key element for regional resilience. Equipping workers with the flexibility to exit from industries where labour has been displaced by technology and capital, and enter into industries where new skills are needed at the foundation of making regions more resilient to industrial transition (OECD, 2018a). 
When looking at industrial employment in Europe between 1990-2014 (Figure 1.1), it becomes evident that industrial transition did not spread evenly. While some regions, notably in Eastern Europe, experienced growing shares in manufacturing, employment in manufacturing declined for the majority of Western European regions. The heavy reliance of these regions on traditional manufacturing is being replaced by a demand for higher quality, service-oriented industrial production. In both East and West, investments in intangibles (e.g. human capital, software, etc.), a factor typically associated with the fourth industrial transition, is increasingly a source of growth.

\section{Current long-term megatrends are transforming the industrial base of different types of regions}

Across the EU and the OECD, new technological advancements coupled with increasing production outsourcing to lower-cost countries have led to a shift from traditional manufacturing to high-end, serviceoriented industrial production. In addition, the distinction between industry and services is becoming less distinct and new production technologies determine the availability and nature of work in different types of regions (OECD, 2019a).

The fourth industrial transition has the potential to boost labour productivity and enhance well-being in all regions, but concerns remain regarding the potential impact of automation on unemployment and inequality. A common characteristic of all industrial transitions is the simplification (or even complete automation) of a broad range of originally labour-intensive activities. Historically, technological progress is a key determinant of long-term economic and sustainable wage growth. In the short term, however, automation displaces jobs, and the new jobs enabled by the technological transition can take longer to be created and/or be located in a different region.

The diffusion of industrial robots may best illustrate both technological penetration and the fear of job automation in the workplace. Although robots have existed for decades, their diffusion and capabilities have accelerated within and beyond the manufacturing sector (Brynjolfsson and McAfee, 2014). Data from the International Federation of Robotics indicate that orders of industrial robots increased about fivefold between 2003 and 2017, and this trend is expected to accelerate, including in OECD countries where the number of industrial robots per employee doubled over the last 15 years (Figure 1.2). 
Figure 1.1. Changes in manufacturing employment, 2000-16

Average annual growth of the share of employment in manufacturing as a share of total employment, TL3 level

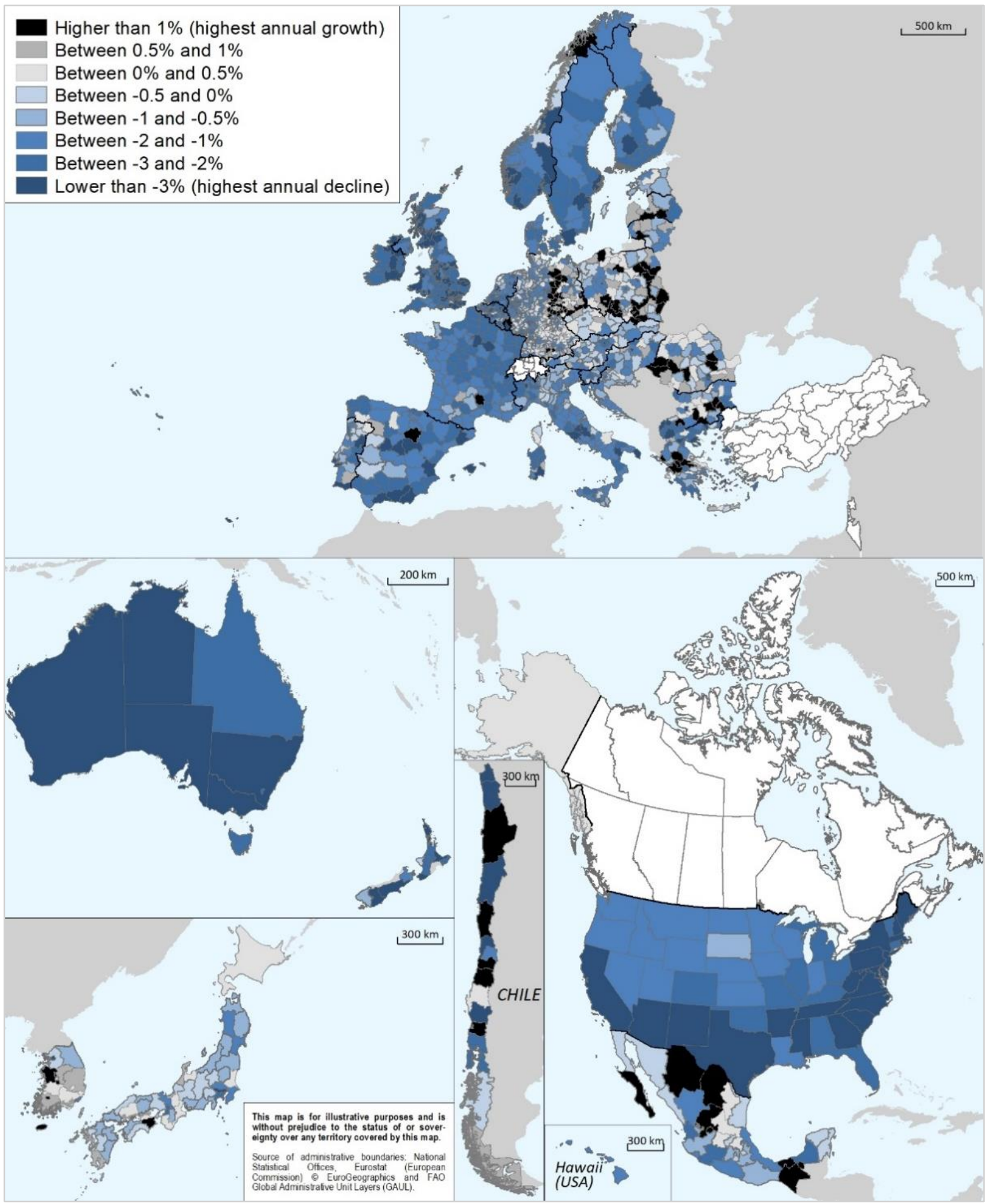

Note: First available year: 2003 for Belgium, 2006 for Poland, 2008 for Norway, 2009 for Japan. Last available year: 2015 for Australia, Finland, France, Germany, Hungary, Lithuania, the Netherlands, Poland and the United States; 2017 for Belgium, Bulgaria, Denmark, Estonia, Mexico, Slovenia and the United Kingdom. Annual average growth in the share of employment in manufacturing, except Japan (share of industry). All data are TL3 regions except for Australia, Chile, Mexico, and the United States (TL2).

Source: OECD Regional Statistics [Database]. 
Figure 1.2. The march of the robots

Panel A. Worldwide annual supply of industrial robots, thousands

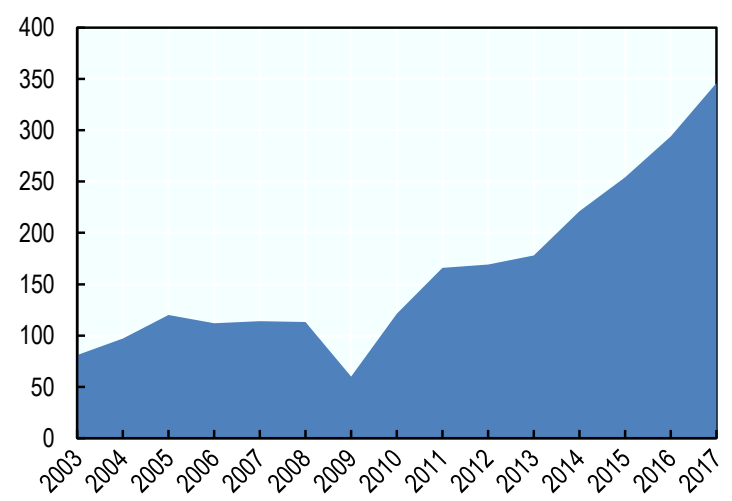

Panel B. Number of robots per employees, all sectors, selected OECD countries

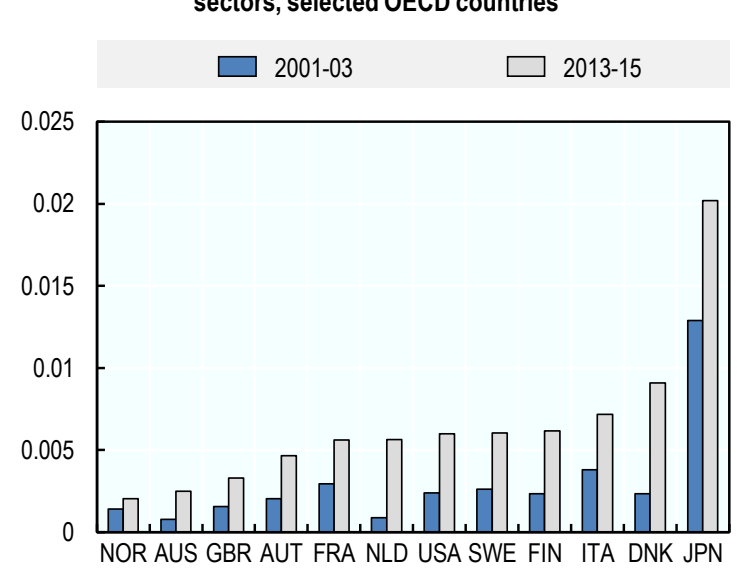

Note: In Panel A, 2017 figures are estimates. In Panel B, the initial period (in blue) refers to an average of the indicator between 2001 and 2003 ; the last period (in grey) refers to an average of the indicator between 2013 and 2015.

Source: OECD (2018) based on IFR World Robotics 2017 and Calvino et al. (2018), "A taxonomy of digital intensive sectors", OECD Science, Technology and Industry Working Papers, No. 2018/14, https://doi.org/10.1787/f404736a-en.

The rapid development and integration of new technologies in society and industry affect skills, tasks and jobs in regional labour markets. On the one hand, this leads to new growth opportunities, and on the other, it contributes to growing concerns of job displacement and talent shortages. The impact of the megatrends will differ by type of region and may be felt most strongly by those regions that are still shifting from traditional and resource-heavy industries to modern high-end manufacturing or services. In many cases, such regions need to manage past industrial decline and simultaneously remain focused on the opportunities that industrial transformation can bring.

\section{Regions undergoing an industrial transition are confronted with a range of very specific (policy) challenges}

Successful transition is a difficult task. For displaced workers, finding new jobs, especially those with equivalent income, is not evident. As the nature of jobs changes, the knowledge and skills specific to the job become obsolete. Jobs that are easily accessible, such as taxi driver or bartender, might not yield the same income as previously well-paid manufacturing jobs and may require moving to an area where demand for such services is higher. A manufacturing worker accustomed to operating heavy equipment or assembling materials might have difficulties transitioning into a position as a manager in retail, for example. Technological progress is typically associated with at least temporary job losses. Temporary does not always mean short-lived, however, nor are the disruptions evenly distributed across workers or regions in a country.

Regions in industrial transition, therefore, face challenges in modernising their industrial base, upgrading the skills of the workforce, compensating for job losses in key sectors and low productivity that limits income growth. These regions may find it difficult to re-orient local innovation capacities towards new and emerging activities, to raise or attract sufficient investment to encourage innovation and to spur small firm innovation and entrepreneurial activity.

Successful industrial transition requires technological, industrial and institutional change to occur simultaneously. The infusion of new technology is necessary for industrial change, but hardly sufficient. The big challenge for policymakers in regions in industrial transition lies in strengthening appropriate 
competencies and resources for innovation at the firm level, to encourage local actors to engage with innovation processes and to ensure broad networks, strong interaction and knowledge exchange between actors across different policy domains. Box 1.5 summarises the key policy challenges for regions in industrial transition.

\section{Box 1.5. What are key policy challenges for regions in industrial transition?}

Ensure the benefits outweigh the costs: The costs of industrial transition pose a significant risk that regions fall further behind. Policy development has a pivotal role in steering transition towards the right development path.

The need to address technological change: The significance of technological change as an integral part of the transition process has to be recognised in terms of identifying and addressing major technological lock-in and by seeking to engage and frame the investment choices around new and future-oriented activities.

The need to manage the risk of structural unemployment: Transitions results in periods of structural unemployment. Early anticipation of these risks and the development of a range of (innovative) responses to restructuring in key sectors and the regional economy more broadly is important to alleviate the worst outcomes.

The capacity to steer transition towards positive structural change and economic growth: Depending on the right policy mix and associated scale of investment, dynamic economic changes in regions in industrial transition can increase long-term productivity and economic growth, contributing to rising living standards and well-being.

The ability to balance different trade-offs and ensure a just transition. Industrial transition means to balance economic, social and environmental and climate challenges to industrial transition. Considering the social aspect of the transition towards a climate-neutral economy is crucial for gaining social approval for the changes taking place.

The synergies with other policies: Adjustment policies likely coincide with changes in broader economic models, such as the provision of support for recycling of factor resources, avoidance of market rigidities and restrictions, and the creation of the right framework conditions.

\section{Strategies for managing industrial transition}

Regions in industrial transition are facing challenges in today's fast-moving environment of technological disruption, digitisation, automation and decarbonisation. Effectively managing industrial transition will help regions better understand current and future challenges and identify gaps in their approaches to managing such transition. Key considerations include how to increase the resilience of current employment and create opportunities for new job creation in a period of great change; how to broaden innovation strategies to improve diffusion of new technologies and ideas; how to promote entrepreneurship to diversify and strengthen the regional economy; how to ensure the low-carbon energy transition and harness its opportunities; and how to strengthen inclusive growth.

\section{Preparing for the future of work}

Rapidly evolving technologies mean that labour markets in European and OECD regions will inevitably undergo major transformations in the coming years and decades. Firms and regions that do not keep up 
with the pace of innovation risk falling behind. While seizing the opportunities of new technologies and business models will lead to new growth paths, how to achieve this may not be self-evident. For policy design, an additional challenge is increased technological unpredictability. Support for skill development or large-scale investment might rapidly become obsolete as new technologies become available.

Regions that have experienced industrial decline or still base their current economic activity on traditional manufacturing or extractive industries are in a vulnerable position. Based on their capacities and accumulated knowledge in existing industries, companies in these regions have a strong potential to capture the benefits of the future of work. At the same time, the adoption and successful integration of new technologies and the development of new business models is constrained by significant and specific barriers that this type of region is facing. Regions in industrial transition often face a drastic decline in established job profiles due to the phasing out of traditional industries. In parallel, these regions are confronted with skills gaps in local labour markets when it comes to job profiles related to future technologies, such as professions in web-and app-enabled markets, machine learning skills and software developers.

Preparing for the future of work in regions in industrial transition requires a policy strategy that combines skills and employment policies with those that stimulate investment in new sources of employment and productivity growth. Tapping into new and emerging sources of growth and employment can help regions in industrial transition avoid being locked-in to old industries and help create job opportunities that increase productivity, wages and ultimately prosperity.

\section{Broadening and diffusing innovation}

Evidence shows that firms and industries adopting advanced technologies and innovative behaviour have above-average productivity and employment growth (OECD, 2018b). The introduction of new technologies leads to more efficient production processes and lower costs as well as the development of new products and the creation of new demand. Diffusing innovation through to low-performing firms requires enhancing the ability of firms to identify, absorb and build on technologies over the long term.

Regions in industrial transition often face large challenges in improving productivity, and even more so when they have insufficient institutional capacity, fragile industrial links or a low-skilled workforce. These regions may be unable to attract sufficient investment to encourage innovation, or commercial research structures and firms that could contribute to industrial modernisation. In many cases, although they may contain firms at the European or national technology frontier, there are significant problems in innovation diffusion and take-up in firms further away from the technological frontier. These latter firms may account for a large part of employment and output and are less resilient to shocks from international competition and technological change.

For successful industrial modernisation, it is essential that innovation-led regional development policies focus not only on cutting-edge frontier innovation but also on adopting processes or technologies that already exist elsewhere. Such a broader innovation policy should not be limited to the supply of research and development (R\&D) or direct innovation support, but also strive to support education and capital investment that match the need of local industries, increasing their absorptive capacity and innovative capability. Public policy can stimulate the effective transfer of knowledge through labour mobility and collaborative networks, fostering knowledge circulation and interactive learning. Policies in this context can be platforms for knowledge diffusion and support better linkages between universities and industry.

\section{Innovative entrepreneurship for new industrial path development}

Innovative entrepreneurship is a critical factor for regional industrial modernisation and a key tool for job creation, economic growth and innovation. As such, governments are eager to promote it. The prevalence of start-ups is systematically and strongly related to local employment growth across and within regions 
(OECD, 2019b). Established firms may have less incentive to innovate than young firms, as innovation will consume part of an established firm's current revenue stream by introducing new products and services that disrupt their existing products and services.

In the context of a knowledge-based economy and in the face of technological uncertainty, the role of entrepreneurship will be greater than ever. However, in order for innovative entrepreneurship to successfully diversify local economies, a range of barriers needs to be overcome in regions in industrial transition. Barriers include a weak entrepreneurship culture based on a long tradition of contract work in manufacturing, a lack of existing risk capital for innovative companies to scale up and underutilised knowledge networks.

Scaling-up innovative entrepreneurship in regions in industrial transition requires a functioning regional innovation ecosystem that drives industrial modernisation through a combination of policies in the area of entrepreneurship, SME, innovation, education and science at the regional level. Local and regional authorities have therefore an important role in connecting, developing and supporting the regional innovation and entrepreneurship ecosystem through organising the mapping of available capacities and involving different stakeholder groups in a demand-driven and collaborative approach towards successful industrial transition.

\section{Transition towards a climate-neutral economy}

Regions and cities play an important role in order to reach the objective set in the 2015 Paris Agreement of holding the global average temperature increase to well below 2 degrees Celsius and pursue efforts to limit it to 1.5 degrees Celsius above pre-industrial levels. Addressing climate change will require profound changes to currently dominant structures, practices, technologies and policies.

The transition to a climate-neutral economy will not affect every region in the same way. The progressive phasing out of carbon-intensive and extractive industries will present particular challenges for many traditional industrial regions because they are frequently characterised by weak economic diversification and firms operating in carbon-intensive sectors often count for a large share of employment. In such situations, ensuring a just transition requires achieving deep emission reductions while minimising the impact on workers and poorer households.

Promoting a just transition means combining climate action with public support in managing structural change in local economies and the impact on the local workforce. Policymakers need to pursue a dual strategy of supporting low-carbon investments while helping displaced workers at the same time. New opportunities for workers can be stimulated through investments in green technologies and green business opportunities. This helps firms in two ways. First, better environmental performance can improve the local competitiveness of existing firms. Second, promoting new technologies and business models can help upgrade and diversify the local economy, thereby re-orienting the regional knowledge base towards new activities. This is particularly important for regions in industrial transition that face the danger of being locked into existing industrial pathways due to the dominance of incumbent firms in old industries.

\section{Promoting inclusive growth during industrial transition}

Successful industrial transition not only depends on reviving economic growth but also on ensuring that growth is fairly distributed and creates opportunities for all. Globalisation and technological change affect different social groups and places differently, not least visible through widening income disparities over the last three decades in most OECD regions.

Regions in industrial transition face very specific impediments to generating greater inclusiveness. The sluggish growth experienced in the context of manufacturing decline results in prolonged periods of unemployment and relatively low prosperity compared to previous moments in time. Low incomes and high unemployment rates result in economic and mental hardship for affected segments of society. Persistent 
unemployment among certain social groups, such as women, youth and immigrants, and in certain places, as well as rising relative poverty since the global financial crisis, highlight the multitude of policy challenges that need to be addressed. In the context of industrial transition, it is important that policies promoting new job creation, innovation diffusion, entrepreneurship and environmental and energy transitions are as inclusive as possible.

Inclusive growth in industrial transition also requires closing spatial gaps between frontier and lagging places within one region. Often, changes in regional structures also come with shifts in prospering and distressed local communities. Making sure that once-prosperous and now declining communities are not forgotten over the success of new economic centres and vibrant research hubs within the same region strengthens social cohesion and protects declining places. Addressing inequalities of opportunities within one region requires better access to high-quality education, investment opportunities and infrastructure across social groups and across local communities within and across a region. Not addressing these inequalities would be particularly damaging for regions in industrial transition because they "lock in" privilege and exclusion, thereby undermining the potential that regions in industrial transition have to leverage the growth opportunities arising from transition.

\section{What makes industrial transition successful? Crosscutting lessons and key considerations}

\section{A strong regional and place-based dimension is key to support economic growth and well-being}

Regions in industrial transition need to match arising opportunities with local resources. Cutting-edge innovation activities leading to higher growth might be difficult to achieve for these regions, given their local capabilities and resources. Often, using existing potential can be an important step towards an incrementally managed industrial transition. Local and regional authorities have an important role in connecting, developing and supporting a regional innovation ecosystem that brings together different stakeholders to unlock existing potential and that actively stimulates new knowledge and capacities in the region.

\section{There are several pathways to industrial transition}

Industrial transition comes in many shapes, rendering a "one-policy-fits-all" approach to developing new industrial pathways difficult. According to Grillitsch and Asheim (2018), three broad forms of industry transition can be distinguished: i) upgrading; ii) diversification; and iii) the emergence of new regional industrial paths (Table 1.1).

\section{Table 1.1. Types of new regional path development}

\begin{tabular}{l|l}
\hline \multicolumn{1}{c|}{ Types } & \multicolumn{1}{c}{ Mechanisms } \\
\hline Upgrading & $\begin{array}{l}\text { Major change of a regional industrial growth path based on new technologies or organisational innovations, or new } \\
\text { business models }\end{array}$ \\
\hline Diversification & Diversification into a new industry based on related or unrelated knowledge combinations \\
\hline Emergence & $\begin{array}{l}\text { Setting up of an established industry that is new to the region (e.g. through non-local firms or through radical new } \\
\text { technologies and scientific discoveries) and unrelated to existing industries }\end{array}$ \\
\hline
\end{tabular}

Source: Grillitsch, M. and B. Asheim (2018), "Place-based innovation policy for industrial diversification in regions", European Planning Studies, Vol. 26/8, pp. 1638-1662. 
Upgrading existing industrial paths makes a qualitative change to existing industries and, in some regional settings, is the easiest way to spur economic growth and enhance competitiveness. An example of upgrading can be local firms moving up the value chain in global production networks through transitioning towards higher value-added activities.

Industrial diversification refers to firm-level processes where knowledge and resources from existing industries are used in new industries. The literature differentiates between two concepts, related and unrelated variety (Content and Frenken, 2016). Related variety refers to different industries that build on similar types of knowledge. Diversification based on related variety is a process where firms mainly diversify into technologically related products (Boschma, 2009). For instance, the maritime industry may apply competencies originally used to install oil platforms to the installation of offshore wind parks, thereby moving into the renewable energy sector (Grillitsch and Asheim, 2018). By contrast, unrelated variety refers to industries that do not share similar knowledge.

Finally, emergence means that new industries may emerge in regions that have no link to existing industries. The most radical form of new industry emergence is the creation of completely new industries. Sources for path creation are new technologies, scientific breakthroughs or radical innovations based on new business models, user-driven or social innovations.

Although useful to grasp industrial modernisation, these categories represent industrial modernisation typologies. Regions undergoing industrial transition might experience a combination of some or all of these pathways. Which industrial pathway to choose depends, among other things, on the sophistication of the regional innovation and entrepreneurship support system.

\section{Regional preconditions determine the scope for industrial modernisation}

The regional context shapes opportunities for successfully managing industrial transition. This context is constructed from the capabilities of regional actors, including their ability to use cutting-edge knowledge and adopt new technologies, their resource endowment and financial capabilities. Many regions experiencing industrial transition are home to high-capability actors - i.e. local universities, a developed business sector, public administration and civil society - that can contribute to and provide resources for successful industrial transition.

Regions with a heritage of manufacturing activity often have strong and established interactions between industry, research, public services and civil society in core areas of expertise. Yet, these interactions are not always used to mobilise novel combinations of knowledge and resources. This suggests that more systemic network building between sectors and better knowledge circulation at the local level and on a global scale is needed. Sourcing knowledge from outside the region can be an effective channel of industrial modernisation because an over-reliance on local sources may create lock-in and reduce innovativeness as incumbent local players may have fewer incentives to change current production outcomes and processes (Fitjar and Rodriguez-Pose, 2011).

Finally, the quality of governance influences regional innovativeness as well as the quality of policy instruments. Governance of existing policy mixes can be a major factor for diverging economic performance in regions with initially similar preconditions (Morgan, 2016). This underscores the need to adapt support systems to region-specific needs and opportunities using a place-based approach to industrial transition.

\section{Choosing the right strategy also depends on legacies and industrial profiles}

The preconditions for successful regional industrial modernisation depend on local institutional and organisational abilities and on the region's existing industrial profile. Regions in industrial transition, even those heavily reliant on traditional manufacturing, may have varying degrees of industrial diversification. Local bottlenecks to successfully manage industrial transition might differ depending on the type of region. 
For example, regions with a strong specialisation in a small number of industries could be exposed to a very homogeneous knowledge base, while highly diversified regions might be either successfully diversifying their economies or facing the danger of being stuck in low-value low skills activities across a range of sectors.

Addressing the challenges arising from industrial transition needs a strong place-based dimension to regional development and a tailored approach to local conditions. Promoting development models for successful industrial transition will require building on each region's past legacy and using policy experimentation to identify policy tools that best fit the local context and legacy.

\section{Regions in industrial transition face very specific governance challenges that need to be addressed across policy themes}

Industrial transition provides many opportunities in terms of jobs and competitiveness by creating pathways towards innovation and investment, bringing in new business models and setting targets towards a resource-efficient economy. Realising these opportunities requires actively managing, or guiding, the transition process towards positive outcomes. Effective transition governance includes the co-ordination of internal (government) and external stakeholders, ensuring an enabling environment for innovation and experimentation (e.g. supportive regulatory and administrative frameworks), well-designed performance measurement systems and effective stakeholder engagement.

Because regional governments are embedded in national and supranational structures, policies and regulatory frameworks, successful transition management also requires a realistic assessment of what regional governments can influence and what they cannot. Moreover, each region in industrial transition also needs to carefully assess its starting-point in the light of changing policy thinking and how the reorientation from old to new and emerging industries can be done in the context of an already existing and evolving - policy landscape.

\section{Understanding the evolution of current policy mixes as a precondition to make useful predictions}

Capabilities, endowments, policies and governance structures in regions in industrial transition are not static but evolve over time. Before introducing new policies to support industrial transition, policymakers need to understand the evolution of the current policy mix, how and to what extent it constrains the range of options available now, and how existing policies interact with each other. Regions in industrial transition have often introduced a range of policies in various policy fields, such as innovation policies, education and skills policies, and SME and entrepreneurship policies. These policies were in some cases effective drivers of existing industrial specialisations and knowledge and may need to be adapted to accommodate current structural change.

\section{Getting the current policy mix right}

Policy instruments do not work in isolation. Public policy unfolds over time and new policy instruments do not emerge in a vacuum but represent an intervention in a continuous stream of unfolding events. Policy mixes can be thought of in a way similar to the prescription of medication. Different medications interact with each other and the underlying medical problem in a highly complex manner. As a result, the overall medication mix may be far from optimal, as some drugs might counteract the effect of other drugs. Such interactions might also accumulate over time when new medications are introduced into the treatment regime. Based on this analogy, the same can hold true for policies. Few policy instruments are highly standardised interventions and how they react with each other is not always easy to understand. 
At the same time, successful industrial transition depends on "system innovations", i.e. a need for simultaneous changes in technology, business models, competency bases, resource use and supporting infrastructure. Achieving this requires integrated policy mixes that combine different policy instruments and create effective processes through which these instruments interact towards a shared vision of industrial modernisation.

\section{Reflecting on goals and rationales}

Policy dynamics co-evolve with other dynamics, such as budgetary, political and economic cycles. The changing economic context in regions in industrial transition calls upon policymakers to critically reflect on goals, rationales and instruments used to pursue regional development. Yet, past decisions will constrain the range of options available for current decision-makers. New policies are adopted into a context of pre-existing policy and actor mixes and institutional frameworks that have emerged over time. For instance, in the Basque country, implementing a new regional development strategy involved building on a series of existing policies and institutional actors, including a landscape of supporting actors and structures built-up over decades under earlier and very different rationales (Valdaliso et al., 2014).

Within this context, the challenge of industrial transition is particular and requires strong leadership and openness to policy experimentation and learning. Old models of development that have made regions experiencing industrial transition become leading innovation hubs in the past may no longer work. At the same time, past decisions will tend to constrain the range of options available to current decision-makers.

\section{Allowing for policy experimentation and learning}

Dealing with policy complexity requires active policy learning and adaptation. This includes learning from failure, active experimentation, and trial and error. Allowing some freedom of action for local experimentation thus becomes important for industrial transition to be successful.

The idea of experimentation takes into account the need for a flexible approach. For regions in industrial transition, this means that interventions may need to be piloted, or combined, or adapted within a given initiative. For example, there could be variations in the criteria for innovation partnerships or various options for cost-sharing in R\&D funding. Once a project has been rolled out, flexibility and openness to changing plans in order to adapt to shifting conditions arising from transition is fundamental.

\section{Balancing short-term actions and political interests with long-term strategic objectives}

Reconciling long-term transition ambition with short-term priorities can be challenging because it might not be easy to garner public approval for policy measures that have a limited immediate effect. This puts regions in industrial transition in a difficult situation. One the one hand, they need to cope with the immediate needs for action resulting from a decline in traditional industries, such as higher unemployment, income losses and degrading living conditions for parts of the population. On the other hand, they need to take action to seize opportunities associated with industrial modernisation, such as attracting higher valueadded industry, creating and/or attracting new companies and business models and making better use of enabling technologies. Carefully designing policies that can harness the benefits and limit the downsides of a fair transition becomes imperative.

\section{Providing regional leadership}

Regional leadership contributes to industrial modernisation by formulating and implementing both a vision and a strategy. In addition, leadership can help transform the identity of a region to the rest of the world as well as the region's own self-image, which is important in order to attract and retain talent and to foster human interactions among local agents. 
The role of regional policymakers is to construct a shared vision for and with local actors with the objective of jointly designing a pathway towards industrial modernisation. Creating a shared vision requires identifying, engaging and gathering leaders from different regional stakeholder groups such as local industries, academia, public authorities and non-profits, and pursuing participative governance processes defining regional innovation strategies.

Industrial modernisation processes are likely to fail if local agents do not support the broad strategic vision for regional economic modernisation. In addition to a well-defined vision, it is important for regions in industrial transition to support exchange between local leaders and to allow new players to enter existing markets and industries. Appropriate tools to accomplish this include the promotion of internal events (for local networking) or external events (as representing the region/regional entrepreneurs at trade fairs), and incentives for collaborative R\&D.

\section{Managing financial considerations}

To prepare for industrial modernisation, regional governments and other stakeholders need to ensure adequate and appropriate financing mechanisms to realise policy and programming objectives. Both the direction and the type of finance provided and leveraged are important. Stimulating investment in new sources of employment and productivity growth requires providing support to firms and workers to become more innovative and adjust from traditional sectors to new technologies. Financial support also helps encourage knowledge exchange and co-operation between local actors, such as small and large firms and universities. Such support in local collaboration and networking helps to create an attractive innovation ecosystem.

Financial incentives can be provided in various forms, including through grants (e.g. vouchers), loans or loan guarantees. However, care needs to be taken not to crowd out the private sector and to take into account competition policy concerns. To this end, regional governments can also promote alternative sources of financing. Public financing offers should be reviewed on a regular basis in order to ensure that local firms and workers have access to appropriate financing. While regions in industrial transition might have a good range of financial tools in place, these might not always correspond to the needs of businesses with models that rely on intangible assets or display high-risk profiles.

\section{Strengthening (multi-level) governance processes}

Industrial transition takes place in a complex governance environment, spanning multiple levels (local, regional, national and supranational) and involving a wide variety of actors. To successfully manage industrial transition within a region, improving co-ordination among public and private sector actors and civil society as well as ensuring a cross-sectoral and multi-stakeholder approach is vital.

Because regional governments must be responsive to national and supranational policy and regulatory frameworks, successful transition management also requires a realistic assessment of what regional governments can influence and how. In addition, "active relationship management" is necessary among the various levels of government involved in order to ensure that priorities are clear and aligned, that policies are coherent and that the objectives of all levels of government can be attained. Promoting co-ordination and capacity building at the national and subnational levels is a large and critical step toward accomplishing this.

\section{Monitoring and evaluation of the policy mix}

Because innovation and innovation policy operate in a complex, dynamic and uncertain environment, a commitment to performance measurement systems, including monitoring and evaluation, is fundamental. Not only do they paint a picture of whether or not innovation policies are meeting their objectives, they offer insight into what needs to be adjusted and build evidence bases for future policy and programming design. 
Yet, performance measurement in innovation policy is a challenge, as regions often face financial and staff resources and skills limitations, as well as gaps in technical knowledge with regard to defining performance indicators and setting quantitative objectives.

In addition, with a broader understanding of what innovation can be and what it encompasses, there is a need to improve the indicators traditionally used. Available measurements largely reflect the industrial era and less so the knowledge-based and digitalised economy, leaving policymakers struggling to capture the impact of the digital transformation, for example. For regions in industrial transition, where broadening innovation policy is fundamental for a successful transition, the lack of effective monitoring and evaluation mechanisms is particularly difficult. Improving monitoring and evaluation capacities includes more consultation with stakeholders to develop goals and design programmes, more stringent collection of programme data, better monitoring of progress, adjusting programmes towards industrial modernisation, and overcoming of societal and disruptive challenges related to transition.

\section{References}

Boschma, R. (2009), "Evolutionary economic geography and its implications for regional innovation policy", Papers in Evolutionary Economic Geography, Vol. 9/12, http://econ.geo.uu.nl/boschma/OECD.pdf.

Brynjolfsson, E. and A. McAfee (2014), The Second Machine Age: Work, Progress, and Prosperity in a Time of Brilliant Technologies, MIT, Boston, https://wwnorton.com/books/the-second-machine-age/.

Calvino et al. (2018), "A taxonomy of digital intensive sectors", OECD Science, Technology and Industry Working Papers, No. 2018/14, https://doi.org/10.1787/f404736a-en

Content, J. and K. Frenken (2016), "Related variety and economic development: A literature review", European Planning Studies, Vol. 24/12, pp. 2097-2112.

European Commission (2017a), Reflection Paper on Harnessing Globalisation, https://ec.europa.eu/commission/sites/beta-political/files/reflection-paper-globalisation en.pdf.

European Commission (2017b), Reflection Paper on Towards a more sustainable Europe by 2030, https://ec.europa.eu/commission/sites/beta-political/files/rp sustainable europe 30-01 en web.pdf.

Fitjar, R.D. and A. Rodríguez-Pose (2011), 'When local interaction does not suffice: Sources of firm innovation in urban Norway", Environment and Planning A, Vol. 43/6, pp. 1248-1267.

Grillitsch, M. and B. Asheim (2018), "Place-based innovation policy for industrial diversification in regions", European Planning Studies, Vol. 26/8, pp. 1638-1662.

Morgan, K. (2016), "Nurturing novelty: Regional innovation policy in the age of smart specialisation", Environment and Planning C: Government and Policy, Vol. 35, pp. 569-583.

OECD (2019a), OECD Employment Outlook 2019: The Future of Work, OECD Publishing, Paris, https://doi.org/10.1787/9ee00155-en.

OECD (2019b), OECD SME and Entrepreneurship Outlook 2019, OECD Publishing, Paris, https://doi.org/10.1787/34907e9c-en.

OECD (2018a), Job Creation and Local Economic Development 2018: Preparing for the Future of Work, OECD Publishing, Paris, https://doi.org/10.1787/9789264305342-en.

OECD (2018b), OECD Science, Technology and Innovation Outlook 2018: Adapting to Technological and Societal Disruption, OECD Publishing, Paris, https://doi.org/10.1787/sti in outlook-2018-en.

Valdaliso, J. et al. (2014), "Path dependence in policies supporting smart specialisation strategies: Insights from the Basque case", European Journal of Innovation Management, Vol. 17/4, pp. 390-408. 


\title{
Annex 1.A. Toolkit to assess policy responses to industrial transition
}

\author{
Annex Table 1.A.1. Overview of policy issues and policy responses for regions in industrial \\ transition
}

\begin{tabular}{|c|c|}
\hline Policy issue & Policy responses \\
\hline \multicolumn{2}{|r|}{ Preparing for the future of work } \\
\hline $\begin{array}{l}\text { Lack of skilled workers to move into } \\
\text { new and emerging activities }\end{array}$ & $\begin{array}{l}\text { - Better anticipate skills needs for industrial transition } \\
\text { - Strengthen capacity of firms to address their human resource needs internally } \\
\text { - Involve local stakeholders in the planning and design of regional skills initiatives }\end{array}$ \\
\hline $\begin{array}{l}\text { Spatially concentrated lack of job } \\
\text { opportunities for low- and middle- } \\
\text { skilled workers }\end{array}$ & $\begin{array}{l}\text { - Support vulnerable workers during the period of industrial transition } \\
\text { - Provide workforce and management development for start-ups and scale-ups through training and } \\
\text { upskilling programmes } \\
\text { - Foster the integration of youth, women and older people in the labour market }\end{array}$ \\
\hline $\begin{array}{l}\text { Limited investment in new sources of } \\
\text { employment and productivity growth }\end{array}$ & $\begin{array}{l}\text { - Provide support for firms to become more innovative and adjust from "traditional sectors" to new } \\
\text { technologies } \\
\text { - Assist firms in better using skills at the workplace } \\
\text { - Encourage knowledge exchange and co-operation between larger and/or newer firms with smaller } \\
\text { and/or older firms }\end{array}$ \\
\hline $\begin{array}{l}\text { Lack of co-ordination and financing } \\
\text { mechanisms }\end{array}$ & $\begin{array}{l}\text { - Implement effective multi-level partnerships } \\
\text { - Ensure sufficient and well-targeted financing and investment }\end{array}$ \\
\hline \multicolumn{2}{|r|}{ Broadening and diffusing innovation } \\
\hline $\begin{array}{l}\text { Creating and sustaining } \\
\text { comprehensive innovation } \\
\text { ecosystems }\end{array}$ & $\begin{array}{l}\text { - Broaden the notion of innovation and build private and public sector capabilities for innovation } \\
\text { - Strengthen innovation financing and reduce barriers to investment } \\
\text { - Improve monitoring and evaluation of innovation policies }\end{array}$ \\
\hline $\begin{array}{l}\text { Lack of (small) business capabilities } \\
\text { for innovation }\end{array}$ & $\begin{array}{l}\text { - Accelerate the digital transformation } \\
\text { - Scale business innovation networks and support clusters } \\
\text { - Support effective university-industry co-operation }\end{array}$ \\
\hline $\begin{array}{l}\text { Territorial disparities in innovation } \\
\text { diffusion }\end{array}$ & $\begin{array}{l}\text { - Leverage the potential of cities and tradable sectors } \\
\text { - Capitalise on unique regional strengths for innovation } \\
\text { - Strengthen skills development and skills utilisation }\end{array}$ \\
\hline \multicolumn{2}{|r|}{ Promoting entrepreneurship and private sector engagement } \\
\hline $\begin{array}{l}\text { Limited access to finance for start-ups } \\
\text { and scale-ups }\end{array}$ & $\begin{array}{l}\text { - Facilitate access to finance and broaden the range of financial instruments } \\
\text { - Strengthen financial literacy }\end{array}$ \\
\hline $\begin{array}{l}\text { Limited access to entrepreneurship } \\
\text { skills and networks for start-ups and } \\
\text { scale-ups }\end{array}$ & $\begin{array}{l}\text { - Support entrepreneurs with information, training, coaching and mentoring } \\
\text { - Strengthen entrepreneurial networks } \\
\text { - Enhance start-up and SME participation in collaborative research }\end{array}$ \\
\hline $\begin{array}{l}\text { Improving the entrepreneurial } \\
\text { enabling environment }\end{array}$ & $\begin{array}{l}\text { - Ensure a friendly regulatory environment through simplified regulations and registration } \\
\text { procedures } \\
\text { - Foster an entrepreneurship culture through the development of entrepreneurial mindsets } \\
\text { - Monitor and evaluate SME and entrepreneurship policies }\end{array}$ \\
\hline
\end{tabular}




\begin{tabular}{|c|c|}
\hline Policy issue & Policy responses \\
\hline \multicolumn{2}{|r|}{ Transitioning towards a climate-neutral economy } \\
\hline $\begin{array}{l}\text { Creating job opportunities for the } \\
\text { transition to the climate-neutral } \\
\text { economy }\end{array}$ & $\begin{array}{l}\text { - Support green skills and jobs through training and upskilling } \\
\text { - Support workers in transition through dedicated job-search training and Flexicurity in labour } \\
\text { markets } \\
\text { - Support measures to a just transition }\end{array}$ \\
\hline $\begin{array}{l}\text { Lack of business opportunities for } \\
\text { green innovations }\end{array}$ & $\begin{array}{l}\text { - Stimulate green behaviour in firms } \\
\text { - Encourage innovation in environment-friendly technologies }\end{array}$ \\
\hline $\begin{array}{l}\text { Reconciling the long-term strategic } \\
\text { dimensions of a climate-neutral } \\
\text { transition with short-term action }\end{array}$ & $\begin{array}{l}\text { - Foster local energy transitions through financial and strategic support schemes } \\
\text { - Integrate the transition to a climate-neutral economy into larger regional development strategies } \\
\text { - Ensure an enabling environment for transition }\end{array}$ \\
\hline \multicolumn{2}{|r|}{ Promoting inclusive growth } \\
\hline Strengthening regional well-being & $\begin{array}{l}\text { - Integrate vulnerable populations into the labour market } \\
\text { - Develop and implement a regional-level well-being framework }\end{array}$ \\
\hline $\begin{array}{l}\text { Spatial discrepancies and territorial } \\
\text { linkages }\end{array}$ & $\begin{array}{l}\text { - Encourage territorial co-operation through rural-urban partnerships } \\
\text { - Ensure digital connectivity and digital services in remote regions }\end{array}$ \\
\hline $\begin{array}{l}\text { Improving inclusive growth } \\
\text { governance }\end{array}$ & $\begin{array}{l}\text { - Building strategic partnerships and stakeholder engagement } \\
\text { - Make inclusive growth an explicit goal across levels of government }\end{array}$ \\
\hline
\end{tabular}





\section{Preparing for the jobs of the future}

Increased globalisation and rapid technological change, together with demographic, migration and industry developments, are altering the structure of local labour markets and skills requirements across OECD countries - and these trends are expected to continue in the foreseeable future. This chapter explores how regions in industrial transition can seize the benefits of automation and digitalisation for industrial modernisation while also managing the costs of structural adjustment. The chapter identifies a range of specific jobs and skills barriers that regions in industrial transition face and discusses policy approaches and instruments to overcome them. It also highlights factors that can support an effective policy agenda for regions in industrial transitions to prepare for the future of work. 


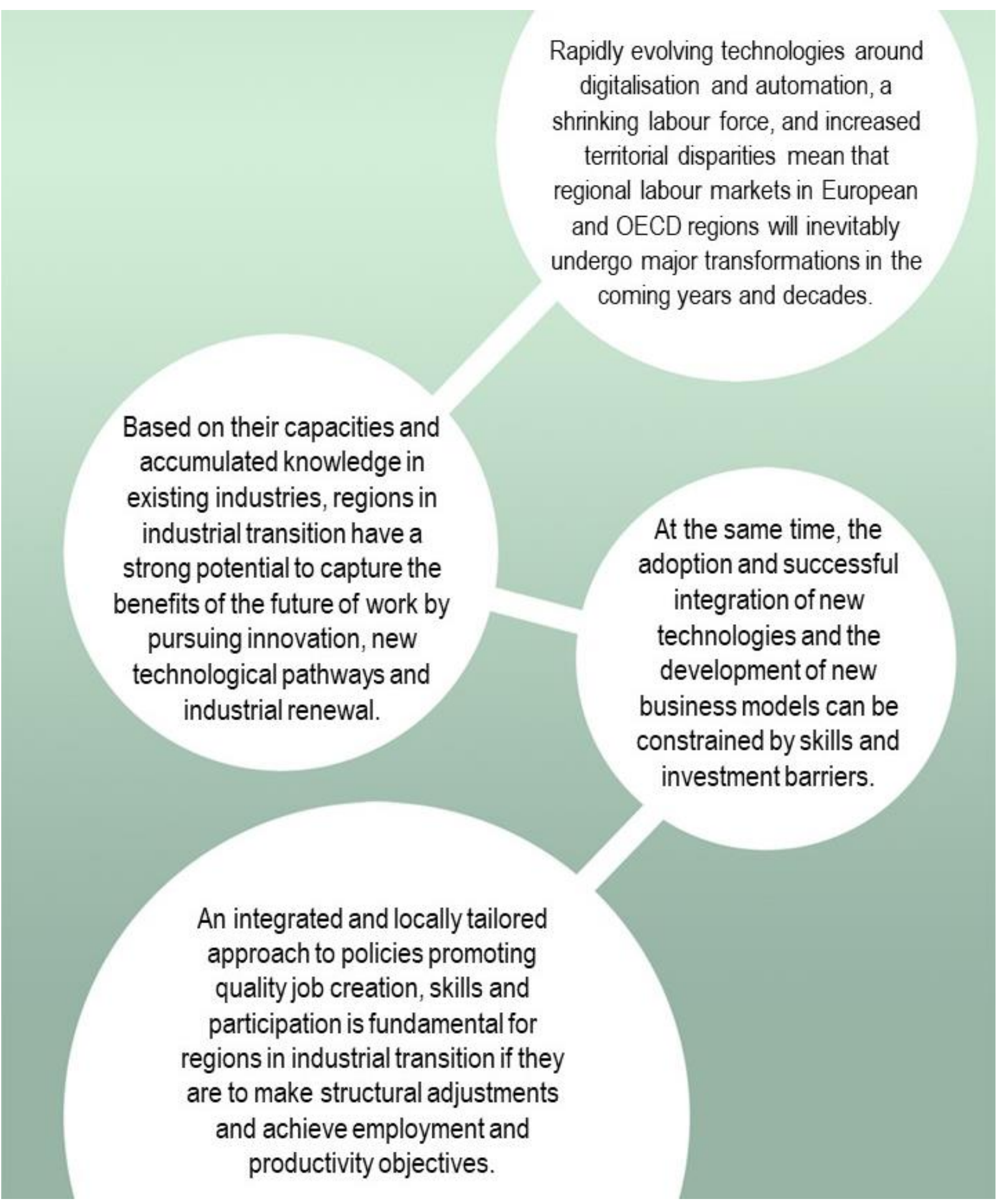




\section{Changing skills and jobs profiles affect regions in industrial transition}

Regions that have experienced industrial decline or that still base their economic activity on traditional manufacturing or extractive industries are increasingly confronted with the need to modernise their industrial base. A key challenge for successful industrial transition centres on how such regions and industries can pursue innovation and new technological opportunities pathways to break out of locked-in paths of development and generate industrial renewal. Technological innovation and organisational innovation are an opportunity to encourage broad industrial modernisation. They are also a source of concern with respect to outsourcing and job losses in these regions.

Because industrial transition often requires a shift from old and traditional manufacturing industries to future-oriented activities (even in traditional sectors), industrial transition can lead to higher than average unemployment (at least temporarily) due to locally concentrated deindustrialisation, as well as a skills base in declining sectors. It is crucial that policies to address industrial transition help workers and local communities manage the transition with the least possible disruption while maximising potential benefits.

\section{Automation will critically affect local labour markets and regions in industrial transition in specific ways}

Job tasks have been automated for centuries, boosting productivity and giving rise to new jobs that provide employment and contribute to rising living standards. The introduction of steam power is a prominent early example of technology that saved labour on a massive scale. Historically, the changing nature of workplace skills, a requirement of technological progress, has led to fears of "technological unemployment" (Keynes, 1931). At the same time, technological innovation has always led to new jobs, while productivity growth from automation has been the most important driver of rising living standards (Autor and Salomons, 2018).

Yet, automation also poses challenges. First, technology can change labour markets very suddenly, while it may take considerable time to create new jobs and replace those lost to technological progress. Second, the skills profiles of jobs lost to automation and those required to replace the jobs lost might not be the same. The automation of jobs, therefore, can lead to a temporary (in principle) but potentially prolonged period of unemployment (OECD, 2018a).

Previous waves of technological breakthroughs have shown that automation does not spread evenly across territories. On the contrary, certain occupations and sectors are more exposed to automatable tasks than others and neither occupations nor sectors are evenly distributed within national borders. The OECD has shown that substantial in-country differences exist when considering the number of jobs at high risk of automation (OECD, 2018a). For instance, the share of workers in jobs with a risk of automation equal to or larger than $50 \%$ varies more than two-fold across regions in the OECD countries for which data is available. The share of jobs at risk of automation is as low as $28 \%$ in Helsinki and the surrounding region while reaching $70 \%$ in Western Slovakia (Figure 2.1).

Regions in industrial transition are likely to be part of those territories that are more, rather than less, affected by automation because they are often home to traditional manufacturing industries with a higher proportion of jobs that rely on routine tasks. This is likely to lead to more disruption than in other places.

The automation of existing jobs means that there is a potential for new jobs to be created and even more jobs will be changed. If managed well, these changes can lead to economic growth via contributions to productivity and higher value-added activities. However, as the jobs of the future will use different skills and may have higher educational requirements, workers may need to switch occupations and acquire new skills. Upskilling and retraining the existing workforce should be high on the agendas of policymakers in these regions in order to prepare workers for the future of work. 
Figure 2.1. Risk of automation across European TL2 regions, 2016

Share of regional workers at risk of job automation higher than $50 \%$

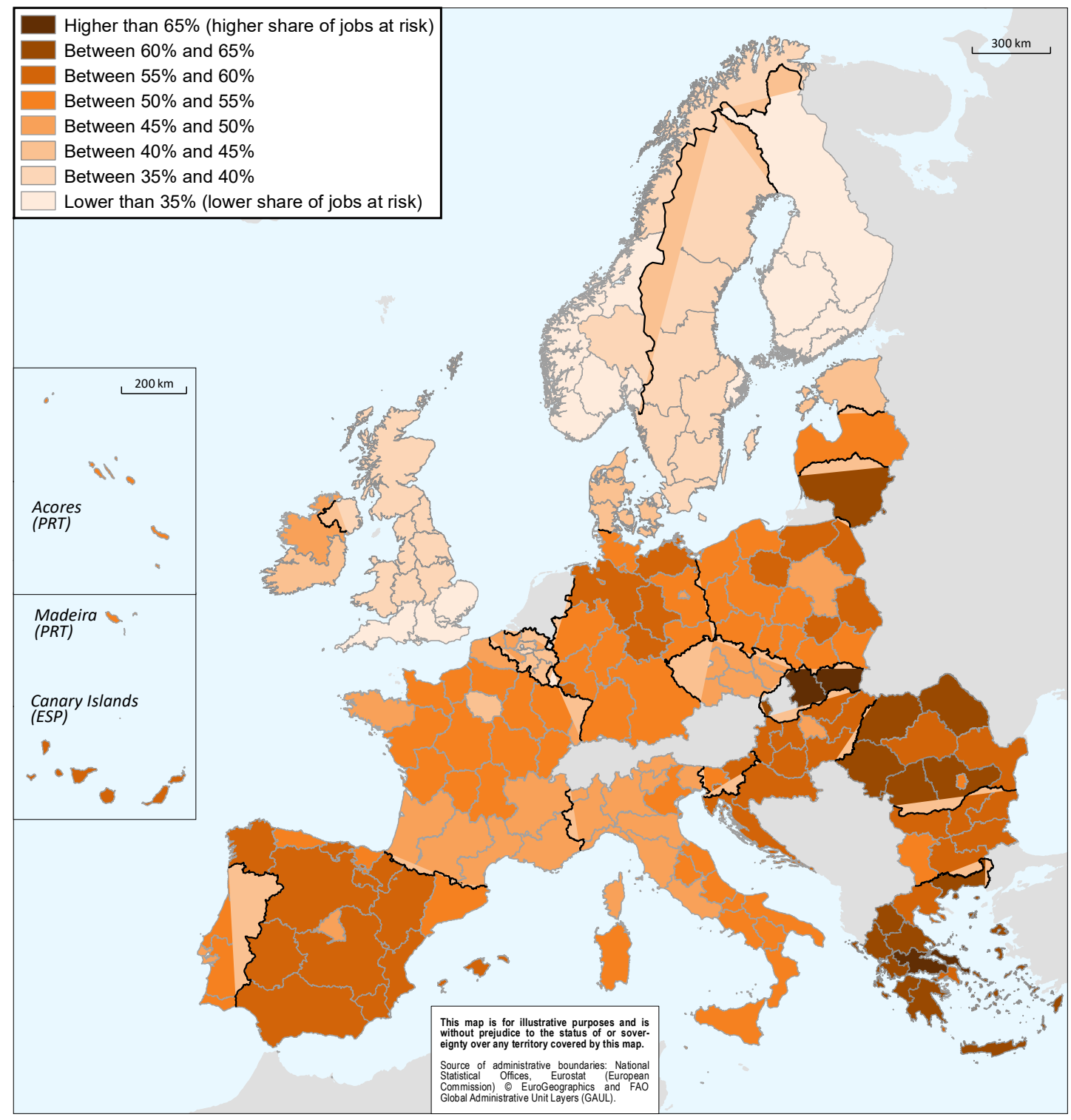

Notes: $A$ job is considered to be at risk of automation if it has a $50 \%$ or higher probability of being automated. Estimates for the share of workers in jobs at risk of automation/significant likelihood of change are based on estimates that combine the risk of automation for individual tasks with the specific tasks performed in occupations and the distribution of occupations across regions (for the methodology see Nedelkoska and Quintini, 2018). Data that links tasks and occupations come from the OECD Survey of Adult Skills (Programme for the International Assessment of Adult Competencies, PIAAC) and have been regionalised in OECD, 2018a. For countries where PIAAC data and is not available, estimates are based on a weighted average for the occupation-specific risk of automation from the three most similar countries with available data. Similar countries and the weights for the average are based on an iterative matching procedure that considers the industrial, occupation and education structure of OECD countries and regions. See Box 3.1 in OECD (2019b) for further details.

Reference years and territorial level: Reference year 2016. Data from Norway corresponds to the year 2016. Large regions (Territorial Level 2 of the OECD Regional Statistics [Database]), except for Flanders (Belgium), for which sub regions are considered (corresponding to NUTS2 level of the European Classification), as well as for France (regions prior 2016 territorial reform).

Sources: OECD calculations based on Nedelkoska, L and G. Quintini (2018), "Automation, skills use and training", https://doi.org/10.1787/2e2f 4eea-en, and National Labour Force Surveys (2016). Published in OECD (2018a), Job Creation and Local Economic Development 2018: Preparing for the Future of Work, https://doi.org/10.1787/9789264305342-en. 


\section{Industrial transition may come with increased job polarisation}

Jobs destroyed through automation disproportionately involve routine or repetitive tasks. By contrast, demand has increased for individuals with transversal skills such as making sense of new unstructured information, negotiating and striking deals or caring for others. What these tasks have in common is that they do not follow a precise set of rules and are more difficult to articulate and codify so that a computer can execute them. Because these tasks tend to be associated with either high-skilled or low-skilled occupations, automation is said to bring about a "hollowing-out" of middle-skilled jobs (Autor, 2015; Brynjolfsson and McAfee, 2014; OECD, 2016a).

Over the past two decades, middle-skill and middle-wage employment as a share of the workforce has declined in OECD countries. At the same time, workers who carry out non-routine tasks have increased their share of total employment. These jobs are either high-skilled (e.g. managerial positions) or low-skilled (e.g. basic services). Thus, both ends of the skill-distribution spectrum of jobs have increased while the middle has declined (Figure 2.2).

\section{Figure 2.2. Changes in the share of jobs by skills level}

Percentage point change in the share of total employment, 1995-2015

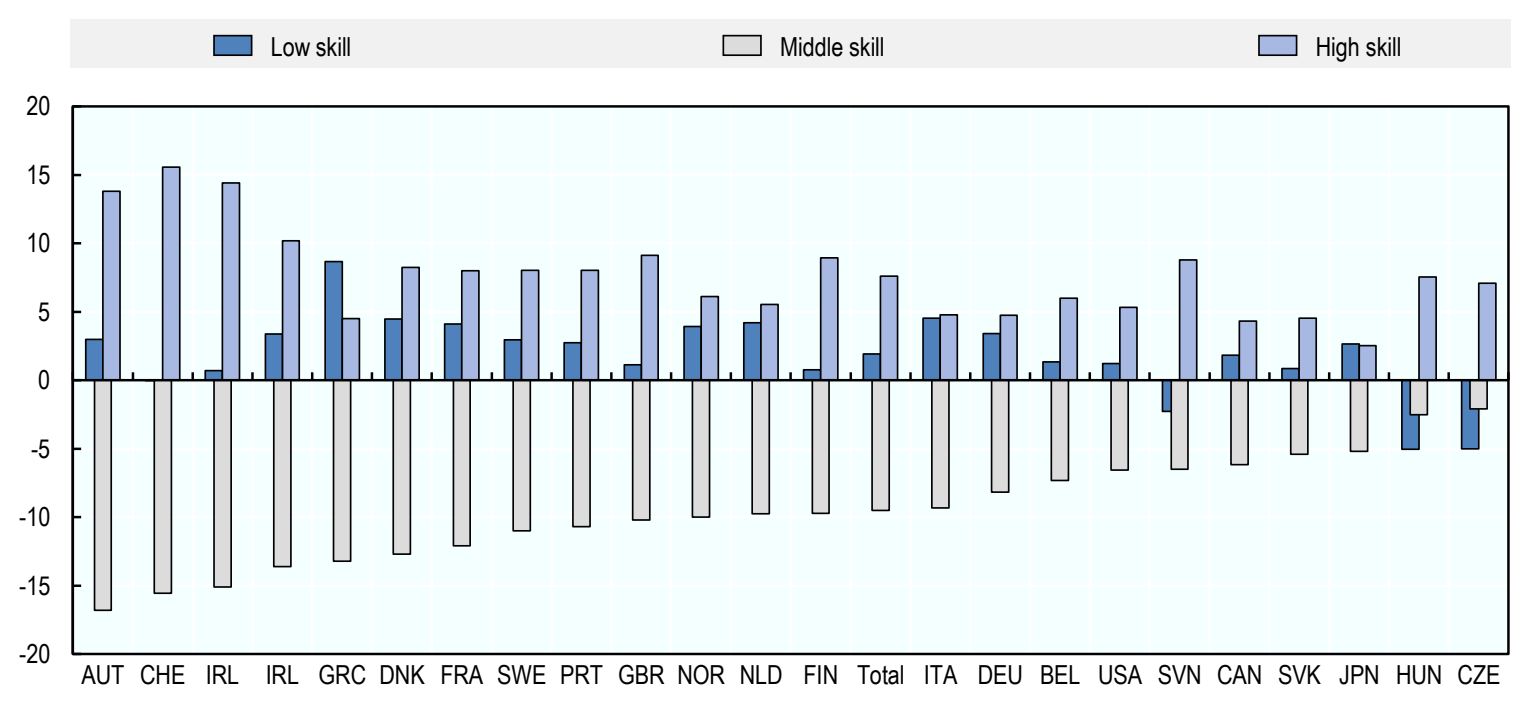

Note: High-skill occupations include jobs classified under the ISCO-88 major groups 1, 2, and 3. Middle-skill occupations include jobs classified under the ISCO-88 major groups 4, 7, and 8. Low-skill occupations include jobs classified under the ISCO-88 major groups 5 and 9 . For more details refer to the OECD Employment Outlook 2017.

Source: OECD (2018a), Job Creation and Local Economic Development 2018: Preparing for the Future of Work, https://doi.org/10.1787/97892 64305342-en.

Selecting a policy approach in the face of an ever more polarised labour market will require a nuanced response by policymakers in regions in industrial transition. Given the rapid pace of technological improvements, shifts in tasks undertaken by humans might occur quickly and even high-skilled workers need to become more flexible to cope with a situation in which tasks are being taken over by machines. Policymakers in affected regions also need to ensure that this does not lead to a situation in which a more polarised labour market leads to higher income inequality and a dual labour market, with one part of the population being significantly better off than the other. Ensuring that the employees in new jobs created have adequate social rights and employment protection is an important part of the story. 


\section{Non-standard work might become increasingly prevalent in some regions in industrial transition}

Technological progress not only leads to automation, it also promotes the emergence of new forms of employment, including the growth of non-standard work, defined as temporary, part-time and selfemployment (Eurofound, 2015). Non-standard work provides job opportunities for many individuals, thanks to greater flexibility. It helps match workers to jobs, integrate those who are marginalised in the labour market and, in certain cases, can offer a better work-life balance. Yet non-standard work can also reduce access to social protection and healthcare benefits. People in non-standard jobs often face lower levels of skills investment than standard employees; evidence shows that this category of jobs may sometimes be an opportunity of last resort rather than a worker's choice. Non-standard work can create a dichotomy in the labour market between individuals with a stable career and those jumping from one non-standard job to the next, and has been rising in most OECD countries since 1985. There are, however, large regional differences within countries. For instance, in Greece, the share of non-standard work as part of total jobs grew by $7 \%$ in western Greece while declining by $11 \%$ in Epirus.

Focusing on temporary work only, the OECD has shown that the presence of a large pool of low-skilled workers (those with less than secondary education) is associated with a large share of temporary work (OECD, 2018a). This may be related to the lower prevalence of specific skills in low-skilled jobs, which facilitates substituting one worker for another. Furthermore, the regional rate of unemployment is strongly associated with the prevalence of temporary work in a given region. This is because regional labour markets with higher unemployment rates should see more competition for jobs, reducing the bargaining power of individual workers (OECD, 2018a).

OECD analysis at the regional level reveals a complex picture, with some regions contributing more than others to the rise of temporary work. The increase in the share of temporary work could be the consequence of an increasing number of jobs with temporary contracts but also a relatively smaller reduction of temporary contracts compared to permanent jobs. Some regions in industrial transition could experience an increase in non-standard work if traditional manufacturing sectors are restructuring or are ceasing activity. While some of the laid-off workers will be able to transition and upgrade jobs, others will seek alternative, potentially non-standard job routes. The probability of non-standard work will be higher for those workers who did not finish secondary school.

\section{What challenges and opportunities do regions in industrial transition face in preparing for the future of work?}

To successfully meet the future of work, regions in industrial transition need to simultaneously reap the benefits and address the risks of automation, in particular greater job polarisation, and a rise in non-standard work. Taking an integrated approach to quality job creation, skills and participation can help regions in industrial transition make structural adjustments and achieve employment and productivity objectives. Complementary investment policies are needed too. Firms should be encouraged to move towards higher value-added activities to reduce the risk of automation for a given occupation. Furthermore, the growth of economic sectors with a low risk of automation should be supported. To do this effectively, policymakers at all levels need to tailor policies to the economic conditions in regions undergoing a transition.

Regions in industrial transition are often confronted with job polarisation and firms in two different stages of development. These regions are frequently home to companies with a large share of highly qualified workers, good digital infrastructure, a high assessment of digital potentials and a priority to train employees. 
They also comprise firms - usually small- and medium-sized enterprises (SMEs) - with a low share of highly qualified workers, poor digital infrastructure, a low assessment of digital potential and a low priority to train employees. These two types of firms are often unevenly spread across a region's territory. Highlyskilled workers and productive firms might be geographically concentrated, giving rise to widening inequalities between places of high productivity and a high-skilled workforce, and low productivity and a low-skilled workforce. Such polarisation can widen gaps in competitiveness, employment opportunities and overall well-being, and ultimately increase inequalities within and across regions.

Higher than average youth unemployment is an additional factor that many regions in industrial transition must consider. Young people, as well as other disadvantaged and under-represented groups such as older people or women, are disproportionally affected by long-term unemployment, often driven by a lack of education and limited work experience. Being isolated from the labour market affects several dimensions of youth well-being. It decreases overall life satisfaction and increases the risk of social exclusion and of dropping permanently out of the labour force, while also decreasing optimism about the future (Eurofound, 2017). Policy has an important role in supporting youth in education and employment in order to make sure that youth are able to participate in the labour market and earn their own income (see also Chapter 6 on inclusive growth).

\section{Getting skills development right drives successful transition}

Regions in industrial transition are typically home to a large pool of high-skilled labour in traditional fields of industry. Although well trained for their current employment, these workers often possess a homogeneous knowledge base with a lack of future-oriented skills. However, embracing industrial modernisation and technological upgrading requires highly skilled employees, ones able to perform complex tasks that help drive firm competitiveness and productivity growth (OECD, 2016b). Skills development is, therefore, critical, particularly in the context of growing digitalisation and globalisation.

Skilled workers typically possess strong cognitive skills (e.g. numeracy, literacy and problem-solving) and management and communication skills. Information and communication technology (ICT) skills are particularly relevant for making use of emerging digital technologies, such as cloud computing, the Internet of Things or Big Data (OECD, 2017b). However, companies also need workers who not only have strong cognitive skills but also emotional and communication skills, and a readiness to learn (Grundke et al., 2017).

While regions in industrial transition tend to lack a sufficient number of highly-skilled workers for futureoriented and technology-rich environments, they are not the only ones. Across the OECD, two-thirds of adults are unsuitably skilled to participate in technology-rich environments. For workers without tertiary education, this changing environment leads to greater difficulty in finding employment given the higher demand for workers with technical expertise (OECD, 2017b).

\section{Regions in industrial transition need to avoid falling into a "low-skills equilibrium"}

If the skill supply does not match the type or level of skills that employers demand or if the supply is not aligned with how local employers use available skills, then skills mismatches arise. Skills mismatches and shortages have multiple sources. Often, students, workers, employers or training institutions lack information on the skills required in the short-, medium- and long-term, driving mismatches. In addition, co-ordination failures can occur, for example, when the firms are not able to adapt their processes to the available skills stock (OECD, 2016b).

Assessing the relationship between the levels of skills of the current workforce (the supply) and the level of skills needed for available jobs (the demand) can provide important information on the potential for local 
job creation. The OECD has developed a diagnostic tool that classifies subnational areas into four categories based on their relationship between the supply and demand of skills relative to other subnational areas within the same country. For example, when considering France and the United Kingdom, the supply and demand of skills within local economies varies greatly (Figure 2.3). In France, about one-third of all subregions were in a "high skills equilibrium", with both a relatively high supply of and demand for skills. Another group of subregions were in a "low-skills trap". Here, both the supply of skills and the demand for skills were relatively low; some of these subregions may find it hard to move to higher-skilled, higher-value-added products and services. The remaining subregions were in a position of imbalance, with a relatively high supply of skills and low demand for skills (skills surplus) or vice versa (skills deficit). In the UK, 45 subregions were in a "high skills equilibrium", with both a relatively high supply of and demand for skills. Another 45 subregions were in a "low-skills trap" (relatively low supply of and demand for skills) and the remaining subregions were in a position of imbalance, with a relatively high supply of skills and low demand for skills (skills surplus) or vice versa (skills deficit).

\section{Figure 2.3. Combining skills supply and skills demand at the regional level in French (2012) and UK subregions (2013)}
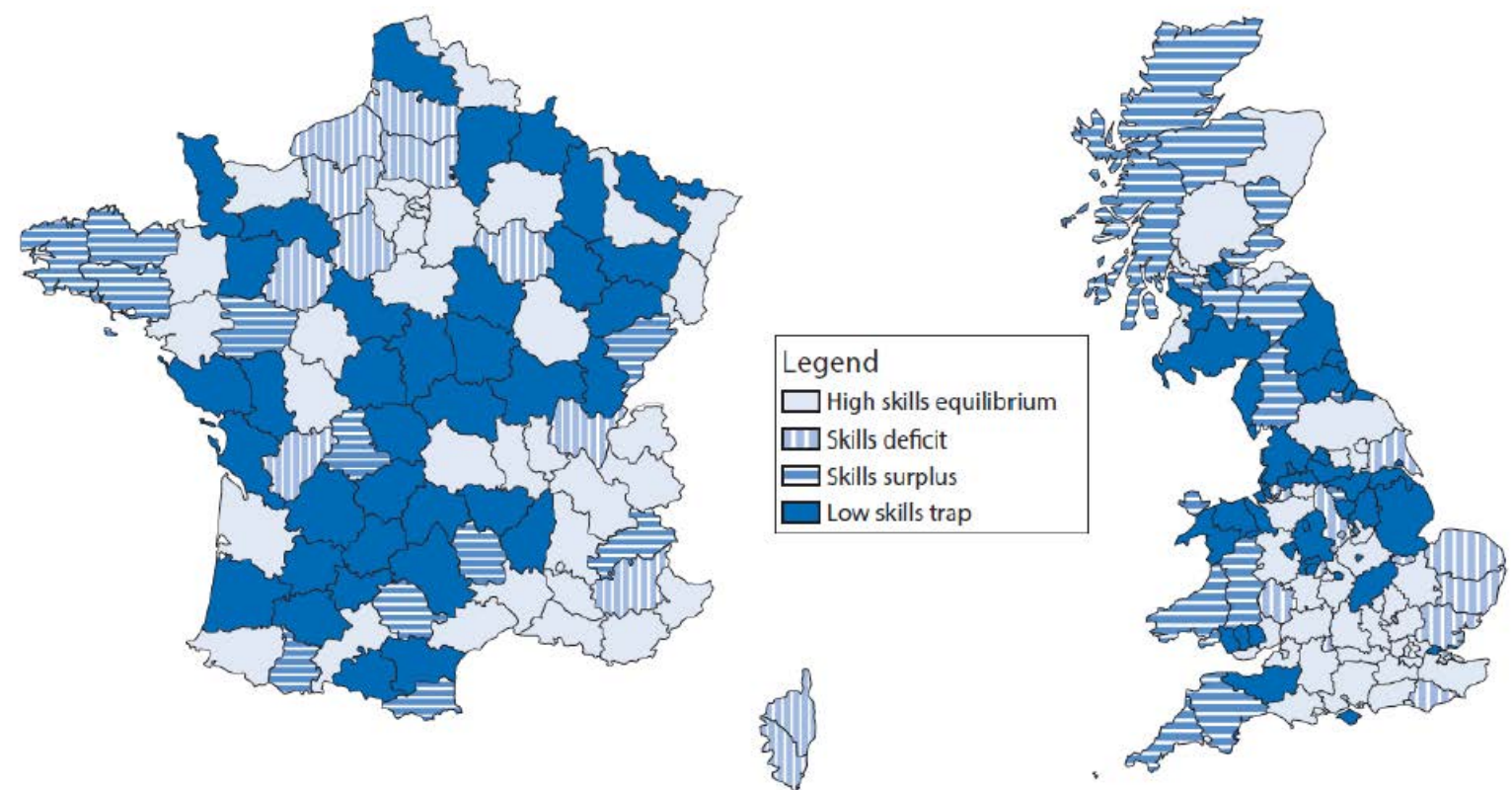

Source: OECD (2016c), Job Creation and Local Economic Development 2016, https://doi.org/10.1787/9789264261976-en.

The example highlights considerable variation in the supply and demand for skills at the regional level. Some areas are characterised by low-skilled, low-quality and poorly productive jobs. Such areas can fall into a "low-skills equilibrium", where it does not pay for individuals to invest in building or upgrading their skills if they are not valued by local employers (OECD, 2016c). Local employers, in turn, have little incentive to move to higher-skilled production and services, knowing that the local workforce does not have the required skills level to fill these types of jobs. Retaining and attracting talent can be an additional challenge for areas faced with a low-skills trap. Because regions in industrial transition often have a lower than average skilled workforce and are home to traditional industries, they risk being trapped in a low-skills equilibrium. 
Finding the right entry point to break this cycle is challenging. Structural adjustments to achieve national employment and productivity objectives will likely require an integrated approach to skills. In some cases, this can mean actively working with firms to help increase product development and marketing strategies, or providing training to workers in order to increase the intensity of the skills of local production processes, for example.

\section{SMEs often lack soft skills for innovation}

Employees of SMEs are more likely to face difficulties in adapting to a changing industrial and employment environment. This is often attributed to a lack of specific skills that are particularly relevant for increasing firm performance and innovation, including cognitive skills and soft skills, such as communication, creativity, problem-solving and interpersonal interaction.

Evidence suggests that employees in large firms are more likely to have innovation-related transversal skills than their counterparts in SMEs. Results from the OECD Survey of Adult Skills (PIAAC) show that workers in large firms have higher scores on management and communication skills than employees in small firms (Figure 2.4, Panel A). The survey also shows how skills related to readiness to learn and problem-solving are more concentred in larger firms rather than in SMEs, Panel B).

\section{Figure 2.4. Smaller firms lack soft skills for innovation}

Distribution of skills across countries by firm size and sector

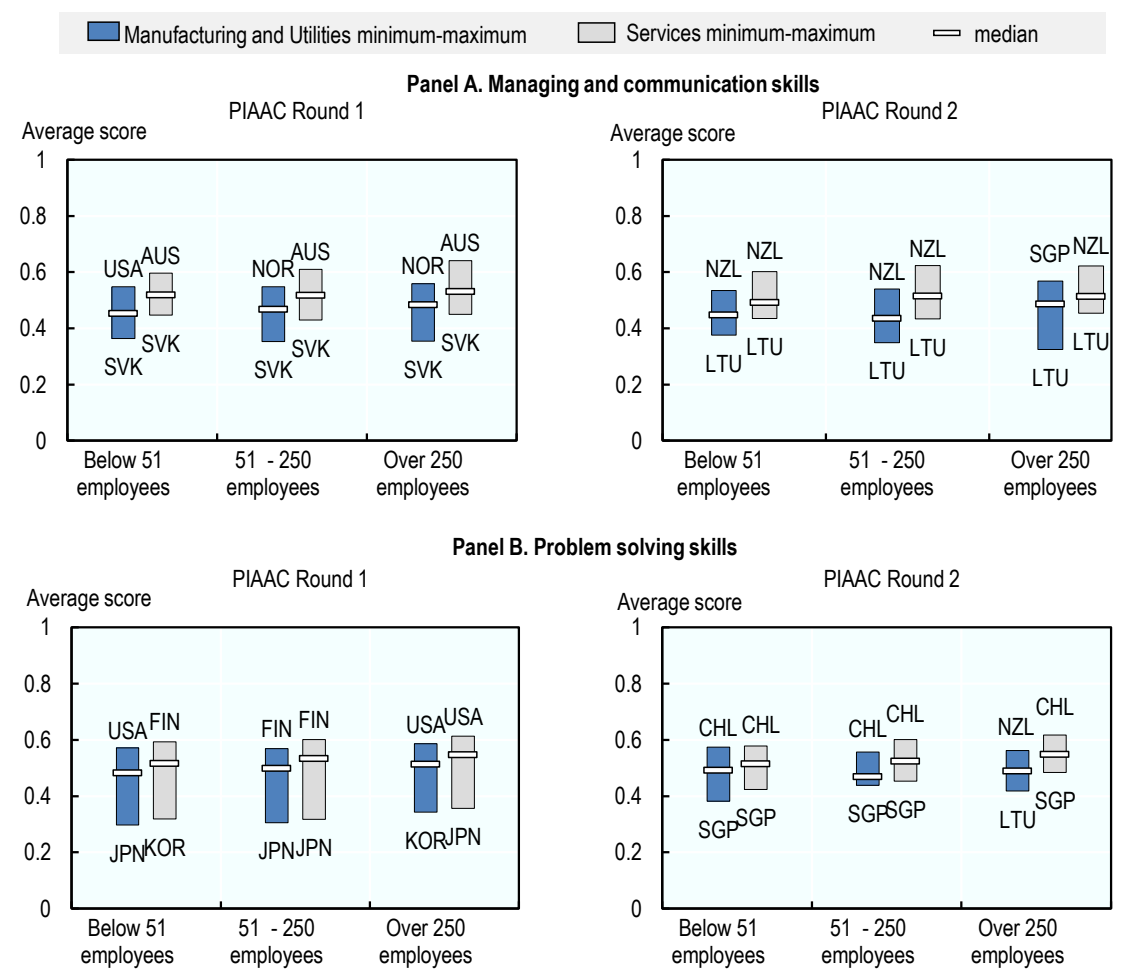

Note: PIAAC tests the cognitive skills of adults on different dimensions (literacy, numeracy and problem-solving in technology-rich environments) as well as the type of tasks they frequently perform. PIAAC Round 1 was conducted in 2008-13 and Round 2 was conducted in 2012-16. Source: Grundke, R. et al. (2017), "Skills and global value chains: A characterisation", https://doi.org/10.1787/cdb5de9b-en, based on OECD PIAAC data. 
Policy challenges for regions in industrial transition centre on how to best support skills development in SMEs, how to deliver training to local SMEs and how to attract talented individuals to local SMEs instead of large firms.

\section{Upgrading skills is critical but how can it be done?}

Regions undergoing a shift in their industrial base often face an increased skills shortage in new and emerging areas of activity. They are also confronted with decreasing employment of skilled workers in traditional occupations. This leads to a situation where more and better jobs with attractive remuneration and working conditions may be available but a lack of skilled employees results in a large number of unfilled vacancies. In order to fill these jobs, skilled workers from traditional occupations need to be retrained and upskilled in order to ensure that the labour force corresponds to the demanded skillset.

Across the OECD, only $41 \%$ of adults participate in formal or non-formal job-related training in a given year (OECD, 2019a). Moreover, the adults who are most vulnerable in the labour market, such as those with few qualifications, the long-term unemployed and those with skills at high risk of job automation are least likely to participate in training. Engaging those who do not participate in education or training is a fundamental task for regions in industrial transition in order to prepare their workforce to meet changing skills needs.

Many workers in regions in industrial transition and beyond want to take-up lifelong learning opportunities but face a variety of obstacles in doing so. One of the leading barriers to participation in training programmes is a lack of time, while paradoxically a lack of employer support is one of the least cited reasons (OECD, 2019a) (Figure 2.5).

\section{Figure 2.5. Barriers to participation in training programmes in OECD countries}

Reasons for non-participation (\% of adults who wanted to participate but did not)

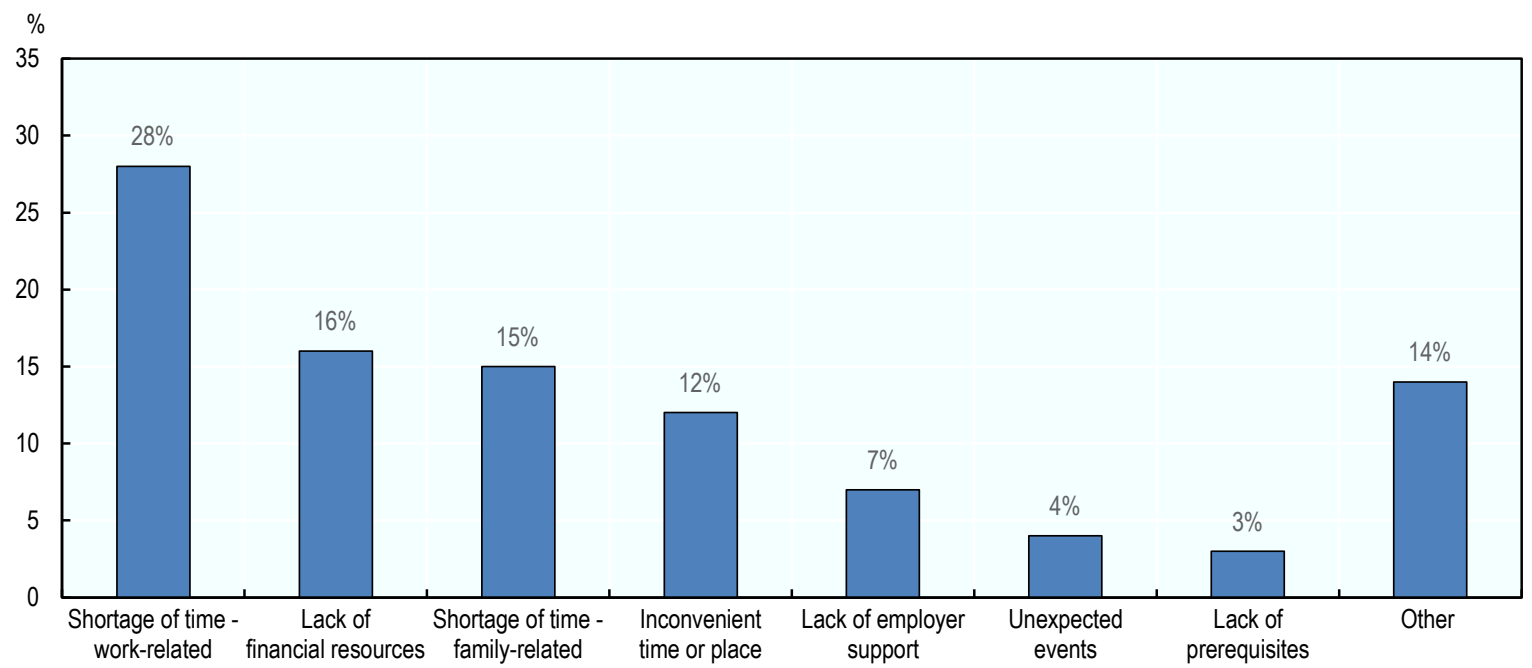

Note: Average of OECD countries participating in PIAAC.

Source: OECD 2019a, based on PIAAC data $(2012,2015)$.

A second challenge that regions in industrial transition face is the supply of the right training content to prepare for future skills needs. Good quality data on skills supply and demand often lacks at a regional 
level. In addition, local employer engagement can be low and it may also not always be clear how to involve key stakeholders. Questions arise such as "Should universities focus predominantly on world-class research or follow the demands of local employers?" and "Should regional governments play a stronger role skills training, for example in leadership and entrepreneurship?". The answers are often not an "either/or" and so solutions are not mutually exclusive, but they may take time to be constructed and implemented.

Third, the margin for manoeuvre by regional governments is often limited when it comes to education or training policy. In many countries, changes in the educational system are a national-level responsibility. Thus, effective multi-level governance practices and frameworks are needed for regional and national governments to work together, including to identify, implement and support effective regionally led interventions in skills and education. Governments may also need to work more closely with the private sector to deliver appropriate training.

Fourth, ensuring adequate and sustainable financing for upskilling and retraining is often a challenge for regions in industrial transition that operate with tight budgetary constraints. As demand for training is likely to increase in the current context of megatrends (e.g. automation and digitalisation), additional financial resources will need to be devoted to adult learning in the near future.

\section{What can policy do (better) to support a successful transition into the future of work?}

Regions in industrial transition are often home to skilled and well-trained labour force in core industries. In addition, some transition regions are starting to build a labour force in future-oriented and digital occupations. In order to successfully modernise their local industrial base, it is critical for transition regions to upgrade the skills and production capabilities of existing industries while simultaneously promoting the diversification of the local economy. Major changes to existing industries can come through new technologies, new business models and organisational innovation. A key element to support innovation is appropriate human capital. Strengthening the skills and competencies of local actors in relation to future emerging technologies and industries is one key to regional growth.

Successfully transitioning into the future of work requires tailoring employment and skills development policies to local labour market conditions. At the same time, the supply of skills needs to be matched with skills demand. For regions in industrial transition, this means that education and labour market policies need to be well co-ordinated with investment policies in order to connect people to jobs. Better anticipating future skills needs and appropriate retraining and upskilling of workers need to be combined with policies that stimulate investment in new sources of employment and productivity growth.

\section{Supplying the right skills for new and emerging activities}

Although a certain level of skills shortages and mismatches is inevitable in a dynamic and constantly changing labour market, several policy instruments exist to reduce their incidence. These can include improved career guidance services, better co-ordination between the labour market and the education system, more offers for work-based training and addressing rigid wage-setting and employment protection legislation that prevents workers and firms from adjusting to mismatches (OECD, 2016b). 
Table 2.1. Supplying the right skills for new and emerging activities: Policy issues, instruments and rationales

\begin{tabular}{|c|c|c|c|}
\hline Policy issue & Policy response & $\begin{array}{l}\text { Potential suite of implementation } \\
\text { mechanism }\end{array}$ & Rationale/additional benefits \\
\hline \multirow[t]{5}{*}{$\begin{array}{l}\text { Lack of skilled workers to } \\
\text { move into new and } \\
\text { emerging activities }\end{array}$} & $\begin{array}{l}\text { Better anticipate skills } \\
\text { needs for industrial } \\
\text { transition }\end{array}$ & $\begin{array}{l}\text { - Foresight, skills mapping } \\
\text { - Workforce Intelligence Networks } \\
\text { - Expert Groups on Future Skills Needs }\end{array}$ & $\begin{array}{l}\text { Informs policymaking } \\
\text { Avoids skills shortages and skills } \\
\text { mismatches }\end{array}$ \\
\hline & \multirow[t]{2}{*}{$\begin{array}{l}\text { Strengthen the capacity of } \\
\text { firms to address their } \\
\text { human resource needs } \\
\text { internally }\end{array}$} & \multirow{2}{*}{$\begin{array}{l}\text { - Strengthen human resources (HR) } \\
\text { management capacity of SMEs } \\
\text { - Link with SME support policies with } \\
\text { education and training policies } \\
\text { - Strengthen links between firms, } \\
\text { universities and research bodies }\end{array}$} & $\begin{array}{l}\text { Improves responsiveness of training } \\
\text { provision to market needs }\end{array}$ \\
\hline & & & $\begin{array}{l}\text { Strengthens co-ordination between } \\
\text { different policy areas }\end{array}$ \\
\hline & \multirow[t]{2}{*}{$\begin{array}{l}\text { Involve local stakeholders } \\
\text { in the planning and } \\
\text { design of regional skills } \\
\text { initiatives }\end{array}$} & \multirow[t]{2}{*}{$\begin{array}{l}\text { - Participation in employers' councils } \\
\text { - Collaborations and partnerships with } \\
\text { vocational schools, universities and } \\
\text { small and large firms }\end{array}$} & $\begin{array}{l}\text { Targeted training in new technologies and } \\
\text { sectors of strategic importance }\end{array}$ \\
\hline & & & $\begin{array}{l}\text { Anchors local employers in regional } \\
\text { economic development }\end{array}$ \\
\hline
\end{tabular}

\section{Better anticipating skills needs supports industrial transition}

Skills anticipation and assessment exercises (e.g. skill needs assessments, forecast and foresight exercises) can provide information to more effectively tailor the offer of education and training programmes to local needs. In principle, such exercises provide evidence bases for regions in industrial transition to design policies in accordance with projected labour-market trends by sector, local area and/or occupation, thereby helping generate more successful transition outcomes. In Wallonia, Belgium, the Public Employment Service is undergoing an extensive exercise to identify skills needed in specific business sectors (Box 2.1).

\section{Box 2.1. Industry and skills mapping by the Public Employment Service in Wallonia}

Wallonia's Public Employment Service (PES) is undertaking a prospective analysis - the Le Forem Study - to identify local skills needs in specific sectors. The objective of the exercise is to develop appropriate training offerings for the Wallonia's competitive and business clusters and to communicate the identified skill needs to relevant audiences. The analysis first classifies future occupations and associated core skills in eight sectors. It then identifies a set of related or secondary skills that could subsequently arise from developing the sectors. The approach follows a five-step qualitative process:

1. Analytical staff from the PES produce reports by sector.

2. A panel of experts answers to a set of questions that are then included in the sector reports. The objective is to check the sectoral trends and particularly to detect the effects that these trends may have on occupations.

3. The reports are then produced and disseminated.

4. A method called Abilitic2Perform is used to identify the skills required for each occupation or skills group. Four expert workshops, organised by occupation, identify key evolution factors and the potential evolution scenarios. They then select the most likely (or desired) scenario, identifying also the associated skills needs. 
5. The local training department receives the results of the analysis in order to start designing appropriate training programmes. The results are also published on the Internet and sent to the education authorities.

The sectors and associated industries value the programme since they themselves do not have the capacity or resources to undertake such an extensive study.

Source: Wallonia (2018), "Peer Learning in Regions in industrial transition: Workshops good practice template", Le Forem, the Public Employment Service, Prepared for the Peer Learning in Regions in Industrial Transition Workshop "Preparing Jobs of the Future", 8-9 March 2018, Brussels, Belgium, Unpublished.

\section{Engaging local employers in regional skills development initiatives}

OECD research highlights the importance of better engaging employers in skills development programmes to ensure that training programmes are well aligned to the needs of industry (OECD/ILO, 2017b). For regions in industrial transition, focusing on apprenticeship programmes that combine both on- and off-thejob training to smooth the transition from school to work or help apprentices obtain tertiary level diplomas can be valuable. Apprenticeship programmes are especially useful for young people entering the labour market as these provide workplace experience and establish a solid foundation for future labour market attachment. Subnational leadership can play a critical role in reaching out to employers to promote awareness and participation in apprenticeship training. The region of Piemonte, Italy, is actively promoting apprenticeships as a means to create stronger ties between academia and business while also helping apprentices obtain tertiary education degrees (Box 2.2).

\section{Box 2.2. Apprenticeships for higher education and research}

Piemonte's "Apprenticeship for Higher Education and Research" is a pilot project dedicated to helping apprentices obtain tertiary level diplomas (technical or academic) or doctorate degrees with the help of an apprenticeship contract. Each individual training programme is based on an employer's need and includes "internal" training in the company and "external" training at the education institution. Through the programme, apprentices gain specialised and rapidly employable competencies. At the end of the apprenticeship, the company can confirm whether the apprentice receives a job contract.

The initiative has been well received by participating companies, and as of March 2018, 350 apprentices had received employment contracts. The programme also aims to increase innovation processes and technology transfers by supporting the placement of young researchers and highly specialised professionals as apprentices in regional firms. Initially established for large firms, Piemonte intends to incorporate SMEs into the programme as well.

Source: Piemonte (2018b), "Peer learning in regions in industrial transition: Workshops good practice template", Apprenticeship for Higher Education and Research, Prepared for the Peer Learning in Regions in Industrial Transition Workshop "Preparing Jobs of the Future", 8-9 March 2018, Brussels, Belgium, Unpublished.

In addition to supporting apprenticeships, there is a large potential in supporting employer-led training initiatives. Given the strong presence of small firms in regions in industrial transition, it is important to involve SMEs in skills planning. This can take the form of encouraging their participation in regional employer councils or in co-designing and co-delivering training initiatives with vocational and training 
colleges, universities and large firms. Such networks also help foster trust-based relationships among firms, knowledge sharing and generate opportunities to pool training costs and resources.

\section{Supporting workers in transition}

An important element in managing industrial transition is to help workers affected by lay-offs phase out of previously dominant industries and into new ones. New jobs might not appear where old jobs have been lost. If new jobs are created in distant regions, then workers are faced with a decision to leave their communities for employment, which can have potentially destabilising effects on family and community life. Some workers may refuse to move and decide to transition into unemployment. Using transition support to protect and support such workers to find new jobs without having to relocate is an important element of successfully managing industrial transition.

Policies aimed at improving the probability of finding jobs thanks to improved skillsets and helping make the match between the newly skilled and job vacancies can help regions in industrial transition support structural adjustments. Policy responses to temporary unemployment arising from transition include redesigning and strengthening local public employment services (PES) and providing workforce and management training for workers. Special attention needs to be paid to the integration of underrepresented and disadvantaged groups, such as women, youth and older people, in the labour market (Table 2.2).

Table 2.2. Protecting vulnerable workers in transition: Policy issues, instruments and rationales

\begin{tabular}{l|l|l|l}
\hline \multicolumn{1}{c|}{ Policy issue } & \multicolumn{1}{|c|}{ Policy response } & \multicolumn{1}{c}{$\begin{array}{c}\text { Potential suite of implementation } \\
\text { mechanism }\end{array}$} & \multicolumn{1}{c}{ Rationale/additional benefits } \\
\hline $\begin{array}{l}\text { Spatially concentrated } \\
\text { lack of job opportunities } \\
\text { for low- and middle-skilled } \\
\text { workers }\end{array}$ & $\begin{array}{l}\text { Support vulnerable } \\
\text { workers during the period } \\
\text { of industrial transition }\end{array}$ & $\begin{array}{l}\text { - Redesign local employment services } \\
\text { - Use the Internet as a channel of } \\
\text { delivery }\end{array}$ & $\begin{array}{l}\text { Provides the unemployed with new job } \\
\text { opportunities }\end{array}$ \\
\cline { 2 - 4 } & $\begin{array}{l}\text { Provide workforce and } \\
\text { management } \\
\text { development for start-ups } \\
\text { and scale-ups through } \\
\text { training and upskilling } \\
\text { programmes }\end{array}$ & $\begin{array}{l}\text { - Training subsidies and vouchers, } \\
\text { training leave allowances, tax } \\
\text { incentives } \\
\text { - Personal Training Accounts }\end{array}$ & $\begin{array}{l}\text { Workers gain highly specialised } \\
\text { competencies needed by firms }\end{array}$ \\
\hline & $\begin{array}{l}\text { Foster the integration of } \\
\text { youth, women and older } \\
\text { people in the labour } \\
\text { market }\end{array}$ & $\begin{array}{l}\text { - Dedicated training initiatives and } \\
\text { courses, provision of role models }\end{array}$ & Managers gain additional knowledge \\
\cline { 2 - 4 } & & $\begin{array}{l}\text { Reduces gaps in labour market } \\
\text { participation }\end{array}$ \\
\hline
\end{tabular}

\section{Supporting vulnerable workers transition to new jobs}

Public employment services play a fundamental role in responding to structural adjustments and assisting workers in job transitions. The changing nature of work means that employment services in regions in industrial transition will need to focus not only on placing individuals in a job but also on ensuring that these individuals are equipped with a good range of generic and basic skills to remain resilient in the workplace. This requires good job matching and transition support schemes to help potentially displaced workers find new employment.

Local employment services can support implementing strategies to re-structure and respond to the future of work but success depends on their flexibility and ability to take a strong leadership role. The OECD Reviews on Local Job Creation series has shown that giving local employment services more room to 
respond to changes in local labour markets must be accompanied by guarantees regarding the accountability of decision-making and the efficiency of service delivery. Front-line staff needs to have good local labour market information as well as strong contacts with employers so they can become quickly aware of new employment opportunities as they arise.

Digitalisation and automation also provide opportunities to improve the delivery of job brokering services. Online technologies can be used for standardised procedures such as initial registration and posting job vacancies, personalised interactions between PES staff and clients, casework counselling functions, and skills training and development. In a number of OECD countries, online vacancy databases are the most used vacancy platforms as measured by the proportion of all vacancies in the economy being notified to the PES database. For example, in Germany, approximately $50 \%$ of all vacancies are reported to the PES (Bundesagentur für Arbeit, 2015). In many OECD countries, public employment services are now using online apps to enable workers and employers to connect in a more efficient manner. This technology provides more robust and accessible labour market information to potential workers on available job opportunities, expected wages as well as the required education and training for employment (OECD, 2016c).

Strengthening public employment services goes hand-in-hand with an ability to better identify upcoming skills needs. The foresight analysis undertaken by the region of East and North Finland is an example of how examining skills needs helps re-skill workers, enabling them to participate in the changing economy (Box 2.3).

\section{Box 2.3. Regional foresight in East and North Finland}

In East and North Finland, regional foresight co-ordination is a statutory responsibility of regional councils, and duties related to it are set in the Act on Regional Development (1651/2009). The objective of the regional foresight work is to monitor the regional operating environment, changes in industry sectors, the needs of the labour force and its existing skills and expertise. Region-specific operational foresight platforms are guiding the foresight work in each region.

A key success factor of regional foresight in Finland is close co-operation among different foresight actors in order to create a shared understanding of future challenges in the region, a shared vision around future development objectives and means to reach set targets. Each region has launched placespecific regional foresight models and produced local analysis reports that feed into the support of regional policy strategies and programmes.

Source: North and East Finland (2018), "Peer learning in regions in industrial transition: Workshops good practice template", Regional Foresight, Prepared for the Peer Learning in Regions in Industrial Transition Workshop "Preparing Jobs of the Future", 15-16 May 2018, Brussels, Belgium, Unpublished.

\section{Engaging firms in training and education}

More actively engaging firms in training and education can help boost productivity and ultimately enhancing the contribution of local firms to industrial modernisation. Common mechanisms to support workforce development in existing firms include financial incentives such as training subsidies, training vouchers and tax incentives to encourage employees to take training or for employers to provide training. Training measures include support to handle digital technologies or helping firm managers to better identify training needs in their company. 
In the context of the future of work, Individual Training Accounts (or Lifelong Learning Accounts) can also help workers better manage their labour-market future. The overarching purpose of these accounts is for workers to invest in training at any point in their careers by using these funds - either to help career advancement or to adjust to a new job as resulting from job change. In France, for example, every employee has a personal training account that can be accessed online and is valid throughout their entire career (OECD, 2017a).

Another option to raise awareness for training is to leverage local employer networks to promote skills upgrading in firms. Collaboration across firms supports knowledge sharing and pooled investment in training. Innovative diffusion in regional supply chains can also help firms integrate into global value chains (GVCs), thereby reducing regional vulnerability to automation (OECD, 2018d). Singapore's SkillsFuture programme provides a platform offering workplace learning and guidance for firms in areas of emerging skills (Box 2.4).

\section{Box 2.4. Singapore's SkillsFuture Programme}

In 2018, Singapore established the National Centre of Excellence for Workplace Learning to help companies set up on-the-job training structures. SkillsFuture targets skills training for early- and midcareer professionals recognising that technology and globalisation are changing the nature of jobs at a rapid pace. As part of the programme, all Singaporeans aged 25 and above receive an opening credit of USD 500 to use towards lifelong learning and training. Companies can apply for grants from SkillsFuture Singapore and SMEs can receive up to $90 \%$ of the cost of training in-house trainers. It is expected to help more than 1000 companies, especially SMEs, in the 5 years from its introduction. The programme also offers guidance on industry-relevant training programmes that focus particularly on emerging skills: i) data analytics; ii) finance; iii) tech-enabled services; iv) digital media; v) cybersecurity; vi) entrepreneurship; vii) advanced manufacturing; and viii) urban solutions.

Source: SkillsFuture Singapore (n.d.), About SkillsFuture, http://www.skillsfuture.sg/AboutSkillsFuture.

\section{Fostering the integration of under-represented and disadvantaged groups}

Firm restructuring and reallocation in industrial transition often leads to job losses. Being laid off can have catastrophic implications in the short-run for individuals and places when large employers suddenly shed a high number of jobs. Public policy can support displaced workers to transition into other jobs. Regional policymakers play a large role in supporting laid-off workers: they can put together support packages for concrete cases of large firm restructuring, prolonged unemployment or poor working conditions.

Age and gender may represent further challenges to industrial transition because youth, older people and women might be disproportionately affected by the new world of work. Younger workers might find it more difficult to break into existing labour markets due to a lack of education or work experience. Older workers with abundant experience in one area might find it difficult to find new employment due to shifting skill demands. Female entrepreneurs and business owners might face additional barriers to enter the labour market. Public policy can help overcome these barriers in a number of ways. Information campaigns can begin removing negative perceptions of age and gender. For older workers, certain OECD countries move to reduce labour costs associated with this cohort by introducing age-specific wage subsidies or labourtax reductions. Meanwhile, programmes stimulating decent working conditions, such as the one in Saxony, Germany (Box 2.5) help promote attractive jobs for disadvantaged and under-represented groups in the labour market. 


\section{Box 2.5. The "Decent Work for Saxony" programme}

Saxony's "Decent Work for Saxony" programme aims to promote better jobs with attractive pay and working conditions in the region, as well as boost collective bargaining capabilities. The programme offers training and skills upgrading, and supports reinforced health and safety regulations. It offers firms bonus funding for those enterprises with a union presence. Overall, the programme provides a comprehensive strategy to help protect workers' rights while also acquiring skills needed for technologically driven changes in the economy.

Source: Sachen Freistaat (2018), "Sachen", PowerPoint Presentation for the Peer Learning in Regions in Industrial Transition Workshop "Preparing Jobs of the Future", 8-9 March 2018, Brussels, Belgium, Unpublished.

\section{Investing in new and emerging sources of growth and employment}

Tapping into new and emerging sources of growth and employment can help regions in industrial transition prevent being locked-in to old industries and create job opportunities that increase productivity, wages and ultimately prosperity. Public support entails investing in technology and ICT training provisions, and actively encouraging the private sector (especially SMEs) to invest in new technologies and business models. A range of policy instruments exist to support new growth and employment opportunities for regions in industrial transition (Table 2.3). These include support for firms to become more innovative, make better use of skills in the workplace and encourage knowledge exchange and co-operation (see also Chapters 3 and 4).

\section{Table 2.3. Providing investment for new sources of growth: Policy issues, instruments and rationales}

\begin{tabular}{|c|c|c|c|}
\hline Policy issue & Policy response & $\begin{array}{l}\text { Potential suite of implementation } \\
\text { mechanism }\end{array}$ & Rationale/additional benefits \\
\hline \multirow{4}{*}{$\begin{array}{l}\text { Limited investment in new } \\
\text { sources of employment } \\
\text { and productivity growth }\end{array}$} & \multirow{2}{*}{$\begin{array}{l}\text { Provide support for firms } \\
\text { to become more } \\
\text { innovative and adjust } \\
\text { from "traditional" sectors } \\
\text { to new technologies }\end{array}$} & \multirow{2}{*}{$\begin{array}{l}\text { - ICT training and technology extension } \\
\text { programmes } \\
\text { - Human Resource Development } \\
\text { Consortia at the sectoral level }\end{array}$} & $\begin{array}{l}\text { Facilitates access to and benefit from } \\
\text { global value chains }\end{array}$ \\
\hline & & & $\begin{array}{l}\text { Support for transversal skills to manage } \\
\text { innovation and technological change }\end{array}$ \\
\hline & $\begin{array}{l}\text { Assist firms in better } \\
\text { using skills in the } \\
\text { workplace }\end{array}$ & $\begin{array}{l}\text {-Workplace Leadership Centres, Local } \\
\text { Employer Networks } \\
\text { - Workplace Challenge programmes }\end{array}$ & Enhances cross-industry innovation \\
\hline & $\begin{array}{l}\text { Encourage knowledge } \\
\text { exchange and } \\
\text { co-operation between } \\
\text { larger and/or newer firms } \\
\text { with smaller and/or older } \\
\text { firms }\end{array}$ & $\begin{array}{l}\text { - SME participation in employer } \\
\text { networks, foster industry clusters, } \\
\text { create regional brands, enhance } \\
\text { product market strategies, company } \\
\text { learning networks }\end{array}$ & $\begin{array}{l}\text { Creates an attractive innovation } \\
\text { ecosystem }\end{array}$ \\
\hline
\end{tabular}

\section{Using technology extension services to improve innovation outcomes}

Technology extension services can be an interesting policy instrument to support industrial sectors with relatively low competitiveness in regions in industrial transition or to promote the restructuring and diversification of industries in crisis. The first observed use of this instrument was in 19th-century Ireland. 
After the potato famine, agricultural advisors funded by the government-supported Irish potato farmers to successfully diversify into different food crops (Shapira, Youtie and Kay, 2011).

Technology extension services are often provided by a network of trained specialists (e.g. engineers) who can proactively reach out to companies and visit firms in the region. These services can target individual firms or a group of companies in need of advice and training on similar challenges. Technology extension services usually start with an assessment of the firm's current level of operation. Based on the initial assessment, an improvement plan is developed and accompanied by assistance. Services can include providing information on how to improve existing technologies, advising in quality management and certification, and training company staff in effectively using more advanced technologies. The first stages of review and diagnosis are generally free of charge, more intensive projects often require co-financing by the firm, although at lower than market prices for more traditional consulting services.

\section{Making better use of skills in the workplace}

Most traditional approaches to skills development are supply-side focused. This means that regional and national initiatives tend to focus on increasing the number of people with post-secondary or vocational education qualifications. However, increasing job polarisation, as well as limited productivity growth in regions in industrial transition, require stronger efforts to optimise the use of skills in the workplace.

Improving the use of skills in the workplace has several benefits for workers, firms and the local economy as a whole (Table 2.4). From the worker perspective, improving skills use can result in greater job satisfaction and higher wages. For employers, better skills use can improve the retention of workers, reduce turnover and ultimately improve the productivity of the firm. From a local economic development perspective, workers that use their skills in the workplace, especially in non-routine tasks, are less vulnerable to potential offshoring of economic production (OECD/ILO, 2017a). Improving skills use can also result in potential gains in aggregate productivity at the national level across many OECD countries (McGowan and Andrews, 2015).

\section{Table 2.4. The benefits of better using skills}

\begin{tabular}{l|l}
\hline Individuals & $\begin{array}{l}\text { Job-related well-being and satisfaction } \\
\text { Increased job quality } \\
\text { Higher wages }\end{array}$ \\
\hline Firms & $\begin{array}{l}\text { Improved retention of workers } \\
\text { Higher productivity } \\
\text { Greater employee engagement and improved relations between management and workers }\end{array}$ \\
\hline Local economies & $\begin{array}{l}\text { Gains in aggregate productivity } \\
\text { Better investment climate }\end{array}$ \\
\hline
\end{tabular}

Source: OECD/ILO (2017a), Better Use of Skills in the Workplace: Why It Matters for Productivity and Local Jobs, https://doi.org/10.1787/9789 264281394-en.

Regions in industrial transition can use employment, skills and managerial training policies to improve skills utilisation, thereby improving productivity and job quality. Local employment services can identify firms with an abnormal turnover rate, which may signal a low degree of skills utilisation. Training programmes can be particularly useful when designed to provide workers and managers with the skills needed to reorganise their structures to enhance adaptability and flexibility to fast-changing technologies and environments 
Depending on the local context, training to strengthen management capacities can be organised by public organisations, colleges and universities, or private sector consultants.

OECD research highlights the importance of raising awareness and recognising employers that create and sustain high-performance workplaces (OECD/ILO, 2017a). This research also underscores the importance of providing specific support to help employers re-shape their workplaces. For example, in northern Italy's Rivera del Brenta industrial district, a local employers' association helped raise productivity and skills utilisation in local footwear firms by pooling investment in training provision and helping firms to collectively upgrade their product market strategies. Anchor institutions, such as universities, vocational education and training institutions, chambers of commerce or major local employers, can reach out to employers to support changes in the workplace. These institutions usually act as brokers and often require a specific skillset to guide, facilitate and deliver training and other services dedicated to enhancing the demand for skills. In addition, creating or leveraging local employer networks, as seen with the Skillnet Programme in Ireland, can also be effective in promoting programmes supporting better use of skills in the workplace (Box 2.6).

\section{Box 2.6. The Skillnet programme in Ireland}

Established in 1999, Ireland's Skillnet programme actively supports and works with businesses to identify and address their skills needs. It also works with the unemployed to train and upskill workers. The programme funds 65 training networks, supporting over 14000 companies and 50000 trainees. Member companies determine their training needs and how and where the training is offered. Programmes are optimised to suit the needs of already employed learners through formal and informal learning that ranges from further education to higher education provision. The Skillnet networks support enterprise networking and offer businesses a flexible, agile way to respond to changing skill demands. They help companies achieve economies of scale and greater efficiency in the provision of staff training. Programmes include the Finuas Networks Programme, targeting the international financial services sector, the Future Skills Needs Programme, which designs innovative training to address future skill needs; a workplace activation initiative to help job seekers obtain employment, and a programme for management development, which supports SME owner-managers. Skillnet is funded through the National Training Fund, associated with Ireland's Department of Education and Skills.

Source: Skillnet (n.d.), Skillnet Statement of Strategy, https://www.skillnetireland.ie/publication/statement-of-strategy-2016-2019-summaryl.

\section{Encouraging knowledge exchange and co-operation}

A firm's innovation capacity is related to learning and the ability of the surrounding region to catch up on knowledge (Tödtling and Trippl, 2005). Firms, research institutes, universities and other higher education institutes, as well as government and non-governmental organisations belong to regional innovation environments. Their geographic proximity, shared culture and mutual trust strengthen their ties within local networks.

Enhanced knowledge sharing is fundamental to economic development and industrial modernisation. Nurturing the development of knowledge hubs around future-oriented activities that build on regional strengths and involve a large range of local stakeholders can foster innovation networks in regions in industrial transition. These hubs - be they formal or informal - bring together policymakers, practitioners, companies, universities and civil society around specific issues. 


\section{Creating adequate co-ordination and financing mechanisms}

Redesigning education and skills systems to fit the new world of work is a complex task, requiring policies to pursue a variety of objectives and reach across different target groups. Responsibility for this lies with regional policymakers but also with national ministries and employment agencies and is often split across stakeholders. In this context, good co-ordination mechanisms are essential to ensure that policies reinforce rather than duplicate each other. This is true with respect to financing as well. Given the number of actors - from government, to private sector, academia and civil society, as well as workers - effective co-ordination is essential to administer separate budgets and be sensitive to different financial capacities. Creating and implementing effective co-ordination mechanisms and better encouraging firms and individuals to help finance training is key for regions in industrial transition to succeed in industrial modernisation (Table 2.5).

\section{Table 2.5. Creating adequate co-ordination and financing mechanisms: Policy issues, instruments and rationales}

\begin{tabular}{l|l|l|l}
\hline \multicolumn{1}{c|}{ Policy issue } & \multicolumn{1}{c|}{ Policy response } & $\begin{array}{c}\text { Potential suite of implementation } \\
\text { mechanism }\end{array}$ & \multicolumn{1}{|c}{ Rationale/additional benefits } \\
\hline $\begin{array}{l}\text { Lack of co-ordination and } \\
\text { financing mechanisms }\end{array}$ & $\begin{array}{l}\text { Implement effective } \\
\text { multi-level partnerships }\end{array}$ & $\begin{array}{l}\text { - Increasing stakeholder participation in } \\
\text { local skills ecosystems, better } \\
\text { co-ordination arrangements, capacity- } \\
\text { building initiatives }\end{array}$ & $\begin{array}{l}\text { Coherent development of transition } \\
\text { policies across levels of government }\end{array}$ \\
\cline { 2 - 4 } & $\begin{array}{l}\text { Ensure sufficient and } \\
\text { well-targeted financing } \\
\text { and investment }\end{array}$ & $\begin{array}{l}\text { - Tax incentives and subsidies, paid } \\
\text { training leave, loans, personal training } \\
\text { accounts }\end{array}$ & $\begin{array}{l}\text { Improved policy effectiveness and } \\
\text { efficiency }\end{array}$ \\
\hline
\end{tabular}

\section{Implementing effective multi-stakeholder partnerships}

Strategic partnerships help regional governments adapt employment and skills programmes to the changing nature of work at the local level. Local partnerships can define local problems and needs, as well as identify and implement potential solutions. An effective partnership between public authorities and regional employers will leverage knowledge and resources and help remove barriers to employment by enhancing workforce skills.

Local networking among public agencies is a critical source of social capital. Local and regional contexts are the settings where "coalitions of purpose" can be effectively built across the public, private and not-forprofit sectors in order to respond to structural changes in the local economy. Examples of important governance instruments are effectively designed monitoring and evaluation systems, better co-ordination arrangements, strengthened capacity-building initiatives and increased cross-sector co-operation.

Effective partnerships among different levels of government are equally important for regions in industrial transition, particularly as transition policies can be simultaneously implemented at the national, regional and local levels. Introducing appropriate incentive mechanisms for co-operation and/or creating working groups across programmes, sectors and/or among different levels of government can provide coherence and provide overall performance. 


\section{Ensuring adequate and sustainable financing}

Education and skills systems need adequate and sustainable financing from companies and individuals. Regional governments can encourage greater investment in training through financial incentives for individuals and/or employers (Table 2.6). While financial incentives for individuals/firms exist in all education areas beyond compulsory schooling, they are particularly important for adult learning, which is more often delivered by private training providers and thus more costly. Virtually all OECD countries use financial incentives to encourage firms to provide training and financially contribute to adult learning. This also helps individuals to reduce the direct cost of learning.

Table 2.6. Financial incentives for individuals and employers

\begin{tabular}{l|l|l}
\hline & \multicolumn{1}{|c}{ Individuals } & \multicolumn{1}{c}{ Employers } \\
\hline Reduce cost of training & $\begin{array}{l}\text { Subsidies } \\
\text { Tax incentives }\end{array}$ & $\begin{array}{l}\text { Subsidies } \\
\text { Tax incentives }\end{array}$ \\
\hline Decrease opportunity cost of training & $\begin{array}{l}\text { Paid training leave } \\
\text { Allowance for unemployed/job seekers }\end{array}$ & Job rotation \\
\hline Tackle temporary liquidity constraints & Loans & Loans \\
\hline Set resources aside for future training & Savings and asset building mechanisms & Training levylfund \\
\hline
\end{tabular}

Source: OECD, 2019a.

\section{Key considerations and conclusions}

Successfully managing industrial transitions means balancing the need to support innovation-led-growth as a driver of productivity growth while preparing the workforce for potential job losses and reorienting skills profiles. In particular, older industrial regions with a long heritage in industrial manufacturing are confronted with a situation in which workers and firms need support to successfully manage the transition from old and traditional industries to new fields of activity. Often, these regions have the capacity and knowledge necessary to reorient to modern and emerging industries, but they are unable to make full use of this potential. Barriers to benefitting from the unfolding industry changes often lie in insufficient investment and a lack of local industry innovation.

Counteracting such developments requires an integrated policy approach that can connect people to jobs. Policymakers, employers and individuals in regions in industrial transition could consider the following points when starting to address the growing need for training and investment.

\section{Engaging a broad range of local stakeholders in skills dialogue is important}

Building stakeholder dialogue can help manage change processes through mutual learning and co-operation. In the context of preparing for the future of work, actively engaging with stakeholders can help regions in industrial transition identify future skills needs and upcoming new business activities in the region by bringing in the resources and expertise of local employers, training associations, universities, VET providers and civil society. Successful dialogue also increases local capacity to find solutions and the willingness of all actors to commit to a shared vision of future economic development. Successful skills dialogue among stakeholders requires that regional policymakers take an active leadership role. Policymakers must be able to convince local employers of the need for change, to be prepared for 
differences in opinion, and to allocate sufficient time, human and financial resources to build up contacts and generate trust among all parties involved.

\section{Education and skills systems should be more inclusive}

In a changing world of work, firms must have access to the skills necessary to stay competitive. For example, across the OECD, the participation in training by adults with low skill levels is 23 percentage points lower than among those with medium and higher skills. This has implications for regions in industrial transition. In the context of rising skill demands, failing to engage these workers in training could translate in constantly higher rates of long-term unemployment.

\section{Taking an integrated approach to local job creation requires investment}

New jobs are created when industries expand and new firms start up and grow. Encouraging skills is important for job creation in regions in industrial transition. However, skills and education policies need to be complemented with investments in innovation, technology and business development. In order for new jobs to be created, businesses need access to resources, including skilled people, business networks, finance and space to start up and grow. Policymakers must develop integrated approaches to addressing the future of work, approaches that maximise employment opportunities and help to tackle inequalities and social exclusion. This requires greater co-ordination between investment, innovation and labour market policies at a regional level.

\section{Good governance mechanisms must be in place}

Redesigning education and employment systems is challenging for regions in industrial transition. For example, responsibilities may split across different types of actors at different levels of government and industry. In this context, good co-ordination mechanisms are essential to ensure that policies reinforce rather than duplicate each other. Moreover, policies aiming to support the labour market in the face of industrial transition should be sufficiently adaptable to specific regional contexts since the challenges faced may vary significantly from one region to the next. 


\section{References}

Autor, D. (2015), "Why are there still so many jobs? The history and future of workplace automation", Journal of Economic Perspectives, Vol. 29/3, pp. 2015-3, http://dx.doi.org/10.1257/jep.29.3.3.

Autor, D. and A. Salomons (2018), "Is automation labor share-displacing? Productivity growth, employment, and the labor share", Brookings Papers on Economic Activity, Vol. 2018/1, pp. 1-87.

Brynjolfsson, E. and A. McAfee (2014), The Second Machine Age: Work, Progress, and Prosperity in a Time of Brilliant Technologies, MIT, Boston, https://wwnorton.com/books/the-second-machine-age/.

Bundesagentur für Arbeit (2015), Monatsbericht Januar 2015, https://statistik.arbeitsagentur.de/Statistikdaten/Detail/201501/arbeitsmarktberichte/monatsberichtmonatsbericht/monatsbericht-d-0-201501-pdf.pdf

Eurofound (2017), Long-term Unemployed Youth: Characteristics and Policy Responses, Eurofound, http://dx.doi.org/10.2806/940447.

Eurofound (2015), New Forms of Employment, Eurofound, https://www.eurofound.europa.eu/sites/default/files/ef publication/field ef document/ef1461en.pdf

Grundke, R. et al. (2017), "Skills and global value chains: A characterisation", OECD Science, Technology and Industry Working Papers, No. 2017/05, OECD Publishing, Paris, https://doi.org/10.1787/cdb5de9b-en.

Keynes, J. (1931), "Economic possibilities for our grandchildren", in Essays in Persuasion, Palgrave Macmillan UK, London, http://dx.doi.org/10.1007/978-1-349-59072-8 25.

McGowan, A. and D. Andrews (2015), "Labour Market Mismatch and Labour Productivity: Evidence from PIAAC Data", OECD Economics Department Working Papers, No. 1209, OECD Publishing,

Paris, https://doi.org/10.1787/5js1pzx1r2kb-en.

Nedelkoska, L and G. Quintini (2018), "Automation, skills use and training", OECD Social, Employment and Migration Working Papers, No. 202, OECD Publishing, Paris, https://doi.org/10.1787/2e2f4eeaen.

North and East Finland (2018), "Peer learning in regions in industrial transition: Workshops good practice template", Regional Foresight, Prepared for the Peer Learning in Regions in Industrial Transition Workshop "Preparing Jobs of the Future", 15-16 May 2018, Brussels, Belgium, Unpublished.

OECD (2019a), Getting Skills Right: Future-Ready Adult Learning Systems, Getting Skills Right, OECD Publishing, Paris, https://doi.org/10.1787/9789264311756-en.

OECD (2019b), OECD Regional Outlook 2019: Leveraging Megatrends for Cities and Rural Areas, OECD Publishing, Paris, https://doi.org/10.1787/9789264312838-en.

OECD (2018a), Job Creation and Local Economic Development 2018: Preparing for the Future of Work, OECD Publishing, Paris, https://doi.org/10.1787/9789264305342-en.

OECD (2018d), Productivity and Jobs in a Globalised World: (How) Can All Regions Benefit?, OECD Publishing, Paris, https://doi.org/10.1787/9789264293137-en.

OECD (2017a), OECD Employment Outlook 2017, OECD Publishing, Paris, https://doi.org/10.1787/empl outlook-2017-en.

OECD (2017b), The Next Production Revolution: Implications for Governments and Business, OECD Publishing, Paris, https://doi.org/10.1787/9789264271036o-en.

OECD (2016a), OECD Regional Outlook 2016: Productive Regions for Inclusive Societies, OECD Publishing, Paris, http://dx.doi.org/10.1787/9789264260245-en.

OECD (2016b), Getting Skills Right: Assessing and Anticipating Changing Skill Needs, Getting Skills Right, OECD Publishing, Paris, https://doi.org/10.1787/9789264252073-en. 
OECD (2016c), Job Creation and Local Economic Development 2016, OECD Publishing, Paris, https://doi.org/10.1787/9789264261976-en.

OECD/ILO (2017a), Better Use of Skills in the Workplace: Why It Matters for Productivity and Local Jobs, OECD Publishing, Paris, https://doi.org/10.1787/9789264281394-en.

OECD/ILO (2017b), Engaging Employers in Apprenticeship Opportunities: Making It Happen Locally, OECD Publishing, Paris. http://dx.doi.org/10.1787/9789264266681-en.

Piemonte (2018b), "Peer learning in regions in industrial transition: Workshops good practice template", Apprenticeship for Higher Education and Research, Prepared for the Peer Learning in Regions in Industrial Transition Workshop "Preparing Jobs of the Future", 8-9 March 2018, Brussels, Belgium, Unpublished.

Sachen Freistaat (2018), "Sachen", PowerPoint Presentation for the Peer Learning in Regions in Industrial Transition Workshop "Preparing Jobs of the Future", 8-9 March 2018, Brussels, Belgium, Unpublished.

Shapira, P., J. Youtie and L. Kay (2011), "Building capabilities for innovation in SMEs: A cross-country comparison of technology extension policies and programmes", International Journal of Innovation and Regional Development, Vol. 3/3-4, pp. 254-272.

Skillnet (n.d.), Skillnet Statement of Strategy, Skillnet, Dublin, Ireland, https://www.skillnetireland.ie/publication/statement-of-strategy-2016-2019-summary/.

SkillsFuture Singapore (n.d.), About SkillsFuture, http://www.skillsfuture.sg/AboutSkillsFuture.

Tödtling, F. and M. Trippl (2005), "One size fits all?: Towards a differentiated innovation-led regional development policies approach", Research Policy, Vol. 34/8, pp. 1203-1219.

Wallonia (2018), "Peer Learning in Regions in industrial transition: Workshops good practice template", Le Forem, the Public Employment Service, Prepared for the Peer Learning in Regions in Industrial Transition Workshop "Preparing Jobs of the Future", 8-9 March 2018, Brussels, Belgium, Unpublished. 


\title{
Annex 2.A. Overview of policy issues and responses in preparing for the future of work
}

\author{
Annex Table 2.A.1. Overview of policy issues, implementation mechanisms and rationales in \\ preparing for the future of work in regions in industrial transition
}

\begin{tabular}{|c|c|c|c|}
\hline Policy issue & Policy response & $\begin{array}{l}\text { Potential suite of implementation } \\
\text { mechanism }\end{array}$ & Rationale/additional benefits \\
\hline \multirow[t]{5}{*}{$\begin{array}{l}\text { Lack of skilled workers } \\
\text { to move into new and } \\
\text { emerging activities }\end{array}$} & $\begin{array}{l}\text { Better anticipate skills } \\
\text { needs for industrial } \\
\text { transition }\end{array}$ & $\begin{array}{l}\text { - Foresight, skills mapping } \\
\text { - Workforce Intelligence Networks } \\
\text { - Expert Groups on Future Skills Needs }\end{array}$ & $\begin{array}{l}\text { Informs policymaking } \\
\text { Avoids skills shortages and skills } \\
\text { mismatches }\end{array}$ \\
\hline & \multirow[t]{2}{*}{$\begin{array}{l}\text { Strengthen capacity of } \\
\text { firms to address their } \\
\text { human resource needs } \\
\text { internally }\end{array}$} & \multirow{2}{*}{$\begin{array}{l}\text { - Strengthen HR management capacity } \\
\text { of SMEs } \\
\text { - Link with SME support policies with } \\
\text { education and training policies } \\
\text { - Strengthen links between firms, } \\
\text { universities and research bodies }\end{array}$} & $\begin{array}{l}\text { Improves responsiveness of training } \\
\text { provision to market needs }\end{array}$ \\
\hline & & & $\begin{array}{l}\text { Strengthens co-ordination between } \\
\text { different policy areas }\end{array}$ \\
\hline & \multirow{2}{*}{$\begin{array}{l}\text { Involve local stakeholders } \\
\text { in the planning and } \\
\text { design of regional skills } \\
\text { initiatives }\end{array}$} & \multirow{2}{*}{$\begin{array}{l}\text { - Participation in employers' councils } \\
\text { - Collaborations and partnerships with } \\
\text { vocational schools, universities and } \\
\text { small and large firms }\end{array}$} & $\begin{array}{l}\text { Targeted training in new technologies and } \\
\text { sectors of strategic importance }\end{array}$ \\
\hline & & & $\begin{array}{l}\text { Anchors local employers in regional } \\
\text { economic development }\end{array}$ \\
\hline \multirow{6}{*}{$\begin{array}{l}\text { Spatially concentrated } \\
\text { lack of job opportunities } \\
\text { for low- and middle- } \\
\text { skilled workers }\end{array}$} & \multirow{2}{*}{$\begin{array}{l}\text { Support vulnerable } \\
\text { workers during the period } \\
\text { of industrial transition }\end{array}$} & \multirow{2}{*}{$\begin{array}{l}\text { - Redesign local employment services } \\
\text { - Use the Internet as a channel of } \\
\text { delivery }\end{array}$} & $\begin{array}{l}\text { Provides the unemployed with new job } \\
\text { opportunities }\end{array}$ \\
\hline & & & $\begin{array}{l}\text { Ensures job opportunities across } \\
\text { territories }\end{array}$ \\
\hline & \multirow{2}{*}{$\begin{array}{l}\text { Provide workforce and } \\
\text { management } \\
\text { development for start-ups } \\
\text { and scale-ups through } \\
\text { training and upskilling } \\
\text { programmes }\end{array}$} & \multirow{2}{*}{$\begin{array}{l}\text { - Training subsidies and vouchers, } \\
\text { training leave allowances, tax } \\
\text { incentives } \\
\text { - Personal Training Accounts }\end{array}$} & $\begin{array}{l}\text { Workers gain highly specialised } \\
\text { competencies needed by firms }\end{array}$ \\
\hline & & & Managers gain additional knowledge \\
\hline & \multirow{2}{*}{$\begin{array}{l}\text { Foster the integration } \\
\text { of youth, women and } \\
\text { older people in the } \\
\text { labour market }\end{array}$} & \multirow{2}{*}{$\begin{array}{l}\text { - Dedicated training initiatives and } \\
\text { courses, provision of role models }\end{array}$} & Retains human capital \\
\hline & & & $\begin{array}{l}\text { Reduces gaps in labour market } \\
\text { participation }\end{array}$ \\
\hline \multirow{3}{*}{$\begin{array}{l}\text { Limited investment in } \\
\text { new sources of } \\
\text { employment and } \\
\text { productivity growth }\end{array}$} & \multirow{2}{*}{$\begin{array}{l}\text { Provide support for firms } \\
\text { to become more } \\
\text { innovative and adjust } \\
\text { from "traditional" sectors } \\
\text { to new technologies }\end{array}$} & \multirow{2}{*}{$\begin{array}{l}\text { - ICT training and technology extension } \\
\text { programmes } \\
\text { - Human Resource Development } \\
\text { Consortia at the sectoral level }\end{array}$} & $\begin{array}{l}\text { Facilitates access to and benefit from } \\
\text { global value chains }\end{array}$ \\
\hline & & & $\begin{array}{l}\text { Support for transversal skills to manage } \\
\text { innovation and technological change }\end{array}$ \\
\hline & $\begin{array}{l}\text { Assist firms in better } \\
\text { using skills at the } \\
\text { workplace }\end{array}$ & $\begin{array}{l}\text { - Workplace Leadership Centres, Local } \\
\text { Employer Networks } \\
\text { - Workplace Challenge programmes }\end{array}$ & Enhances cross-industry innovation \\
\hline
\end{tabular}


60

\begin{tabular}{|c|c|c|c|}
\hline Policy issue & Policy response & $\begin{array}{l}\text { Potential suite of implementation } \\
\text { mechanism }\end{array}$ & Rationale/additional benefits \\
\hline & $\begin{array}{l}\text { Encourage knowledge } \\
\text { exchange and } \\
\text { co-operation between } \\
\text { larger and/or newer } \\
\text { firms with smaller } \\
\text { and/or older firms }\end{array}$ & $\begin{array}{l}\text { SME participation in employer } \\
\text { networks, foster industry clusters, } \\
\text { create regional brands, enhance } \\
\text { product market strategies, company } \\
\text { learning networks }\end{array}$ & $\begin{array}{l}\text { Creates an attractive innovation } \\
\text { ecosystem }\end{array}$ \\
\hline \multirow{3}{*}{$\begin{array}{l}\text { Lack of co-ordination } \\
\text { and financing } \\
\text { mechanisms }\end{array}$} & \multirow[t]{2}{*}{$\begin{array}{l}\text { Implement effective multi- } \\
\text { level partnerships }\end{array}$} & \multirow{2}{*}{$\begin{array}{l}\text { - Increasing stakeholder participation in } \\
\text { local skills ecosystems, better } \\
\text { co-ordination arrangements, capacity- } \\
\text { building initiatives }\end{array}$} & $\begin{array}{l}\text { Coherent development of transition } \\
\text { policies across levels of government }\end{array}$ \\
\hline & & & $\begin{array}{l}\text { Improved policy effectiveness and } \\
\text { efficiency }\end{array}$ \\
\hline & $\begin{array}{l}\text { Ensure sufficient and } \\
\text { well-targeted financing } \\
\text { and investment }\end{array}$ & $\begin{array}{l}\text { - Tax incentives and subsidies, paid } \\
\text { training leave, loans, personal training } \\
\text { accounts }\end{array}$ & $\begin{array}{l}\text { Stimulation of private sector engagement } \\
\text { in the provision of training }\end{array}$ \\
\hline
\end{tabular}




\section{Broadening and diffusing innovation}

This chapter discusses the challenge of diffusing knowledge and innovation in regions in industrial transition. Innovation and innovation diffusion are drivers of industrial renewal and productivity growth, ultimately helping regions in industrial transition "catch up" to more productive regions. Transition regions, however, face a number of obstacles in making the most of this possibility. These obstacles include stimulating the development of knowledge-intensive industries and linking them to global value chains, addressing innovation gaps between thriving and lagging areas, and better capitalising on local innovation strengths. The chapter highlights a series of factors that are crucial to broadening innovation, such as building higher innovation capacity in regions in industrial transition and better linking innovation policies with other policy areas. It discusses these challenges and offers policy lessons to stimulate knowledge transfer and enhance inclusive innovation processes. 


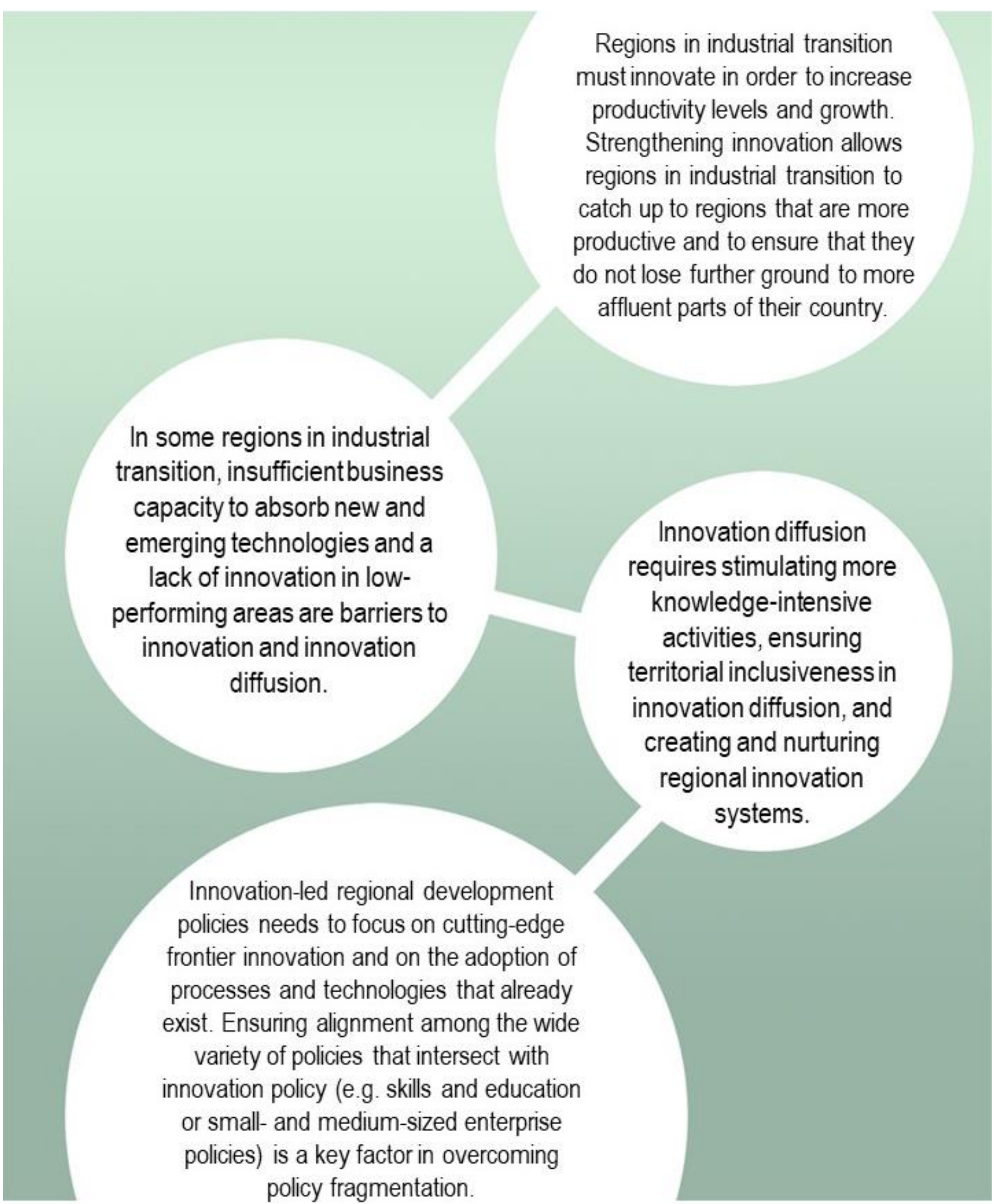




\section{Broadening and diffusing innovation is fundamental for industrial transition}

Innovation and innovation diffusion are key factors in renewing the economic fabric of regions in industrial transition and strengthening productivity levels and growth. Regions in industrial transition are often home to traditional industries and technology fields with high-value and high-skill activities, and a strong support system targeted at the respective specialisation. This renders the existing industry landscape an important asset for industrial modernisation.

For these regions, reaping the benefits from ongoing technological and organisational change requires simultaneous efforts to modernise old industries and diversify the local economy towards new and emerging industries. In some regions in industrial transition, key players of the local innovation ecosystem, such as large and incumbent firms and local universities, are driving industrial modernisation. This dynamic needs to be nurtured and maintained in order for these regions to best utilise the opportunities arising from automation and digitalisation. At the same time, it is important for policymakers in these regions to ensure that innovation does not rest with a small number of key players but that it spreads to rural areas and disadvantaged groups.

\section{Focusing on innovation diffusion supports "catching up" to frontier regions}

Regions in industrial transition are usually characterised by a long heritage of traditional industries and low levels of productivity in at least some parts of the local economy. It is, therefore, critical for these regions to strengthen innovation diffusion in order to catch up to more productive places within the same country and beyond.

Many regions across the European Union (EU) have narrowed the gap with the European productivity frontier, but others are only keeping pace or diverging. The European productivity frontier is composed of those regions in the $25 \mathrm{EU}$ member states that have the highest productivity (gross domestic product [GDP] per worker) and represent $10 \%$ of total employment in the EU. The regions displayed as catching up in Figure 3.1 are those regions that grew at least 5 percentage points more than the European frontier regions in the 2000-16 period. The diverging regions grew less than 5 percentage points than the frontier regions over the same period. The figure highlights that productivity growth differs across regions. It also suggests that there might be untapped potential to increase productivity by improving the performance of regions. In order to increase productivity, regions in industrial transition may make better use of their existing potential to increase productivity in existing firms - including large-scale manufacturers - through technological and organisational upgrading of existing production facilities and management practices.

\section{Productivity gaps are widening between frontier and other firms}

Innovation is a central driver of productivity growth. Supporting the innovation potential among firms of all sizes should be a fundamental objective for regions in industrial transition. While these regions may also be home to firms at the national or global technology frontier, their firm ecosystem often has difficulty with innovation take-up and diffusion.

Across the OECD, productivity gaps are widening between frontier firms and other firms. Figure 3.2 shows the evolution of labour productivity for firms at the global productivity frontier, non-frontier firms and all firms. Frontier firms are the top 100 most productive firms globally. In the manufacturing sector, frontier firms have expanded labour productivity at an average annual rate of $3.5 \%$, compared to an average growth in labour productivity of just $0.5 \%$ in non-frontier firms. This pattern is even more pronounced in the services sector. 
Figure 3.1. Productivity levels at the regional level in the EU

Classification of TL2 regions, 2000-16

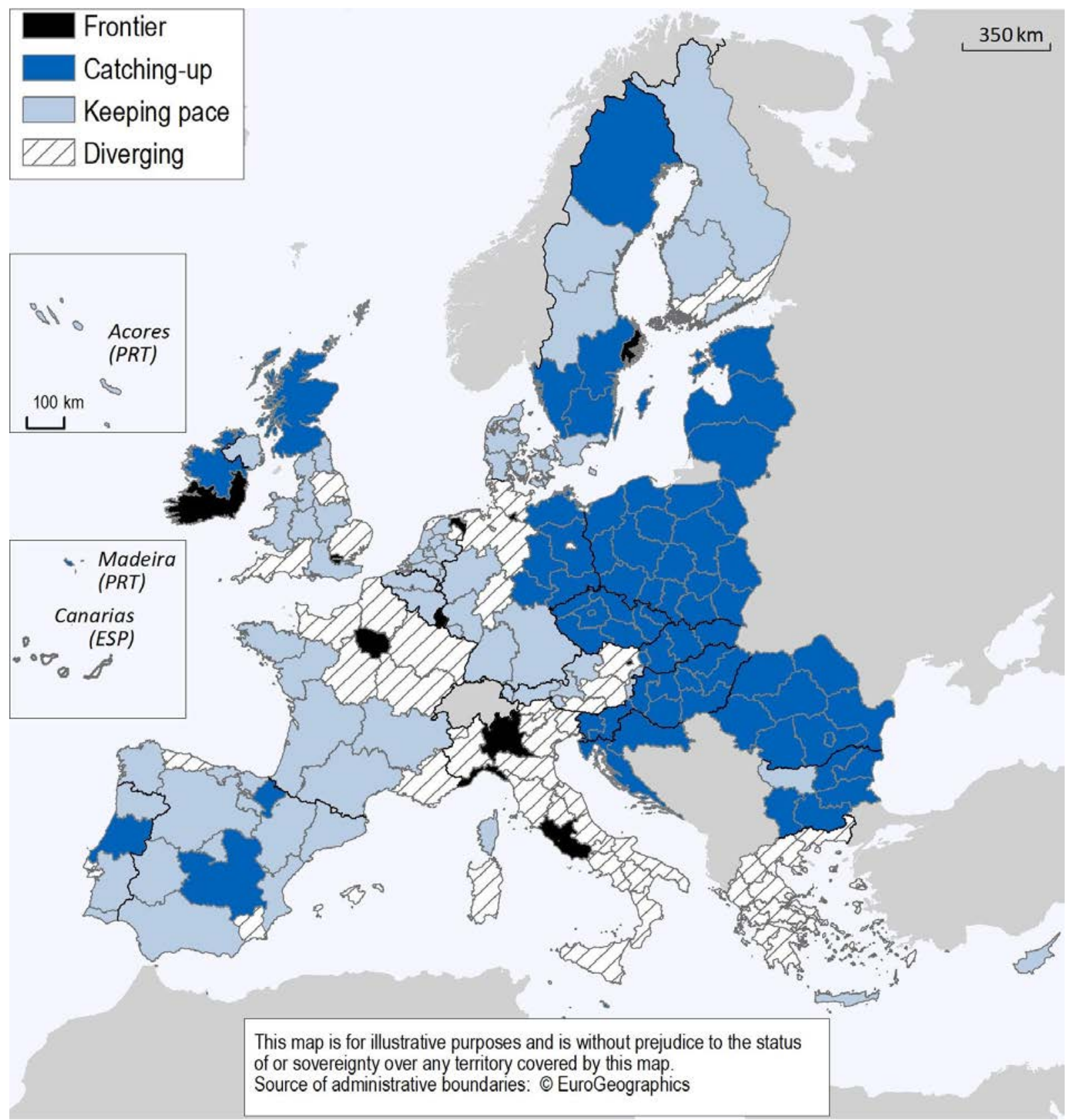

Note: Frontier region is defined at the European level as the aggregation of regions with the highest productivity (GDP per worker) among 25 EU countries and representing 10\% of total employment in the EU. Catching-up/diverging regions grew by at least 5 percentage points more/less than the European frontier over the 2000-16 period. Keeping-pace regions fall in between. The EU frontier is composed of 13 out of 200: Vienna (Austria), Brussels region (Belgium), Île-de-France (France), Hamburg (Germany), Southern and Eastern (Ireland), Lazio, Liguria, Lombardy (Italy), Groningen (Netherlands), Stockholm (Sweden), Greater London (United Kingdom), Luxembourg.

Source: OECD Regional Statistics [Database]. 


\section{Figure 3.2. Productivity gaps between frontier firms and other firms are widening}

Labour productivity $(2001=0), 2001-09$
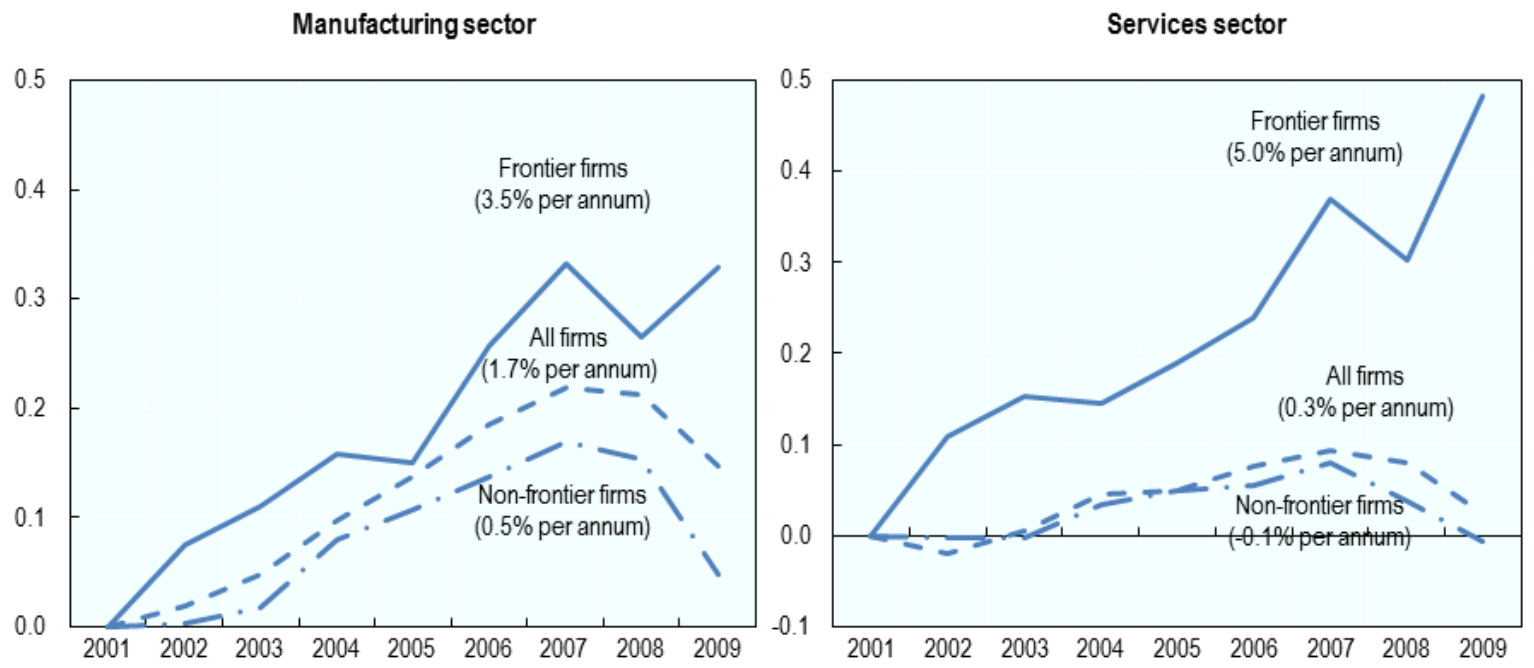

Note: Labour productivity is defined using value-added based labour productivity. Services refer to non-financial business services. All firms are computed from industry-level data using OECD STAN, which is meant to provide a benchmark for the productivity trend obtained using the sample of firms in ORBIS. Frontier firms refer to the Top 100 ORBIS firms.

Source: Andrews, D., C. Criscuolo and P. Gal (2015), "Frontier Firms, Technology Diffusion and Public Policy: Micro Evidence from OECD Countries", https://doi.org/10.1787/5jrql2q2jijb-en.

The figure suggests that the capacity of other firms to learn from the frontier may have diminished over time. The rising gap between "the best and the rest" raises important questions for regions in industrial transition about what might prevent non-frontier firms from adopting seemingly well-known innovations. It also suggests that seizing the benefits of transition will largely depend on reviving the diffusion machine.

\section{The changing nature of innovation offers new ways to foster innovation diffusion}

OECD countries are shifting away from innovation based predominantly on research and development (R\&D) activity towards a definition that includes non-technological innovation (OECD, 2018a). Evidence of this is grounded in changes in innovation objectives, forms of innovation, actors involved and instruments used. There is also a move towards more open or user-driven innovation, which has its origins in the recognition that innovation diffusion, and not just knowledge creation, is key to productivity and employment growth (OECD, 2018f).

The 2018 edition of the OECD/Eurostat Oslo Manual acknowledges a broader role for innovation and seeks to fill gaps on how different types of innovation can be measured (OECD/Eurostat, 2018). According to the manual, two main types of innovation exist:

1. A product innovation is a new or improved good or service that differs significantly from the firm's previous goods or services and that was introduced on the market.

2. A business process innovation is a new or improved business process for one or more business functions that differs significantly from the firm's previous business processes and that was brought into use by the firm. 
As these definitions reveal, innovation is much broader than just R\&D or technological change. Innovation also goes beyond the business sector. Public sector innovation, the role of non-for-profit actors and a systematic approach to innovation support are all contributing elements (Box 3.1).

\section{Box 3.1. Broadening the conceptual understanding of innovation}

A broader understanding of innovation can help policymakers expand its impact, while also contributing to other policy concerns, such as sustainability, inclusiveness and social issues. Key elements supporting a broader understanding of innovation include:

- Innovation as a concept spanning the whole chain of knowledge production from fundamental research to market launch.

- A "systemic understanding" of innovation, in which innovation is seen as the result of the co-operation and interaction of a multitude of various actors.

- A notion of innovation policy that is not restricted to promoting innovation as an end in itself, or for purely economic motives, but that considers innovation as an important tool in overcoming major societal challenges.

- A broad understanding of innovation policy, which extends beyond traditional science and technology policy, embracing education as well as other directly relevant sectoral policies and indirectly related socio-economic policies in addressing major global challenges such as climate change, health or biodiversity.

- Exploring the links between technological and non-technological innovation in firms.

- Greater attention to public sector and social innovation.

Source: OECD (2018b), "OECD Experience on Broadening Innovation and Innovation Diffusion", Scoping Paper for Peer Learning Workshop, Lille, 11-12 April, OECD Paris, Unpublished.

Broadening the understanding of innovation also creates new opportunities for excluded groups to become involved in the innovation process, to create new jobs and to grow incomes. For example, digitalisation and enhanced access to information technologies can open new paths for all entrepreneurs to become successful innovators. This supports the "democratisation of innovation" as the group of successful innovators is potentially enlarged to include actors that did not previously participate in innovation processes. Well managed, this process can support greater industrial and territorial inclusiveness (OECD, 2015a).

\section{What challenges and opportunities do regions in industrial transition face in broadening and diffusing innovation?}

\section{Regions in industrial transition need to build up more knowledge-intensive industrial activities}

One challenge for regions in industrial transition is to invest in and attract more strategically important R\&D investments and to work equally with larger firms and small- and medium-sized enterprises (SMEs) towards using R\&D for industrial modernisation. More R\&D activities mean more basic research, applied research and experimental development with the purpose of increasing human knowledge and devising new applications and products based on it. As products, applications and processes become increasingly complex, R\&D collaborations between the private sector and universities become more and more 
important to solve wicked problems. Creating and maintaining local innovation networks that include incumbent as well as emerging firms, research institutes, clusters and government actors is therefore critical for regions in industrial transition.

Increasing levels of R\&D is not an easy task. Across the OECD, innovation measured by R\&D is highly concentrated in a few regions (Figure 3.3). Research and development expenditures as a percentage of GDP ranged in 2015 from 6\% of GDP to less than 1\%. In Austria, Denmark, Germany, Korea and Sweden, expenditure on R\&D was particularly high, with an average outlay of around $3 \%$ of GDP or more. In those countries, regional differences are also substantial. For instance, around $5 \%$ of GDP is spent on R\&D in Styria (Austria) and Baden-Württemberg (Germany), which is approximately 5 times and 3.5 times higher than in Burgenland (Austria) or Saxony-Anhalt (Germany) respectively.

\section{Figure 3.3. Substantial differences exist in subnational R\&D expenditures}

R\&D expenditures as percentage of GDP in TL2 regions, 2015

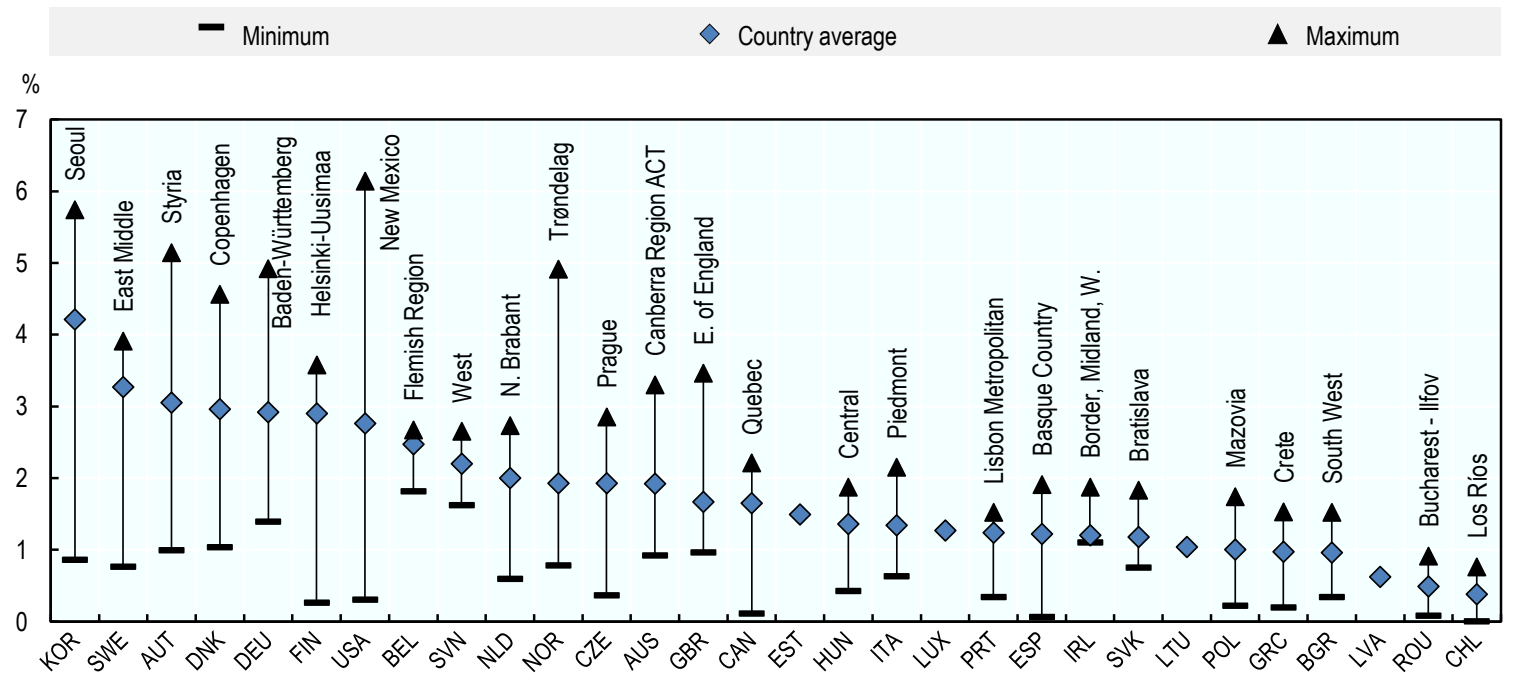

Source: OECD (2018g), OECD Regional Statistics (database), http://dx.doi.org/10.1787/region-data-en.

An important element of increasing levels of R\&D and strategically targeting R\&D towards new and emerging industries is encouraging higher private sector engagement. This is important for a number of reasons. First, private R\&D contributes to modernising the industrial base and enhances local competitiveness. Second, private R\&D often helps to maintain a high level of skills and the ability of firms to adopt technologies developed elsewhere (Archibugi and Filippetti, 2018). Third, private R\&D can help overcome societal challenges in areas such as transport, health, energy or the circular economy. Importantly, these challenges also constitute industrial opportunities and, therefore potential sources of jobs and growth in regions in industrial transition. Fourth, while public financing of R\&D can complement private R\&D, public budgets on their own are often insufficient to provide the scale of investment needed.

\section{Better integration of new technology in existing businesses supports positive transition outcomes}

Innovation is more than the commercialisation of science, and the importance of R\&D versus non-R\&D innovation varies by sector. Different types of non-R\&D innovation, such as capital investment in equipment (often produced by high-tech sectors), or non-technological innovation (marketing, organisation), can be equally important sources of innovation. Traditionally, regions in industrial transition 
have a large company base. While these firms often possess large resources and strong capabilities in long-established industrial activities, they do not always have the required business capabilities, i.e. the resources, knowledge and management skills needed to absorb emerging and enabling technologies, such as advanced manufacturing methods, bio- and nanotechnology or artificial intelligence (AI) applications. However, for technology diffusion to lead to productivity gains, firms must integrate new technology into their business processes and make complementary investments in skills and business models.

Small firms, in particular, might find it challenging to absorb new and digital technologies. OECD research shows that the uptake and diffusion of digital technologies and activities are much lower among SMEs than among large firms (Figure 3.4). A number of factors may drive this, including less knowledge about digital technologies and how they can improve business in small firms, lower R\&D levels and a lack of incentives to change traditional working methods. Strengthening business capabilities, in particular in SMEs, and finding ways to stimulate innovation is one of the challenges for policymakers in regions in industrial transition.

\section{Figure 3.4. SMEs take up and diffuse digital technologies much slower than large firms}

Diffusion of selected information and communication technology (ICT) tools and activities in enterprises, OECD, 2010 and 2018, as a percentage of enterprises with ten or more persons employed

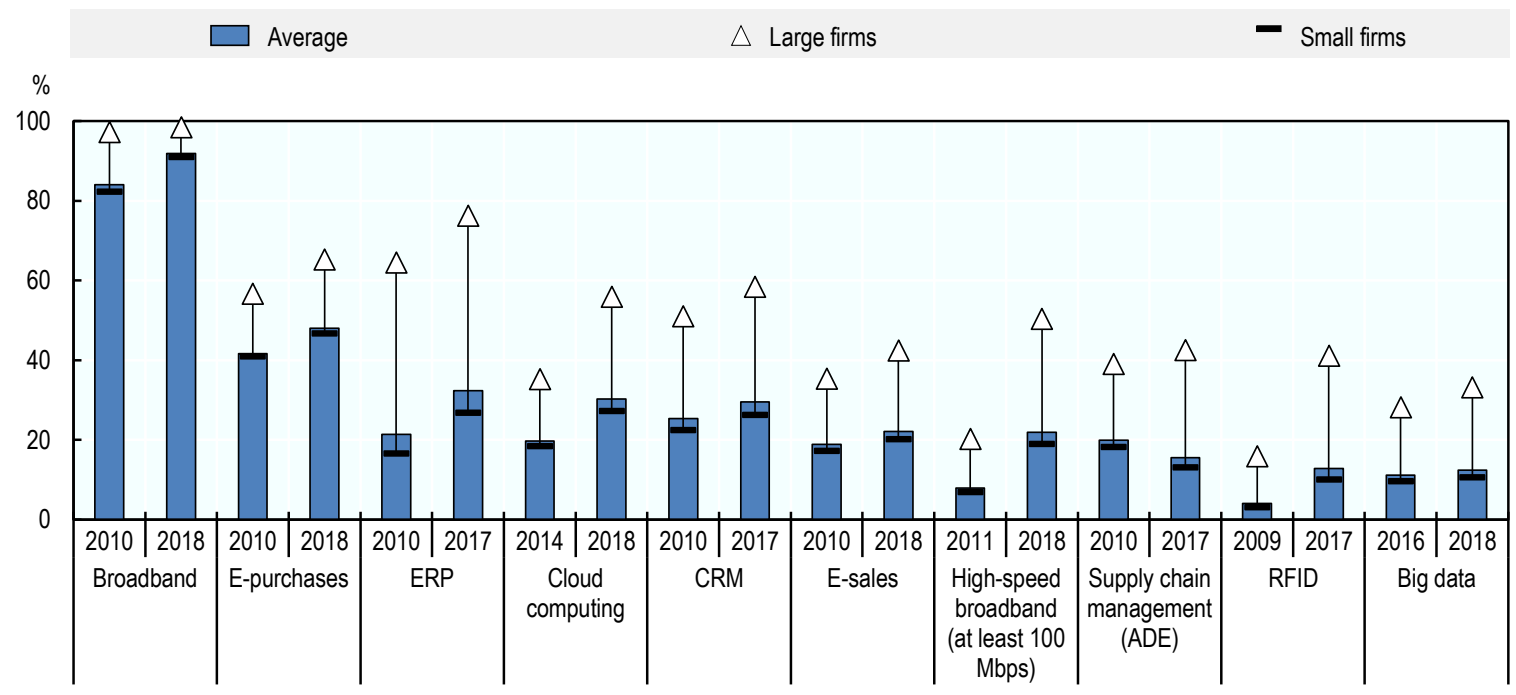

Sources: OECD (2019), OECD Regional Outlook 2019: Leveraging Megatrends for Cities and Rural Areas, https://doi.org/10.1787/978926431 2838-en, based on OECD, ICT Access and Usage by Businesses Database, http://oe.cd/bus, January 2019.

\section{Universities can be major drivers of industrial transition if their potential is well used}

Universities are major contributors to local innovation ecosystems. Strong universities play a leading role in organising networks for the development of future-oriented regional innovation strategies. For regions in industrial transition, universities are important knowledge generators that can contribute to innovation and actively support the transition from old to new industries by bringing new knowledge and networks into the region. However, in order to successfully support industrial modernisation, universities need to be strong regional innovators themselves. Academic research institutions might, for example, be too slow to respond to current trends in technological change, which leads to foregone research opportunities in new technologies.

More and better incentive systems to link academia with businesses and adapt teaching activities to changing labour market requirements are necessary for regions in industrial transition. Better linking 
universities with their local innovation ecosystems in order to offer education in line with changing skills profiles - while at the same time maintaining world-class research - is a policy challenge for regions in industrial transition.

\section{Financing innovation activities remains challenging}

Finance, be it from public or private sources, is a cornerstone of innovation. It allows companies and organisations to conduct research and adopt new technologies as well as to commercialise innovation (Kerr and Nanda, 2015). Access to finance for innovation is often a particular challenge for seed and early stages of business development. While large firms can more easily finance their R\&D activities through internal resources or by raising equity, start-ups and small firms have fewer assets at their disposal. Therefore, many governments use different types of interventions to increase the amount of finance available for innovation activities. Instruments can include direct funding, such as R\&D grants, but also debt risk-sharing schemes such as credit guarantee schemes and fiscal measures. Regions in industrial transitions often face resource limitations, including tight budgets. An important policy challenge in this context is to increase the availability of equity finance for innovative firms, such as venture capital schemes.

\section{Barriers to investment beyond financing also remain}

The challenge of financing innovation is embedded in a broader range of investment barriers. Public and private investment tends to remain below pre-crisis levels across European regions, generating a persistent and troublesome investment gap (EIB, 2019). Some regions in industrial transition face administrative challenges to investment. These can include deficiencies in multi-level governance, difficulties in accessing and managing investment funds, an unfavourable business environment and a lack of skills in future-oriented activities. The scope and degree of how these multiple barriers to investment affect industrial transition likely differ among regions and the challenge for policymakers in each region is how to tackle these barriers in a holistic manner. Moreover, overcoming some of these challenges will likely require addressing them at different levels of government and ensuring a clear allocation of responsibilities among each level.

\section{Some regions in transition face large territorial disparities in innovation}

It is neither desirable nor realistic to expect a uniform distribution of innovation within and across regions and businesses. However, an increasing divergence in innovation and productivity performance can lead to widening income and wage disparities, ultimately exacerbating territorial disparities. Policy has a role to play in ensuring that innovation diffuses across firms and territories.

Regions in industrial transition often face difficulties in spreading innovation beyond cities, which are often home to universities, research organisations and companies with high R\&D activities. In addition, remote regions in industrial transition face a situation in which firm headquarters may move to larger metropolitan areas outside their own region or where large companies outsource R\&D capabilities to more dynamic places in other regions. Broadening and diffusing innovation can help support a broader range of places and firms and reduce spatial gaps in innovation activity.

\section{More needs to be done to create and nurture regional innovation systems}

A well-functioning regional innovation system encourages the rapid diffusion of knowledge, skills and best practice within a region. Regional actors involved are universities and non-university research organisations, firms, regional and local government or administration, intermediaries (e.g. advisory bodies) and their networks, financial institutions and more. Regional innovation systems matter for regions in industrial transition because they support new and collaborative innovations that help foster industrial modernisation. 
In order for innovation and innovation diffusion to thrive in regional innovation systems, a fundamental ingredient is the existence of and access to local and global networks within and across sectors. Networks between industry, research, public services and civil society provide opportunity for new knowledge and resources, making them invaluable to regions in industrial transition. Yet, many regions struggle to establish such networks and a lack of (formal and informal) links and partnerships between universities, large and small firms and the public sector persists. This calls upon policymakers to create channels such as regular networking events, thematic project calls and dedicated websites through which firms and universities are willing to share what they know and open up to external knowledge.

\section{Monitoring and evaluating innovation and innovation policies remains a large challenge}

Because innovation and innovation policy operate in a complex, dynamic and uncertain environment, a commitment to performance measurement systems, including monitoring and evaluation, is fundamental. These systems can paint a picture of whether or not innovation policies are meeting their objectives, offer insight into what needs to be adjusted, and build evidence bases for future policy and programming design. Yet, performance measurement in innovation policy is a challenge, as regions often face financial and staff resources and skills limitations, as well as gaps in technical knowledge with regard to defining performance indicators and setting quantitative objectives.

In addition, with a broader understanding of what innovation can be and what it encompasses, there is a need to improve the indicators traditionally used. Available measurements largely reflect the industrial era and less the knowledge-based and digitalised economy, and policymakers struggle to capture the impact of networking and linkages policies, for example. Developing more relevant indicators is an exercise that is not yet complete at the regional, national or international levels, leaving regions at a loss with respect to effective measurement. For regions in industrial transition, where broadening innovation policy is fundamental for a successful transition, the lack of effective monitoring and evaluation mechanisms is particularly difficult.

\section{How can policy (better) support broadening and diffusing of innovation?}

Policy support to innovation diffusion dates back to the 1980s. In its early stages, the focus was on disseminating advanced manufacturing technologies (e.g. machine tools and robotics) to industry in order to raise productivity. However, it became evident that many of the obstacles to the successful adoption and use of technology were internal to the firm, such as a lack of resources, limited management capabilities, inadequate workforce skills or technological capabilities. In the 1990s and 2000s, greater attention was given to addressing these internal obstacles at the firm level. Policymakers began experimenting with networking initiatives and business advisory services to help firms implement complementary organisational, workforce and technical changes (OECD, 2015b). Building on this, today's emphasis is on increasing the technological absorptive capacity of firms, building local and global links to integrate firms and places into global value chains, and creating and nurturing holistic innovation support systems that include firms, universities and the public sector.

\section{Creating and sustaining comprehensive innovation ecosystems}

Regions in industrial transition need to stimulate the use of new technology but this is not enough. Focus also needs to be placed on experimentation processes with alternative firm strategies and business models, and co-ordination between innovation-led regional development policies and other policy domains. For these regions, subsidising research and development activities - a common public policy tool to support innovation- may have limited effects in itself as only some local firms would recognise and leverage value in the adoption of radically new technologies for their business. Instead, firms in regions in industrial transition need to become more aware of current challenges, trends and opportunities for their 
sector and identify what type of support is needed to remain competitive and to find new market opportunities. The role of policymakers then becomes one of facilitating dialogue between firms, knowledge organisations and public sector organisations to articulate needs for innovation, as well as possible solutions to needs and pathways for local innovation (Table 3.1).

\section{Table 3.1. Supporting innovation ecosystems: Policy issues, instruments and rationales}

\begin{tabular}{|c|c|c|c|}
\hline Policy issue & Policy response & $\begin{array}{l}\text { Potential suite of implementation } \\
\text { mechanism }\end{array}$ & Rationale/additional benefits \\
\hline \multirow{6}{*}{$\begin{array}{l}\text { Creating and sustaining } \\
\text { comprehensive innovation } \\
\text { ecosystems }\end{array}$} & \multirow[t]{2}{*}{$\begin{array}{l}\text { Broaden the notion of } \\
\text { innovation }\end{array}$} & \multirow{2}{*}{$\begin{array}{l}\text { - Building public and private sector } \\
\text { capabilities for innovation } \\
\text { - Innovation-friendly public } \\
\text { procurement }\end{array}$} & $\begin{array}{l}\text { Strong local support and engagement in } \\
\text { innovation processes }\end{array}$ \\
\hline & & & $\begin{array}{l}\text { Strategic prioritisation of innovation- } \\
\text { enhancing assets }\end{array}$ \\
\hline & \multirow{2}{*}{$\begin{array}{l}\text { Strengthen innovation } \\
\text { financing and reducing } \\
\text { barriers to investment }\end{array}$} & \multirow{2}{*}{$\begin{array}{l}\text { - Public funding for co-operation and } \\
\text { networks and linkage building } \\
\text { - Review of public investment choices } \\
\text { and barriers }\end{array}$} & Support for new and emerging industries \\
\hline & & & $\begin{array}{l}\text { Strengthened capacity for public } \\
\text { investment decisions }\end{array}$ \\
\hline & \multirow{2}{*}{$\begin{array}{l}\text { Improve monitoring and } \\
\text { evaluation of innovation } \\
\text { policies }\end{array}$} & \multirow{2}{*}{$\begin{array}{l}\text { - Stakeholder engagement in policy } \\
\text { design } \\
\text { - More and better data collection } \\
\text { - Programme adjustments }\end{array}$} & Better measurement of impact \\
\hline & & & Optimal allocation of scare resources \\
\hline
\end{tabular}

\section{Broadening innovation}

Innovation measures across the OECD have broadened to include non-technological innovation such as innovative project management in firms, supply chain innovations, improved customer experiences and new and digital business models. For regions in industrial transition, broadening the focus of innovation policy to include non-technological innovation is essential for industrial modernisation because these regions are often home to a large number of firms that have strong potential to seize opportunities from organisational progress. In East and North Finland, a partnership among the seven participating subregions is leading to broader innovation approaches, peer learning and the emergence of collaborative initiatives (Box 3.2).

\section{Box 3.2. Innovations in East and North Finland}

\section{Circular economy in the Central Ostrobothnia region}

The Kokkola Industrial Park (KIP) is the biggest inorganic chemistry cluster in Nordic countries. KIP is home to 80 companies, which generated EUR 1.5 billion of exports in 2017 and employ 2200 staff. KIP is private-public partnership and is an example of industrial symbiosis where one firm's waste is another firm's input (heat, steam, gases, metals, etc.). The Biovalley Consortium has 24 partners, joint campus facilities, a project portfolio worth EUR 40 million and 150 R\&D personnel. Biovalley is an expertise hub that combines the expertise of several industries found in the area: chemical industry, the bioeconomy and the mineral economy.

\section{Aligning non-governmental organisation (NGOs) with regional development in North Karelia}

North Karelia counts 3700 registered NGOs. Whilst the majority are sports-, cultural- and hobby-related associations, a significant number serve unemployed people, immigrants and the elderly, and play significant roles in social inclusion. Social and health associations have important role in ongoing structural change and the delivery of services. Civil society supports the services of public and private social and health services and voluntary work is considered a significant instrument in empowerment, 
inclusion and well-being for the whole society. According to statistics, each Finnish person belongs, on average, to three civil society organisations. NGOs feed into the regional development ecosystem through an overarching initiative. The insights given by this co-operation have been valuable in ensuring the quality and effectiveness of the development actions.

Local business support organisations and innovation agencies can help firms implement effective production and management practices, thereby lending innovation support. Innovation support should be aligned with strategic investment promotion activities in the region in order to build innovation and technology capabilities in areas of strategic interest. Local industry associations can connect firms with each other and facilitate exchange and learning. Public authorities can support private sector-led efforts as long as they do not result in collusion. The region of Limburg in the Netherlands has successfully broadened its innovation policy support and has taken a holistic approach to innovation (Box 3.3).

\section{Box 3.3. Broadening innovation in Limburg, the Netherlands}

The closure of 13 Limburg coal mines in the early 1970s triggered a process of regional innovation system thinking which has become the guiding paradigm for regional development policy in the Province. Limburg was one of the first of four Regional Technology Plan (RTP) pilot regions in Europe. It completed its plan in 1996 and followed it up with a Regional Innovation and Technology Transfer Strategies and Infrastructures Plan (RITTS), a Regional Innovation Strategy (RIS) and a smart specialisation strategy (S3) as of 2014. Limburg is classified as an innovation leader in Europe based on a sustained approach to internal and external collaboration, partnerships and implementation. Limburg is focused on developing its innovation system to include more integrated themes, better address sustainability issues, implement improved governance processes and create evidence-based information (e.g. R\&D/patent information) for strategy building.

A particular innovation emerging from Limburg's experience is the use of innovation vouchers - a concept pioneered by Limburg in 1997. This first pilot explicitly aimed at encouraging knowledge transfer and building collaboration between SMEs and research institutions. The goal was to encourage, advice and support SMEs in Limburg as they undertook measures to maintain or improve their competitiveness in the domestic and international markets. The project's target group was SMEs located in Limburg with 15-250 employees and DSM Research, a private research and development campus where vouchers could be utilised.

Source: OECD (2018f), "OECD Experience on Broadening Innovation and Innovation Diffusion", Presentation for Peer Learning Workshop, 14-15 June, OECD Paris, Unpublished.

\section{Supporting innovation-oriented public procurement}

Public procurement can be a lever of innovation diffusion in regions with large purchasing power and can pull demand for innovation. Innovation-oriented public procurement can be justified on a number of grounds. Making public procurement more innovation-friendly through the incorporation of innovationrelated criteria can stimulate the supply of innovation and new technologies. The request of a specific or new technology by public administration can also be a strategic asset for regions that want to prioritise their activities in a certain industry or enable a technology. Finally, innovation-friendly public procurement can also promote technological advances that require R\&D before any market solution is in sight. In some cases, pre-commercial procurement is used to offset biases against innovation driven by new and small companies (OECD, 2011). 
Using public procurement as an innovation-generating policy instrument can be challenging too. The traditional focus on value for money, as well as the problem of fragmentation of public demand (often among different levels of government) can limit the potential effect of innovative procurement. Furthermore, the agencies or local governments with responsibilities for public procurement can operate separately from line ministries or government agencies with a mandate to support innovation.

\section{Supporting innovation financing and overcoming barriers to investment}

Innovation financing is important for the creation, survival and growth of innovative businesses. A lack of finance may prevent firms from investing in innovative projects and improving their productivity (see also Chapter 4). For regions in industrial transition, suitable finance is critical to reorient old industrial pathways towards modern industries. This implies a need to innovate and broaden financing mechanisms beyond traditional finance offers.

Beyond financing innovation, territorial obstacles to investment are often related to multi-level governance and public administration challenges, including co-ordination with other levels of government and sectors. Regions in industrial transition often lack the appropriate tools and governance arrangements to make the best use of investment funds. The OECD has highlighted that the challenges are often much broader than just financing investment and that the impact of public investment depends to a significant extent on how governments manage it. Co-ordination, capacity and framework conditions are three systematic challenges hindering the achievement of the best possible outcomes. For this reason, the OECD Council adopted a Recommendation on Effective Public Investment across Levels of Government (OECD, 2014), organised around three pillars (Box 3.4).

\section{Box 3.4. OECD Principles on Effective Public Investment across Levels of Government}

Across the OECD, subnational governments are responsible for about two-thirds of direct public investment - with notable variation among countries. Well-managed public investment can be growth enhancing and contribute to higher levels of productivity growth. Poor investment choices, on the contrary, may not only waste public resources but also hamper future growth.

In 2014, the OECD Council adopted a Recommendation on Effective Public Investment across Levels of Government. The principles set out in the recommendation are meant to help governments assess the strengths and weaknesses of their public investment capacity and set priorities for improvement. The 12 recommendations are grouped into 3 pillars representing multi-level governance challenges to public investment:

1. Co-ordinate public investment across levels of government and policies. This pillar focuses on the importance of seeking and creating complementarities in policies and programmes across policy sectors, vertically across levels of government and horizontally among subnational governments to increase the effectiveness of public investment.

2. Strengthen capacities for public investment and promote policy learning at all levels of government. This pillar highlights different capacities that should be present at all levels of government to bolster conditions for effective investment and to promote continuous improvement from the strategic selection of investment to its execution and monitoring.

3. Ensure proper framework conditions for public investment at all levels of government. This pillar emphasises the importance of good practices on fiscal decentralisation, public financial management, public procurement and regulatory quality at all levels of government.

Source: OECD (n.d.), Effective Public Investment Toolkit, http://www.oecd.org/effective-public-investment-toolkit/. 


\section{Innovation monitoring and evaluation}

Innovation and innovation-diffusion policy is crosscutting with results based on multiple policy agendas that extend beyond R\&D investments. In order to best support innovation and innovation diffusion, regions in industrial transition need to improve monitoring and evaluation capacities of innovation policies. This includes more consultation with stakeholders to develop goals and design programmes, more stringent collection of programme data, better monitoring of progress, adjusting programmes towards industrial modernisation and overcoming societal and disruptive challenges related to transition (OECD, 2019).

Adjusting policy interventions over time involves testing and experimenting, and learning and adapting. The idea of experimentation takes into account the need for a flexible approach. For regions in industrial transition, this means that interventions may need to be piloted, or combined, or adaptable within a given initiative. For example, there could be variations in the criteria for innovation partnerships or various options for cost-sharing in R\&D funding. Once a project has rolled out, flexibility and openness to changing plans in order to adapt to shifting conditions arising from transition is fundamental. Spain's Basque region has successfully implemented a monitoring and evaluation system for its regional innovation system (Box 3.5).

\section{Box 3.5. Monitoring and evaluation of innovation in the Basque region}

Spain's Basque Country has been gradually implementing its monitoring and evaluation system. In 2012, it began monitoring and evaluating results by trying to unite different inputs and assess a programme's contribution in terms of input, output and impact indicators. Resources and results are monitored, and companies are regularly surveyed to determine whether input indicators are clear and on expected output. Only after three years did the Basque regional authorities begin to ask for results and with this information, they then were able to begin measuring impact. While it is difficult to change the time dimension, it is possible to streamline the measurement approach. For example, the Basque system focuses on indicators to measure two specific objectives linked to their industrial and innovation policy: increasing employment and supporting internationalisation.

Source: Adapted from Oyón, C. (2018), "PCTI EUSKADI 2020: A smart specialisation strategy oriented to boost Economic and Sustainable Development", PowerPoint Presentation for the Peer Learning in Regions in industrial transition Workshop: Broadening Innovation and Innovation Diffusion, Presented by Mario Cervantes, 11-12 April, 2018, Lille, France.

\section{Strengthening knowledge transfer and innovation capabilities}

Regions in industrial transition are currently revising their innovation-policy packages to better support innovation and technology diffusion. A key challenge for these regions is to strengthen business capabilities for innovation and to avoid political lock-in in well-established and traditional industries. Relevant policy instruments include strengthening workforce and management skills for innovation, accelerating the digital transformation to scale business innovation networks and fostering effective industry-university relationships (Table 3.2).

For regions in industrial transition, the uptake of digital technologies is a key lever to support industrial modernisation and embrace the digitalisation of production and processes. As digitalisation is radically changing certain industries, including manufacturing, new and digital business models, firms in regions in industrial transition can make use of this development to increase their digital presence, create new contact channels to customers, and ultimately improve efficiency and productivity. Making the digital transformation work for industrial modernisation requires coherent and well-coordinated policies that proactively consider those who benefit from digitalisation and those who risk being left behind. Fully benefitting from the opportunities linked to digitalisation will require that individuals, businesses and regional governments in 
transition regions have reliable and affordable access to Internet and digital services. However, good access to digital networks alone does not ensure effective use. Policy also needs to help equip workers and citizens with appropriate skills to make effective use of digital technology.

\section{Table 3.2. Strengthening knowledge transfer: Policy issues, instruments and rationales}

\begin{tabular}{|c|c|c|c|}
\hline Policy issue & Policy response & $\begin{array}{l}\text { Potential suite of implementation } \\
\text { mechanism }\end{array}$ & Rationale/additional benefits \\
\hline \multirow[t]{6}{*}{$\begin{array}{l}\text { Lack of (small) business } \\
\text { capabilities for innovation }\end{array}$} & \multirow[t]{2}{*}{$\begin{array}{l}\text { Accelerate the digital } \\
\text { transformation }\end{array}$} & \multirow{2}{*}{$\begin{array}{l}\text { - Financial support and technical } \\
\text { assistance (loans, vouchers, aids) } \\
\text { - Training and guidance (personal } \\
\text { advice, webinars, events) } \\
\text { - Information campaigns, cluster-wide } \\
\text { initiatives }\end{array}$} & Enhances digital companies in firms \\
\hline & & & Supports industrial modernisation \\
\hline & \multirow[t]{2}{*}{$\begin{array}{l}\text { Scale up business } \\
\text { innovation networks }\end{array}$} & \multirow{2}{*}{$\begin{array}{l}\text { - Supporting industrial clusters and } \\
\text { cross-cluster fertilisation } \\
\text { - Linking GVCs to cluster policies } \\
\text { - Supporting open innovation and the } \\
\text { use of open data }\end{array}$} & $\begin{array}{l}\text { Integration of local industries into global } \\
\text { value chains }\end{array}$ \\
\hline & & & Industrial diversification and upgrading \\
\hline & \multirow{2}{*}{$\begin{array}{l}\text { Support effective } \\
\text { university-industry } \\
\text { co-operation }\end{array}$} & \multirow{2}{*}{$\begin{array}{l}\text { - Collective research agreements } \\
\text { - Licenses and patents } \\
\text { - Spin-off firms } \\
\text { - Labour mobility between academia } \\
\text { and industry }\end{array}$} & Creates knowledge spill-overs \\
\hline & & & $\begin{array}{l}\text { Improves the opportunities of SMEs to } \\
\text { participate in research commercialisation }\end{array}$ \\
\hline
\end{tabular}

\section{Accelerating the digital transition}

Policymakers in regions in industrial transition can support digital take-up by people, firms and local governments in different ways. They can provide financial support and technical assistance on topics such as online marketing, digital business process or information technology (IT) security. Policy instruments can range from targeted loans and regional vouchers to non-repayable aid to small firms to support digitalisation. Training support can include a mix of support activities, events, webinars, analysis tools and training programmes to foster digital competencies. Often these programmes have a specific focus on SMEs, as they often lag behind in the adoption of digital technologies. The German Mittelstand initiative on digitalisation shows one way to structure digital training for SMEs (Box 3.6). In addition to the targeted instruments described above, information campaigns, as well as cluster-wide approaches and solutions, can be important instruments to accelerate technology diffusion in regions in industrial transition.

\section{Box 3.6. Mittelstand-Digital, Germany}

Germany has 2.5 million SMEs. Many of these are skilled craft workshops confronted with the challenge of remaining competitive in the digital revolution. To enhance their productivity growth the German Federal Ministry of Economic Affairs and Energy (Bundesministerium für Wirtschaft und Energie, BMWi) launched Mittelstand-Digital, an initiative consisting of 18 regional competency centres nationwide to support SMEs in digitising, networking and introducing Industry 4.0 applications.

Support is offered in a number of areas, such as work organisation and digitisation strategies, intelligent production and IT security, and legal issues and standardisation affairs. The competency centres include learning and demonstration factories, so that SMEs can learn how digital technologies might transform a business, and they provide information sessions and practical use cases. 
Key lessons stemming from the initiative include:

- Care is needed to ensure that the Mittelstand-Digital programme is presented in a format and language that is appropriate for connecting with SMEs and skilled craft workshops.

- The challenges of digitalisation vary across regions (for example, learning cultures vary across regions), such that the format of events (e.g. webinars, entrepreneurs' breakfasts, weekend meetings) and publications need to be tailored to the recipient SMEs.

- Trust is an important aspect for SMEs: they are often more willing to accept the official and unbiased information provided by the German federal government as opposed to that of private consultants, which has implications for the choice of an appropriate IT consultant.

- The benefits of the programme appear to improve if SMEs can take advantage of peer learning, whereby SME participants learn from each other.

- SMEs may harbour the belief that "what costs nothing is worth nothing", which may make them less receptive to the value of the advice offered in the context of the programme.

Sources: OECD (2016), Job Creation and Local Economic Development 2016, http://dx.doi.org/10.1787/9789264261976-en; Bundesministeriums für Wirtschaft und Energie (n.d.), Mittelstand Digital, https://www.mittelstand-digital.de.

\section{Scaling up business innovation networks}

Well-developed clusters can yield a range of benefits for regions in industrial transition. First, by physically locating firms close to one another, agglomeration effects and economies of scale can be created. This is particularly important for those regions in industrial transition whose territories are characterised by low firm and/or population density. Second, clusters can also contribute to learning and knowledge sharing at the regional level. Firms today need to be able to interact with researchers, inventors and entrepreneurs, as well as with other firms, in order to define new products and identify new markets. While the isolated inventor in a garage remains the stereotype of an innovator, research shows that $47 \%$ of new product and process innovations occur through external partnerships (Carlino and Kerr, 2014). Clusters offer important platforms for nurturing such partnerships and can support industrial transition by helping an industry to upgrade or new industries to develop. At the same time, regions in industrial transition face the danger of pursuing cluster policies that predominantly support old and mature industries if there are no attempts of industry modernisation or upgrading through these clusters. In this case, insufficient diversification and over-reliance on local champion firms can slow down entrepreneurial dynamism.

OECD countries and regions see the emergence of a network-based development model, in which clusters across different industrial sectors are pushed to establish cross-cluster linkages domestically and internationally. Such an approach often strengthens the cluster research component, builds stronger industry-science ties and fosters cross-sectoral links (OECD, 2017b). Norway is an example of a country that has successfully developed a network-based cluster model (Box 3.7). Support for cross-cluster linkages is vital if regions in industrial transition are to transform their local economies around new and knowledge-based activities. Going beyond individual cluster support, cross-cluster collaboration can strengthen innovation diffusion by exploiting emerging links between economic activities that can cut across traditional cluster boundaries. 


\section{Box 3.7. Norwegian Innovation Clusters}

Norwegian Innovation Clusters is a government-supported cluster programme organised by Innovation Norway in a joint effort with Norway's Industrial Development Co-operation and the Norwegian Research Council. The programme's objectives are to increase the innovation capability and value creation in different clusters and to support cross-fertilisation between clusters.

Through annual open calls, clusters compete to be part of the programme. Criteria for participation include cluster resources, potential for growth and position in the industry, and that the wish to build a financially supported cluster is based on the commitment and leadership of the companies forming the cluster.

Clusters are supported on three levels:

1. Early clusters: Clusters that are in an early phase of organised cluster collaboration. The support period is 3-5 years with EUR 200000 to EUR 300000 per cluster

2. Norwegian Centres of Expertise: Mature clusters with a national position. The support period is 5-10 years with EUR 500000 to EUR 600000 per cluster.

3. Global Centres of Expertise: Mature clusters in global positions. The support period is up to 10 years with EUR 1 million per cluster.

Financial support takes the form of co-funding (50\%) of basic cluster activities through a cluster facilitator and targeted support schemes on cluster sustainability, entrepreneurship, innovation and the support of "change agents". Networking and advisory services are also part of the package.

Source: Norwegian Innovation Clusters (n.d.), Homepage, http://www.innovationclusters.no/english.

\section{Linking Global Value Chains to cluster policies}

Regional cluster policies help regions in industrial transition generate necessary knowledge and innovation spillovers by creating a space for diverse regional and external actors to interact and exchange ideas. Without the formalised mechanism of a cluster, regions in industrial transition may find it harder than frontier regions to keep the necessary innovation actors in the region and attract external actors to participate. It can also increase the possibility of participation in global value chains (GVCs), which adds an important international dimension. Linking regional businesses with multinational companies can facilitate knowledge spillovers from the frontier to regions in industrial transition.

Knowledge diffusion from global to local businesses can be sporadic and unstructured when it is based strictly on regular contacts among employees. More structured learning takes place in GVCs through hierarchical or captive relations between firms, when dominant firms provide targeted knowledge to subordinate forms to help them acquire the skills they need. However, knowledge diffusion along the supply chain does not always occur. Competitive relationships between firms and the inability of "tacit" knowledge to travel along supply chains can undermine the creation of spill-overs.

Policymakers in regions in industrial transition can encourage knowledge sharing along GVCs in two main ways. First, they can motivate regional firms to diversify across different value chains, thereby (ideally) diversifying across markets and increasing productivity. Second, they can seek partnerships with locally dominant firms in GVCs to encourage these to share more knowledge across the value chain (Pietrobelli and Rabellotti, 2011). 


\section{Supporting open innovation and the use of open data}

All firms, even the most innovative, increasingly need to deal with complex knowledge, which can be difficult when relying only on internal resources. In the open innovation model, a company does not strive to generate the best ideas entirely by itself. Rather, it seeks to utilise internal and external ideas in an optimal manner, to be more effective at managing cost and risk and to accelerate technology development. Sources of knowledge typically include suppliers, research centres, universities, customers, competitors, and companies with complementary offerings (Chesbrough, 2003).

The provision of open government data by public sector and governmental bodies may also lead to new and innovative business models through applying open innovation instruments. For example, open data business models support entrepreneurs in reusing and combining available open data sources to provide services. The EU estimates the total direct and indirect economic gains from open data re-use would be in the order of EUR 194 billion by 2030 (European Commission, 2018).

Open innovation systems in regions in industrial transition can complement or extend existing in-house innovation. They allow SMEs and start-ups to contribute to and engage with large businesses in the region and to develop partnerships and networks. This can stimulate entrepreneurial activity and facilitate more integrated and embedded networks between large and small firms. An example is the Centre-Val de Loire region in France, which has successfully built an innovation and economic development network (Box 3.8).

\section{Box 3.8. Innovation networks in Centre-Val de Loire}

Centre-Val de Loire (CVL) is a French region with EUR 1.3 billion in R\&D activities, and which has built a regional innovation and economic development network over the last decade. The network has 350 members that interact with firms across the region. Its aim is to strengthen the regional ecosystem in order to improve the effectiveness of the regional innovation/smart specialisation strategy (RIS3). The network benefits from executive-level support from participating businesses and is working to further professionalise membership through the "Economic Developer University" in order to improve the quality of business services, particularly for SMEs. The network benefits from the input of stakeholders involved in the regional innovation ecosystem and from political support at the regional level to improve the effectiveness of the innovation system. It, however, takes a neutral stance, as there are competitors even at the board level.

The management of the network by a dedicated organisation (a regional innovation agency) is considered a critical factor of its success, particularly in creating projects and supporting private sector research, development and innovation (RDI) investments. The European Regional Development Fund Thematic Objective 1 results indicator set an increase in the number of innovative companies from 1000 to 1500 to be attained in the 2014-20 programming period. By the end of 2017, 1620 were listed in the database.

Source: OECD (2018b), "OECD Experience on Broadening Innovation and Innovation Diffusion", Scoping Paper for Peer Learning Workshop, Lille, 11-12 April, OECD Paris, Unpublished.

\section{Creating effective university-industry collaboration}

Universities are major players in regional open innovation systems and numerous benefits derive from university-industry relationships, including innovative products and technologies, skills and knowledge provision to students, spin-off creations and higher rates of patenting. Given these benefits, many regions in industrial transition have adopted strategies and programmes to promote university-industry 
partnerships. However, some of these are considered fragmented, uncoordinated and limited in scope by a number of policymakers in regions in industrial transition (see Annex A).

There is a range of policy tools available to regions in industrial transition to support university-industry partnerships in a more coherent and structured manner (Table 3.3). These include collaborative research tools such as grants and innovation vouchers, and contract opportunities to develop, in partnership, innovative products or organisational practices that can increase productivity, fundamental for these regions. Universities can also receive funding from the public sector to support spin-offs and academic entrepreneurship, one good way to spur entrepreneurial dynamism in the region (see also Chapter 4). Open research laboratories or student hiring are additional instruments to support exchange between industry and university.

Table 3.3. Formal and informal mechanisms of knowledge transfer

\begin{tabular}{l|l|l}
\hline \multicolumn{1}{c|}{ Channels/tools } & \multicolumn{1}{|c}{ Description } & \multicolumn{1}{c}{ Examples } \\
\hline Collaborative research & $\begin{array}{l}\text { An agreement by which scientists and private } \\
\text { companies jointly commit resources and } \\
\text { research efforts to projects. }\end{array}$ & $\begin{array}{l}\text { - Open Innovation Policy Platforms, e.g. Finland and } \\
\text { Catapult Centres (UK). } \\
\bullet \text { Matching grants, e.g. University of California (IUCRP). } \\
\bullet \text { Austrian Competence Centre programme (COMET) and } \\
\text { laboratories by the Christian Doppler Research } \\
\text { Association (CDG). }\end{array}$ \\
\hline Licences and patents & $\begin{array}{l}\text { Legal rights to use a specific piece of university } \\
\text { intellectual property (IP). Academic researchers } \\
\text { may appear as inventors in firms' patent filings } \\
\text { as a result of them being a contract researcher } \\
\text { or through academic consulting. }\end{array}$ & $\begin{array}{l}\bullet \text { Knowledge Transfer and IPR commercialisation offices } \\
\text { in Germany (Fraunhofer Institute), Austria (Technology } \\
\text { Transfer Offices in several universities) and Japan } \\
\text { (e.g. SACl, Tokyo University). }\end{array}$ \\
\hline Spin-off firms & $\begin{array}{l}\text { A new entity that is formed around the faculty } \\
\text { research or a university licence. }\end{array}$ & $\begin{array}{l}\text { - Programmes to support university spin-offs, such as } \\
\text { EXIST (Germany), SBIR (USA), AplusB Centres } \\
\text { (Austria). }\end{array}$ \\
\hline $\begin{array}{l}\text { Student or academic hired into } \\
\text { the industry }\end{array}$ & $\begin{array}{l}\text { A graduate student or an academic is hired by a } \\
\text { firm to develop research inhouse. }\end{array}$ & $\begin{array}{l}\bullet \text { CIFRE convention (France). } \\
\text { Rural growth pilots (Denmark). }\end{array}$ \\
\hline
\end{tabular}

Sources: Adapted from Brown, R. (2016), "Mission impossible? Entrepreneurial universities and peripheral regional innovation systems", Industry and Innovation, Vol. 23/2, pp. 189-205, and OECD (2018a).

Clear framework conditions need to be in place for industry-university collaboration to be successful. They include adequate and sustainable funding, clear rules on property rights and confidentiality issues, career incentives for professors to be involved in industry collaboration and sufficient trust among actors (Etzkowitz and Zhou, 2017). University activities such as co-ordinating innovation labs, filing patent applications and developing innovative products for industry partners or spin-offs are suitable mechanisms to encourage such partnerships.

Research and technology organisations (RTOs) have developed in many European countries and regions to support local industry, often around specific industrial technologies or sectors (Charles and Stankova, 2014). They play an important role for regions in industrial transition through their ability to identify industry needs and technological opportunities. They can also facilitate access to global knowledge for regional firms through their networks and research collaborations and facilitate cluster interactions among firms. RTOs are often non-profit organisations funded by industry. Examples are the AIMEN Technology Centre in Spain, the EURAC research centre in Italy, and the VTT Technical Research Centre in Finland. 


\section{Ensuring innovation diffusion reaches left-behind places and firms in regions in industrial transition}

Innovation has implications for inclusiveness since the distribution of innovation capacities across the local economy, among firms, regions, universities and public research institutes, is not evenly spread among industries and/or across a territory. As economies become increasingly knowledge-based, regions in industrial transition might be confronted with a situation in which successful innovation can easily be captured by leading firms. This can lead to a stronger concentration of innovation capacities in those areas, which have the most established innovation systems.

If well managed, digitalisation has the potential to support the "democratisation of innovation" by opening up new opportunities for small and lagging firms. Industrial and territorial inclusiveness depend on conditions generating a favourable environment for innovation and the diffusion of innovation. Regions in industrial transition can support places and firms behind the frontier in their regions by leveraging the potential of cities and tradable sectors, capitalising on the innovation strengths of the region and supporting skills development and utilisation in lagging places (see also Chapter 2) (Table 3.4).

\section{Table 3.4. Enhancing territorial inclusiveness: Policy issues, instruments and rationales}

\begin{tabular}{l|l|l|l}
\hline \multicolumn{1}{c|}{ Policy issue } & \multicolumn{1}{c|}{ Policy response } & $\begin{array}{c}\text { Potential suite of implementation } \\
\text { mechanism }\end{array}$ & \multicolumn{1}{c}{ Rationale/additional benefits } \\
\hline $\begin{array}{l}\text { Territorial disparities in } \\
\text { innovation diffusion }\end{array}$ & $\begin{array}{l}\text { Leverage the potential of } \\
\text { cities and tradable sectors }\end{array}$ & $\begin{array}{c}\text { - Policy co-ordination across } \\
\text { administrative boundaries } \\
\text { - Transport connections } \\
\text { - Linking rural businesses with the } \\
\text { urban support system }\end{array}$ & $\begin{array}{l}\text { Strengthens productivity in rural areas } \\
\text { Ensures job opportunities across } \\
\text { territories }\end{array}$ \\
\cline { 2 - 4 } & $\begin{array}{l}\text { Capitalise on unique } \\
\text { regional strengths for } \\
\text { innovation }\end{array}$ & $\begin{array}{l}\text { - Tegional branching build on local } \\
\text { innovation assets }\end{array}$ & $\begin{array}{l}\text { Capitalises on unique strengths to branch } \\
\text { out into new activities }\end{array}$ \\
\cline { 2 - 4 } & Creates a positive regional image \\
\hline
\end{tabular}

\section{Leveraging the potential of cities and tradable sectors}

It is well-established that agglomeration areas with a high density of people and economic activity offer several productivity advantages for new and established businesses (Feldman, 2000; Duranton and Puga, 2004). Educated and skilled workers tend to flow to large cities because of labour market prospects as well as the local availability of diverse amenities. Likewise, knowledge-intensive and high-tech firms, R\&D and headquarter services tend to locate in large cities, in part because of access to skills and connectivity.

Regions undergoing an industrial transition are often home to dynamic cities but also to more rural and left-behind places. Cities can serve as hubs for businesses in rural areas if links between the metropolitan and other areas are effective. In order to realise the potential of cities for rural areas, co-ordination of policies across administrative boundaries and across policy fields is required. Importantly, connections should be understood in a broader sense, including physical connectivity (i.e. facilitating physical connections such as with transport infrastructure) but also non-physical connections. For example, businesses in rural areas should be connected to other firms and universities that create innovation and to financial support organisations (OECD, 2018a). Startup Sweden is an example of how rural digital businesses receive support to benefit from the entrepreneurship ecosystem in Stockholm (Box 3.9). 


\section{Box 3.9. Startup Sweden: Connecting digital start-ups from rural areas to Stockholm}

Startup Sweden, launched in 2016 , is a boot camp for digital start-ups from rural areas in Sweden. The boot camp takes place 4 times a year, with each bootcamp providing 10 companies with the opportunity to go to Stockholm and expand their networks via contacts with other companies, financiers, potential customers and partners. The main idea of the programme is to develop and leverage networks and connect firms to a broader entrepreneurial ecosystem.

Participating companies also get practical advice and knowledge in business development - from other start-ups as well as from experts in various fields. They can also practice their sales pitch for an audience of companies, coaches, sales pitch experts and investors. The selected companies are further given the opportunity to meet with private and public investors at Sweden's biggest demo day for digital enterprises - Sweden Demo Day - as well as the possibility to get priority access to selected actions and international networks, such as the Mobile World Congress (MWC), Innovate46 and Slush.

Some of the success factors are:

- The policy initiative connects start-ups from rural areas across Sweden with the entrepreneurial ecosystem in Stockholm. Internal documentation suggests that 12 out of 80 participating firms have acquired SEK 75 million in external financing, and $75 \%$ of these firms are located outside Stockholm.

- Continued collaboration with participating firms takes place after the boot camp. The agency works with a digital platform to create an online community in which the agency and the firms can remain in contact and help each other in matters such as financing, marketing, public relations (PR) and contacts.

- Participants can grow globally by establishing contacts with entrepreneurial ecosystems in other countries.

A challenge has been to reach firms outside of Stockholm and to attract good quality applications. The agency has undertaken a number of measures to better market the policy initiative. One strategy has been to use alumni firms to disseminate information about the boot camp and to collaborate with local actors to reach out to local firms outside Stockholm.

Source: Swedish Agency for Economic and Regional Growth (n.d.), Homepage, https://tillvaxtverket.se/english.

More generally, policymakers in regions in industrial transition need to think beyond regional boundaries even if their focus is on developing their own region's economy. Often, productivity in one place can be raised through spill-overs and connections established within another region or country. To identify and use these opportunities, regions need to co-operate with each other and exchange information.

In addition to supporting urban agglomerations, OECD research has highlighted the importance of the tradable sector for regions to "catch up" with the European productivity frontier (Figure 3.1). Regions and countries with a higher share of economic activity in tradable sectors innovate more, are more productive, have higher wages and narrow the "productivity gap" faster (OECD, 2018a). Tradable sectors are those sectors whose output in terms of goods and services are traded internationally, such as manufacturing. The non-tradable sector usually consists of services, including, for example, health, retail and construction. Firms in tradable sectors tend to be more innovative because of global competition; thus, moving into tradable sectors can be one channel for these regions to increase the innovation levels of local firms. Regional policymakers can strengthen tradable sectors in various ways. For example, well-designed cluster policies can facilitate investment in related activities and support knowledge spill-overs and diversification based on regional strengths. 


\section{Capitalising on unique innovation strengths for future-oriented activities}

Regions in industrial transition can have a highly developed and specialised knowledge-generation and diffusion system. However, there is a danger that these regions overspecialise in mature and declining industries. A key challenge for regional development is helping these industries break out of locked-in paths by pursuing innovation and exploring new technological pathways.

Following the argument of regional branching, new industry formation arises from the recombination of different but related knowledge, skills and competencies found in existing industries in the region (Asheim et al., 2011). Successful regional innovation strategies are founded on identifying unique characteristics of the region and focusing on how businesses can use existing strengths to grow. Typical regional strengths can be location (e.g. proximity to the sea might lead to specialisation in port technologies), natural resources, or specialisation in a certain type of activity or industry (e.g. aviation, automotive, etc.). A strong focus on these endogenous growth factors should be at the heart of local strategies. Concentrating on regional strengths is a better competitiveness strategy than a race to the bottom by which regions try to outperform each other by lowering environmental standards or tax rates for example.

Finally, territorial branding can be a useful tool for regions in industrial transition. Territorial branding highlights the uniqueness of a region and local specialisations and communicates regional excellence. In order to be successful, territorial branding should be based on local actions that realise the potential of the brand, such as promoting the brand through regional chambers of commerce and industry (Donner, 2016). Investments in productive activities related to the brand (e.g. in agri-business, tourism or industry clusters) should underpin it. Examples of successful territorial/regional branding are the brand Produit en Bretagne (Made in Brittany) in France and the Cherry Festival in Fundão, Portugal.

\section{Key considerations and conclusions}

Strengthening innovation and innovation diffusion is critical for successful industrial transition. Managing innovation opportunities in regions undergoing an industrial transition demands policies that are sensitive to people and place. This can mean re-thinking how innovation is best stimulated to trigger productivity growth and job creation, given a region's particular industrial profile and capacity. This section offers a number of key considerations and conclusions in policy design and implementation that are of particular relevance to regions in industrial transition.

\section{Innovation policy needs to address dynamic and left-behind places simultaneously}

It is important for regions in industrial transition to recognise that policies for innovation are part of a broader regional development agenda. Regions in industrial transition need to ensure that the gains of innovation are widespread and are not concentrated in urban or metropolitan areas. Accomplishing this may mean ensuring that innovation policies do not focus on incumbent firms over new entries and pursuing territorial inclusiveness by addressing all entrepreneurs beyond those residing and operating in cities.

\section{Be aware of risks - Innovation creates winners and losers}

Innovation inherently creates winners and losers in the process of creative destruction, with some firms and individuals benefitting through substantial returns to their invested labour and capital. In regions in industrial transition, technological change has tended to be skill-biased, favouring those with the highest skills, sometimes to the detriment of those with lower or medium-level skills. If there is no upskilling and retraining of those with lower skill sets, growing income inequality will likely be the result. Governments in regions in industrial transition must have a range of policies in place to seize the opportunities arising from innovation but also to manage some of its associated risks. 


\section{Policy alignment and multi-level governance of innovation policies are important}

The precise application of innovation policies will differ according to the context in each transition region. These policies may also be affected by the sector or technology concerned, and by the specific objectives of innovation. Ensuring alignment among the wide variety of policies that intersect with innovation policy including policies in skills, education, labour market, science and technology, SME, etc. - is a key component to overcoming the fragmentation that can accompany innovation policy and its implementation. This should be addressed at the national as well as subnational level. The development and implementation of innovation policies also require a capacitated public sector, trust in government and multi-stakeholder support.

\section{Do not create paper tigers - Test and adjust regional innovation strategies}

Establishing a regional strategy for innovation and economic development is one thing; its implementation is often another matter. Innovation policies operate in a complex, dynamic and uncertain environment, where government action will not always get it right. A commitment to policy monitoring and evaluation, to experimentation and pilots, and to learning from experience in order to adjust policies over time, can help ensure that government action is efficient and reaches its objectives.

\section{Innovation diffusion is often embodied in "tacit" knowledge}

The process of diffusion is more than the one-way flow of technology embodied in equipment. It is the process whereby an innovation, including the "tacit" knowledge of how it should be applied, spreads from the original innovator to other users. It involves a range of private and public institutions and individuals, including large firms, clusters of firms, suppliers, customers and public research institutions. For regions in industrial transition, stimulating knowledge transfer and scaling local, national, and global innovation linkages and networks is crucial because too few firms are integrated into local and global innovation networks, which would allow them to benefit from knowledge and innovation spill-overs.

\section{Organisational changes require different skills profiles for innovation}

The concepts of innovation and diffusion have broadened to cover all the actions firms and universities take to exploit the benefits of innovation. Among these, organisational change is widely seen as a prerequisite for firms and researchers to be able to absorb and exploit innovation. The new production technologies, such as the Internet of Things (IoT), 3D printing, etc., increasingly depend on data processing capabilities and modularisation of tasks through software. These production processes require intensive organisational changes and new skill requirements that will determine the absorptive capacity of firms or their abilities to exploit new technology. Re-orienting training and upskilling towards these developments are critical in regions in industrial transitions in order to fully reap the benefits of automation and digitalisation.

\section{References}

Andrews, D., C. Criscuolo and P. Gal (2015), "Frontier Firms, Technology Diffusion and Public Policy: Micro Evidence from OECD Countries", OECD Productivity Working Papers, No. 2, OECD Publishing, Paris, https://doi.org/10.1787/5jrql2q2ij7b-en.

Archibugi, D. and A. Filippetti (2018), "The retreat of public research and its adverse consequences on innovation”, Technological Forecasting and Social Change, Vol. 127, pp. 97-111.

Asheim, B.T., R. Boschma and P. Cooke (2011), "Constructing regional advantage: Platform policies based on related variety and differentiated knowledge bases", Regional Studies, Vol. 45/7, pp. 893904. 
Brown, R. (2016), "Mission impossible? Entrepreneurial universities and peripheral regional innovation systems", Industry and Innovation, Vol. 23/2, pp. 189-205.

Bundesministeriums für Wirtschaft und Energie (n.d.), Mittelstand Digital, https://www.mittelstanddigital.de.

Carlino, G., \& Kerr, W. R. (2014). Agglomeration and innovation (No. w20367). National Bureau of Economic Research.

Charles, D. and K. Ciampi Stancova (2014), Research and Technology Organisations and Smart Specialisation, S3 Policy Brief Series, No. 15/2015, European Commission, Joint Research Centre.

Chesbrough, H.W. (2006), Open Innovation: The New Imperative for Creating and Profiting from Technology, Harvard Business Press.

Donner, M. (2016), “Understanding place brands as collective and territorial development processes", Wageningen University, Montpellier SupAgro.

Dorn, D. et al. (2017), "The fall of the Labor share and the rise of superstar firms", No. w23396, National Bureau of Economic Research.

Duranton, G. and D. Puga (2004), "Micro-foundations of urban agglomeration economies", in Handbook of Regional and Urban Economics, Vol. 4, Elsevier, pp. 2063-2117.

EIB (2019), Investment Report 2018/2019. Retooling Europe's Economy, https://www.eib.org/attachments/efs/economic investment report 2018 key findings en.pdf.

Etzkowitz, H. and C. Zhou (2017), The Triple Helix: University-industry-government Innovation and Entrepreneurship. Routledge.

European Commission (2018), Impact Assessment Support Study for the Revision of the Public Sector Information Directive, https://ec.europa.eu/digital-single-market/en/news/impact-assessment-supportstudy-revision-public-sector-information-directive.

Feldman, M.P. (2000), "Location and innovation: The new economic geography of innovation, spillovers, and agglomeration", The Oxford Handbook of Economic Geography, Vol. 1, pp. 373-395.

Kerr, W.R. and R. Nanda (2015), "Financing innovation", Annual Review of Financial Economics, Vol. 7 , pp. 445-462.

OECD (2019), OECD Regional Outlook 2019: Leveraging Megatrends for Cities and Rural Areas, OECD Publishing, Paris, https://doi.org/10.1787/9789264312838-en.

OECD (2018a), Productivity and Jobs in a Globalised World: (How) Can All Regions Benefit?, OECD Publishing, Paris, http://dx.doi.org/10.1787/9789264293137-en.

OECD (2018b), "OECD Experience on Broadening Innovation and Innovation Diffusion”, Scoping Paper for Peer Learning Workshop, Lille, 11-12 April, OECD Paris, Unpublished.

OECD (2018c), OECD Regional Statistics (database), http://dx.doi.org/10.1787/region-data-en.

OECD (2017a), OECD Science, Technology and Industry Scoreboard 2017: The Digital Transformation, OECD Publishing, Paris, https://doi.org/10.1787/9789264268821-en.

OECD (2017b), Small, Medium, Strong. Trends in SME Performance and Business Conditions, OECD Publishing, Paris, https://doi.org/10.1787/9789264275683-en.

OECD (2016), Job Creation and Local Economic Development 2016, OECD Publishing, Paris, http://dx.doi.org/10.1787/9789264261976-en.

OECD (2015a), Innovation Policies for Inclusive Growth, OECD Publishing, Paris, https://doi.org/10.1787/9789264229488-en.

OECD (2015b), The Future of Productivity, OECD Publishing, Paris, https://doi.org/10.1787/9789264248533-en.

OECD (2014), "Recommendation of the Council on Effective Public Investment across Levels of 
Government", adopted on 12 March 2014, available at: http://www.oecd.org/regional/regionalpolicy/PrinciplesPublic-Investment.pdf.

OECD (2011), Demand-side Innovation Policies, OECD Publishing, Paris, https://doi.org/10.1787/9789264098886-en.

OECD (n.d.), Effective Public Investment Toolkit, http://www.oecd.org/effective-public-investment-toolkit/.

OECD/Eurostat (2018), Oslo Manual 2018: Guidelines for Collecting, Reporting and Using Data on Innovation, 4th Edition, The Measurement of Scientific, Technological and Innovation Activities, OECD Publishing, Paris/Eurostat, Luxembourg, https://doi.org/10.1787/9789264304604-en.

Oyón, C. (2018), "PCTI EUSKADI 2020: A smart specialisation strategy oriented to boost Economic and Sustainable Development", PowerPoint Presentation for the Peer Learning in Regions in industrial transition Workshop: Broadening Innovation and Innovation Diffusion, Presented by Mario Cervantes, 11-12 April, 2018, Lille, France.

Norwegian Innovation Clusters (n.d.), Homepage, http://www.innovationclusters.no/english.

Pietrobelli, C. and R. Rabellotti (2011), "Global value chains meet innovation systems: are there learning opportunities for developing countries?”, World Development, Vol. 39/7, pp. 1261-1269.

Swedish Agency for Economic and Regional Growth (n.d.), Homepage, https://tillvaxtverket.se/english. 


\title{
Annex 3.A. Overview of policy issues and responses in broadening and diffusing innovation
}

\author{
Annex Table 3.A.1. Overview of policy issues, implementation mechanisms and rationales in \\ broadening and diffusing innovation in regions in industrial transition
}

\begin{tabular}{|c|c|c|c|}
\hline Policy issue & Policy response & $\begin{array}{l}\text { Potential suite of implementation } \\
\text { mechanism }\end{array}$ & Rationale/additional benefits \\
\hline \multirow{6}{*}{$\begin{array}{l}\text { Creating and sustaining } \\
\text { comprehensive innovation } \\
\text { ecosystems }\end{array}$} & \multirow[t]{2}{*}{$\begin{array}{l}\text { Broadening the notion of } \\
\text { innovation }\end{array}$} & \multirow{2}{*}{$\begin{array}{l}\text { - Building public and private sector } \\
\text { capabilities for innovation } \\
\text { - Innovation-friendly public procurement }\end{array}$} & $\begin{array}{l}\text { Strong local support and engagement in } \\
\text { innovation processes }\end{array}$ \\
\hline & & & $\begin{array}{l}\text { Strategic prioritisation of innovation- } \\
\text { enhancing assets }\end{array}$ \\
\hline & \multirow{2}{*}{$\begin{array}{l}\text { Strengthening innovation } \\
\text { financing and reducing } \\
\text { barriers to investment }\end{array}$} & \multirow{2}{*}{$\begin{array}{l}\text { - Public funding for co-operation and } \\
\text { networks and linkage building } \\
\text { - Review of public investment choices } \\
\text { and barriers }\end{array}$} & Support for new and emerging industries \\
\hline & & & $\begin{array}{l}\text { Strengthens capacity for public } \\
\text { investment decisions }\end{array}$ \\
\hline & \multirow{2}{*}{$\begin{array}{l}\text { Improving monitoring and } \\
\text { evaluation of innovation } \\
\text { policies }\end{array}$} & \multirow{2}{*}{$\begin{array}{l}\text { - Stakeholder engagement in policy } \\
\text { design } \\
\text { - More and better data collection } \\
\text { - Programme adjustments }\end{array}$} & Better measurement of impact \\
\hline & & & Optimal allocation of scare resources \\
\hline \multirow{6}{*}{$\begin{array}{l}\text { Lack of (small) business } \\
\text { capabilities for innovation }\end{array}$} & \multirow{2}{*}{$\begin{array}{l}\text { Accelerating the digital } \\
\text { transformation }\end{array}$} & \multirow{2}{*}{$\begin{array}{l}\text { - Financial support and technical } \\
\text { assistance (loans, vouchers, aids) } \\
\text { - Training and guidance (personal } \\
\text { advice, webinars, events) } \\
\text { - Information campaigns, cluster-wide } \\
\text { initiatives }\end{array}$} & Enhances digital companies in firms \\
\hline & & & Supports industrial modernisation \\
\hline & \multirow[t]{2}{*}{$\begin{array}{l}\text { Scaling business } \\
\text { innovation networks }\end{array}$} & \multirow{2}{*}{$\begin{array}{l}\text { - Supporting industrial clusters and } \\
\text { cross-cluster fertilisation } \\
\text { - Linking GVCs to cluster policies } \\
\text { - Supporting open innovation and the } \\
\text { use of open data }\end{array}$} & $\begin{array}{l}\text { Integration of local industries into global } \\
\text { value chains }\end{array}$ \\
\hline & & & Industrial diversification and upgrading \\
\hline & \multirow[b]{2}{*}{$\begin{array}{l}\text { Supporting effective } \\
\text { university-industry co- } \\
\text { operation }\end{array}$} & \multirow{2}{*}{$\begin{array}{l}\text { - Collective research agreements } \\
\text { - Licenses and patents } \\
\text { - Spin-off firms } \\
\text { - Labour mobility between academia } \\
\text { and industry }\end{array}$} & Creates knowledge spillovers \\
\hline & & & $\begin{array}{l}\text { Improves the opportunities of SMEs to } \\
\text { participate in research commercialisation }\end{array}$ \\
\hline \multirow{4}{*}{$\begin{array}{l}\text { Territorial disparities in } \\
\text { innovation diffusion }\end{array}$} & \multirow{2}{*}{$\begin{array}{l}\text { Leveraging the potential } \\
\text { of cities and tradable } \\
\text { sectors }\end{array}$} & \multirow{2}{*}{$\begin{array}{l}\text { - Policy co-ordination across } \\
\text { administrative boundaries } \\
\text { - Transport connections } \\
\text { - Linking rural businesses with the } \\
\text { urban support system }\end{array}$} & Strengthens productivity in rural areas \\
\hline & & & $\begin{array}{l}\text { Ensures job opportunities across } \\
\text { territories }\end{array}$ \\
\hline & \multirow{2}{*}{$\begin{array}{l}\text { Capitalising on unique } \\
\text { regional strengths for } \\
\text { innovation }\end{array}$} & \multirow{2}{*}{$\begin{array}{l}\text { - Regional branching build on local } \\
\text { innovation assets } \\
\text { - Territorial branding }\end{array}$} & $\begin{array}{l}\text { Capitalises on unique strengths to branch } \\
\text { out into new activities }\end{array}$ \\
\hline & & & Creates a positive regional image \\
\hline
\end{tabular}




\section{Promoting entrepreneurship and private sector engagement}

This chapter discusses the role of entrepreneurship and private sector engagement in driving structural change and renewal in regions in industrial transition. A number of barriers to innovative entrepreneurship often persist in regions with a strong industrial heritage, notably low levels of start-up and scale-up activity, weak entrepreneurship cultures and a lack of innovation and effectively linked knowledge networks. The chapter sheds light on overcoming these barriers by making use of appropriate finance, skills and knowledge exchange policies. It identifies a suite of potential policy instruments and highlights the role of local and regional authorities in designing integrated and locally tailored policy packages. Finally, it summarises key considerations for policymakers in regions in industrial transition to make more strategic use of local innovation and entrepreneurship ecosystems in order to stimulate entrepreneurial activity and innovation-led growth.

The statistical data for Israel are supplied by and under the responsibility of the relevant Israeli authorities. The use of such data by the OECD is without prejudice to the status of the Golan Heights, East Jerusalem and Israeli settlements in the West Bank under the terms of international law. 


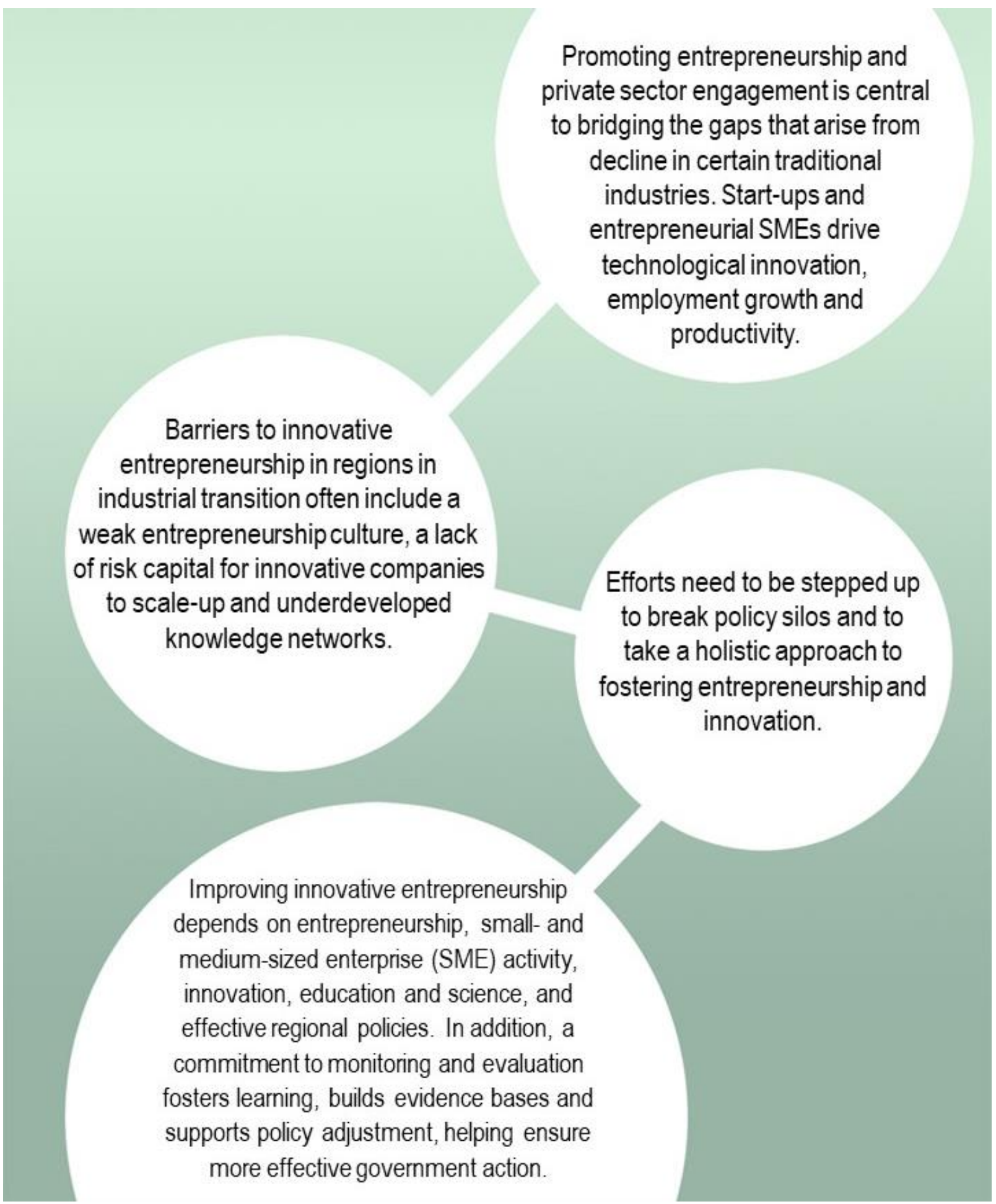




\section{Innovative entrepreneurship can help renew old industrial structures}

Entrepreneurship and private sector engagement are key drivers of regional industrial diversification and future competitiveness. Entrepreneurial start-ups, scale-ups and entrepreneurial employees in large companies spur economic growth and new job generation in emerging fields of (industrial) activity. Economic development does not emerge automatically; entrepreneurs who experiment at the level of new and established firms are needed. While some of these experiments fail, others succeed as innovations and create wealth for society.

Regions in industrial transition are often characterised by capital-intensive, sometimes declining industry dominated by large (often multinational) companies, creating high barriers to entry for entrepreneurs and start-ups. Empowering and encouraging entrepreneurship is even more important in this type of region than in other regions because it helps diversify the local economy and move into new activities.

\section{Start-ups and scale-ups can drive job creation}

Compared to very dynamic regions, those in industrial transition are typically home to older firms in longestablished industries with relatively low churn. These regions are also home to fewer young and highgrowth firms. This can be problematic as it is young firms, especially, that contribute to job creation (Figure 4.1) (Criscuolo, Gal and Menon, 2014). The aggregate figures, however, mask the heterogeneity among these firms: only a small fraction of start-ups contribute substantially to job creation, while the majority either fail in the first year or remain small (Criscuolo, Gal and Menon, 2014). Addressing policy failures, such as burdensome bankruptcy regulations or weak contract enforcement, is important in order to strengthen local high growth potential in regions in industrial transition. New businesses and small- and medium-sized enterprises (SMEs) also contribute to productivity growth and play a key role in supporting innovation. They help commercialise new knowledge and contribute to breakthrough innovations (Andersson, Braunerhjelm and Thulin, 2012).

\section{Figure 4.1. Young firms contribute disproportionally to job creation}

Employment, job creation and job destruction by firm age and size, percentage share

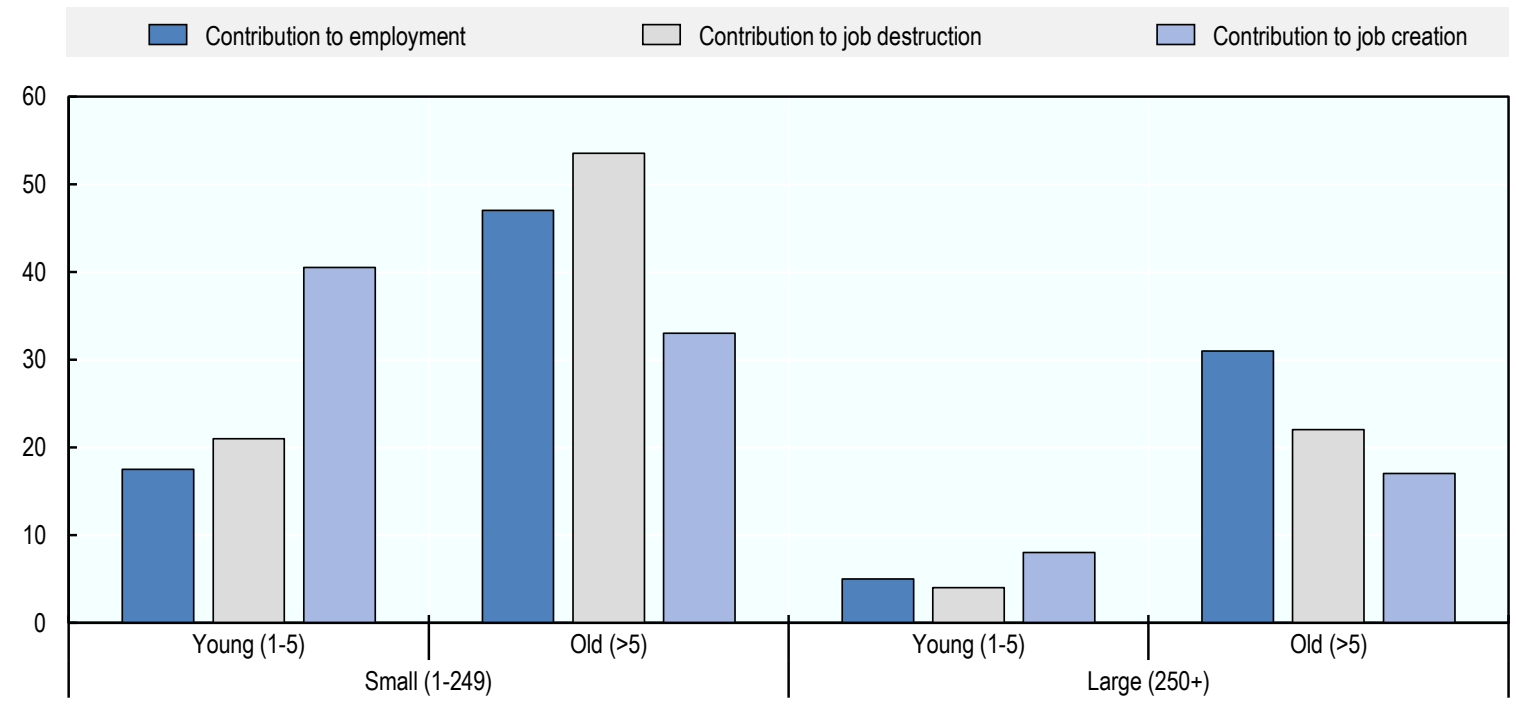

Source: Criscuolo, C., P. Gal and C. Menon (2014), "The Dynamics of Employment Growth: New Evidence from 18 Countries", https://dx.doi.0 rg/10.1787/5jz417hi6hg6-en. 


\section{Stimulating entrepreneurship helps the emergence of new firms and boosts innovation in old firms}

In recent years, there has been a growing emphasis on the entrepreneurial and innovative attributes and activities of larger firms. Such businesses, whether multinational enterprises or domestic firms, are not only leading employers but also engines of economic development. Promoting entrepreneurial mindsets within large companies can help these companies reorient their future activities through inhouse process or product innovation triggered by employees with a desire to innovate.

Regions in industrial transition need to support start-up and scale-up development and entrepreneurship and innovation in large firms. Because these regions are often home to large and incumbent business in traditional and long-established industries, harnessing the entrepreneurial capacities and capabilities of employees in these firms can make an important contribution to industrial diversification. At the same time, these regions often face a decline in traditional activities that can be compensated by new economic activity arising from innovative start-ups and young firms. Such firms help transform traditional industrial activities and stimulate the emergence of new regional growth paths.

\section{Regions in industrial transition need to support innovative entrepreneurship in a range of areas}

Regions in industrial transition are home to a large range of local actors with a high potential to drive industrial modernisation and develop territorial strategies for innovation. Industrial modernisation and new industry emergence in a region are rarely due to the actions of a single individual or a single intervention. The emergence of new activities typically depends on their co-creation by many actors and the interplay of a set of factors, such as leadership, culture, capital markets and open-minded customers, that combine in a complex way to stimulate entrepreneurship.

Regions in industrial transition have a long legacy in manufacturing and are often home to large-scale companies in established industries. Given this, successful industrial modernisation should build on the knowledge and expertise acquired in these industries in order to move into new and emerging activities. It is, therefore, important to include these firms as key players in local entrepreneurial ecosystems and to build future-oriented management skills in important local employers.

Different regions in industrial transition display very different initial entrepreneurship ecosystems and drivers and barriers to innovative entrepreneurship often vary by region. This is also the case for regions that have undergone or are undergoing an industrial transition. Entrepreneurship policy needs to be responsive to local contexts, carefully targeting specific regional conditions. At the same time, innovative entrepreneurship requires well-sequenced action in a variety of areas, ranging from providing access to finance and supporting skills, to simplifying regulations, enhancing competencies and culture, and strengthening knowledge exchange (Figure 4.2). 
Figure 4.2. Key areas for regional intervention

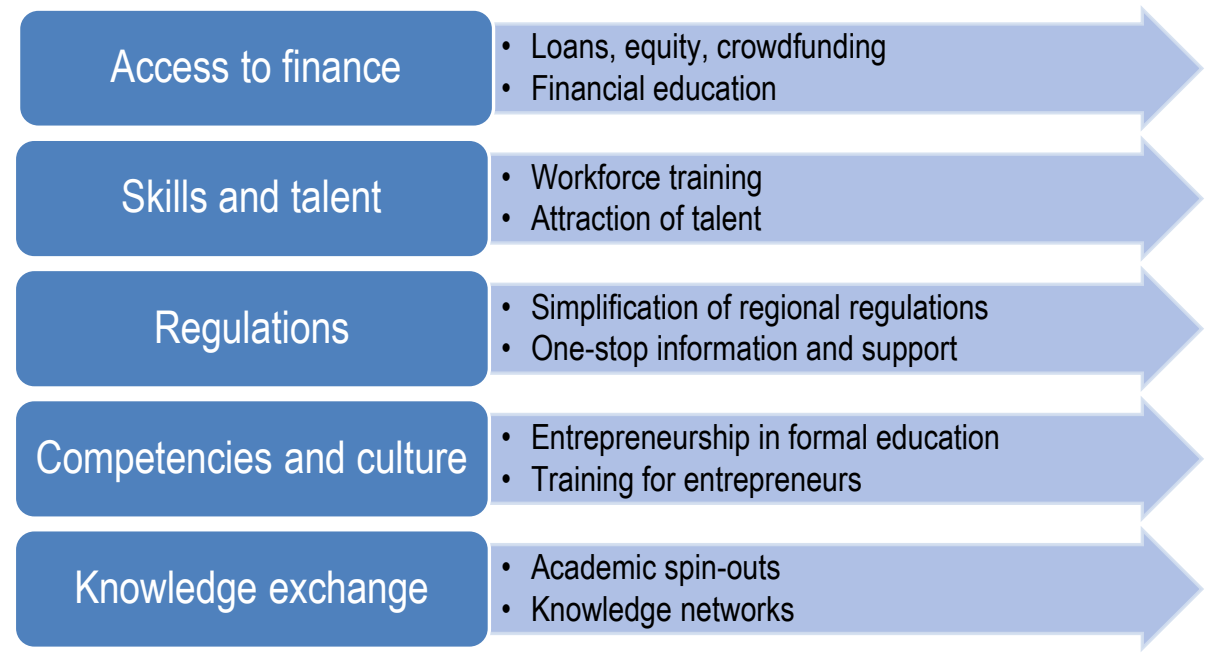

Source: OECD (2018c), "Promoting entrepreneurship and mobilising the private sector", PowerPoint Presentation for the Peer Learning in Regions in industrial transition Workshop: Promoting Entrepreneurship and Mobilising the Private Sector, Presented 7-8 June 2018, Turin, Italy, Unpublished.

\section{What challenges and opportunities do regions in industrial transition face in promoting entrepreneurship and private sector engagement?}

New technologies and ways of working are likely to have a profound impact on the nature of work in firms and industries (see Chapter 2). This comes with strong opportunities for entrepreneurs and small businesses to advance into new markets. However, seizing such opportunities is not self-evident for regions in industrial transition. Generating entrepreneurial skills and creating networks among firms, universities, civil society and public institutions are challenging for many of these regions. A lack of management experience and entrepreneurial skills, particularly among younger entrepreneurs, frequently pose a barrier to entrepreneurship. Businesses with scale-up ambitions need to attract and retain talent in order to continue growing and innovating and can face a lack of skilled workers. Researchers in universities often lack the necessary entrepreneurial skills, particularly in management and business, needed to transform research into promising commercial activities for the region. Lastly, more policy entrepreneurs and creative thinkers are needed in public institutions and civil society to actively engage in regional entrepreneurial discovery processes.

\section{Access to appropriate finance often poses a challenge for firms in regions in industrial transition}

Regions undergoing an industrial transition must seize the potential of innovative entrepreneurship to successfully modernise their industries and guide the local economy towards new and emerging activities. Yet, among regions in industrial transition, there can be start-ups and SMEs that struggle to attract adequate and sustained financing. Experience among some regions in industrial transition points to finance offerings that do not always correspond to the needs of scale-ups and start-ups that rely on intangible assets or display particularly high-risk profiles. This may pose a barrier to the development of innovative entrepreneurship in these regions, as many businesses do not invest in new business models if the funding is not secured. Furthermore, in certain regions in industrial transition (Annex A), SMEs are still largely dependent on debt-based financing instruments, making them more vulnerable to shifts in credit markets. 
New and alternative sources of finance and a better understanding of emerging trends and opportunities for financing start-ups and scale-ups can help regions in industrial transition improve their entrepreneurship conditions and better support their entrepreneurs. However, alternative sources of finance such as, for example, venture capital, account only for a small percentage of gross domestic product (GDP) among OECD countries, particularly its European members (Figure 4.3). This further limits companies with high growth ambitions to embark on riskier endeavours.

\section{Figure 4.3. Venture capital investments by country}

As a percentage of GDP, 2015

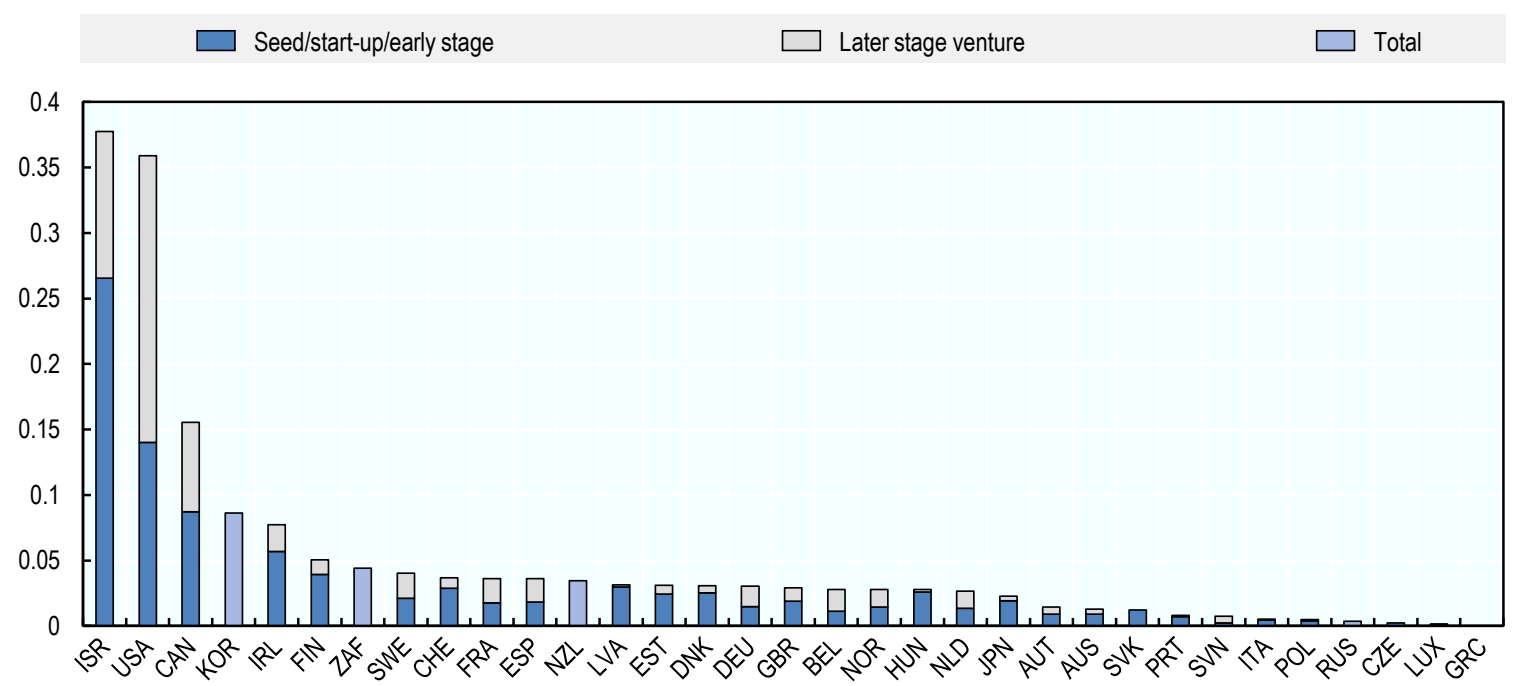

Source: OECD (2017b), Small, Medium, Strong. Trends in SME Performance and Business Conditions, https://dx.doi.org/10.1787/978926427 5683-en.

\section{Unlocking entrepreneurial potential requires more investment in entrepreneurial skills and culture}

Entrepreneurship is an important driver of industrial modernisation and developing entrepreneurship potential in regions in industrial transition is one role for concerned policymakers. It enables the creation of new firms and businesses and helps avoid being locked into existing and dominant industrial structures. Regions in industrial transition with a highly specialised industrial base often face more negative social attitudes towards entrepreneurship than regions where industry size has traditionally been diverse (Huggins and Thompson, 2014).

Entrepreneurial culture is also closely associated with self-perceived entrepreneurial skills. Even where people are motivated to start a business, they may be constrained by the belief that they do not have sufficient capability to do so successfully. In the European Union, about one-third of women (34.1\%) reported that they had the knowledge and skills to start a business over the 2012-16 period relative to half of men (49.9\%) (Figure 4.4). Given the long tradition of manufacturing and the presence of well-established companies in traditional sectors in regions in industrial transition, self-perceived entrepreneurial skills are likely to be low rather than high in many of these regions. 
Figure 4.4. Entrepreneurship skills as a barrier to business creation for men and women, 2012-16

Percentage of population (18-64 year-olds) who responded "yes" to: "Do you have the knowledge and skills to start a business?"

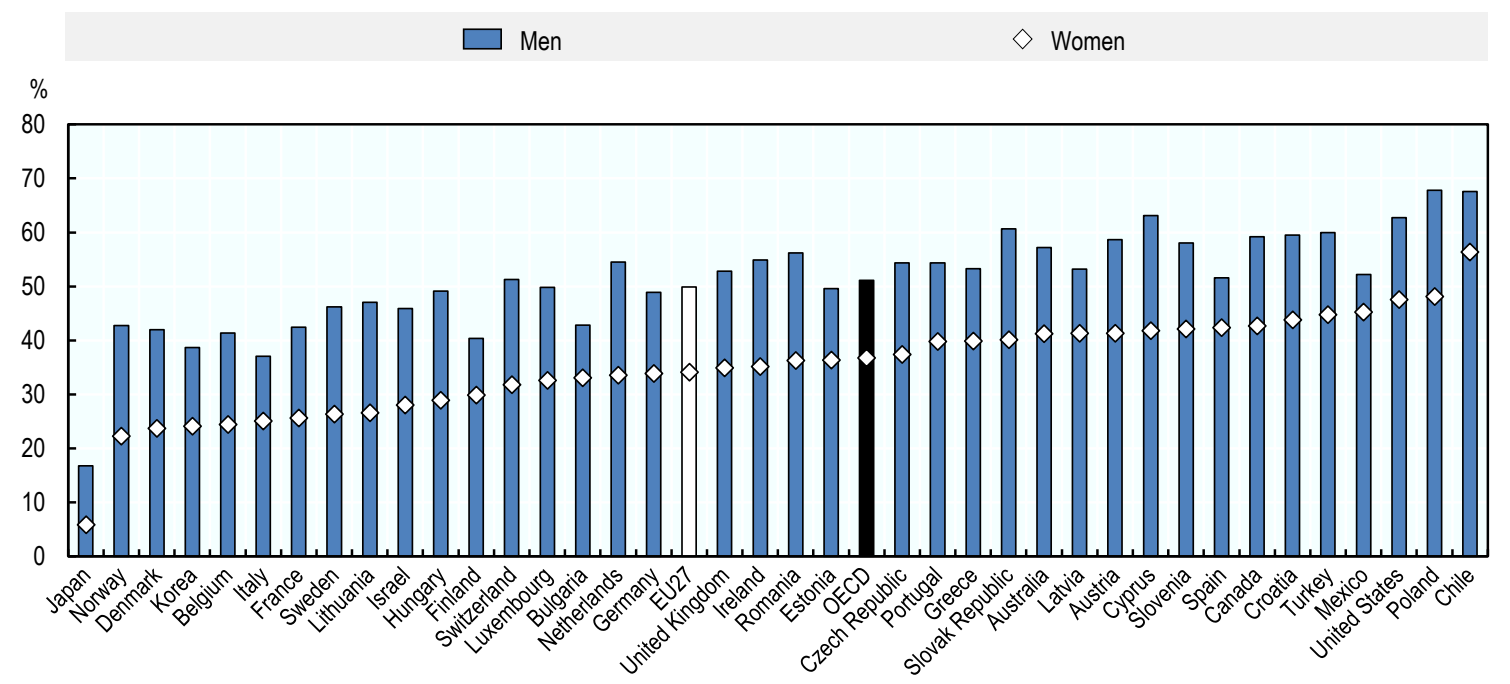

Note by Turkey:

The information in this document with reference to "Cyprus" relates to the southern part of the Island. There is no single authority representing both Turkish and Greek Cypriot people on the Island. Turkey recognises the Turkish Republic of Northern Cyprus (TRNC). Until a lasting and equitable solution is found within the context of the United Nations, Turkey shall preserve its position concerning the "Cyprus issue".

Note by all the European Union Member States of the OECD and the European Union:

The Republic of Cyprus is recognised by all members of the United Nations with the exception of Turkey. The information in this document relates to the area under the effective control of the Government of the Republic of Cyprus.

Sources: (OECD/EC 2017), originally from GEM (2017), Special Tabulations of the 2012-16 Adult Population Surveys, Global Entrepreneurship Monitor.

In addition to a lack of perceived skills, a negative attitude toward failure can affect entrepreneurial culture. Places and cultures where failure is seen as a chance to learn and improve before starting on the next venture provide better environments for entrepreneurship to flourish than those where failure is seen as a weakness or flaw. Barring the existence of an enabling culture, entrepreneurship requires clear and concise framework conditions, and empowering potential entrepreneurs by providing them with the necessary entrepreneurial skills and confidence.

\section{How can policy (better) support entrepreneurship and private sector engagement?}

Entrepreneurship policy and private sector engagement aim to address a range of concrete problems for SMEs and entrepreneurs and support creating an enabling business environment for industrial modernisation. For regions in industrial transition that face barriers to innovative entrepreneurship based on their legacy as old manufacturing regions, better access to finance for start-ups and scale-ups, higher levels of investment in entrepreneurial skills, connections and learning, as well as an improved regulatory environment helps stimulate innovative entrepreneurship. 


\section{Several policy approaches exist to support start-up and scale-up financing}

Policies to support an entrepreneur's access financing are rooted in addressing market failures such as information asymmetries and financing gaps. There are a number of policy approaches to improve access to finance for start-ups and scale-ups, including the use of traditional policy instruments, promoting alternative sources of finance and strengthening financial education (Table 4.1).

\section{Table 4.1. Access to finance: policy issues, instruments and rationales}

\begin{tabular}{|c|c|c|c|}
\hline Policy issue & Policy response & $\begin{array}{c}\text { Potential suite of implementation } \\
\text { mechanism }\end{array}$ & Rationale/additional benefits \\
\hline \multirow[t]{5}{*}{$\begin{array}{l}\text { Limited access to finance } \\
\text { for start-ups and scale-ups }\end{array}$} & \multirow{3}{*}{$\begin{array}{l}\text { Facilitate access to } \\
\text { finance and broaden the } \\
\text { range of financial } \\
\text { instruments }\end{array}$} & \multirow{3}{*}{$\begin{array}{l}\text { - Traditional instruments: grants, soft } \\
\text { loans, loan guarantees } \\
\text { - Alternative and non-bank sources of } \\
\text { finance: crowdfunding, peer-to-peer } \\
\text { lending, business angel networks, } \\
\text { venture capital } \\
\text { - Digital finance opportunities: Fintech, } \\
\text { blockchain }\end{array}$} & $\begin{array}{l}\text { Reduces start-up and SME reliance on } \\
\text { debt instruments }\end{array}$ \\
\hline & & & Generates employment \\
\hline & & & $\begin{array}{l}\text { Creates an attractive entrepreneurship } \\
\text { ecosystem in different types of regions }\end{array}$ \\
\hline & \multirow[t]{2}{*}{$\begin{array}{l}\text { Strengthen financial } \\
\text { literacy }\end{array}$} & \multirow{2}{*}{$\begin{array}{l}\text { - Training and mentoring programmes, } \\
\text { provision of accessible information } \\
\text { and guidance }\end{array}$} & $\begin{array}{l}\text { Makes firms more attractive clients to } \\
\text { financial service providers }\end{array}$ \\
\hline & & & $\begin{array}{l}\text { Provides firms with tailored advice on } \\
\text { financing needs }\end{array}$ \\
\hline
\end{tabular}

\section{Alternative funding instruments can support entrepreneurs in regions in industrial transition}

For regions in industrial transition, alternative financing instruments provide an important addition to traditional debt instruments, which entrepreneurs with innovative business models might not be able to access due to a high-risk profile. The spectrum of available alternative financing instruments is large and covers different financing needs, firm characteristics and risk profiles (Figure 4.5). In principle, asset-based finance and alternative debt mechanisms are available to a wide range of firms and are particularly suitable for firms that have a low risk of default, but also limited returns. Hybrid instruments combine debt and equity schemes and are most suitable to more mature or high-growth firms. Public and private equity instruments target high-growth, high-risk ventures.

Figure 4.5. Alternative debt-financing instruments by firm profile and stage of development

Type of financing instrument

\begin{tabular}{|c|c|c|c|c|c|c|}
\hline Low risk/ & turn & Me & $\mathrm{m}$ risk/return & \multicolumn{3}{|c|}{ High risk/return } \\
\hline Asset-Based Finance & Alterna & e Debt & "Hybrid" Instruments & Public equity & Private & \\
\hline $\begin{array}{l}\text {-Asset-based lending } \\
\text { - Factoring } \\
\text {-Purchase order finance } \\
\text {-Warehouse receipts } \\
\text { - Leasing }\end{array}$ & $\begin{array}{l}\text {-Crowdfunding } \\
\text { (debt)/p2p } \\
\text { lending }\end{array}$ & $\begin{array}{l}\text { - Corporate bonds } \\
\text { - Securitised debt } \\
\text { - Covered bonds } \\
\text { - Venture debt } \\
\text { - Private } \\
\text { placements }\end{array}$ & $\begin{array}{l}\text { - Subordinated loans/ bonds } \\
\text { - Silent participations } \\
\text { - Participating loans } \\
\text { - Profit participation rights } \\
\text { - Convertible bonds } \\
\text { - Bonds with warrants }\end{array}$ & $\begin{array}{l}\text {-Specialised } \\
\text { platforms for } \\
\text { public listing of } \\
\text { SMEs }\end{array}$ & $\begin{array}{l}\text {-Business angel } \\
\text { investments } \\
\text {-Crowfunding } \\
\text { (equity) }\end{array}$ & $\begin{array}{l}\text {-Venture } \\
\text { capital } \\
\text { - Other } \\
\text { private } \\
\text { equity }\end{array}$ \\
\hline $\begin{array}{l}\text {-Available to a wide } \\
\text { range of SMEs } \\
\text { - Especially relevant } \\
\text { for firms with limited } \\
\text { (verifiable) } \\
\text { creditworthiness }\end{array}$ & $\begin{array}{l}\text { - Firms in need for } \\
\text { smaller amounts } \\
\text { of funds } \\
\text { - When lacking } \\
\text { collateral/imited } \\
\text { credit history }\end{array}$ & $\begin{array}{l}\text { - Requires certain } \\
\text { size and scale } \\
\text { - More mature } \\
\text { firms with proven } \\
\text { business model }\end{array}$ & $\begin{array}{l}\text {-Mature companies } \\
\text { undergoing transitions } \\
\text { and restructuring } \\
\text { - High-growth firms } \\
\text { beyond the early stages } \\
\text { of development }\end{array}$ & $\begin{array}{l}\text { - Highly structured } \\
\text { governance and } \\
\text { management } \\
\text { systems, and } \\
\text { extensive disclosure } \\
\text { - Firms in need of } \\
\text { large fund injections }\end{array}$ & $\begin{array}{l}\text { - Early stages of } \\
\text { the life cycle } \\
\text { - Innovative } \\
\text { firms, but } \\
\text { possibly from a } \\
\text { wide range of } \\
\text { sectors }\end{array}$ & $\begin{array}{l}\text { - Concentrated } \\
\text { in knowledge- } \\
\text { based } \\
\text { industries } \\
\text { - Somewhat } \\
\text { later stage of } \\
\text { life cycle }\end{array}$ \\
\hline
\end{tabular}

Source: Revised from OECD (2018d), "Enhancing SME access to diversified financing instruments", http://www.oecd.org/cfe/smes/ministerial/ documents/2018-SME-Ministerial-Conference-Plenary-Session-2.pdf. 
New opportunities for SME financing are also found in a range of technology-enabled financial service innovations, such as Fintech, digital platforms and blockchain technologies. A basic example of a Fintech offering is the mobile banking services offered by most traditional banks. As they often drive transactions costs down, these technological developments will likely make it more profitable for financial institutions to serve a client base that includes (small) businesses in remote or rural areas (OECD, 2018a). Blockchain technology will further allow start-ups and scale-ups to undertake transactions at increased speed and transparency, offering a number of opportunities, including the development of smart contracts, reducing reliance on intermediaries and raising additional funding.

In regions in industrial transition, the availability and access to different sources of financing is constrained by a combination of barriers. Many entrepreneurs and business owners lack the financial knowledge, resources or sometimes the willingness to successfully access financing beyond debt-based resources. Public policy dedicated to financial literacy programmes can help increase the awareness and capacity of SMEs to access external financing. These programmes aim to improve the quality of loan applications and financial pitches, and to increase knowledge of different financing options.

Governments in regions in industrial transition can help increase knowledge and awareness of the range of instruments available

Governments in transition regions can help facilitate access to financing for start-ups and scale-ups by offering grants (e.g. vouchers), loans or loan guarantees. Care needs to be taken however, not to crowd out the private sector. To this end, regional governments can also promote alternative sources of financing. One technique is to help develop business angel networks. Another is to back private venture capital schemes through co-investment, particularly in the case of early-stage entrepreneurial ventures, as seen in Saxony, Germany (Box 4.1). Regional governments can also offer co-financing based on contractual arrangements.

\section{Box 4.1. The TGFS venture capital fund in Saxony}

\section{Using state and private capital to invest in young firms and start-ups}

TGFS is a venture capital fund that uses private and public funding in order to support innovative startups. The fund's investors are the region of Saxony, regional saving banks and two regional investment companies. The programme offers an alternative to debt-based funding methods by providing fully liable equity. Innovative young firms may receive between EUR 100000 and EUR 5 million, generally granted in stages. TGFS invests as a minority stakeholder, a silent partner or through subordinated loans. Companies are expected to exit the fund after three to six years.

Thus far, 56 investments have been made, with 459 jobs created and a financial leverage effect of EUR 53 million. Regional capital investment companies manage the fund and invest in Saxon SMEs that are active in emerging high-tech and innovative industries.

Source: Saxony (2018), "TGFS: The venture capital funds for Saxony”, PowerPoint Presentation for the Peer Learning in Regions in industrial transition Workshop: Promoting Entrepreneurship and Mobilising the Private Sector, 7-8 June 2018, Torino, Italy, Unpublished.

\section{Supporting entrepreneurs with access to training, coaching, networks and partnerships}

A successful industrial transformation also hinges on the ability of public authorities, companies and entrepreneurs to identify new markets and potential transition opportunities. A number of policy instruments exist to support start-ups, scale-ups and entrepreneurial employees with entrepreneurship training, skills development and knowledge transfer (Table 4.2). 
Table 4.2. Policy issues, instruments and rationales in access to entrepreneurship skills and networks for start-ups and scale-ups

\begin{tabular}{|c|c|c|c|}
\hline Policy issue & Policy response & $\begin{array}{l}\text { Potential suite of implementation } \\
\text { mechanisms }\end{array}$ & Rationale/additional benefits \\
\hline \multirow{5}{*}{$\begin{array}{l}\text { Limited access to } \\
\text { entrepreneurship skills } \\
\text { and networks for start-ups } \\
\text { and scale-ups }\end{array}$} & \multirow{2}{*}{$\begin{array}{l}\text { Support entrepreneurs } \\
\text { with information, training, } \\
\text { coaching and mentoring }\end{array}$} & \multirow{2}{*}{$\begin{array}{l}\text { - One-stop-shops and information } \\
\text { centres } \\
\text { - Entrepreneurship training courses } \\
\text { provision } \\
\text { - Dedicated mentoring programmes } \\
\text { - Incubators and accelerators }\end{array}$} & $\begin{array}{l}\text { Creates an attractive entrepreneurship } \\
\text { ecosystem }\end{array}$ \\
\hline & & & $\begin{array}{l}\text { Provides start-ups and scale-ups with } \\
\text { important business foundations }\end{array}$ \\
\hline & $\begin{array}{l}\text { Strengthen } \\
\text { entrepreneurial networks }\end{array}$ & $\begin{array}{l}\text { - Networking and platform events } \\
\text { organised by local (public) } \\
\text { stakeholders } \\
\text { - Provision of online platforms }\end{array}$ & $\begin{array}{l}\text { Strengthens sales and export networks } \\
\text { and partner search }\end{array}$ \\
\hline & \multirow[t]{2}{*}{$\begin{array}{l}\text { Enhance start-up and } \\
\text { SME participation in } \\
\text { collaborative research }\end{array}$} & \multirow{2}{*}{$\begin{array}{l}\text { - Enhanced start-up and SME } \\
\text { participation through vouchers, } \\
\text { science parks, incubators and } \\
\text { accelerators } \\
\text { - Exploitation of research through } \\
\text { spin-off creation }\end{array}$} & $\begin{array}{l}\text { Supports innovation in entrepreneurial } \\
\text { activity }\end{array}$ \\
\hline & & & Creates knowledge spill-overs \\
\hline
\end{tabular}

\section{Strengthening entrepreneurship through dedicated training}

Entrepreneurship support typically aims to increase an entrepreneur's knowledge about starting or growing a business and provide networking opportunities. For regions in industrial transition, entrepreneurship support programmes can increase levels of information and awareness about entrepreneurship as an alternative route to the labour market. Effective policy packages should include a suite of tools, certainly including essential information but also covering including more intense forms of support such as coaching and mentoring provided by incubators and accelerator programmes.

Entrepreneurship support programmes are often most effective when combining and tailoring intervention areas to a local context. The Ben Franklin Technology Partners programme in the state of Pennsylvania (United States) provides an example of how entrepreneurship is supported in a holistic manner (Box 4.2). Three important functions for regional governments in regions in industrial transition can be identified:

1. An intelligence function: In order for regional-level entrepreneurship policies to be successful, there needs to be a clear sense and vision of the nature of the challenges and opportunities that the region faces in stimulating entrepreneurship. Regions can play a role in defining economic vision and smart specialisation for their territories.

2. A support function: Regions can build and strengthen the local entrepreneurship system through supportive policy actions in a range of areas, such as entrepreneurship and SME policy, education and science policy, including as part of a broader regional development policy.

3. A linkage function: Regions as institutional entrepreneurs can also facilitate networks for enhancing knowledge spill-overs between firms, higher education institutions, civil society and government.

Box 4.2. Entrepreneurship as a pillar of regional development: Lessons from Ben Franklin Technology Partners

Ben Franklin Technology Partners is a technology-based economic development programme in Pennsylvania, United States. Launched in 1983, the programme was originally designed as a grantgiving institution to help commercialise research. Today, it consists of four regional bodies that link 
young companies with funding, expertise, universities and other resources to fill gaps in the entrepreneurial system that may otherwise discourage entrepreneurialism. Ben Franklin Technology Partners helps young firms in a variety of ways: by making them more attractive to different kinds of investors, providing incubator space, creating networks with colleges and universities, and helping to develop and commercialise products.

The programme is funded by the state of Pennsylvania and while it is accountable to the state government, it is completely independent in its funding decisions. The majority (51\%) of its board members must be from the private sector in order to avoid bringing a political dimension into investment decisions.

The programme concentrates its support on young enterprises in three main areas: capital, networks and knowledge. In addition to providing entrepreneurs and young firms with capital, the programme's experts and mentors provide specialised support in marketing and other areas. The impact of the programme has been striking. In 2017, there were 1900 jobs created and 189 new companies formed thanks to Ben Franklin Technology Partners. Furthermore, third-party evaluation has shown that for every USD 1 invested in the programme, there is a return of an additional USD 3.60 in state tax revenues.

Source: Glenn, R. (2018), "Entrepreneurship: An economic development strategy", PowerPoint Presentation for the Peer Learning in Regions in industrial transition Workshop: Promoting Entrepreneurship and Mobilising the Private Sector, 7-8 June 2018, Turin, Italy, Unpublished.

\section{Coaching and mentoring can boost entrepreneurship if the match "works"}

Coaching and mentoring relationships between experienced and new entrepreneurs can offer many benefits. They help increase awareness of entrepreneurship, develop entrepreneurial attitudes and provide helpful advice during business creation and development. An important consideration in successful mentoring is the quality of the match between the experienced entrepreneur (i.e. "mentor") and the new entrepreneur (i.e. "mentee"). Mentoring programmes can use a number of techniques to improve the quality of the match, including mentor matching software tools and personal interviews. The Start:up Slovenia initiative has successfully mobilised mentors from diverse backgrounds to support new businesses with advice (Box 4.3).

\section{Box 4.3. Start:up Slovenia}

Established in 2014, Start:up Slovenia aims to raise the level of entrepreneurial talent by developing networks that encourage company growth on international markets, contribute to higher capital accessibility and activate various ecosystem stakeholders. The initiative mobilises a network of mentors from various backgrounds to provide entrepreneurs and young firms with tailored advice. Through this personal mentorship, young firms can access new networks that can help them grow and fulfil their potential. The expected outcomes on a yearly basis are to create 1000 new jobs in start-ups, to connect at least 50 start-up companies with the most important ecosystem and to create or attract at least 150 start-up companies with global potential.

Source: Slovenia (2018), "Peer learning in regions in industrial transition: Workshops good practice template", Start:up Slovenia, Prepared for the Peer Learning in Regions in Industrial Transition Workshop "Promoting entrepreneurship and mobilising the private sector", 7-8 June 2018, Torino, Italy, Unpublished. 


\section{Business incubators and business accelerators provide strong support to start-ups and scale-ups}

Business incubators and business accelerators provide a package of services to entrepreneurs prior to business creation and at early stages of the business life cycle. Services offered include business coaching and advice, workshops, seminars and networking opportunities. In addition, business incubators often provide facilitates for participating (potential) start-ups to operate.

For regions in industrial transition, incubators and accelerators are important policy instruments that can potentially generate substantial benefits for emerging firms and the wider economy by speeding up entrepreneurship and innovation processes. The shift in the nature of production away from manufacturing towards services may also increase the proportion of employment in activities for which co-working models such as incubators and accelerators are relevant. Shifts in employment patterns from the traditional worker's contract to rising self-employment and sole traders may also lead to greater demand for entrepreneurship advice and training.

Evidence suggests that business incubators and business accelerators provide effective support for new and growing businesses. Businesses associated with incubators tend to have higher survival rates, create more jobs and generate more revenue (Mubaraki and Busler, 2011).

\section{Business support can have positive impacts on productivity and output}

Evaluations of whether public support to entrepreneurship, in general, has a positive impact on business activity is mixed, though tends to lean toward the positive. Often, outcomes are positive for some measurements of business outcome, but not for all. In the United Kingdom, the What Works Centre has reviewed 23 evaluation studies on the impact of support measures on business outcomes, such as productivity, employment, sales or exports. Out of the 23 evaluation studies reviewed, 14 found that business advice has a positive impact on at least 1 out of in total 12 business outcomes. However, several evaluations found that business advice has no or negative impact on the chosen 12 business measures (What Works Centre, 2016). A key theme in evaluations seems not whether to provide support but how best to provide it. The OECD has come up with several guiding principles on policy design for business support (Box 4.4).

\section{Box 4.4. The "how to" of business support policy design}

Based on an international policy workshop conducted together with the UK Department for Business and Energy, the OECD developed several guiding design principles on the provision of business development services (OECD, 2018b). These principles serve to improve the design and delivery of business development support, including entrepreneurship training, advice, mentoring and coaching.

- Policymakers should understand demand-side constraints in the provision of entrepreneurship support. Low uptake of support services can also indicate demand-side gaps, such as limited SME growth ambitions, lack of awareness on the services offered, doubts about the usefulness of the services, or legitimacy issues around public operators.

- It is important to build rather than crowd out markets. While the public sector has a responsibility to diagnose a gap to be filled by public policy, policy delivery can be more effective through external experts. This helps build a private market rather than crowd it out.

- Tapping into firm networks and trigger points helps to target firms. Existing enterprise-led networks, such as regional clusters or chambers of commerce, are effective for outreach and to help build trust. 
- Be careful in stimulating demand where the cost is high. The cost-effectiveness of programmes is likely to be greatest where businesses have ambition and potential to grow. Resistance to growth and limited demand for business support entail a risk of over-investment in public entrepreneurship support programmes.

Source: OECD (2018b), Leveraging Business Development Services for SME Productivity Growth: International Experience and Implications for UK Policy, http://www.oecd.org/industry/smes/Final\%20Draft\%20Report_V11.pdf (accessed on 26 May 2019).

\section{Entrepreneurial networks are key sources of expertise and knowledge}

Governments in regions in industrial transition can help connect innovative and new entrepreneurs to existing local and global networks and value chains and support cross-fertilisation between existing networks. Innovative entrepreneurship is largely influenced by knowledge spill-overs and networks accessible to start-ups and small firms, as well as by the broad innovation system in which they are embedded. As innovation increasingly involves collaboration among a variety of players such as suppliers, customers, competitors and universities - as well as government and entrepreneurs - a key challenge for start-ups and small businesses is to connect to appropriate knowledge networks at the local, national and global levels.

Engagement in entrepreneurial networks provides start-ups and scale-ups with access to business partners, ideas, clients, financing, and help to share knowledge and expertise (OECD, 2017a). Start-ups, in particular, might have smaller and less well-developed networks and thus less access to important business resources and clients. It is, therefore, important for policymakers to increase the scale of resources available to new and potential entrepreneurs by helping them expand their networks, for example by creating networking events and developing online platforms to connect entrepreneurs with the wider business community. Entrepreneurship centres, such as that established in Cantabria, run a range of entrepreneurship training programmes to diffuse an entrepreneurship culture and provide an important platform for networks amongst future and established entrepreneurs (Box 4.5).

\section{Box 4.5. The Cantabria Entrepreneurship Centre}

The Cantabria Entrepreneurship Centre (CISE) was started in 2012 as part of the Cantabria International Campus of the University of Cantabria. Its mission is to encourage creative, entrepreneurial and innovative skills among students interested in entrepreneurship and to promote a comprehensive entrepreneurship culture through the creation of networks among entrepreneurs. For this purpose, the centre operates in co-operation with programmes sponsored by public and private organisations to stimulate entrepreneurship. The programmes cover entrepreneurship training classes, individual mentoring support and networking events to facilitate connections between future and current entrepreneurs. The Government of Cantabria supports the different programmes carried out by the entrepreneurship centre as part of their strategy to promote entrepreneurship in the region.

Sources: Presentation for the Peer Learning in Regions in industrial transition Workshop: Promoting Entrepreneurship and Mobilising the Private Sector, 13-14 September, Orleans, France, Unpublished; OECD (2018c), OECD Science, Technology and Innovation Outlook 2018: Adapting to Technological and Societal Disruption, https://dx.doi.org/10.1787/sti_in_outlook-2018-en. 


\section{Universities can act as knowledge brokers for start-ups and SMEs}

In addition to their teaching and research obligations, generating and maintaining ties with entrepreneurs and young companies could be considered a "third mission" for universities (OECD/EU, 2018). Experience among some regions in industrial transition shows that start-ups and SMEs in regions in industrial transition can have difficulties in participating in university research and cannot usually afford to divert human resources to organise and manage collaborations. In such cases, universities can contribute to improving the conditions for innovation diffusion in SMEs and in overcoming absorptive capacity problems. Policy instruments that can support and promote the relationship between SMEs and universities through instruments include SME innovation vouchers, and start-up and SME integration in science parks.

Higher education institutions also provide a regional economy with new knowledge that can be exploited through university spin-offs. A university spin-off is an entirely new business formed around a university innovation and can be owned by the university or created by outside partners (Shane and Stuart, 2002). A unique feature of these spin-offs is that they are often very closely aligned with public research, thus providing a mechanism to transfer tacit knowledge from the research team to those responsible for the daily operations of a firm. The creation of spin-offs, however, often requires considerable financial and human capital. Such capital can be built through such targeted policy interventions as supporting the entrepreneurial competencies of researchers and providing business advice. For regions in industrial transition, this can be of particular interest in future-oriented sectors such as information and communication technology (ICT) or smart manufacturing, as also illustrated by the support scheme for innovative start-ups and spin-offs in Piemonte, Italy (Box 4.6).

\section{Box 4.6. Supporting innovative start-ups and spin-offs resulting from public research in Piemonte, Italy}

Piemonte is supporting innovative start-ups and spin-offs with origins in public research. The initiative is managed by Finpiemonte, a regional development agency and investment firm, and is implemented by university incubators. The aim is to support the creation of new enterprises in three sectors: i) knowledge and technology-intensive manufacturing; ii) ICT; and iii) tourism and culture. The target groups, i.e. potential entrepreneurs, are academic researchers, youth and/or unemployed people with innovative ideas and a secondary-school diploma.

The programme revolves around four specific services or sub-schemes. First, there are preliminary advisory services to stimulate entrepreneurial attitude and identify promising entrepreneurial ideas. Second, training and tutoring services are available to candidate entrepreneurs to verify the validity of the entrepreneurial idea and to prepare the business plan. Third, ex post consultancy and tutoring services are also available in order to move from business plan to enterprise creation. Lastly, the scheme provides financial support in the first stages of business creation.

Source: Piemonte (2018), "Peer learning in regions in industrial transition: Workshops good practice template", Prepared for the Peer Learning in Regions in industrial transition Workshop "Promoting entrepreneurship and mobilising the private sector", 7-8 June 2018, Torino, Italy, Unpublished.

\section{Ensuring a friendlier regulatory environment encourages entrepreneurial activity}

Stimulating a generally positive entrepreneurial environment has a determinative influence on future entrepreneurs. Healthy entrepreneurial activity requires an enabling regional environment - one that is business-friendly and supportive of the unique challenges entrepreneurs and their young companies face (Table 4.3). 
Table 4.3. Policy issues, instruments and rationales in improving the entrepreneurial enabling environment

\begin{tabular}{|c|c|c|c|}
\hline Policy issue & Policy response & $\begin{array}{l}\text { Potential suite of implementation } \\
\text { mechanism }\end{array}$ & Rationale/additional benefits \\
\hline \multirow{6}{*}{$\begin{array}{l}\text { Improving the } \\
\text { entrepreneurial-enabling } \\
\text { environment }\end{array}$} & \multirow{3}{*}{$\begin{array}{l}\text { Ensure a friendly } \\
\text { regulatory environment } \\
\text { through simplified } \\
\text { regulations and } \\
\text { registration procedures }\end{array}$} & \multirow{3}{*}{$\begin{array}{l}\text { - Introduction of one-stop-shops and } \\
\text { web portals } \\
\text { - Measurement of compliance costs and } \\
\text { application of Regulatory Impact } \\
\text { Assessments (RIA) } \\
\text { - Introduction of e-government services } \\
\text { - Regular consultations with firms to } \\
\text { identify regulatory burden } \\
\text { - Promoting second chance }\end{array}$} & Improves efficiency \\
\hline & & & Cuts transaction costs for entrepreneurs \\
\hline & & & $\begin{array}{l}\text { Creates an attractive entrepreneurship } \\
\text { ecosystem }\end{array}$ \\
\hline & \multirow[t]{2}{*}{$\begin{array}{l}\text { Foster an } \\
\text { entrepreneurship culture } \\
\text { through the development } \\
\text { of entrepreneurial } \\
\text { mindsets }\end{array}$} & \multirow{2}{*}{$\begin{array}{l}\text { - Supporting entrepreneurial mindsets } \\
\text { in schools and universities } \\
\text { - Organisation of public events for } \\
\text { children/student, digital hubs } \\
\text { - Entrepreneurship promotion through } \\
\text { media campaigns, direct interactions, } \\
\text { school visits of entrepreneurs, } \\
\text { business games in schools }\end{array}$} & $\begin{array}{l}\text { Promotes entrepreneurship as an } \\
\text { alternative to contract work }\end{array}$ \\
\hline & & & $\begin{array}{l}\text { Provides under-represented groups such } \\
\text { as women or youth with role models }\end{array}$ \\
\hline & $\begin{array}{l}\text { Monitor and evaluate } \\
\text { SME and } \\
\text { entrepreneurship policies }\end{array}$ & $\begin{array}{l}\text { - Qualitative monitoring (e.g. measures } \\
\text { of satisfaction) } \\
\text { - Quantitative assessment (e.g. random } \\
\text { control trial) }\end{array}$ & $\begin{array}{l}\text { Informs decision-making and supports } \\
\text { building evidence bases }\end{array}$ \\
\hline
\end{tabular}

\section{Creating a level playing field}

Lengthy and costly company registration procedures are a major business constraint. Their impact is most heavily felt by micro- and small-sized enterprises, and they can discourage entrepreneurial activity by acting as a significant barrier for new start-ups (van Stel and Stunnenberg, 2006). Although most regulatory policy for business is designed and enacted at the national level, there is room for regional actors to play a role in managing the administrative and regulatory burden that entrepreneurs in their areas might face. Regional governments can help entrepreneurs navigate the regulatory system and often ensure that regional-level regulations are sufficiently simple but still in line with national regulatory requirements. Among the policy approaches that can be adopted at the regional level are:

- Consultation with the business sector: Consultations support regional policymakers in identifying what regulatory requirements firms perceive as burdensome.

- Applying regional Regulatory Impact Assessment: Regulatory Impact Assessments (RIA) at the regional level can contribute to reducing the regulatory burden on local SMEs.

- Creating one-stop-shops: One-stop-shops offer entrepreneurs information about national and regional regulations as well as public support programmes. They can be accessed via the Internet (i.e. as a web portal) and potentially backed up by a call centre.

- Introducing e-government services: National- and regional-level ICT solutions can cut transaction costs for entrepreneurs, improving the efficiency of public administration, generating savings on data collection and transmission, providing of information to and communicating with businesses, and enhancing government information and its accessibility (thereby increasing transparency).

\section{Entrepreneurship is hard and failure should be encouraged}

Many businesses fail and there is often a stigma attached to this. The importance of giving entrepreneurs a second chance stems from the notion that failure should be considered a learning experience rather than 
a disgrace. Business failure can be an opportunity for an invigorated restart. Existing evidence suggests that countries and regions favouring second chances for failed entrepreneurs and encouraging the risktaking needed for a successful second start of business activities also have higher levels of entrepreneurship (Burchell and Hughes, 2006). Businesses set up by restarters also grow faster and create more turnover and jobs than first-time starters (Audretsch, 2007). For regions in industrial transition, particularly those with a strong culture of risk-aversion, policies that support or are tolerant of failure are important to help create an enabling environment for entrepreneurs. Several public policy mechanisms can promote a second chance; notable among them are:

- Discharge from bankruptcy. Discharge procedures in bankruptcy laws are important mechanisms to release an entrepreneur from bankruptcy debt following a final court decision.

- Promoting a positive attitude towards giving entrepreneurs a fresh start. Regional governments encourage potential restarters through information campaigns and training on second chances.

\section{Supporting entrepreneurial mindsets through entrepreneurship education}

Young people with entrepreneurship education are more likely to set up their own companies and businesses started by individuals with entrepreneurship training are more ambitious (Galloway and Brown, 2002). However, entrepreneurial competencies are not only vital for business innovation and business growth. Entrepreneurship education can also be understood as a journey providing individuals at every age with skills and attitudes to develop a "can do" confidence, proactivity and flexibility. For regions in industrial transition, entrepreneurship education can contribute to successful industrial modernisation. These regions tend to be home to firms with traditional business and operational models and a risk-averse attitude to innovation. Supporting entrepreneurship education in regions in industrial transition can help trigger new business models and allow entrepreneurs and established companies to move into new markets.

Entrepreneurship competencies can be acquired either through entrepreneurship education in the formal education system, starting from a young age, or through entrepreneurship training programmes at the workplace or at the university. In the workplace, entrepreneurship education enables potential entrepreneurs and entrepreneurial employees in established companies to provoke and adapt to change. Building local entrepreneurship education systems includes engaging teachers and school administrations in teaching entrepreneurship skills. Experimental and hands-on-learning can also be provided by locally organised extracurricular activities, such as business plan competitions. There is also a role for local universities to help take the entrepreneurial skills and spirit learned to a higher level. Higher education institutions (HEls), such as research universities and universities of applied science, have become important contributors to the development of entrepreneurial mindsets (Box 4.7).

\section{Box 4.7. HEInnovate - Higher education and entrepreneurship}

Higher education institutions (HEls) play an important role in promoting entrepreneurship and entrepreneurial mindsets. Engaged, entrepreneurial HEls represent important partners for innovative firms, including SMEs and start-ups. They help individuals develop and update their skills in order to match the evolving requirements of employers and be more resilient on the labour market - by providing students with an entrepreneurial mindset, and helping universities to promote creativity, problemsolving capacities, teamwork attitude and other important soft skills. HEls can also help their regional ecosystems take advantage of cultural and natural amenities to create job opportunities and development.

In order to support entrepreneurship and innovation in HEls, the OECD Centre for Entrepreneurship, SMEs, Cities and Regions (CFE) and the European Commission have launched a joint action, 
HEInnovate, to help HEls be innovative, foster entrepreneurship and generate value for society and the economy.

Since 2013, CFE and the European Commission have been developing an HEInnovate Guiding Framework that encompasses three components:

1. An online self-assessment tool, which has been used by approximately $1000 \mathrm{HEls}$ aiming to measure their own performance in terms of "engagement".

2. HEInnovate country reviews, which focus on a national case study to support governments and HEls adopting the entrepreneurial and innovation agenda - the country reports produced in 2015-18 represent an important source of information about successful practices and stakeholder networks.

3. A Policy Learning Network (PLN) that gathers governments and HEl representatives from countries that have hosted a country review process. PLN meetings are organised to discuss successful practices and help their dissemination at the international level. The first PLN meeting was held in Vienna in November 2018.

Source: OECD/EU (n.d.), HEInnovate Hompage, www.heinnovate.eu.

\section{Promoting a positive attitude to entrepreneurship through role models and ambassadors}

The importance of role models for entrepreneurial motivation is well supported by research. Role models can help develop positive collective mindsets with respect to entrepreneurship and signal that entrepreneurship is a favourable career option. Several studies have shown that children of self-employed (entrepreneurial) parents are more likely to become self-employed themselves (Dunn and Holtz-Eakin, 2000; Laspita et al., 2012). For regions in industrial transition, role models can contribute to industrial modernisation by helping improve entrepreneurship cultures and stimulating innovative entrepreneurship activity. Channels to promote entrepreneurship are numerous and can include positive representations and stories in newspapers and online media, exposure to direct interaction with successful entrepreneurs, award programmes and entrepreneurship campaigns.

\section{More needs to be done to develop monitoring and evaluation capacity}

Monitoring and evaluation are needed to assess the economic efficiency of SME and entrepreneurship policies and to inform the design and mix of SME and entrepreneurship programming. Creating effective monitoring and evaluation frameworks can be challenging for all regions, but especially those with limited experience or capacity in the design and implementation of performance measurement systems, as is the case for some regions in industrial transition. Common challenges include clearly identifying policy objectives, establishing targets and indicators, making better use of existing data and collecting new data, and capitalising on the possibilities offered by Big Data. A further challenge is evaluating the impact of policy interactions and their outcomes.

Across the OECD, data and methodologies available to monitor and evaluate SME and entrepreneurship policy has improved dramatically over the last decade. However, high-quality evaluations remain rare and there is little evidence that a comprehensive approach to evaluating entrepreneurship and innovation policies is evolving (OECD, 2018b). The OECD Framework for the Evaluation of SME and Entrepreneurship Policies and Programmes established a "six steps to heaven" approach to monitor and evaluate SME policy. This approach suggests different methods of monitoring and evaluation. It starts with the monitoring of the take-up of schemes, through surveys for example, and ends with sophisticated quantitative evaluation methods (Table 4.4). 
Table 4.4. Six steps to heaven

\begin{tabular}{|c|c|}
\hline \multicolumn{2}{|r|}{ Monitoring } \\
\hline Step I & Take-up of schemes \\
\hline Step II & Recipient opinions \\
\hline Step III & Recipient views of the difference made by the assistance \\
\hline \multicolumn{2}{|r|}{ Evaluation } \\
\hline Step IV & Comparison of the performance of "assisted" and "typical" firms \\
\hline Step V & Comparison with "match" firms \\
\hline Step VI & Taking account of selection bias \\
\hline
\end{tabular}

Source: Based on OECD (2008), OECD Framework for the Evaluation of SME and Entrepreneurship Policies and Programmes, https://doi.org/10.1787/9789264040090-en.

The framework can guide policymakers and programme implementers in charge of monitoring and evaluating SME and entrepreneurship policies and programmes. For the exercise to be effective, however, some critical elements need to be in place, including:

- Clear policy objectives: many policies do not have a clear objective and they often have more than one objective, which makes evaluation difficult.

- A good understanding of the full policy mix: a clear overview of all policies implemented and their potential interactions; and how some instruments may potentially complement or offset each other.

- Good data: studies often fail to find a statistically significant effect when evaluating policies because of poor quality data. More and better data helps widen the scope of evaluations and improve their precision.

- Going beyond outcomes: Policymakers should consider different variables that could affect evaluation effectiveness. These include the selected eligibility criteria, the targeted sample, the spatial unit of reference (e.g. regions or municipalities), how policy is communicated to stakeholders, etc.

- A commitment to evaluation: A monitoring and evaluation culture should permeate all stages of the policy cycle, from defining the problem and setting the vision to evaluating results and adjusting if necessary.

\section{Key considerations and conclusions}

Support to entrepreneurship in regions in industrial transition needs to build on the region's existing strengths and capacities. Regional policymakers have an important role in connecting, developing and supporting the regional innovation and entrepreneurship ecosystem, organising the mapping of available capacities and involving different stakeholder groups in a collaborative approach to setting future industrial goals.

\section{Local decision-making is crucial}

The local environment plays a large role in encouraging entrepreneurship. Regional governments and development agencies in regions in industrial transition need to contribute to a healthy environment for entrepreneurship by promoting an entrepreneurial culture and creating a level playing field for new start-ups vis-a-vis incumbents. In addition, the availability and quality of resources that entrepreneurs need, 
such as financing, premises, human resources, networks and communication infrastructure, are often locally determined. Policy should, therefore, be tailored closely to the specific needs, capabilities and institutional structures of each region and innovation system.

\section{A holistic approach to entrepreneurship is essential}

Businesses do not evolve in a vacuum and specific interventions targeted at companies need to be complemented with holistic policy action. Such action usually focuses on developing networks, building new institutional capacities, aligning priorities and fostering synergies between different stakeholders. Boosting entrepreneurship also requires a combination of policies targeting entrepreneurship, SMEs, innovation, education and science, and regional development. Often, these policy areas are not yet sufficiently integrated in regions in industrial transition and greater effort is necessary to break policy silos and support entrepreneurship and innovation in an integrated manner.

\section{Industries, technologies and generations change}

Technology is developing at an exponential rate and will continue to change business operations. At the same time, lifestyles and preferences change with every generation, and so do the products and processes developed and introduced to meet them. Businesses need to adapt to ongoing trends such as the rise of customer-centric business models, mobile solutions and digital footprints. Policy initiatives promoting entrepreneurship in regions in industrial transition - which often are home to traditional businesses with limited implementation capacity for new technologies and market demands - must take account of ongoing changes in industries and technologies and continuously review their financial and advice package in line with technological and societal developments.

\section{Substitute density with networks in rural and remote areas}

Diversification of rural or remote economies and the creation of job opportunities is a key challenge for regional regions in industrial transition, particularly those with low population density. It might not always be possible in these areas to build all elements of a functioning entrepreneurship and innovation ecosystem. Against this backdrop, local SME and entrepreneurship policy in small and remote local areas may benefit from a combination of inward- and outward-looking policy strategies. One strategy is to compensate remoteness and a possible lack of resources by connecting local entrepreneurs to resources and strategic actors in larger cities or urban areas, for example through start-up boot camps, innovation hubs or similar activities.

\section{Policy evaluation matters}

Regions in industrial transition must strengthen their monitoring and evaluation systems for entrepreneurship and SME policy to better capture the impact of policies on businesses and provide justification for policy calibration where needed. This requires comprehensive monitoring and evaluation tools to evaluate the effectiveness of support schemes. Efforts need to be stepped up to look at the whole policy mix. 


\section{References}

Andersson, M., P. Braunerhjelm and P. Thulin (2012), "Creative destruction and productivity: Entrepreneurship by type, sector and sequence", Journal of Entrepreneurship and Public Policy, Vol. 1/2, pp. 125-146, http://dx.doi.org/10.1108/20452101211261417.

Audretsch, D. (2007), "Entrepreneurship capital and economic growth", Oxford Review of Economic Policy, Vol. 23/1, pp. 63-78, http://dx.doi.org/10.1093/oxrep/grm001.

Burchell, B. and A. Hughes (2006), "The stigma of failure: An international comparison of failure tolerance and second chancing”, No. 334, Centre for Business Research, University of Cambridge, http://www.cbr.cam.ac.uk (accessed on 03 February 2019).

Criscuolo, C., P. Gal and C. Menon (2014), "The Dynamics of Employment Growth: New Evidence from 18 Countries", OECD Science, Technology and Industry Policy Papers, No. 14, OECD Publishing, Paris, https://dx.doi.org/10.1787/5jz417hi6hg6-en.

Dunn, T. and D. Holtz-Eakin (2000), "Financial capital, human capital, and the transition to selfemployment: Evidence from intergenerational links", Journal of Labor Economics, Vol. 18/2, pp. 282-305, http://dx.doi.org/10.1086/209959.

Galloway, L. and W. Brown (2002), "Entrepreneurship education at university: A driver in the creation of high growth firms?", Education+ Training, Vol. 44/8-9, pp. 398-405.

GEM (2017), Special Tabulations of the 2012-16 Adult Population Surveys, Global Entrepreneurship Monitor.

Glenn, R. (2018), "Entrepreneurship: An economic development strategy", PowerPoint Presentation for the Peer Learning in Regions in industrial transition Workshop: Promoting Entrepreneurship and Mobilising the Private Sector, 7-8 June 2018, Turin, Italy, Unpublished.

Huggins, R. and P. Thompson (2014), "Culture, entrepreneurship and uneven development: A spatial analysis", Entrepreneurship \& Regional Development, Vol. 26/9-10, pp. 726-752, http://dx.doi.org/10.1080/08985626.2014.985740.

Laspita, S. et al. (2012), "Intergenerational transmission of entrepreneurial intentions", Journal of Business Venturing, Vol. 27/4, pp. 414-435, http://dx.doi.org/10.1016/j.jbusvent.2011.11.006.

Mubaraki, H. and M. Busler (2011), "Critical activity of successful business incubation", International Journal of Emerging Sciences, Vol. 1/3, pp. 455-465, http://go.galegroup.com/ps/anonymous?id=GALE\%7CA273715593\&sid=googleScholar\&v=2.1\&it=r\&li nkaccess=abs\&issn=22224254\&p=AONE\&sw=w (accessed on 03 February 2019).

OECD (2019), OECD SME and Entrepreneurship Outlook 2019, OECD Publishing, Paris, https://doi.org/10.1787/34907e9c-en.

OECD (2018a), Financing SMEs and Entrepreneurs 2018: An OECD Scoreboard, OECD Publishing, Paris, https://dx.doi.org/10.1787/fin sme ent-2018-en.

OECD (2018b), Leveraging Business Development Services for SME Productivity Growth: International Experience and Implications for UK Policy, OECD, Paris, http://www.oecd.org/industry/smes/Final\%20Draft\%20Report V11.pdf (accessed on 26 May 2019).

OECD (2018c), "Promoting entrepreneurship and mobilising the private sector", PowerPoint Presentation for the Peer Learning in Regions in industrial transition Workshop: Promoting Entrepreneurship and Mobilising the Private Sector, Presented 7-8 June 2018, Turin, Italy, Unpublished.

OECD (2018d), "Enhancing SME access to diversified financing instruments", OECD, Paris, http://www.oecd.org/cfe/smes/ministerial/documents/2018-SME-Ministerial-Conference-PlenarySession-2.pdf.

OECD (2017a), The Geography of Firm Dynamics: Measuring Business Demography for Regional Development, OECD Publishing, Paris, https://dx.doi.org/10.1787/9789264286764-en. 
OECD (2017b), Small, Medium, Strong. Trends in SME Performance and Business Conditions, OECD Publishing, Paris, https://dx.doi.org/10.1787/9789264275683-en.

OECD (2008), OECD Framework for the Evaluation of SME and Entrepreneurship Policies and Programmes, OECD Publishing, Paris, https://doi.org/10.1787/9789264040090-en.

OECD/EU (2018), Supporting Entrepreneurship and Innovation in Higher Education in The Netherlands, OECD Skills Studies, OECD Publishing, Paris, European Union, Brussels, https://dx.doi.org/10.1787/9789264292048-en.

OECD/EU (n.d.), HEInnovate Hompage, www.heinnovate.eu.

Piemonte (2018), "Peer learning in regions in industrial transition: Workshops good practice template", Prepared for the Peer Learning in Regions in industrial transition Workshop "Promoting entrepreneurship and mobilising the private sector", 7-8 June 2018, Torino, Italy, Unpublished.

Saxony (2018), "TGFS: The venture capital funds for Saxony", PowerPoint Presentation for the Peer Learning in Regions in industrial transition Workshop: Promoting Entrepreneurship and Mobilising the Private Sector, 7-8 June 2018, Torino, Italy, Unpublished.

Shane, S. and T. Stuart (2002), "Organizational endowments and the performance of university startups”, Management Science, Vol. 48/1, pp. 154-170, http://dx.doi.org/10.1287/mnsc.48.1.154.14280.

Slovenia (2018), "Peer learning in regions in industrial transition: Workshops good practice template", Start:up Slovenia, Prepared for the Peer Learning in Regions in Industrial Transition Workshop "Promoting entrepreneurship and mobilising the private sector", 7-8 June 2018, Torino, Italy, Unpublished.

What Works Centre (2016), Evidence Review 2 Business Advice, https://whatworksgrowth.org/public/files/Policy Reviews/16-06-15 Business Advice Updated.pdf (accessed on 03 February 2019). 


\title{
Annex 4.A. Overview of policy issues and responses in supporting entrepreneurship and private sector development
}

\author{
Annex Table 4.A.1. Overview of policy issues, implementation mechanisms and rationales to \\ support entrepreneurship and private sector engagement in regions in industrial transition
}

\begin{tabular}{|c|c|c|c|}
\hline Policy issue & Policy response & $\begin{array}{l}\text { Potential suite of implementation } \\
\text { mechanism }\end{array}$ & Rationale/additional benefits \\
\hline \multirow[t]{5}{*}{$\begin{array}{l}\text { Limited access to finance } \\
\text { for start-ups and scale-ups }\end{array}$} & \multirow{3}{*}{$\begin{array}{l}\text { Facilitate access to } \\
\text { finance and broaden the } \\
\text { range of financial } \\
\text { instruments }\end{array}$} & \multirow{3}{*}{$\begin{array}{l}\text { - Traditional instruments: grants, soft } \\
\text { loans, loan guarantees } \\
\text { - Alternative and non-bank sources of } \\
\text { finance: crowdfunding, peer-to-peer } \\
\text { lending, business angel networks, } \\
\text { venture capital } \\
\text { - Digital finance opportunities: Fintech, } \\
\text { blockchain }\end{array}$} & $\begin{array}{l}\text { Reduces start-up and SME reliance on } \\
\text { debt instruments }\end{array}$ \\
\hline & & & Generates employment \\
\hline & & & $\begin{array}{l}\text { Creates an attractive entrepreneurship } \\
\text { ecosystem in different types of regions }\end{array}$ \\
\hline & \multirow[t]{2}{*}{$\begin{array}{l}\text { Strengthen financial } \\
\text { literacy }\end{array}$} & \multirow{2}{*}{$\begin{array}{l}\text { - Training and mentoring programmes, } \\
\text { provision of accessible information } \\
\text { and guidance }\end{array}$} & $\begin{array}{l}\text { Makes firms more attractive clients to } \\
\text { financial service providers }\end{array}$ \\
\hline & & & $\begin{array}{l}\text { Provides firms with tailored advice on } \\
\text { financing needs }\end{array}$ \\
\hline \multirow{5}{*}{$\begin{array}{l}\text { Limited access to } \\
\text { entrepreneurship skills } \\
\text { and networks for start-ups } \\
\text { and scale-ups }\end{array}$} & \multirow{2}{*}{$\begin{array}{l}\text { Support entrepreneurs } \\
\text { with information, training, } \\
\text { coaching and mentoring }\end{array}$} & \multirow{2}{*}{$\begin{array}{l}\text { - One-stop-shops and information } \\
\text { centres } \\
\text { - Entrepreneurship training courses } \\
\text { provision } \\
\text { - Dedicated mentoring programmes } \\
\text { - Incubators and accelerators }\end{array}$} & $\begin{array}{l}\text { Creates an attractive entrepreneurship } \\
\text { ecosystem }\end{array}$ \\
\hline & & & $\begin{array}{l}\text { Provides start-ups and scale-ups with } \\
\text { important business foundations }\end{array}$ \\
\hline & $\begin{array}{l}\text { Strengthen } \\
\text { entrepreneurial networks }\end{array}$ & $\begin{array}{l}\text { - Networking and platform events } \\
\text { organised by local (public) } \\
\text { stakeholders } \\
\text { - Provision of online platforms }\end{array}$ & $\begin{array}{l}\text { Strengthens sales and export networks } \\
\text { and partner search }\end{array}$ \\
\hline & \multirow[t]{2}{*}{$\begin{array}{l}\text { Enhance start-up and } \\
\text { SME participation in } \\
\text { collaborative research }\end{array}$} & \multirow{2}{*}{$\begin{array}{l}\text { - Enhanced start-up and SME } \\
\text { participation through vouchers, } \\
\text { science parks, incubators and } \\
\text { accelerators } \\
\text { - Exploitation of research through } \\
\text { spin-off creation }\end{array}$} & $\begin{array}{l}\text { Supports innovation in entrepreneurial } \\
\text { activity }\end{array}$ \\
\hline & & & Creates knowledge spill-overs \\
\hline \multirow{5}{*}{$\begin{array}{l}\text { Improving the } \\
\text { entrepreneurial enabling } \\
\text { environment }\end{array}$} & \multirow{3}{*}{$\begin{array}{l}\text { Ensure a friendly } \\
\text { regulatory environment } \\
\text { through simplified } \\
\text { regulations and } \\
\text { registration procedures }\end{array}$} & \multirow{3}{*}{$\begin{array}{l}\text { - Introduction of one-stop-shops and } \\
\text { web portals } \\
\text { - Measurement of compliance costs } \\
\text { and application of RIA } \\
\text { - Introduction of e-government services } \\
\text { - Regular consultations with firms to } \\
\text { identify regulatory burden }\end{array}$} & Improves efficiency \\
\hline & & & Cuts transaction costs for entrepreneurs \\
\hline & & & $\begin{array}{l}\text { Creates an attractive entrepreneurship } \\
\text { ecosystem }\end{array}$ \\
\hline & \multirow{2}{*}{$\begin{array}{l}\text { Foster an } \\
\text { entrepreneurship culture } \\
\text { through the development } \\
\text { of entrepreneurial } \\
\text { mindsets }\end{array}$} & \multirow{2}{*}{$\begin{array}{l}\text { - Supporting entrepreneurial mindsets } \\
\text { in universities } \\
\text { - Anchoring of entrepreneurship } \\
\text { curricula in schools, organisation of } \\
\text { public events for children/student, } \\
\text { digital hubs }\end{array}$} & $\begin{array}{l}\text { Promotes entrepreneurship as an } \\
\text { alternative to contract work }\end{array}$ \\
\hline & & & $\begin{array}{l}\text { Provides under-represented groups such } \\
\text { as women or youth with role models }\end{array}$ \\
\hline
\end{tabular}




\begin{tabular}{l|l|l|l}
\hline Policy issue & Policy response & $\begin{array}{c}\text { Potential suite of implementation } \\
\text { mechanism }\end{array}$ & Rationale/additional benefits \\
\hline & & $\begin{array}{c}\text { - Entrepreneurship promotion through } \\
\text { media campaigns, direct interactions, } \\
\text { school visits of entrepreneurs, } \\
\text { business games in schools }\end{array}$ & \\
\cline { 2 - 4 } & $\begin{array}{l}\text { Monitor and evaluate } \\
\text { SME and } \\
\text { entrepreneurship policies }\end{array}$ & $\begin{array}{l}\text { Q Qualitative monitoring (e.g. measures } \\
\text { of satisfaction) } \\
\text { Q Quantitative assessment (e.g. random } \\
\text { control trial) }\end{array}$ & $\begin{array}{l}\text { Informs decision-making and supports } \\
\text { building evidence bases }\end{array}$ \\
\hline
\end{tabular}





\section{Transition towards a climate-neutral economy}

This chapter discusses how regions in industrial transition can successfully manage the transition towards a climate-neutral economy. While the transition can generate jobs and is crucial to ensure well-being in the long term, it also comes with short-term concerns of job and income losses. The chapter outlines the specific barriers that regions in industrial transition face in such a shift and presents a range of policy measures to overcome these. The chapter highlights that many of the choices made by regions in industrial transition in their ambitions towards a climate-neutral economy have the potential to generate profound changes to infrastructure, technology and behaviours. Changing the current allocation of investment will require a "managed" transition towards low-carbon activities and adequate levels of public support. 


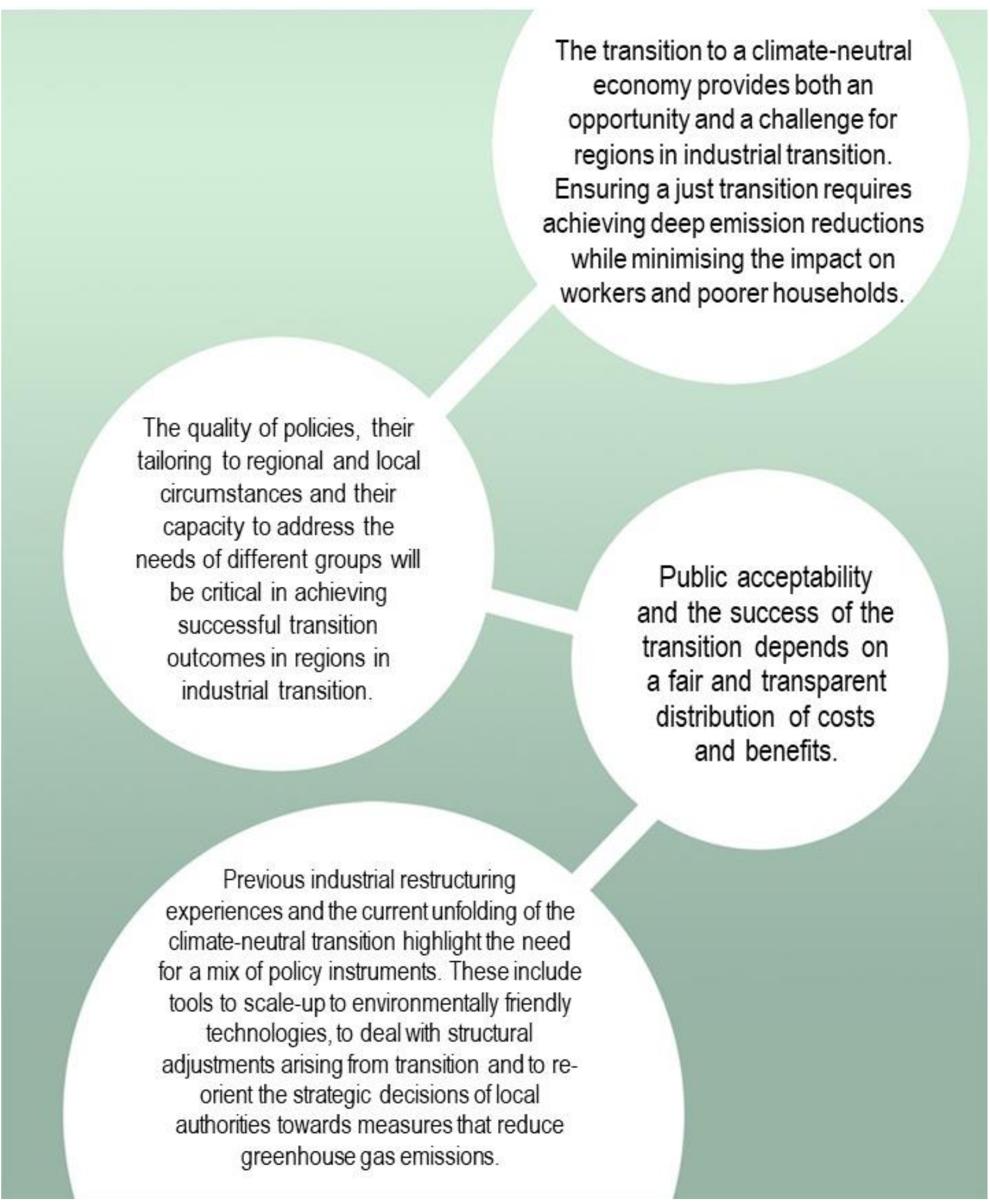




\section{The climate-neutral transition can foster sustainable investment, growth and jobs}

In the Paris Agreement, parties have agreed to a long-term goal to limit climate change to well below $2^{\circ} \mathrm{C}$ and make efforts towards $1.5^{\circ} \mathrm{C}$. There is growing recognition that reaching a climate-neutral and more circular economy will require a paradigm shift. In other words, deep innovations in societal systems are needed to overcome persistent problems such as climate change and resource scarcity by means of profound changes to dominant structures, practices, technologies, policies and lifestyles.

Achieving a climate-neutral economy by 2050 will require progressively phasing out or profoundly changing carbon-intensive industries. This will be particularly challenging for those regions that are home to carbonintensive industries, such as iron and steel production, chemical production or industries that extract hydrocarbon. Firms operating in these sectors can account for a significant share of regional employment. While some workers will manage to transition into new jobs, others might not and the transition can be destabilising for communities and families, particularly where production structures are geographically concentrated. To ensure a road that is as smooth as possible, a "managed" transition is needed - one that deals with the cost of structural adjustment and addresses concerns of short-term trade-offs, for example with regard to jobs lost with transition, while working towards and communicating on the medium- and longer-term gains. It is important that the distribution of the costs and benefits are fully taken into account to ensure a "just" transition.

The transition to a climate-neutral economy presents an important opportunity for regions in industrial transition to reorient investments from carbon-intensive to clean and modern industries. Regional and local policymakers can play a role in advancing the transition and through it inducing profound changes to infrastructure, technology and behaviours in their territories.

\section{Ensuring a just transition is fundamental to growth and well-being}

Investing in a climate agenda and transitioning to a climate-neutral economy can have a positive impact on economic growth (OECD, 2017a). The climate agenda also highlights the opportunities offered by the transition to a climate-neutral economy for national and subnational governments and the potential structural effects of such a transition. Climate-neutral development pathways will differ, as every country and region are at a different starting point with respect to meeting the transition challenge. The variation in starting points can depend on the carbon intensity of a region's energy supply, the energy intensity of gross domestic product (GDP) and the local and national energy mix, as well as on the resource endowment and model of development. To achieve the goals set for greenhouse gas emissions as established in the Paris climate agreement, a steep decline in emissions after 2020 is needed.

Considering the economic and environmental potential of the transition to a climate-neutral economy, while also taking into account the short-term structural changes that may affect already vulnerable populations, it is clear that carefully designed policies are imperative to harness transition benefits and limit its downsides. Several core climate-policy characteristics necessary in order to achieve climate goals include:

- stable and predictable climate policies

- a sufficiently high price on carbon in order to make climate-neutral investment competitive

- strong regulatory support

- targeted policies for low-carbon innovation - for example, higher research and development (R\&D) investment and aligning innovation frameworks with the emergence of low-carbon technology.

Such policies need to be accompanied by measures to support adjustment and ensure that opportunities are created for workers and communities most affected by the transition. 


\section{Large differences persist across regions when it comes to energy transition}

Across European and OECD regions, efforts are being made to decarbonise electricity generation through investments in renewables, including hydropower, and in nuclear power. In $2016,30 \%$ of gross electricity consumption in the European Union came from electricity generated from renewable sources (Eurostat, 2019). However, the proportion of electricity generated from renewable sources differs both across and within countries (Figure 5.1). While former coal and mining regions, such as the province of Limburg in the Netherlands or the Silesia region in Poland, generate less than $5 \%$ of their electricity from renewable sources, there are places, such as Border, Midwest and Western Ireland or Central Norrland in Sweden, that generate $100 \%$ of their electricity from renewable sources. Large in-country differences persist, too. For instance, in France, renewable energy sources make up around 3 percentage points of electricity generation in Normandy and Centre-Val de Loire and more than 75 percentage points in BourgogneFranche-Comté and Brittany.

\section{Figure 5.1. Proportion of electricity generated from renewable energy sources at TL2 level}

\section{5 or most recent year available}

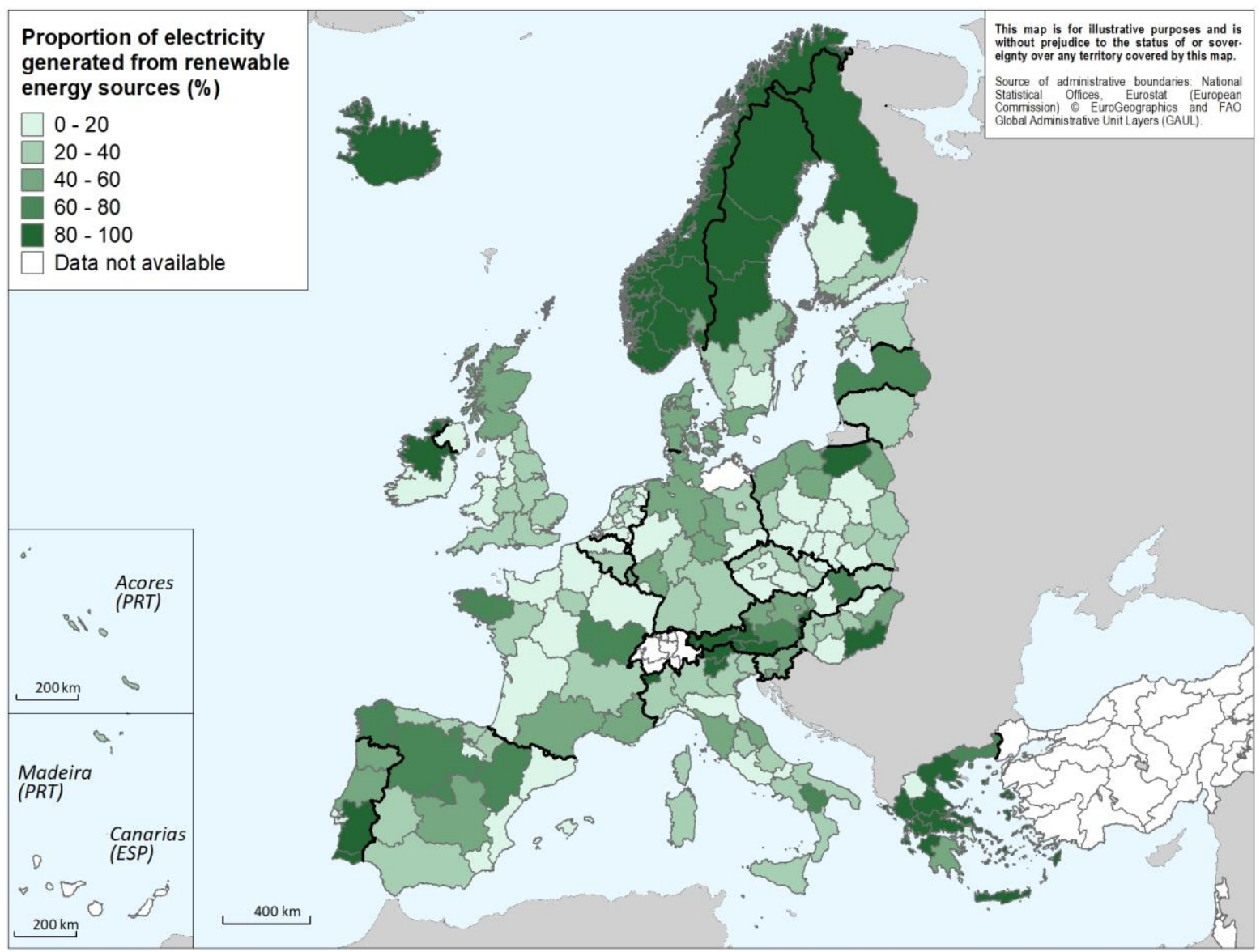

Notes: Proportion of electricity generated from renewable energy sources, calculated from the electricity produced (in GWh) from renewable energy sources divided by the total electricity produced (in GWh) at the regional level. The input data come from different national sources and from the Joint Research Centre (European Commission). The data collected either correspond to the amount of electricity generated for each fuel, energy source or sector (national sources) or to the share of renewables in the electricity generation mix (Joint Research Centre). Renewable energy sources include solar power, wind power, hydropower, geothermal power, tidal power and biomass. Reference years: 2015, except Portugal, 2013; France, Iceland, Norway, 2017; Denmark, Luxembourg, Poland 2018. Source: Data compiled from National Sources and Joint Research Centre, European Commission. 


\section{Regions in industrial transition need to carefully balance short-term interests and long- term gains}

For regions in industrial transition, it is important to be aware of the economic and new business opportunities that can be generated through the transition to a climate-neutral economy and to act upon them. This can include supporting existing enterprises to fulfil their potential as internationally competitive players or to work with small- and medium-sized enterprises (SMEs) to tap into clean energy business opportunities. Furthermore, clearly and regularly communicating business opportunities associated with the transition to a climate-neutral economy can help build and ensure collaboration and commitment among a broad range of actors.

In the short-term, economic and environmental interests may not align but in the long term, the transition to a climate-neutral economy can go hand-in-hand with growth. The experience in North-Rhine Westphalia illustrates this tension and highlights the balance between the economic and environmental considerations behind climate-neutral transitions (Box 5.1). In some cases, economic and environmental drivers may align to drive the transition in regions, necessitating careful policymaking in order to facilitate the process for workers. In other cases, trade-offs between environmental goals and economic opportunities may arrive, which could lead to uncertainty concerning the timing and outcome of a climate-neutral transition. 


\section{Box 5.1. Keys to a successful climate-neutral transition: North-Rhine Westphalia}

North-Rhine Westphalia is one of Germany's most populous states (population approximately 18 million; GDP of EUR 670 billion). Highly industrialised and with a historical dependence on lignite and hard coal mining, it is home to the Ruhr Valley, where the phase-out of hard coal mining is considered a generally successful example of a low-carbon transition.

North-Rhine Westphalia's experience reflects the interplay between economic and environmental considerations, two drivers of the low-carbon transition. The driver behind the phasing out of hard coal mining in the Ruhr area was economic, as low global coal prices made its extraction unprofitable. For years, subsidies were used to support the lack of competitiveness, as hard coal mining was a traditional activity with strong policy support. However, the last five decades have seen a conscious restructuring from coal and steel-based specialisation to a more diversified service economy. Measures to ensure a smooth transition for workers included social protection, retraining, early retirement and other long-term strategies negotiated with key stakeholders. There have also been initiatives to regenerate the physical landscape of the energy-intensive mining sector, with industrial sites being preserved and converted into tourist attractions for those who want to experience the Ruhr industrial culture. One of the largest industrial coal facilities, the "Zollverein", was named a United Nations Educational, Scientific and Cultural Organization (UNESCO) World Heritage Site. The current debate centres on lignite mining in the Rhine area. Since at current low-carbon prices lignite mining remains profitable, environmental ambitions (i.e. meeting climate goals) would be the primary driver for phasing out lignite mining.

Sources: Freistaat Sachsen (2018a), "Climate-neutral Energy Transition: A Saxon Perspective", PowerPoint Presentation for the Peer Learning in Regions in Industrial Transition Workshop "Climate-Neutral Energy Transition", 14-15 May 2018, Brussels, Belgium, Unpublished; Marchal, V. (2018), "For a Successful Low-Carbon Energy Transition", Scoping Paper for Peer Learning Workshop, 14-15 May 2018, OECD, Paris, Unpublished.

\section{The structural impact: Jobs and inequalities}

It is estimated that the low-carbon transition will have a relatively limited impact on labour markets overall, with $0.3 \%$ of jobs affected in OECD countries and $0.8 \%$ of jobs affected in non-OECD countries (Botta, 2018). Yet, these numbers depend on the sectors and regions in which the transition takes place. For example, the mining and fossil fuel electricity sectors could see an estimated $8 \%$ job reduction and this will affect men more than women ${ }^{1}$ (Botta, 2018). Older workers are also more likely to feel the impact of a lowcarbon transition. In light of this, policies should target the workers most affected in order to minimise transition costs. Ensuring a just transition is imperative in this context (Box 5.2).

\section{Box 5.2. An OECD checklist for a just transition}

In order to ensure a just (fair) low-carbon transition, all levels of government need the proper tools to develop integrated and coherent policies. Particularly crucial for success is consistency between climate, social and economic goals. The OECD has identified a series of actions to help guide a just transition, including:

- Political and corporate commitment: Obtain a clear commitment from the public and private sector to achieve a common vision and objective and provide funding for the transition. 
- Develop long-term strategies: Develop a long-term strategy to implement low-emission pathways that goes beyond electoral cycles. A long-term strategy can also identify the communities and assets put at risk due to the transition before adverse effects occur and ideally identify mechanisms to mitigate the impact.

- Look at policy effects: Identify the impact of policies on the population and on the private sector in the short and long term, and across administrative boundaries. The effects of low-carbon policies go beyond city and regional limits, so the implementation of a functional approach to territory is important.

- Integrate approaches to implementation: Ensure policy alignment between sectoral policies (e.g. energy and environment).

- Align policies between levels of government: Clearly define implementation responsibilities and actions, in accordance with competencies.

- Stakeholder participation: Develop vision documents and long-term strategies with the participation of key stakeholders, including trade unions, individual communities, the private sector, other government levels and entities, etc. There should be an active social dialogue regarding the transition.

- Monitoring and reporting: Report on and measure the impact of the strategy, and review it accordingly.

Source: Adapted from OECD (2017e), "Building blocks for coherent implementation of the Sustainable Development Goals", https://doi.org/10.1787/9789264272576-4-en.

There is also a geographic dimension to consider. The decentralisation of renewable energy production compared to centralised and clustered fossil fuel and mining industries can lead to a disparity between the jobs lost and those created. This contributes to inter- and intra-regional inequalities, certainly in terms of GDP and income, but also in terms of services and access to these. The structural changes that will affect the labour market make clear the need to understand who will be affected by the low-carbon transition and where the alternative jobs are located. When confronted with these inequalities, governments in regions in industrial transition must ask themselves how skill gaps can be filled and who can fund retraining programmes or other policies relating to job transitions. They also need to identify mechanisms to create or sustain diversified economies, as these are more resilient in the face of change.

\section{The policy mix required to support the transition will vary from one industrial transition region to another}

The specific policies that can support a just carbon-neutral transition may vary from one region to another, as there is no "one-size-fits-all" pathway. However, it is fundamental to formulate long-term industrial transition strategies towards a climate-neutral economy. While the climate-neutral challenge confronts both national and subnational governments, particular consideration should be given to the role of the regional and local levels, where international agreements and national level policies are often implemented. It is also where a significant amount of public investment takes place. Preliminary estimates indicate that in 30 OECD countries between 2000 and 2016, regions and cities were responsible for $64 \%$ of public investment in selected sectors with a direct implication on climate change (OECD, 2018a).

Ensuring that policies are co-ordinated and aligned is critical, particularly in countries characterised by higher degrees of regional (and local) autonomy. In these cases, "transition" policies and programming might be designed and/or implemented by different levels of government, and care should be taken that 
they do not work against each other. Thus, adequate mechanisms (e.g. mapping of all activities undertaken by different levels of government) should be introduced and employed to ensure horizontal (across the different policy areas) and vertical (among the various levels of government) co-ordination.

\section{What challenges and opportunities do regions in industrial transition face in achieving a climate-neutral economy?}

Regions in industrial transition face a range of challenges in dealing with the expected structural changes brought by a low-carbon transition but can also tap into the potential brought about by green growth opportunities. Advancing the transition to a climate-neutral economy requires decarbonising traditional manufacturing and/or carbon-intensive industries, which means effective investment in energy efficiency and in renewable energy. In this context, some regions in transition are concerned about job losses in industries that are phasing out. In addition, firms in traditional industries may not be aware of the competitive advantages that green technologies can offer, or may not be well-positioned to take advantage of green technologies if they face barriers to its use (e.g. financial or human resource barriers). Transitioning to a climate-neutral economy also requires effective multi-level governance practices, especially with respect to alignment among levels of government and stakeholder engagement.

\section{It is not always clear how to best prepare workers for industrial transition}

Policymakers in regions in industrial transition are necessarily concerned about the potential impact that a low-carbon transition can have on workers. The impact may be particularly strong in traditional industrial regions that are home to coal-mining activities and "brown" industries. These tend to be geographically concentrated, and restructuring may lead to mass lay-offs in the absence of a smooth adjustment process. While such lay-offs typically account only for a small share of total dismissals, their geographic concentration poses restructuring challenges. This might be particularly acute in small or undiversified regional economies where subnational revenues often depend on the local corporate and personal income tax base and can affect local public service delivery (Botta, 2018).

Concerns about effective labour transition strategies are often related to the broader question of skills transferability. For regions in industrial transition, it is often unclear to what extent new jobs will require the same skills as those being phased out and whether the skill sets of jobs in "brown" industries are transferable and adaptable to low-carbon sectors. Studies undertaking an assessment of how the lowcarbon transition affects individual sectors remain scarce. Furthermore, regions in industrial transition struggle to provide the right training packages. The training needs of workers might vary significantly according to past work experience and the next sector in which they seek employment, making it difficult to design training packages that are appropriate for a large number of workers. The importance of engaging employers in the process of skills development is widely acknowledged. Yet, convincing regional employers to invest in training and skills upgrading can be difficult (see Chapter 2).

\section{Growing clean industries can promote successful industrial transition}

Managing a successful industrial transition means investing more in clean energy transition-related technologies, as well as shifting towards more sustainable modes of production and consumption. One of the key challenges for the climate-neutral transition is to reallocate capital from carbon-intensive to climateneutral assets and infrastructure. Regions in industrial transition are traditionally home to manufacturing industries with high environmental impact. Successful industrial modernisation requires stimulating local economic diversification towards clean energy industries through decarbonisation, innovation and digitalisation. Many regions undergoing industrial transition recognise the societal and business value of 
environmental objectives and the low-carbon transition is often part of local transition ambitions. However, because such transitions are complex, obstacles arise.

Regions in industrial transition often face difficulties in stimulating investment in green innovation, particularly among local firms. Common barriers for SMEs are size-related resource constraints, skill deficits and knowledge limitations. SMEs are often unaware of many financially attractive opportunities for environmental improvement. A widespread misperception is that transitioning to the climate-neutral economy is associated with technical complexity, administrative burden and high costs. Even when firms are aware that better environmental performance can improve competitiveness, a lack of appropriate skills and expertise might prevent them from acting upon profitable opportunities. At the same time, SMEs often have fewer resources and are more risk-averse than large firms. This can render them less willing to invest in new and green technologies, partly because of the uncertainty about the return on investment.

Vested interests can be an additional barrier in regions in industrial transition, particularly in those with long-established industries that can hamper the development of new industrial growth paths. However, without the active commitment of leading industry to transition to clean energy production, public authorities might not have the financial means and capacity to facilitate investment in the infrastructure necessary to modernise production and speed-up technology diffusion among consumers (e.g. providing charging stations for e-vehicles). In addition, a large range of stakeholders needs to be involved in transition planning in order to make the transition successful. Historically, transition strategies that showed greater political resilience and a more coherent and comprehensive approach were those where a relative consensus was reached on the need to phase out certain industries (Campbell and Coenen, 2017).

\section{A range of governance challenges can hamper transition co-ordination and speed}

Transitioning to a climate-neutral economy presents a set of complex governance challenges for policymakers. One of these is balancing the long-term strategic dimension of transition with the need for short-term action. While the transition needs long-term strategic thinking and policymaking, it also requires an ability to accommodate electoral cycles and the associated desire of governments and other stakeholders to see the results of implemented projects.

A further related challenge is ensuring that multi-level governance structures and practices can support regional ambitions for a climate-neutral transition. These can include taking action at a proper scale, balancing long-term strategies and shorter-term priorities, fostering an enabling environment for change despite some framework conditions being outside of regional control, having access to appropriate and adequate financing, and building stakeholder engagement.

Acting and investing at the relevant territorial scale often requires co-ordination across levels of government. Large projects, such as testing electric highways, for example, are often the responsibility of national governments. They may also need support from the region where they are implemented. Instead of being a barrier, action at a smaller scale can also be an opportunity to support small and/or remote public administrations, which may face similar issues as SMEs in the climate-neutral transition - i.e. limited resources, limited access to credit and limited attractiveness to the private sector as investment partners. The exact nature and scope of each of these challenges will likely vary by region, highlighting the importance of a targeted, regional approach.

\section{Financing remains a challenge}

Sufficient investment in infrastructure and green innovation are often constrained by limited public budgets, despite the fundamental role that financing plays in advancing a climate-neutral transition. Compounding this challenge are the barriers that local governments often face in leveraging private capital for green 
infrastructure or innovation financing. In addition, local policymakers can lack the capacity to leverage alternative sources of finance for green investments, such as green bonds. Furthermore, given the negative implications that transitioning to climate-neutral economies can have on jobs and income in some regional labour markets, investment in retraining and upskilling programmes are also generally required. As public funds for relevant training might be insufficient, regional governments may need to work with other partners - including the private and third sectors - to ensure that training needs are met.

\section{How can policy (better) support the transition to a climate-neutral economy?}

For regions in industrial transition, the policy challenge of ensuring a just transition is to achieve deep emission reductions in a context often already shaped by higher-than-average unemployment and prominent skills gaps. It is, therefore, important for these regions to seize the opportunities of transition while minimising the impact on workers and poorer households. To this end, previous industrial restructuring experiences and the current unfolding of the low-carbon transition highlight the need for a mix of policy instruments. These include instruments that support scaling up to environmentally friendly technologies, dealing with structural adjustments arising from transition and re-orienting the strategic decisions of local authorities towards measures that reduce greenhouse gas emissions.

\section{Providing labour transition strategies for a climate-neutral economy}

Public policy can help support displaced workers during a transition to a climate-neutral economy, particularly when workers perceive job loss as an exogenous event that is not related to their actions or performance. A range of labour market measures is available to support displaced workers that have lost their jobs in the transition from traditional to modern and green industries. These include training and upskilling offers, job-search training and support measures to ensure a just transition (Table 5.1).

\section{Table 5.1. Supporting labour transitions: Policy Issues, instruments and rationales}

\begin{tabular}{|c|c|c|c|}
\hline Policy issue & Policy response & $\begin{array}{l}\text { Potential suite of implementation } \\
\text { mechanism }\end{array}$ & Rationale/additional benefits \\
\hline \multirow{4}{*}{$\begin{array}{l}\text { Creating job opportunities } \\
\text { for the transition to a } \\
\text { climate-neutral economy }\end{array}$} & \multirow{2}{*}{$\begin{array}{l}\text { Support green skills and } \\
\text { jobs through training and } \\
\text { upskilling }\end{array}$} & \multirow{2}{*}{$\begin{array}{l}\text { - Upskilling and retraining for displaced } \\
\text { workers aligned with local labour } \\
\text { market needs } \\
\text { - Training on environmentally friendly } \\
\text { production methods for existing } \\
\text { workers }\end{array}$} & $\begin{array}{l}\text { Expansion of skillset to move from } \\
\text { declining to emerging industries }\end{array}$ \\
\hline & & & $\begin{array}{l}\text { Progressive greening of existing } \\
\text { industries }\end{array}$ \\
\hline & $\begin{array}{l}\text { Support workers in } \\
\text { transition }\end{array}$ & $\begin{array}{l}\text { - Dedicated job-search training for } \\
\text { displaced workers } \\
\text { - Flexicurity in labour markets }\end{array}$ & Ensures the transition to high-quality jobs \\
\hline & $\begin{array}{l}\text { Support measures to a } \\
\text { just transition }\end{array}$ & $\begin{array}{l}\text { - Age- and gender-tailored measures } \\
\text { - Social housing }\end{array}$ & Ensures a fair transition \\
\hline
\end{tabular}

\section{Support green skills and jobs through training and upskilling}

Effective skills policies are a key ingredient for successfully transitioning to a climate-neutral economy in regions in industrial transition. If workers leave a declining sector, they will probably need to add new competencies to their skillset. In addition, the progressive greening of existing industries in transition regions will also require that workers remaining within a certain sector update their competencies in order to master more environmentally friendly production methods. Within this context, some skills policies will need to focus on displaced workers requiring green skills while others should target employed workers 
who may need additional (not always green) skills. Importantly, in order to identify the most relevant training needs such policies should also keep in mind other megatrends (e.g. ageing, automation) that affect the regional potential for industrial modernisation (see Chapter 2).

Existing evidence suggests that most green jobs will simply require a "topping up" of existing skillsets (Eurofund, 2014). Several instruments exist to promote workforce and management training, including training subsidies and vouchers, training leave allowances, tax incentives and personal training accounts (see Chapter 2). Regions in industrial transition could profit from carrying out a review of available training options to ensure that courses offered cover the specific needs of workers displaced by the transition to a climate-neutral economy. Training programmes could also include specific green skills, such as the ability to evaluate the environmental impact of energy systems or the ability to apply methodologies for environmental and strategic impact assessments (OECD, 2017a).

Training programmes yield the most successful outcomes when they are closely tied to the needs of the labour market. Engaging local employers in regional skills anticipation and development initiatives is critical to ensure that training programmes are well aligned to the needs of industry. Several regions in industrial transition have systems in place for assessing and anticipating skills need. Where needed, these systems should also aim to identify opportunities for workers to move from shrinking industries towards emerging or expanding sectors, including those linked to the climate-neutral economy. A sophisticated system to identify opportunities for workers was introduced in the former region of Alsace, France (now part of Grand Est) (Box 5.3). Even where workers do not face redundancy, investing in training can help them adapt to changing technologies more broadly.

\section{Box 5.3. Assessing skill needs for displaced workers: TransverS'AL}

The region of Alsace lost 8000 jobs between 2003 and 2011 in the automobile, chemical, food processing and machine construction/electronics industries. In response to the decline of manufacturing jobs, the local Employment and Training Centre of Mulhouse (Maison de l'Emploi, MEF Mulhouse) worked with partners to better support the transition of workers to more stable career paths within emerging sectors. Based on an initial 4-month consultation period with relevant local and regional actors, 15 objectives were developed around 4 themes: i) research and analysis; ii) co-operation with companies; iii) training; and iv) communication. As the project progressed, its focus was extended to new and emerging occupations, such as those created by the emerging "low-carbon" sustainable construction cluster. A series of sector studies were carried out in areas such as metalworking, textiles, buildings and public works, personal services, chemicals, plastics, pharmaceutics, temporary work, local shopping, logistics and transport, and automobiles. These focused on assessing firm needs in terms of technology and skills, prospects of labour mobility and future industry orientation. An additional, dedicated study on labour mobility offered insight into job creation and destruction potential. The creation of a website enabled workers and businesses to better understand the horizontal career paths and training options that could support mobility from declining to emerging sectors.

Source: OECD (2014), Job Creation and Local Economic Development 2018: Preparing for the Future of Work, https://doi.org/10.1787/9789264305342-en.

\section{Supporting displaced workers in transition periods}

Displaced workers in a region undergoing industrial and energy transitions may have valuable and relevant skills for other industries, but they may find it difficult to navigate the job market or identify suitable opportunities in other sectors. Regions can facilitate the transition of such workers by supporting job-search 
training, including advice on trainings and future career options, as well as job-search strategies. Such schemes have proven useful in regions that have undergone a transition (e.g. the Ruhr Valley) and can be provided by external actors or by the (former) employer. Self-employment schemes are another policy lever that can support workers after displacement and stimulate business creation in regions in industrial transition. Yet, only between $2 \%$ and $5 \%$ of displaced workers start their own business after having lost their jobs (OECD/EU, 2017).

\section{Ensuring a just transition}

Public policy in regions in industrial transition can also help address the impact of climate change on businesses in rural areas and on low-income families. Remote, low-income or poorer households are disproportionately affected by carbon pricing, as energy and transport tend to make up a higher proportion of their spending (Mclnnes, 2017). Carefully designed social policies can counteract this. For example, recycling carbon tax revenues could become a powerful tool to invest in programmes that address the roots of poverty and inequality. Low-income populations often do not have access to schemes associated with increasing energy efficiency, such as building retrofits. Local or regional government programmes that facilitate access for tenants and low-income households to retrofitting schemes can help make entire urban areas more energy-efficient and resilient, thus reducing energy expenditure. In Greater Manchester, a demonstrator project sought to tackle energy use in social housing by creating a local market (Box 5.4).

\section{Box 5.4. The Greater Manchester Sustainable Communities Project}

The demonstrator project in social housing in Greater Manchester replaced old and inefficient heating systems in 550 social housing properties across Wigan, Bury and Manchester with a range of cuttingedge electrical and hybrid air-source heat pumps (HPs). In addition, an energy aggregation system and an information and communication technology (ICT) platform were installed to control and co-ordinate the electricity usage of the HPs collectively, reducing energy usage during peak periods and testing the effectiveness of this reduction as a system to potentially trade in the electricity market.

Despite participation incentives, tenant sign-up to the project was challenging and uptake slower than anticipated. An unforeseen obstacle arose in maintaining the connectivity of the equipment components in the properties. There was a higher than expected number of ICT broadband disconnections with the cloud based aggregation system, with a review finding that these were largely due to "user" disconnection. Several tenants simply unplugged boxes, removed cables and in several cases changed the provider during the project, thus losing the established connection.

However, the project successfully demonstrated that a significant amount of energy demand could be shifted away from peak demand times across a large number of social housing properties. Outcomes surpassed the expectations of the trial but could have been even higher if all installed properties had been fully connected. One lesson learned is to focus more on awareness-raising and information provision for participating tenants. The project now feeds into the wider Greater Manchester carbon reduction plans.

Source: OECD (2018d), "Peer Learning in Regions in Industrial Transition Workshop: Low-Carbon Energy Transition, Responses from Hauts-de-France, North Middle Sweden, Piemonte, Saxony, Slovenia, Wallonia", Proceedings Paper for Peer Learning Workshop 2-3 July, Manchester, United Kingdom, OECD, Paris, Unpublished. 


\section{Enabling businesses to turn environmental challenges into business opportunities}

It is widely acknowledged that far-reaching innovation is needed to address climate change and to accelerate the shift to a climate-neutral economy. For regions in industrial transition, this means taking the opportunity to influence the direction of innovation towards more environmentally friendly ends and doing so in a way that generates the greatest net benefit to society. Stimulating green behaviour and production processes in firms and encouraging innovation in environmentally friendly technologies are good ways to contribute to green growth in regions in industrial transition (Table 5.2).

\section{Table 5.2. Encouraging green innovations: Policy issues, instruments and rationales}

\begin{tabular}{|c|c|c|c|}
\hline Policy issue & Policy response & $\begin{array}{l}\text { Potential suite of implementation } \\
\text { mechanism }\end{array}$ & Rationale/additional benefits \\
\hline \multirow{3}{*}{$\begin{array}{l}\text { Lack of business } \\
\text { opportunities for green } \\
\text { innovations }\end{array}$} & \multirow[t]{2}{*}{$\begin{array}{l}\text { Stimulate green } \\
\text { behaviour in firms }\end{array}$} & \multirow{2}{*}{$\begin{array}{l}\text { - Regulatory simplifications and } \\
\text { incentives } \\
\text { - Information-based tools (e.g. advice, } \\
\text { sector-specific certification, ecolabels) } \\
\text { - Economic incentives (grants, } \\
\text { low-interest loans, tax incentives) }\end{array}$} & $\begin{array}{l}\text { Creates an attractive innovation } \\
\text { ecosystem for firms }\end{array}$ \\
\hline & & & $\begin{array}{l}\text { Higher awareness for green business } \\
\text { opportunities }\end{array}$ \\
\hline & $\begin{array}{l}\text { Encourage innovation in } \\
\text { environmentally friendly } \\
\text { technologies }\end{array}$ & $\begin{array}{l}\text { - Support for green research and } \\
\text { development } \\
\text { - Innovation clusters } \\
\text { - Environmentally friendly public } \\
\text { procurement }\end{array}$ & $\begin{array}{l}\text { Stimulates investments in green } \\
\text { technologies }\end{array}$ \\
\hline
\end{tabular}

\section{Stimulating green behaviour in firms}

For regions in industrial transition, policies and co-ordinated action for greening SMEs and large firms can contribute to regional development while also meeting climate objectives. Actively steering regional economies towards sustainable green growth helps regions in transition overcome the legacy of traditional manufacturing and/or resource-intensive industries and develop newly productive, carbon-neutral and resource-efficient economies. Regions in industrial transition are using a wide range of strategies and instruments to promote environmental compliance and green business practices. These include regulatory tools, information-based tools, and economic incentives that help businesses move beyond compliance (Table 5.3).

\section{Table 5.3. Policy instruments to promote environmental compliance and green business practices}

\begin{tabular}{|c|c|}
\hline Type of mechanism & Implementation instrument \\
\hline Regulatory tools & $\begin{array}{l}\text { Simplified regulatory requirements (standardised permits, general binding rules) } \\
\text { Regulatory incentives for establishing environmental management systems } \\
\text { Sector-specific strategies to ensure compliance }\end{array}$ \\
\hline Information-based instruments & $\begin{array}{l}\text { Direct business advice } \\
\text { Dissemination of guidance in printed form or electronic } \\
\text { Sector-specific certifications and ecolabels }\end{array}$ \\
\hline Economic incentives & $\begin{array}{l}\text { Grants, low-interest loans and tax incentives } \\
\text { Encouraging supply chain pressure from larger companies } \\
\text { Green public procurement }\end{array}$ \\
\hline
\end{tabular}

Sources: Adapted from OECD (2018a), Environmental Policy Toolkit for SME Greening in EU Eastern Partnership Countries, https://doi.org/10 .1787/9789264293199-en and Hoevenagel, R. et al. (2007), Promoting Environmental Technologies in SMEs: Barriers and Measures, European Commission, Luxembourg. 
When it comes to regulatory and information-based instruments, the benefits of improved environmental performance for businesses, such as increased efficiency and competitiveness, should be the main "selling point" of environmental outreach to firms (OECD, 2018a). Involving public sector organisations and industry associations in programme design and implementation can also be valuable to target support to specific types of businesses.

Governments in regions in industrial transition can introduce a range of economic incentives. For example, public financial institutions might provide favourable loan conditions to businesses willing to invest in green technologies. Direct subsidies and free technical assistance may help increase awareness and secure initial engagement in green practices. However, given the limited availability of public funds, loan-based systems are likely to be more sustainable over the long term. Government authorities should also encourage private banks and insurance companies to provide incentives for good environmental performance among businesses. For example, banks could require an environmental checklist for loan approval. Lastly, regional policymakers can raise awareness and provide information on how businesses can access national and international funds supporting green innovation.

\section{Encouraging innovation in environment-friendly technologies}

Governments in regions in industrial transition can contribute to shaping the direction and quality of innovation that affects the environment. Although it is very difficult to anticipate the exact impact of more public R\&D on innovation outcomes, research suggests that government spending on R\&D for environmentally friendly technologies should be significantly increased (Acemoglu et al., 2016). The conclusion, therefore, is that sensible innovation policy for the transition to a climate-neutral economy should include subsidies for research.

There are numerous ways to design and allocate government-funded R\&D support. For example, governments can subsidise private sector innovation through indirect fiscal incentives such as R\&D tax credits. These are mostly designed at the national level and often there is a limited possibility for regionallevel authorities to influence or adapt the incentives to best support regional innovation priorities. National and regional governments can also provide direct financial support for R\&D through grants or loans, and there is growing empirical evidence of their positive impact on firm innovation outcomes measured by citation-weighted patents, finance, revenue and survival (Howell, 2017). Furthermore, undertaking research in government laboratories and research institutes has proven valuable for promoting innovation in clean energy. Government research can help new energy technologies overcome obstacles to commercialisation, such as disproportionately large capital expenses.

Policymakers in regions in industrial transition also play a role in supporting collaborative R\&D arrangements. Such collaborations can bring together complementary skills and resources between firms and across the innovation spectrum. A large range of policy instruments exist to support collaborative R\&D that can be exploited for green growth, including formal and informal university-industry collaborations, innovation incubators and cluster policies (see also Chapter 3). In Saxony, the energy technology cluster drives the development and commercialisation of clean technologies through partnerships of research institutes with local companies (Box 5.5).

Finally, encouraging more private sector financing of environmentally friendly technologies is particularly important in regions in industrial transition, especially if there is a limited budget for government expenditure to support the transition to a climate-neutral economy. While governments should not provide direct finance to firms to invest in technologies, they can reduce barriers to private investment and facilitate investments, for example, through the provision of patient capital with low-interest loans to businesses. 


\section{Box 5.5. The energy cluster in Saxony}

The energy technology cluster Energy Saxony includes 68 actors from industry, research and government. It combines their competencies and expertise to drive the sustainable development and commercialisation of new technologies in the energy, electro-mobility and digitalisation sectors. Financed in equal parts by the state of Saxony and industry, the cluster seeks to answer diverse issues arising from the low-carbon transition. These include the sourcing of hydrogen, building value chains from wind and solar energy to green hydrogen, as well as technical questions such as planning train lines that run on green hydrogen and how to replace fossil fuels in the agricultural sector. Currently, one of Saxony's largest projects concerning the low-carbon transition is the shift from fossil fuels to renewable sources for energy production. The high density of research institutes and larger corporations in the region is an asset that this cluster seeks to harness for the transition.

Source: Freistaat Sachsen (2018b), "Low-Carbon Energy Transition: A Saxon Perspective", PowerPoint Presentation for the Peer Learning in Regions in Industrial Transition Workshop "Low-Carbon Energy Transition", 14-15 May 2018, Brussels, Belgium.

\section{Supporting green public procurement}

The aim and challenge of sustainable procurement is to integrate environmental and social considerations into the procurement process. The goal is to reduce adverse impacts on health, social conditions and the environment, thereby saving valuable costs for public sector organisations and the community at large (OECD, 2002). For regions in industrial transition, sustainable procurement can be a useful policy instrument to accompany industrial development because it supports industrial renewal based on ecological foundations. It can provide industries with incentives for developing environmentally friendly processes, products and services. This is particularly the case in sectors where public purchasers represent a large share of the market, such as in construction, health services and public transport. Procurement rules in transition regions often focus strictly on cost, without encouraging or supporting broader policy objectives such as innovation or sustainability. This is frequently related to fears that the efficiency of buying processes is disrupted when procurement is used to support socio-economic goals. Setting up consistent legal and policy frameworks to assist buying entities incorporate green procurement rules is important, as is monitoring the results. While procurement guidelines may be set at a national level, regions may have a margin to use their purchasing power in a way that upholds regional and local objectives and benefits local goods, services and practices. This is the idea behind North Middle Sweden's initiative to deliver locally sourced food to the elderly, with one result being lower emissions from transport (Box 5.6).

\section{Box 5.6. Sustainable procurement for food delivery to the elderly in North Middle Sweden}

North Middle Sweden has started using procurement as a tool to promote changes in the meal-situation of the elderly. A project-based initiative was launched in four different municipalities. In all cases, the model developed was based on cross-disciplinary knowledge and a holistic and collaborative approach, where the real needs of each involved actor are first assessed. This insight then formed the basis of a procurement process for meal solutions for the elderly.

From the outset, a set of goals were established for each of the municipalities. Specifically, to: 
- create added-value and quality of life for the end-users

- create new products and services that open up possibilities for new actors to participate, or to open up new directions for established stakeholders

- not be more expensive for the procuring stakeholder, from a holistic perspective

- be compatible with current legislation.

Despite the somewhat different needs of each municipality, the results of the process revealed less waste, decreased transport, increased engagement and improved quality of life for both the elderly and personnel, for instance through increased outdoor activity, enhanced appetite and a stronger sense of community.

North Middle Sweden found that it is possible to identify and implement solutions that are fundamentally new and not necessarily more costly for municipalities. Success, however, can rest on a procurement procedure developed by a cross-disciplinary group that is aware of the diverse effects and clear on the desired outcomes, and when the procedure is based on knowledge about the real needs of the endusers.

Source: InnovationX (n.d.), Innovationsupphandling $X$ - med focus på äldres måltidssituation (Innovation Procurement $X$ - With Focus on the Meal-situation for the Elderly), http://www.innovationx.se/dokumentation.php.

\section{Multi-level governance practices and strategies}

Transitioning to a low-carbon economy presents a set of governance challenges. While the transition calls for long-term strategic thinking and policymaking, it also requires an ability to accommodate electoral cycles and the associated desire of governments and other stakeholders to show the results of implemented projects in a relatively short time. One common challenge is to ensure that the region's multilevel governance systems can support its ambitions for a low-carbon transition. This includes integrating the low-carbon transition in wider regional development strategies, fostering local energy transitions at a proper scale, building stakeholder engagement and ensuring an enabling environment for change despite some framework conditions being outside of the control of the regional government (Table 5.4).

\section{Table 5.4. Overcoming governance challenges: Policy issues, instruments and rationales}

\begin{tabular}{|c|c|c|c|}
\hline Policy issue & Policy response & $\begin{array}{l}\text { Potential suite of implementation } \\
\text { mechanism }\end{array}$ & Rationale/additional benefits \\
\hline \multirow{4}{*}{$\begin{array}{l}\text { Reconcile the long-term } \\
\text { strategic dimensions of a } \\
\text { climate-neutral transition } \\
\text { with short-term action }\end{array}$} & \multirow[t]{2}{*}{$\begin{array}{l}\text { Foster local energy } \\
\text { transitions }\end{array}$} & \multirow[t]{2}{*}{$\begin{array}{l}\text { - Financial and strategic support } \\
\text { schemes } \\
\text { - Strategic collaborations }\end{array}$} & $\begin{array}{l}\text { Reorient investments towards energy and } \\
\text { environmental goals }\end{array}$ \\
\hline & & & Strengthens local leadership \\
\hline & $\begin{array}{l}\text { Integrate the low-carbon } \\
\text { transition into larger } \\
\text { regional development } \\
\text { strategies }\end{array}$ & $\begin{array}{l}\text { - Set low-carbon objectives and } \\
\text { measures } \\
\text { - Build co-operation and stakeholder } \\
\text { alignment }\end{array}$ & $\begin{array}{l}\text { Long-term strategic thinking on how to } \\
\text { reduce carbon emissions }\end{array}$ \\
\hline & $\begin{array}{l}\text { Ensure an enabling } \\
\text { environment }\end{array}$ & $\begin{array}{l}\text { - Structural policies } \\
\text { - Phase out fossil subsidies } \\
\text { - Carbon tax }\end{array}$ & Creates supportive business conditions \\
\hline
\end{tabular}




\section{Fostering local energy transitions}

Achieving climate-neutral pathways requires strategies spanning infrastructure, technology development and innovation in the energy, land-use and agriculture sectors. Radical changes in infrastructure across sectors will be needed for low-emission pathways, not only to reduce the carbon intensity of energy supply but also to create less energy-intensive behaviours and to reduce energy use in transport, buildings and industry.

Local energy transition strongly contributes to achieving national and global energy transition goals. For example, the success of Germany's Energiewende (energy transition) relied to a great extent on energy transitions which were stimulated and supported by municipalities that become part of a thick network of actors on matters of fighting climate change (Moss, Becker and Naumann, 2015).

Infrastructure investment - and its impact - is highly relevant to subnational governments, as almost $60 \%$ of public infrastructure investment occurs at this level (OECD, 2018b). The decisions made by regions and cities regarding infrastructure can influence a country's ability to achieve emissions and other climaterelated targets. Subnational governments are also often responsible for decisions regarding land-use planning, integrated transport planning, and buildings (construction, retrofitting, and demolition) in their territories. How these responsibilities are designed, implemented and maintained will affect the low-carbon transition.

Municipal administrations can have a significant degree of autonomy in designing and implementing policies and programmes within larger frameworks (e.g. regional development plans, national sector strategies, etc.). They can almost certainly determine how to reduce their own energy usage, as well as many aspects of local building regulations and planning - for example through building codes, the provision of energy, public transport and housing - and how best to support and inform their citizens. Piemonte's large number of small public administrations combined with the poor construction quality of public buildings generates a huge potential for energy efficiency gains. The region's Together 2020 project harnesses this potential by specifically targeting small public administrations (Box 5.7).

\section{Box 5.7. Supporting energy efficiency in Piemonte's small public administrations:}

\section{Together 2020}

Together 2020 is an investment programme based on Public-Private Partnerships and Third-Party Investment (TPI) to increase the energy efficiency of public buildings and institutions in Piemonte's small public administrations.

Bringing a low-carbon approach to smaller municipalities was a challenge for the regional government. A lack of financial resources at the local authority level hindered municipal authorities from undertaking infrastructure investments that could increase the energy efficiency of public buildings and in turn, save them money. On the public market, time-to-tender was significant due to the need for high-quality energy auditing work and there was difficulty in keeping a strong level of commitment in small public municipalities. The relative lack of interest among companies in the call for tender by small municipalities was another challenge, driven by municipal size and a perceived lack of critical mass.

Thus far, the programme has been successful: 18 small municipalities have been involved, 50 public buildings have undergone energy auditing, and, without drawing on the public budget, energy-saving investments have resulted in a $12 \%$ decrease in energy consumption.

Source: Piemonte Region (2018), "Workshop 'Low carbon energy transition'”, PowerPoint Presentation for the Peer Learning in Regions in Industrial Transition Workshop "Low-Carbon Energy Transition”, 14-15 May 2018, Brussels, Belgium, Unpublished. 


\section{Taking a strategic approach and aligning actors}

Objectives and measures to implement the low-carbon transition should be part of larger regional economic development plans. Embedding low-carbon goals in broader regional development strategies is important for two reasons. First, policies to foster the transition towards a carbon-neutral economy require the alignment and joint efforts of different policy areas. For instance, regional science and innovation policy matters for supporting new low-carbon technologies, and skills policies need to take into account the requirements of green job profiles. Second, supporting the low-carbon transition might come with shortterm costs. Displaced workers from declining and brown industries might not experience an immediate and smooth transition to new employment. Regional development strategies in regions in industrial transition, therefore, need to take into account the costs of adjustment and foresee the necessary support measures to help workers move into new jobs and to ensure employers create the jobs needed.

Ideally, regional development strategies rest on building socially sustainable growth while driving a lowcarbon transition. Building co-operation among a diverse set of actors is one of the keys to a successful strategic approach. Co-operation can help identify and align priorities and focus effort across sectors and among a variety of groups, such as industry, universities, SMEs and entrepreneurs, financial institutions and different levels of government. Yet regions in industrial transition often find it challenging to create and sustain commitment and interest among different actors. Hauts-de-France's REV3 initiative highlights how low-carbon goals can be embedded in broader regional development strategies and objectives (Box 5.8).

In addition to fostering co-operation, regions must also mobilise and encourage stakeholders to participate in the transition to a climate-neutral economy. This ensures that local strategies turn into concrete actions driven by a shared commitment and engagement of businesses, universities, the government and civil society. On the part of the regional government, this requires communicating to all stakeholders the economic and environmental benefits of transition and providing the necessary incentives to take part in the transition where possible. Care should be taken to ensure that messaging is clear and appropriate to different stakeholder groups. This may require adapting messages so they resonate with the target audience and using audience-appropriate communication channels (e.g. print, websites, social media, etc.)

\section{Box 5.8. Good practice in Hauts-de-France: REV3}

The term "REV3" stands for the regional adaptation of the Third Industrial Revolution concept and is part of the Hauts-de-France regional strategy. It aims to integrate the energy transition, the digital revolution and new economic models in order to decarbonise the regional economy by 2050 , create jobs and boost local innovation. In involving local governments, companies, academia, institutions and the civil society organisations, the goal is to make rev3 a part of the region's identity and a factor of attractiveness.

For its implementation, the rev3 dynamic mobilises research-oriented and competitiveness clusters such as Pôle MEDEE (Maîtrise Energétique des Entrainements Electriques), Pôle IAR (bioeconomy), Energie 2020 and CD2E (energy efficiency in buildings and renewable energy). As part of the regional development strategy, rev3 is embedded in the different regional plans and roadmaps in order to ensure the coherence of regional policies.

Source: Hauts-de-France Region (2018), "Hauts-de-France region", PowerPoint Presentation for the Peer Learning in Regions in Industrial Transition Workshop "Low-Carbon Energy Transition”, 14-15 May 2018, Brussels, Belgium, Unpublished. 


\section{Ensuring an enabling environment}

The regulatory environment is fundamental to ensure a fair transition. Effective business regulations allow micro and small businesses to scale-up and innovate. They also support the creation of (low-carbon) startups that help diversify the local economy. Pro-competition reforms strengthen market entry and can lead to higher investment, innovation and productivity. Flexible labour markets help workers move from one industry to another.

Policymakers in regions in industrial transition need to ensure that policies not directly targeting the lowcarbon transition are also not working against it. Mapping how various sectors and their policies affect climate-neutral goals is one way to accomplish this. The role and interests of governments in supporting fossil fuel activities should also be considered. Many governments still depend on royalties, taxes and other revenues linked to fossil fuels. This financial interest is a large barrier unless the revenue stream is compensated.

Even when framework conditions are outside the control of regional governments, they still may be able to influence change. It is, therefore, crucial for regions in industrial transition to re-evaluate the framework conditions that directly and indirectly relate to low-carbon policies, so that an enabling environment for the low-carbon transition can be established - taking action where they can and working within their governance system to influence change in areas where direct action is not possible. This requires wellco-ordinated transition planning at all levels of government, involving key stakeholders and effective communication among all levels of government.

\section{Key considerations and conclusions}

Past and present industrial transition and the current transition to a climate-neutral economy demands that policymakers smooth the transition by addressing worker reallocation, redeployment, re-skilling or compensation. There are potential lessons to be drawn from "transition management strategies" and the policy frameworks put in place to facilitate these transitions. The following points should be considered in regions in industrial transition when preparing for the transition to a climate-neutral economy.

\section{Balancing short-term trade-offs and long-term benefits is a must}

While many regions in industrial transition are striving to advance the climate-neutral agenda, certain economic sectors, firms and segments of society strongly resist ambitious climate and other environmental policies. This is due to the real or perceived negative impact of greening policies on jobs and competitiveness. The economic and social costs of climate policies are perceived as high, and firms express concern about competitive disadvantage. The perceived threat of climate change is too long term to balance short-term trade-offs and drive ambitious early action. Without addressing such concerns headon and devising possible solutions, regions in industrial transition cannot make sufficient progress on the implementation of green policies.

\section{Resources need to be concentrated on areas with highest adjustment costs}

Changing the current allocation of investments will be challenging for even the most advanced countries and regions. Achieving the greatest impact requires to target resources to those areas that are most in need for it. A "managed" transition provides sufficient degree of public support for areas with highest adjustment costs. For regions in industrial transition, this may require developing strategies to support the reorientation of existing industries in order to increase their efficiency and lessen dependence on fossil 
fuels and to invest in skills development in order to reap the benefits of potential job creation in new green activities.

\section{Regions in industrial transition need to tackle climate, growth and a just transition in a mutually reinforcing way}

In order to implement and deliver the carbon-neutral transition in an inclusive way, tailoring policies to regional and local circumstances and addressing the needs of different groups will be crucial. Policymakers in regions in industrial transition, in close co-operation with the private sector, should systematically work through their existing policy frameworks and make sure they can accommodate new business models and new technologies that are connected to the transition to a low-carbon economy, thereby ensuring that possible opportunities and related benefits can be realised.

\section{The political economy aspects of the climate-neutral transition matter}

There is no one-size-fits-all solution and a successful transition will depend on a number of factors that are specific to a given region. Taking a political economy approach to the low-carbon transition at the regional level can help understand who wins, who loses, how and why, and help design fit-for-purpose transition policies. Regions undergoing an industrial transition should undertake an analysis of structural and distributional consequences of the low-carbon transition. This is fundamental to make sure that industrial modernisation goes hand-in-hand with clean energy objectives and that existing inequalities between people and places are not further exacerbated by climate policies.

\section{References}

Acemoglu, D. et al. (2016), "Transition to clean technology", Journal of Political Economy, Vol. 124(1), pp. 52-104.

Botta, E. (2018), "A review of "transition management" strategies: Lessons for advancing the green lowcarbon transition", Issue note for the GGSD 2018 Forum on "Inclusive Solution for the green Economy".

Campbell, S., \& Coenen, L. (2017). Transitioning beyond coal: Lessons from the structural renewal of Europe's old industrial regions. In CCEP Working Papers. Centre for Climate Economics \& Policy, Crawford School of Public Policy. The Australian National University.

Eurofund (2014), Effects of Restructuring at Regional Level and Approaches to Dealing with the Consequences, Publications Office of the European Union, Luxembourg.

Eurostat (2019), Renewable energy statistics. https://ec.europa.eu/eurostat/statisticsexplained/index.php/Renewable energy statistics

Freistaat Sachsen (2018a), "Climate-neutral Energy Transition: A Saxon Perspective", PowerPoint Presentation for the Peer Learning in Regions in Industrial Transition Workshop "Climate-Neutral Energy Transition", 14-15 May 2018, Brussels, Belgium, Unpublished.

Freistaat Sachsen (2018b), “Low-Carbon Energy Transition: A Saxon Perspective”, PowerPoint Presentation for the Peer Learning in Regions in Industrial Transition Workshop "Low-Carbon Energy Transition", 14-15 May 2018, Brussels, Belgium.

Hauts-de-France Region (2018), "Hauts-de-France region", PowerPoint Presentation for the Peer Learning in Regions in Industrial Transition Workshop "Low-Carbon Energy Transition”, 14-15 May 2018, Brussels, Belgium, Unpublished. 
Hoevenagel, R. et al. (2007), Promoting Environmental Technologies in SMEs: Barriers and Measures, European Commission, Luxembourg.

Howell S. (2017), "Financing innovation: Evidence from R\&D grants", The American Economic Review, http://www.oecd.org/gov/ethics/Going Green Best Practices for Sustainable Procurement.pdf.

InnovationX (n.d.), Innovationsupphandling $X$ - med focus på äldres måltidssituation (Innovation Procurement $X$ - With Focus on the Meal-situation for the Elderly), http://www.innovationx.se/dokumentation.php.

Marchal, V. (2018), "For a Successful Low-Carbon Energy Transition”, Scoping Paper for Peer Learning Workshop, 14-15 May 2018, OECD, Paris, Unpublished.

Mclnnes, G. (2017), Understanding the Distributional and Household Effects of the Low-carbon Transition in G20 Countries, https://www.oecd.org/environment/cc/g20climate/collapsecontents/Mclnnes-distributional-and-household-effects-low-carbon-transition.pdf

Moss, T., S. Becker and M. Naumann (2015), "Whose energy transition is it, anyway? Organisation and ownership of the Energiewende in villages, cities and regions", Local Environment, Vol. 20(12), pp. 1547-1563.

OECD (2018a), Environmental Policy Toolkit for SME Greening in EU Eastern Partnership Countries, OECD Green Growth Studies, OECD Publishing, Paris, https://doi.org/10.1787/9789264293199-en.

OECD (2018b), Subnational Governments in OECD Countries: Key Data (brochure), OECD, Paris, www.oecd.org/regional/regional-policy

OECD (2018c), "Peer Learning in Regions in Industrial Transition Workshop: Low-Carbon Energy Transition, Responses from Hauts-de-France, North Middle Sweden, Piemonte, Saxony, Slovenia, Wallonia", Proceedings Paper for Peer Learning Workshop 2-3 July, Manchester, United Kingdom, OECD, Paris, Unpublished.

OECD (2017a), Getting Skills Right - Good Practice in Adapting to Changing Skill Needs: A Perspective on France, Italy, Spain, South Africa and the United Kingdom, Getting Skills Right, OECD Publishing, Paris, https://doi.org/10.1787/9789264277892-en.

OECD (2017b), "Building blocks for coherent implementation of the Sustainable Development Goals", in Policy Coherence for Sustainable Development 2017: Eradicating Poverty and Promoting Prosperity, OECD Publishing, Paris, https://doi.org/10.1787/9789264272576-4-en.

OECD (2014), Job Creation and Local Economic Development 2018: Preparing for the Future of Work, OECD Publishing, Paris, https://doi.org/10.1787/9789264305342-en.

OECD (2002), "OECD Recommendation of the Council on Improving the Environmental Performance of Public Procurement", OECD, Paris.

OECD/EU (2017), The Missing Entrepreneurs 2017: Policies for Inclusive Entrepreneurship, OECD Publishing, Paris, https://doi.org/10.1787/9789264283602-en.

Piemonte Region (2018), “Workshop 'Low carbon energy transition”, PowerPoint Presentation for the Peer Learning in Regions in Industrial Transition Workshop "Low-Carbon Energy Transition", 14-15 May 2018, Brussels, Belgium, Unpublished.

\section{Note}

1 The share of male employment in high-carbon sectors is higher than that of women: $97 \%$ male employment in mining, and $77 \%$ in electricity. 


\section{Annex 5.A. Overview of policy issues and responses in the transition to a climate-neutral economy}

Annex Table 5.A.1. Overview of policy issues, implementation mechanisms and rationales in the transition to a climate-neutral economy in regions in industrial transition

\begin{tabular}{|c|c|c|c|}
\hline Policy issue & Policy response & $\begin{array}{l}\text { Potential suite of implementation } \\
\text { mechanism }\end{array}$ & Rationale/additional benefits \\
\hline \multirow{4}{*}{$\begin{array}{l}\text { Creating job opportunities } \\
\text { for the transition to the } \\
\text { climate-neutral economy }\end{array}$} & \multirow{2}{*}{$\begin{array}{l}\text { Support green skills and } \\
\text { jobs through training and } \\
\text { upskilling }\end{array}$} & \multirow{2}{*}{$\begin{array}{l}\text { - Upskilling and retraining for displaced } \\
\text { workers aligned with local labour } \\
\text { market needs } \\
\text { - Training on environmentally friendly } \\
\text { production methods for existing } \\
\text { workers }\end{array}$} & $\begin{array}{l}\text { Expansion of skillset to move from } \\
\text { declining to emerging industries }\end{array}$ \\
\hline & & & $\begin{array}{l}\text { Progressive greening of existing } \\
\text { industries }\end{array}$ \\
\hline & $\begin{array}{l}\text { Support workers in } \\
\text { transition }\end{array}$ & $\begin{array}{l}\text { - Dedicated job-search training for } \\
\text { displaced workers } \\
\text { - Flexicurity in labour markets }\end{array}$ & Ensures the transition to high-quality jobs \\
\hline & $\begin{array}{l}\text { Support measures to a } \\
\text { just transition }\end{array}$ & $\begin{array}{l}\text { - Age- and gender-tailored measures } \\
\text { - Social housing }\end{array}$ & Ensures a fair transition \\
\hline \multirow{3}{*}{$\begin{array}{l}\text { Lack of business } \\
\text { opportunities for green } \\
\text { innovations }\end{array}$} & \multirow[t]{2}{*}{$\begin{array}{l}\text { Stimulate green } \\
\text { behaviour in firms }\end{array}$} & \multirow{2}{*}{$\begin{array}{l}\text { - Regulatory simplifications and } \\
\text { incentives } \\
\text { - Information-based tools (e.g. advice, } \\
\text { sector-specific certification, ecolabels) } \\
\text { - Economic incentives (grants, } \\
\text { low-interest loans, tax incentives) }\end{array}$} & $\begin{array}{l}\text { Creates an attractive innovation } \\
\text { ecosystem for firms }\end{array}$ \\
\hline & & & $\begin{array}{l}\text { Higher awareness for green business } \\
\text { opportunities }\end{array}$ \\
\hline & $\begin{array}{l}\text { Encourage innovation in } \\
\text { environmentally friendly } \\
\text { technologies }\end{array}$ & $\begin{array}{l}\text { - Support for green research and } \\
\text { development } \\
\text { - Innovation clusters } \\
\text { - Environmentally friendly public } \\
\text { procurement }\end{array}$ & $\begin{array}{l}\text { Stimulates investments in green } \\
\text { technologies }\end{array}$ \\
\hline \multirow{4}{*}{$\begin{array}{l}\text { Reconciling the long-term } \\
\text { strategic dimensions of a } \\
\text { climate-neutral transition } \\
\text { with short-term action }\end{array}$} & \multirow[t]{2}{*}{$\begin{array}{l}\text { Foster local energy } \\
\text { transitions }\end{array}$} & \multirow{2}{*}{$\begin{array}{l}\text { - Financial and strategic support } \\
\text { schemes } \\
\text { - Strategic collaborations }\end{array}$} & $\begin{array}{l}\text { Reorient investments towards energy and } \\
\text { environmental goals }\end{array}$ \\
\hline & & & Strengthens local leadership \\
\hline & $\begin{array}{l}\text { Integrate the climate- } \\
\text { neutral transition into } \\
\text { larger regional } \\
\text { development strategies }\end{array}$ & $\begin{array}{l}\text { - Set low-carbon objectives and } \\
\text { measures } \\
\text { - Build co-operation and stakeholder } \\
\text { alignment }\end{array}$ & $\begin{array}{l}\text { Long-term strategic thinking on how to } \\
\text { reduce carbon emissions }\end{array}$ \\
\hline & $\begin{array}{l}\text { Ensure an enabling } \\
\text { environment }\end{array}$ & $\begin{array}{l}\text { - Structural policies } \\
\text { - Phase out fossil subsidies } \\
\text { - Carbon tax }\end{array}$ & Creates supportive business conditions \\
\hline
\end{tabular}




\section{Promoting inclusive growth}

Promoting and sustaining inclusive growth is a pre-condition for a fair and inclusive industrial transition. This chapter assesses how adopting an integrated territorial approach to economic development and enhancing individual well-being and labour market inclusion can help regions in industrial transition overcome obstacles to inclusive growth. The chapter points out that less advantaged areas - those that might have been prosperous prior to industrial decline - must solidify ties with those that are now growing. It also highlights that vulnerable groups need to better integrate into the labour market. The chapter further explores how improved urban-rural linkages, better (digital) connectivity, dedicated support for vulnerable groups in transition and stronger coherence in promoting inclusive growth policies can support regions in industrial transition mitigate the effects of slow growth and high unemployment. 


\section{Infographic 5. Key messages: Promoting inclusive growth}

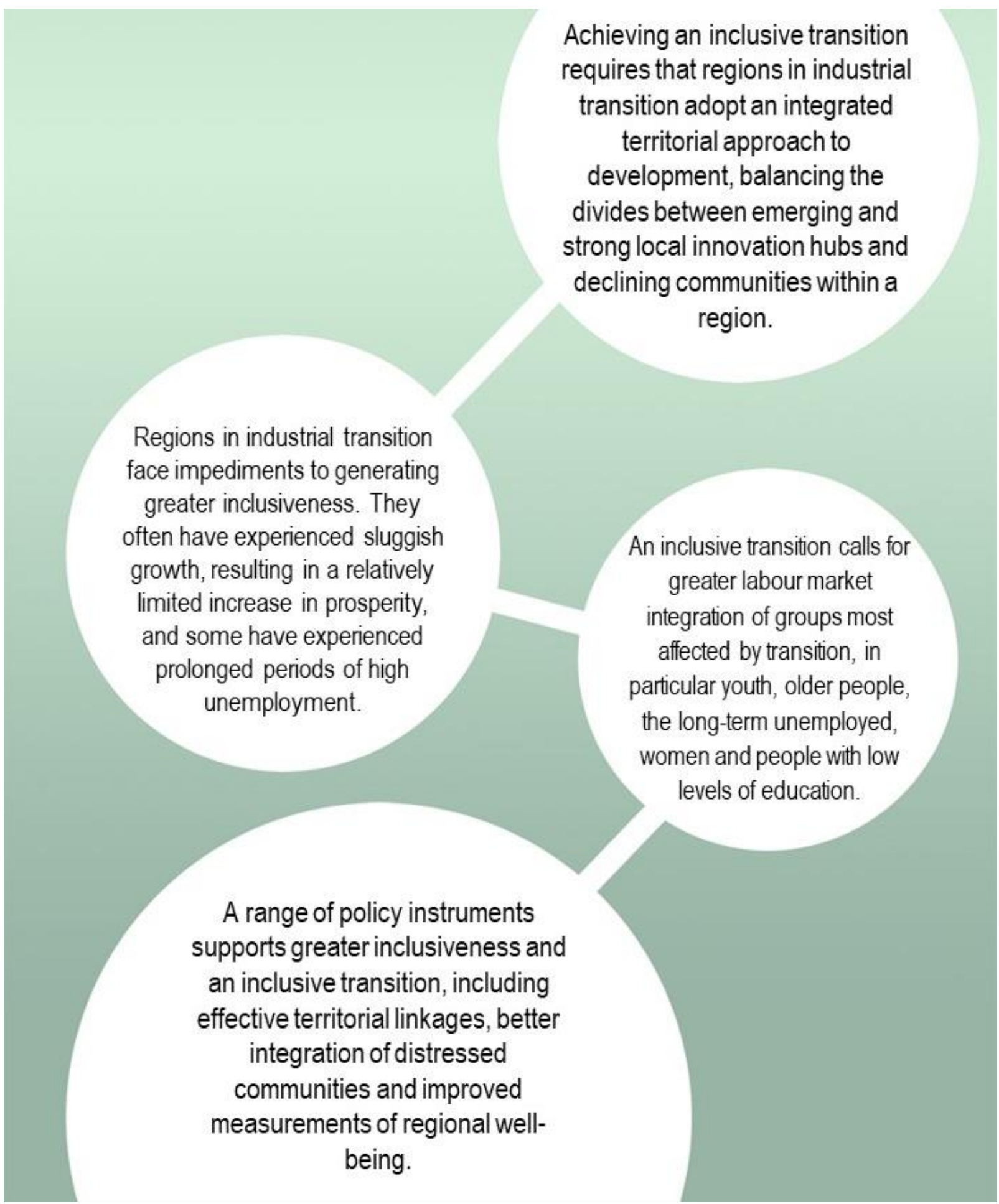




\section{Adopting an integrated territorial approach helps ensure an inclusive transition}

Inclusive growth contributes to an individual's quality of life and their capacity to actively contribute to societal progress. The OECD has identified two fundamental dimensions to inclusive growth that are particularly relevant to regions in industrial transition. One is the importance of adopting a territorial approach to development that ensures spill-overs from thriving to left-behind places. The second is to facilitate industrial transition for vulnerable groups and those most affected by industrial change with appropriate labour market and skills policies.

Prosperity is not shared equally across regions or cities, and large economic divides can persist between lagging territories and those that are drivers of growth. For regions in industrial transition, one of the core challenges is to ensure that the places that once drove regional prosperity and then experienced a decline due to a loss of industry or industrial productivity will be able to benefit from new and emerging economic activity within the region. Left unaddressed, this challenge could weaken social cohesion, increase economic vulnerability and limit social mobility and equality of opportunities. Confronted with such territorial inequalities, regions in industrial transition must ensure an inclusive transition, one that helps lagging areas catch up with more dynamic ones, while also improving quality of life in the territory. For all places, economic growth needs to translate into better living conditions for residents.

\section{A policy approach focused on inclusive growth is essential to avoid further labour market polarisation in regions in industrial transition}

Labour market polarisation can hinder productivity growth and erode employment stability for workers. Low incomes and high unemployment rates, especially when combined with long-term joblessness, inevitably create economic hardship for affected segments of society. However, the impact goes beyond simple monetary conditions. Unemployment, low income and a lack of opportunities can also generate mental and physical health problems (Strully, 2009; Martikainen and Valkonen, 1996).

The experience of some regions in industrial transition indicates that active labour market policies, such as increased flexibility in employment relationships and the modernisation of employment services, are underway. However, considerable efforts are needed to cope with rising polarisation of regional labour markets. Unemployment, and especially long-term unemployment resulting from a decline in traditional manufacturing, is increasing the risk of social exclusion, poverty and inequality in some regions in industrial transition. It is important to ensure good conditions and opportunities for people living in these regions or thinking of living there, which in turn will enhance a smooth transition and support sustainable and inclusive development.

\section{Territorial linkages can reduce polarisation and promote economic growth everywhere}

Productivity and economic wealth have a strong spatial dimension. Large spatial disparities in productivity remain within the same large (TL2) region (Figure 6.1). Regions in industrial transition often experience low gross domestic product (GDP) growth and productivity and are characterised by large spatial disparities in productivity and well-being.

Average productivity in cities is higher than in other places. This is because advanced service sectors are more concentrated in urban economies and their workforce consists of a greater proportion of highly educated and skilled individuals who tend to be more productive. Productivity benefits - so-called "agglomeration benefits" - arise in larger or more densely populated cities and stem from learning and knowledge spill-overs, specialisation opportunities and deep labour markets (OECD, 2015a; Ahrend et al., 2017). 
Figure 6.1. Large spatial differences in productivity persist within the same large (TL) region

Percentage difference in labour productivity of small regions inside large regions, 2015

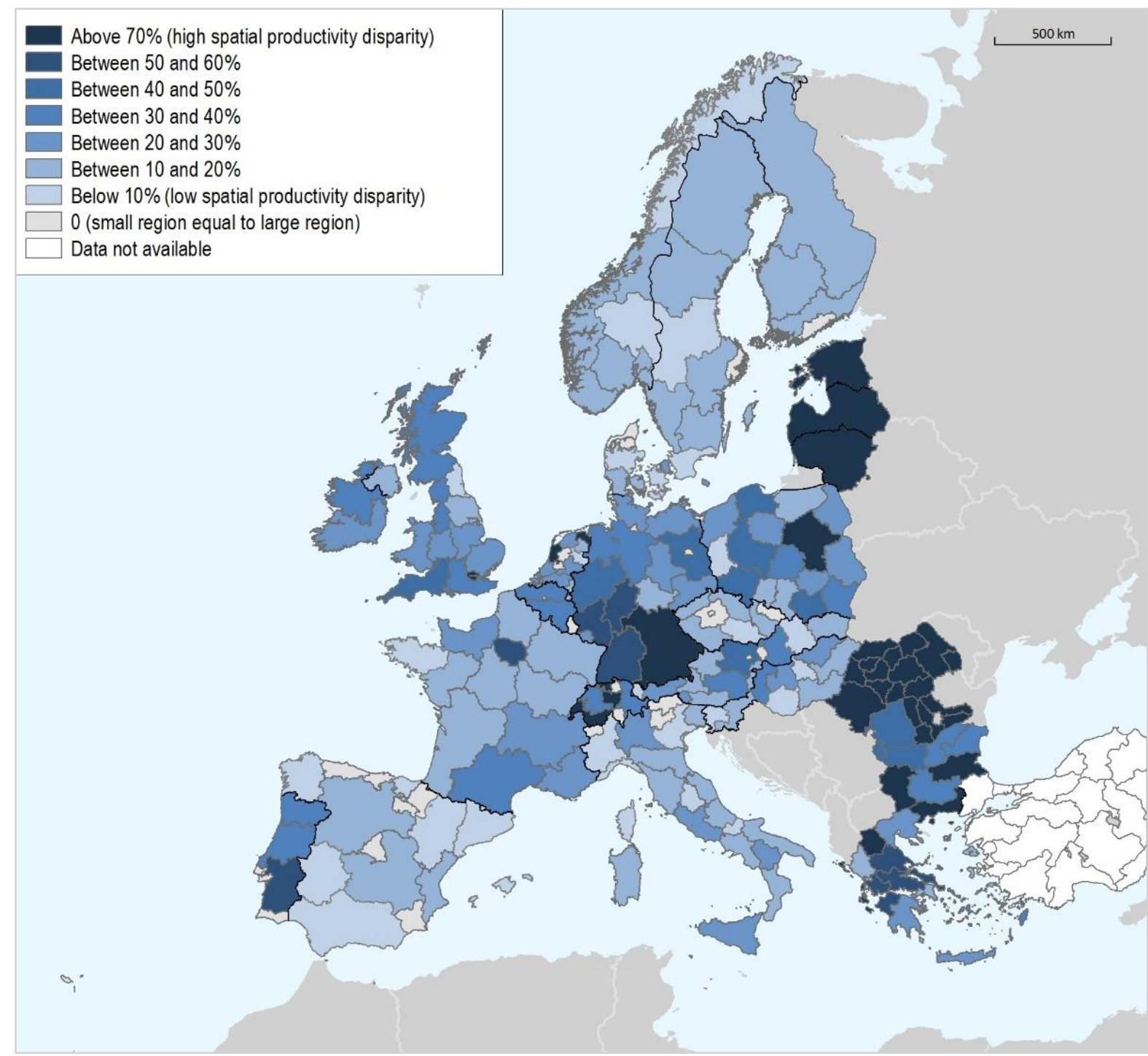

Note: The map shows the percentage difference in labour productivity of the $20 \%$ highest small (TL3) region with respect to the $20 \%$ lowest TL3 region inside the same large (TL2) region. The GDP per worker of the top (bottom) $20 \%$ of TL3 regions are defined as those with the highest (lowest) GDP per worker until the equivalent of $20 \%$ of national employment is reached.

Source: OECD (2018d), OECD Regional Statistics (database), http://dx.doi.org/10.1787/region-data-en.

While rural areas are, on average, significantly less productive than urban ones, connecting rural places to cities can reduce polarisation and promote economic growth. As different places have different assets, there are often complementarities at the basis of urban-rural linkages that can be beneficial for both types of areas. Therefore, ensuring that the potential offered by spatial linkages is fully utilised can enhance productivity and reduce spatial disparities. 


\section{What challenges and opportunities do regions in industrial transition face in promoting inclusive growth?}

Regions in industrial transition are often confronted with job polarisation and intra-regional divides in access to highly qualified workers, good (digital) infrastructure and high-quality jobs. As a result, these regions can be home to companies with a high share of well-qualified workers, good digital infrastructure and a priority to train employees. At the same time, they often also host companies with a low share of highly qualified workers, poor digital infrastructure and no priority to train employees.

One of the reasons for such polarisation is the increasing gap in education and skills. New technology does not inevitably reduce the overall demand for labour but demand has been shifting to different kinds of work. In this context, employment "polarises" relatively high-skill, high-wage jobs from low-skill, lowwage jobs (see also Chapter 2, Figure 2.2). Coping with increased job polarisation provides an opportunity for inclusive growth. A policy directed towards the inclusion of low-skilled people helps increase the employment rate, lowers relative in-work poverty and contributes to reintegrating laid-off workers back into the labour market.

\section{An inclusive transition requires more support for the labour market integration of vulnerable groups}

In order to successfully manage transition, a region's workforce needs the appropriate education levels to increase the share of high-skilled workers. Regions in industrial transition tend to face higher-than-average levels of youth unemployment. Across the OECD, disparities in unemployment rates persist and these are generally much higher for youth unemployment than for total unemployment (Figure 6.2). Youth unemployment and long-term unemployment more generally are sources of exclusion from the labour market and society. Unemployment increases the risk of skills degradation, which further reduces employability. Making sure that youth are able to participate in the labour market and earn their own income is an essential component of inclusive growth. Giving young people the skills and tools to find a job is not only good for their own prospects and self-esteem but is also good for economic growth, social cohesion and widespread well-being.

\section{Industrial decline is often spatially concentrated}

Industrial decline is often geographically concentrated and new jobs are not necessarily located in the same areas as the industries that are declining. Resulting decreases in competitiveness can be compounded if laid-off workers leave to look for employment elsewhere. The connected developments on regional demographics and fiscal capacity can potentially lead to a decline in public services, such as in education, health and social services.

In regions in industrial transition, peri-urban areas with mixed land use and a transitional status between urban and rural have often been affected by a decline in local industrial activity, leaving these places less prosperous than in past moments in time. At the same time, peri-urban areas are often characterised by fast-growing infrastructure facilities, large green areas and lower land prices compared to the city. Future development of these areas requires strengthening their local potential and stimulating new economic activity.

Furthermore, the divide between lagging and prosperous places can be aggravated by an urban-rural divide. The OECD has found that regions closer to cities - and especially to larger cities - have grown faster in terms of GDP per capita than their more remote counterparts. The higher productivity is due to agglomeration benefits, which account for about half of the productivity advantage of cities. 
Figure 6.2. Disparities in youth unemployment remain across regions

Regional youth unemployment as a share of national average, 2017

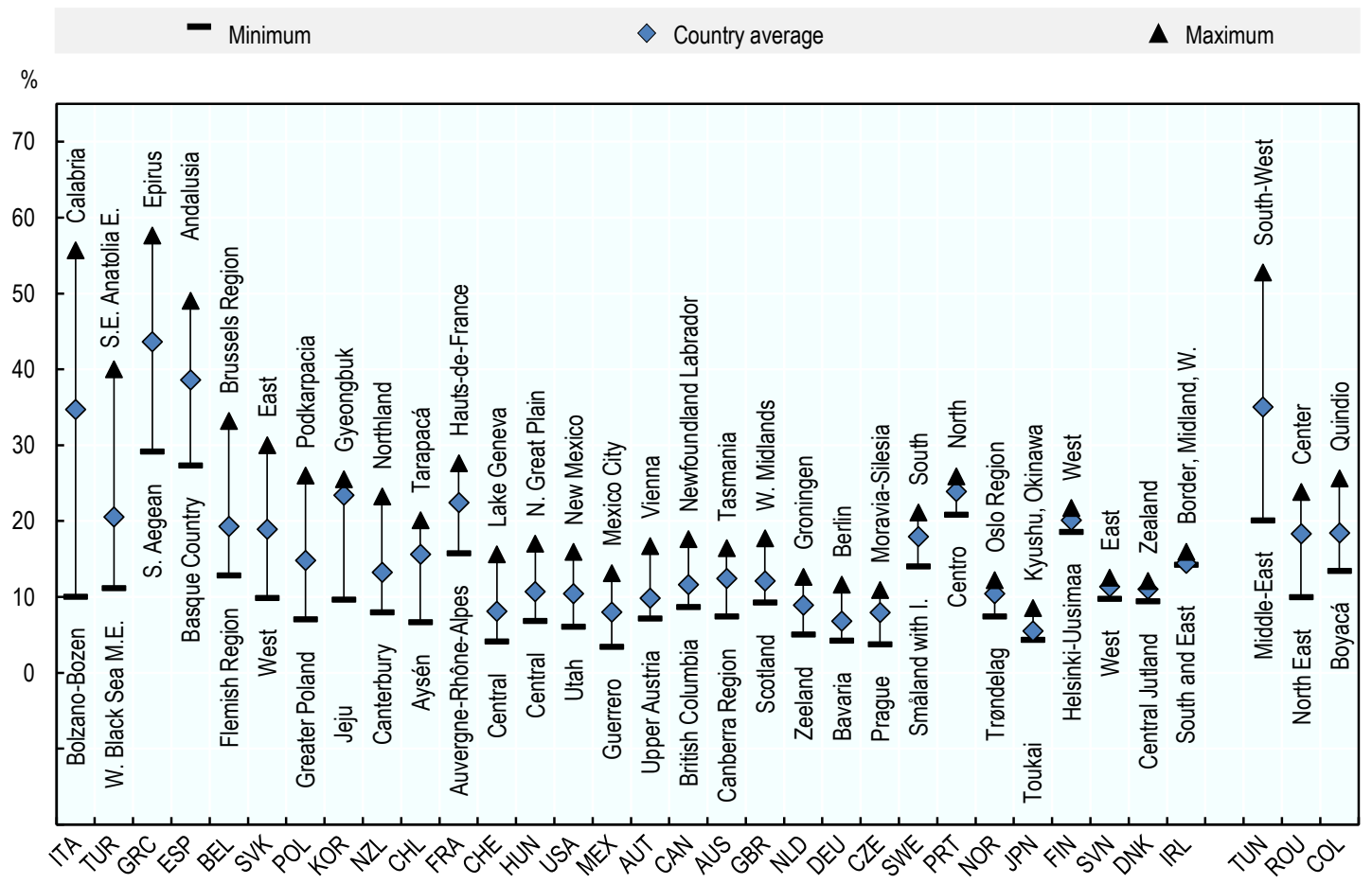

Note: The youth unemployment ratio is defined as people unemployed between 15 and 24 years old over the labour force of the same class of age. Last available year: Australia, Chile, Colombia, Korea, Mexico and New Zealand, 2016; Japan, 2015; Tunisia, 2014.

Source: OECD (2018d), OECD Regional Statistics (database), http://dx.doi.org/10.1787/region-data-en.

\section{Co-ordinating inclusive growth objectives and strategies is often a challenge}

Successfully managing industrial transition requires strong partnerships, be they among government bodies, with the private sector, civil society, non-governmental organisations (NGOs), communities, etc. Securing these partnerships, however, can prove challenging and an incentive structure is often necessary. Ensuring that priorities are well-aligned is fundamental but potentially difficult, as is ensuring that responsibilities are clearly articulated and accepted by each party. Structures that rely on volunteer participation may confront slow uptake by potential partners. In all of these cases, financial incentives may help encourage collaboration; other approaches are also available.

\section{How can policy (better) support inclusive growth?}

Three strategies may be particularly valuable for promoting inclusive growth in regions in industrial transition: i) pursuing a policy approach that includes active support of vulnerable groups in the labour market; ii) adopting an integrated territorial approach and fostering linkages between different places to promote more inclusive development across and within regions; (iii) strengthening coherence in inclusive growth governance. 


\section{Reducing labour market polarisation as a factor for inclusiveness}

The widespread nature of labour market polarisation in regions in industrial transition suggests that there is a clear need for policy instruments that can smooth the transition process for workers. Integrating vulnerable populations into the labour market through education and skills policies, targeted entrepreneurship programming or other active labour market initiatives can generate inclusive employment opportunities and lower the risk of falling into precarious employment. To enhance quality of life, strengthening labour market inclusion, raising educational attainment and supporting life-long learning as well as skill acquisition can help (Table 6.1).

\section{Table 6.1. Regional well-being: Policy issues, instruments and rationales}

\begin{tabular}{|c|c|c|c|}
\hline Policy issue & Policy response & $\begin{array}{l}\text { Potential suite of implementation } \\
\text { mechanism }\end{array}$ & Rationale/additional benefits \\
\hline \multirow[t]{3}{*}{$\begin{array}{l}\text { Strengthening regional } \\
\text { well-being and reducing } \\
\text { labour market polarisation }\end{array}$} & \multirow[t]{2}{*}{$\begin{array}{l}\text { Integrate vulnerable } \\
\text { populations into the labour } \\
\text { market }\end{array}$} & \multirow{2}{*}{$\begin{array}{l}\text { - Support disadvantaged groups (long- } \\
\text { term unemployed, women, youth) } \\
\text { through career guidance and } \\
\text { retraining schemes }\end{array}$} & $\begin{array}{l}\text { Generates inclusive employment } \\
\text { opportunities }\end{array}$ \\
\hline & & & Increases productivity \\
\hline & $\begin{array}{l}\text { Develop and implement a } \\
\text { regional-level well-being } \\
\text { framework }\end{array}$ & $\begin{array}{l}\text { - Development of regional measures of } \\
\text { material well-being and quality of life } \\
\text { - Engaging in civil society and } \\
\text { academia to define well-being } \\
\text { measures }\end{array}$ & Greater well-being outcomes \\
\hline
\end{tabular}

\section{Integrating vulnerable populations into the labour market}

Youth employability requires a comprehensive and forward-looking skills strategy. For regions in industrial transition, this means strengthening the role and effectiveness of vocational education and training (VET) and better integrating low-skilled youth into the labour market. In order to improve the employment prospects of its unemployed youth, Slovenia has introduced a target-counselling programme to reduce secondary school drop-out rates (Box 6.1).

\section{Box 6.1. Addressing youth unemployment in Slovenia}

Slovenia established an integrated, preventative and individualised counselling programme for students who have dropped out of secondary school or are at risk of doing so. It tailors certain education components to their needs and provides opportunities for students to train and work in areas in which they can excel. This is at once highly motivating while also offering the opportunity to develop marketable skills.

Source: OECD (2018e), "Peer Learning in Regions in industrial transition Workshops: Inclusive Growth", Proceedings Paper for Peer Learning Workshop 5 "Inclusive Growth", OECD, Paris, Unpublished.

Regions in industrial transition, like other regions, are also struggling with a gender gap in employment. Employed women tend to work in lower-quality jobs and in conditions that are more vulnerable. From an economic perspective, reducing gender gaps in labour force participation could substantially boost productivity.

A diverse range of policy measures exists to overcome barriers to gender equality. These include programmes aimed at encouraging girls and young women to pursue studies and careers in science, 
technology, engineering and mathematics (STEM). Other programmes support access to early childhood education and care for women. Some policies focus on closing the gender wage gap and promoting gender balance on boards and in senior management (OECD, 2017). Industrial transition can provide a welcome opportunity to support gender equality through new job creation, especially if skills and education systems promote gender balance. Actively integrating gender considerations in regional development strategies, an approach taken in North Middle Sweden, is critical to accomplish this (Box 6.2).

\section{Box 6.2. Building gender inclusiveness in North Middle Sweden}

North Middle Sweden is participating in a national campaign to integrate gender into regional development strategies. The initiative is based on four pillars: i) incorporating gender into policy documents; ii) gender mapping to identify gender inequality in the region with respect to development issues, for example the use of regional development funds; iii) female entrepreneurship; and iv) including a gender perspective in programme planning and implementation. North Middle Sweden focuses on the first, second and fourth areas, creating an action plan with specific interventions. For example, a gender equity assessment is included when considering project funding and actively building evidence bases to generate gender statistics that can further support gender-sensitive programming and policy.

Source: North Middle Sweden (2018), "North Middle Sweden", PowerPoint Presentation for the Peer Learning in Regions in Industrial Transition Workshop "Inclusive Growth", 28-29 June 2018, Tällberg, Sweden, Unpublished.

Workers in regions in industrial transition risk long-term unemployment. Apart from the emotional and material stress on workers and their families that is associated with this, high rates of long-term unemployment indicate structural obstacles that need to be overcome. High-quality education and training systems provide life-long learning opportunities. Skills profiling, retraining and counselling help avoid longterm unemployment. Across the OECD, workforce groups at greater risk of labour market disadvantage, such as women and the older population, receive even less training, both formal and informal, than the ones at lower risk, compounding their disadvantage (OECD, 2018a). Regions in industrial transition need to ensure vulnerable groups are supported through well-targeted training measures and comprehensive support provision. Saxony's Tandem programme takes a comprehensive, family-based approach to supporting labour market integration and, in Wallonia, the Self-Employment Support Structures (SAACE) are offering support to individual job seekers who wish to be self-employed (Box 6.3).

\section{Box 6.3. Labour market policies to integrate long-term unemployed and supporting self-employment}

\section{Tandem: Taking a family-based approach to labour market integration in Saxony}

Saxony's Tandem programme supports labour market integration of long-term unemployed by working with the entire family unit for 12 to 18 months. The programme seeks to ensure: i) employment for at least one parent; ii) assistance for school-age children; iii) increased social competencies and practical life capabilities; iv) solidarity and well-being in the family unit. To accomplish its aims, it offers training and education opportunities for long-term unemployed adults (parents and single parents) to promote better social and professional participation. It also offers practical and educational support the household's children. Interdisciplinary counselling teams composed of specialists (generally social workers and psychologists) help stabilise the family by taking a holistic approach to supporting a return 
to employment. The programme connects job centres and youth welfare offices to offer assistance services.

\section{SAACE: Supporting self-employment in Wallonia}

Wallonia's Self-Employment Support Structures (SAACE) offers individual support to jobseekers wishing to establish their own business or take over an existing one. The SAACE offer pedagogical, legal and financial support to set up a project, test the project before entering the market, obtain financing and receive legal protection. Twelve structures are currently approved and funded by the Walloon government, offering job seekers free coaching for a maximum of 24 months. Nine of the twelve offer a test of the project prior to launch or the possibility to host the activity in order to validate economic viability. By 2017, 611 companies were created with the help of a SAACE, more than 5800 people were welcomed, 2200 people were supported in the trial phase of their initiative and almost 740 people have tested their activity. Interestingly, the structures welcome more women (about $60 \%$ of all beneficiaries).

Sources: OECD (2018e), "Peer Learning in Regions in industrial transition Workshops: Inclusive Growth", Proceedings Paper for Peer Learning Workshop 5 "Inclusive Growth", OECD, Paris, Unpublished; Saxony (2018), "Saxony", PowerPoint Presentation for the Peer Learning in Regions in Industrial Transition Workshop "Inclusive Growth", 28-29 June 2018, Tällberg, Sweden, Unpublished; Wallonia (2018), "Peer Learning in Regions in industrial transition Workshops Good Practice Template", Self-employment Support Structures (SAACE), Prepared for the Peer Learning in Regions in Industrial Transition Workshop "Inclusive Growth", 28-29 June 2018, Tällberg, Sweden, Unpublished.

Policy interventions should encompass maintaining low-skilled people in the labour market and supporting a transition from low-wage jobs to middle- or high-wage jobs, in particular through training and education (Breemersch, Damijan and Konings, 2017). Keeping low-skilled workers in the labour market helps mitigate discouragement and labour market inactivity. Long-term employment policies, however, have to go beyond quick placements and provide training to ensure sustainable transition that enhances people's productivity potential and thereby their labour market security. The inclusion of vulnerable groups in the labour market should be accompanied by social inclusion mechanisms such as income maintenance schemes. These schemes can help reduce poverty arising from involuntary unemployment or transitory inactivity because they guarantee basic income security.

\section{Strengthening regional well-being}

The integration of disadvantaged and under-represented groups into the labour market has to be part of larger efforts to strengthen the well-being of all citizens during periods of industrial modernisation. The OECD Regional Well-being framework (OECD, 2015b) has identified 11 dimensions that are highly relevant for overall quality of life, divided into:

- Material well-being: jobs, income, housing.

- Quality of life: education, health, civic engagement, safety, access to services, environment, sense of community and life satisfaction.

Most factors that directly affect individual well-being are determined locally, often by decisions of subnational governments, and thus should be assessed at the subnational level. Well-being outcome indicators represent a strategic tool for regions that want to assess and improve policy results. Evaluating whether and to what extent changes in well-being outcomes are directly attributable to a given policy or derive from other factors is challenging. It is even more complex at the regional and local levels, where policies from different levels of government intersect. Well-being indicators can enhance coherence across policies by promoting a better understanding of trade-offs and synergies among the different well-being dimensions. Regions and cities thus need to design and articulate a "well-being strategy" around three building blocks: 
1. Developing a regional well-being metric that captures people's daily experience: Embracing individual and territorial characteristics, through both material and non-material dimensions of wellbeing, focusing on outcomes rather than inputs or outputs, taking into consideration the distribution of well-being across territories and across different groups, and assessing regional sustainability and resilience over time.

2. Exploiting complementarities across different dimensions of well-being: Clarifying responsibilities across and within different levels of government and different groups of stakeholders, increasing co-ordination among policies and managing possible trade-offs while maximising synergies.

3. Encouraging citizens to adapt well-being measurement to their needs: Mobilising citizens in an early and continuous participative process to collectively identify the dimensions that matter most to the community, provide input for prioritising policy interventions and monitor progress towards the anticipated results, thereby increasing the legitimacy and effectiveness of the regional wellbeing strategy.

The successful design and implementation of regional well-being strategies based on these building blocks depends on a sequential process within a cycle of continuous information exchange, consultation and participation among different stakeholders (Figure 6.3).

\section{Figure 6.3. Regional well-being measurement cycle: A possible sequencing of steps}

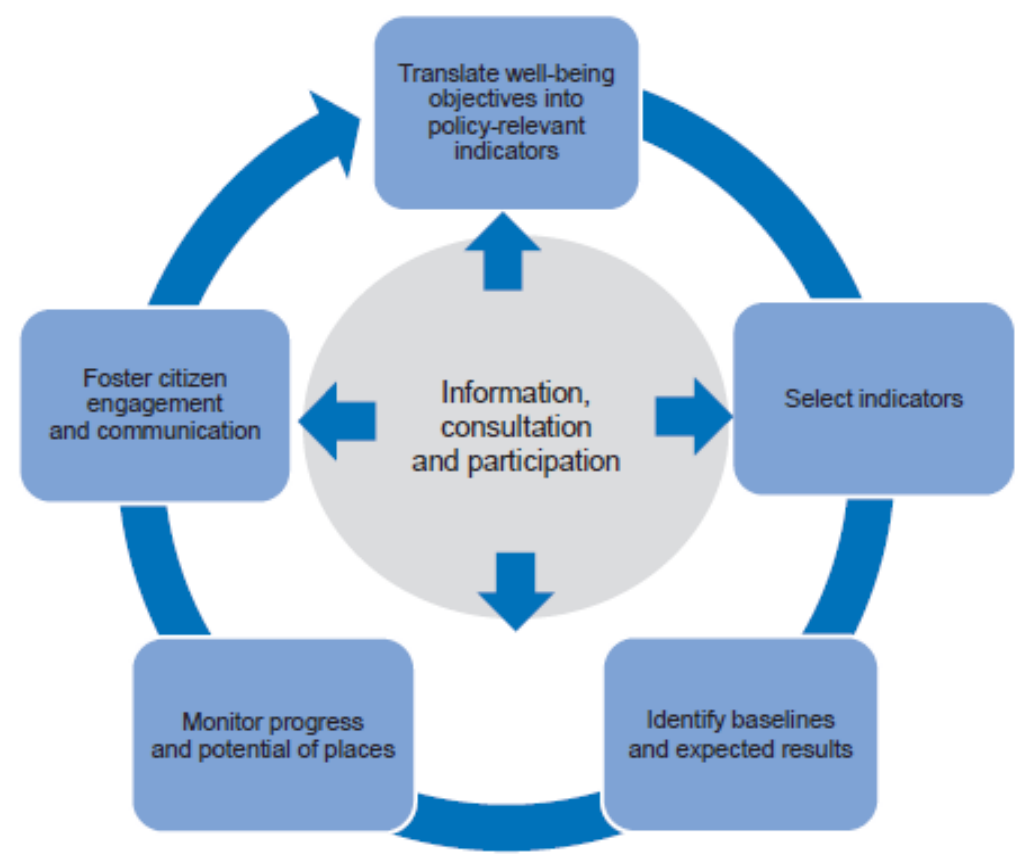

Source: OECD (2018c), "OECD Experience on Pursuing Inclusive Growth in Regions in industrial transition", Scoping Paper for Peer Learning Workshop, Tällberg, 28-29 June, OECD, Paris, Unpublished.

Southern Denmark's experience exemplifies many of the key points highlighted in the OECD's work on regional well-being and illustrates how ensuring citizen well-being can be a driving force in a region's development policy (Box 6.4). 


\section{Box 6.4. Making well-being an integral part of a region's development policy in Southern} Denmark

The Southern Denmark Regional Council's regional growth and development strategy seeks to create the necessary conditions for a "good life", with well-being as its guiding principle. The strategy lays out three aspirations for the region - to be active, attractive and productive - and six "paths" to guide regional projects and initiatives: knowledge, people with potential, business development, green opportunities, vibrant urban regions and strong connections. To implement the strategy, partnerships with all levels of government were vital. Three formal agreements were signed in order to facilitate collaboration and support implementation: i) a political agreement on central matters (qualified labour force, good life locally, city/region development and work across borders in city regions); ii) city-region development agreements to support area-specific challenges and opportunities; and iii) a political co-ordination committee to ensure co-ordinated regional and municipal strategies.

Source: Lundström, J. (2018), "Measuring Good Life in Southern Denmark: Using Well-being Indicators for Policy-Making", PowerPoint Presentation for the Peer Learning in Regions in Industrial Transition Workshop "Inclusive Growth", 28-29 June 2018, Tällberg, Sweden, Unpublished.

\section{Overcoming regional disparities through territorial linkages}

How economic activity spreads within and across neighbouring areas is an important aspect of inclusive growth for regions in industrial transition. Large gaps in economic activity can lead to significant variety in income per capita, productivity and prosperity. Large cities are often at the core of spatial disparities as they are, on average, more productive and prosperous than other types of areas. There are a number of ways to make the most of such linkages, including territorial co-operation and ensuring digital connectivity (Table 6.2).

\section{Table 6.2. Territorial linkages: Policy issues, instruments and rationales}

\begin{tabular}{|c|c|c|c|}
\hline Policy issue & Policy response & $\begin{array}{l}\text { Potential suite of implementation } \\
\text { mechanism }\end{array}$ & Rationale/additional benefits \\
\hline \multirow[t]{3}{*}{$\begin{array}{l}\text { Spatial discrepancies and } \\
\text { territorial linkages }\end{array}$} & \multirow[t]{2}{*}{$\begin{array}{l}\text { Encourage territorial } \\
\text { co-operation through rural- } \\
\text { urban partnerships }\end{array}$} & \multirow{2}{*}{$\begin{array}{l}\text { - Infrastructure (road networks, trains) } \\
\text { - Supply chains (e.g. agro-industry), } \\
\text { links between small- and medium- } \\
\text { sized enterprises (SMEs) and } \\
\text { universities and/or research centres }\end{array}$} & $\begin{array}{l}\text { Utilises urban/rural complementarities } \\
\text { and supports regional development }\end{array}$ \\
\hline & & & $\begin{array}{l}\text { Extends the benefits of agglomeration } \\
\text { economies/increases GDP }\end{array}$ \\
\hline & $\begin{array}{l}\text { Ensure digital connectivity } \\
\text { and digital services in } \\
\text { remote regions }\end{array}$ & $\begin{array}{l}\text { - Information and communication } \\
\text { technology (ICT) investments, virtual } \\
\text { delivery of public services in rural } \\
\text { areas }\end{array}$ & $\begin{array}{l}\text { Stimulates investments in digital } \\
\text { technologies }\end{array}$ \\
\hline
\end{tabular}

\section{Linking areas to capitalise on agglomeration economies}

Supporting co-operation between different types of areas within a region can help support the development of its lagging areas. For example, rural areas have a series of resources that are also essential for urban areas, including natural resources (agricultural products, water or sources of renewable energies), greenfield spaces (to establish new economic activities and accommodate pressure from urbanisation), ecosystem services (e.g. air quality, waste disposal, preservation of biodiversity, etc.) and rural amenities 
for residential and recreational purposes. Furthermore, low-density areas - well connected to urban ones - can be an appropriate environment for locating manufacturing (Glaeser and Kohlhase, 2004).

Public infrastructure linking more distant areas to cities is one tool that can help areas further away from an urban centre "borrow" a city's agglomeration economy and the impact can be significant. In Germany, medium-sized towns that received new stops on the high-speed rail route between Cologne and Frankfurt significantly benefitted from access to those two large cities (Ahlfeldt and Feddersen, 2018). The improved accessibility led to an increase in GDP of approximately $8.5 \%$ and raised labour productivity by $3.8 \%$ within 6 years in counties where an intermediate stop on the rail connection was opened. In addition, smaller cities can also "borrow" agglomeration from neighbouring cities: for a doubling of the population living at a given distance in urban agglomerations within a 300-kilometre radius around a city, the productivity of the city in the centre increases by $1 \%-1.5 \%$ (Ahrend et al., 2017).

\section{Enhancing rural-urban linkages}

As engines of economic development, urban areas concentrate resources relevant for the liveability and the prosperity of rural and remote areas such as universities, most jobs in advanced services and capital flows, as well as financial institutions. Furthermore, urban areas offer large markets, benefit from agglomeration economies and concentrate political and administrative capacity (OECD, 2015a). Appropriate partnerships between urban and rural areas help rural and remote areas access urban benefits (Table 6.3). They can also help regions in industrial transition boost competitiveness in remote areas while also addressing policy challenges such as depopulation and declining access to basic services.

\section{Table 6.3. Policy challenges addressed by rural-urban partnerships by type of urban-rural interaction}

\begin{tabular}{|c|c|c|c|c|}
\hline $\begin{array}{c}\text { Type of urban-rural } \\
\text { linkage }\end{array}$ & Subtype & $\begin{array}{l}\text { Possible purposes of } \\
\text { urban-rural partnership }\end{array}$ & Challenges & Observed examples \\
\hline \multirow[t]{2}{*}{$\begin{array}{l}\text { Economic transactions } \\
\text { and innovation activity }\end{array}$} & Productive relations & $\begin{array}{l}\text { Fostering supply chains } \\
\text { (e.g. agro-industry) }\end{array}$ & $\begin{array}{l}\text { Boosting activities with a } \\
\text { high territorial multiplier }\end{array}$ & Forli-Cesena (Italy) \\
\hline & $\begin{array}{l}\text { Knowledge diffusion and } \\
\text { innovation links }\end{array}$ & $\begin{array}{l}\text { Fostering links between } \\
\text { SMEs and universities } \\
\text { and research centres }\end{array}$ & $\begin{array}{l}\text { Boosting competitiveness } \\
\text { in remote areas }\end{array}$ & $\begin{array}{l}\text { Forli-Cesena (Italy) } \\
\text { Nuremberg (Germany) }\end{array}$ \\
\hline \multirow[t]{2}{*}{ Public service delivery } & $\begin{array}{l}\text { Public service (education, } \\
\text { health, waste, etc.) }\end{array}$ & $\begin{array}{l}\text { Developing information } \\
\text { and communication } \\
\text { technology (ICT) } \\
\text { infrastructure for service } \\
\text { provision }\end{array}$ & $\begin{array}{l}\text { Ensuring access to basic } \\
\text { services and combating } \\
\text { depopulation in remote } \\
\text { areas }\end{array}$ & Central Finland (Finland) \\
\hline & Public transport & $\begin{array}{l}\text { Co-ordinating investments } \\
\text { in transport within } \\
\text { functional areas }\end{array}$ & $\begin{array}{l}\text { Ensuring access to both } \\
\text { urban and rural resources }\end{array}$ & $\begin{array}{l}\text { Nuremberg (Germany) } \\
\text { Rennes (France) }\end{array}$ \\
\hline \multirow[t]{2}{*}{$\begin{array}{l}\text { Other "governance" } \\
\text { interactions }\end{array}$} & Joint planning & $\begin{array}{l}\text { Setting a common } \\
\text { development plan }\end{array}$ & $\begin{array}{l}\text { Improving the efficiency of } \\
\text { public policy }\end{array}$ & $\begin{array}{l}\text { Geelong (Australia) } \\
\text { Rennes (France) }\end{array}$ \\
\hline & $\begin{array}{l}\text { Co-ordination among local } \\
\text { authorities }\end{array}$ & $\begin{array}{l}\text { Building a common voice } \\
\text { in dealing with higher } \\
\text { government }\end{array}$ & $\begin{array}{l}\text { Increasing political } \\
\text { relevance and access } \\
\text { to funds }\end{array}$ & $\begin{array}{l}\text { Geelong (Australia) } \\
\text { Brabant (Netherlands) }\end{array}$ \\
\hline
\end{tabular}

Source: Adapted from OECD (2018c), "OECD Experience on Pursuing Inclusive Growth in Regions in industrial transition", Scoping Paper for Peer Learning Workshop, Tällberg, 28-29 June, OECD, Paris, Unpublished. 


\section{Supporting digital connectivity and rural and remote businesses}

Fully utilising the potential arising from the complementarity of urban and rural areas is mutually beneficial - exploiting untapped economic potential and raising productivity. For regions in industrial transition, ensuring digital connectivity and digital services in order to reduce the cost of services linked to distance or remoteness and to connect rural businesses is important for two reasons. First, it can better ensure equitable access to public service in rural or remote areas. For example, digitising health and welfare provision can help overcome connectivity challenges by "virtual" delivery of healthcare. This makes healthcare more accessible and improves citizen health and wellness outcomes. Second, digitalisation also supports rural and remote businesses. In rural and remote areas, entrepreneurship often suffers from low connectivity to clients and the financial support provided in cities. Better digital connectivity combined with dedicated support to local entrepreneurship supports business creation and growth, thereby reducing inequalities in productivity and well-being.

\section{Strengthening coherence in inclusive growth governance}

Tackling regional problems that inhibit inclusive growth and affect well-being requires comprehensive approaches. This is particularly important given the complexity associated with inclusion, exclusion and well-being. In many cases, challenges transcend sectors and require input from a variety of actors with diverse competencies, including different levels of government, the private sector, community organisations and social service providers. For regions in industrial transition, an inclusive approach to development is important to make sure that everyone gains from the creation of new industries and new ways of working. Taking a strategic approach to inclusive growth means integrating inclusiveness into broader development strategies, co-ordinating diverse sectors and actors and building engagement among all relevant stakeholders (Table 6.4).

\section{Table 6.4. Inclusive growth governance: Policy issues, instruments and rationales}

\begin{tabular}{l|l|l|l}
\hline \multicolumn{1}{c|}{ Policy issue } & \multicolumn{1}{|c|}{ Policy response } & $\begin{array}{c}\text { Potential suite of implementation } \\
\text { mechanism }\end{array}$ & Rationale/additional benefits \\
\hline \begin{tabular}{l|l|l} 
Improving inclusive growth \\
governance
\end{tabular} & $\begin{array}{l}\text { Build strategic partnerships } \\
\text { and stakeholder } \\
\text { engagement }\end{array}$ & $\begin{array}{l}\text { - Multi-level partnerships, political } \\
\text { co-ordination committees, local } \\
\text { working groups, collaborative open } \\
\text { networks, platforms and agencies }\end{array}$ & Fosters stakeholder engagement \\
\cline { 2 - 4 } & $\begin{array}{l}\text { Make inclusive growth an } \\
\text { explicit goal across levels } \\
\text { of government }\end{array}$ & $\begin{array}{l}\text { - Formal and non-formal co-operation } \\
\text { mechanisms, working groups, } \\
\text { guidelines }\end{array}$ & $\begin{array}{l}\text { Stimulates investments in green } \\
\text { technologies }\end{array}$ \\
\hline
\end{tabular}

\section{Taking a strategic approach to inclusive growth}

There is no "one" or "best" way to build inclusiveness. Inclusive growth can be generated through labour market integration programmes, addressing gender bias, building social innovation, sponsoring programmes to help families in underprivileged areas, and promoting digitisation in remote and rural areas. Supporting inclusive growth requires parallel action across a diverse set of policy areas (e.g. labour market, education, skills and infrastructure). In addition, inclusive growth requires an integrated, comprehensive and strategic approach, one that ensures coherence in the implementation of policies and programming across relevant sectors. One way to accomplish this is by introducing or designating an entity responsible for ensuring a joined-up approach to building inclusiveness. For example, in Greater Manchester, the University of Manchester, and the Joseph Rowntree Foundation created an Inclusive Growth Analysis Unit within the University to act as a source of data and analysis to support City policy, as well as to suggest 
synergies and further enable coherence among the multiple policy areas that promote greater well-being and inclusiveness (Box 6.5).

\section{Box 6.5. Research meets policy and practice in Greater Manchester}

The Joseph Rowntree Foundation (JRF) has been working on the relationship between economic growth and poverty for some time. The Inclusive Growth Analysis Unit was initially set up within the Manchester Urban Institute, and co-funded by the Faculty of Humanities, University of Manchester and JRF in 2016 to promote and further develop work on inclusive growth. The aim was to apply academic and research analysis to support place-practice; and to support stakeholders to achieve their goals, and learn from each other.

A core part of the initial work was an Inclusive Growth Monitor which enables comparisons across different parts of the UK. JRF chose Greater Manchester because of the scale of the challenges, devolution of powers from central government, which enables new ways of doing things, as well as local capabilities. Despite recent high growth rates, there remain relatively low wages and low productivity across the region, as well as within particular sectors; high levels of in-work poverty as insecure jobs. For the University of Manchester, it very much fitted with its desire to do work which benefitted the cityregion, and particularly linked with one of its themes of inequalities.

The IGAU has had successes in helping ensure inclusive growth is at the heart of Greater Manchester's economic strategies, bringing stakeholders together across the region as a trusted broker, and supporting the development of the Greater Manchester Good Employment Charter, as well as Local Industrial Strategy. It convenes stakeholders; influences and supports key policy and practice actors; monitors, spotlights people and places in poverty; as well as researching policy and practice to fill local evidence gaps.

Source: OECD (2018f), PowerPoint Presentations for the Peer Learning in Regions in industrial transition Workshops: Inclusive Growth, 2223 October, Joensuu, Finland, Unpublished.

\section{Social innovation as a catalyst for inclusive growth}

Social innovation seeks to address pressing social challenges and meet social needs in an innovative way while serving the general interest and common good of the community. Social innovation plays an important role in addressing social, economic and environmental challenges while fostering inclusive growth, shared prosperity and social inclusion. Moreover, social innovation contributes to job creation, democratic participation and improved welfare service delivery. Regions in industrial transition have a strong interest in supporting social innovation as a means to successfully manage transition. However, many entrepreneurs interested in social innovation lack the business knowledge needed to succeed. Investing in business support helps potential social entrepreneurs in the early phases of business development, as seen in France's regions of Centre-Val de Loire and Grand Est (Box 6.6).

\section{Box 6.6. Social Innovation in Centre-Val de Loire and Grand Est}

\section{A regional incubator for social innovation in Centre-Val de Loire - Alter'Incub}

Benefitting from EUR 500000 per year, the Alter'Incub initiative seeks to align economic development with social and territorial impact. Its objective is to strengthen the social economy ecosystem and social innovation within the region. By applying the same level of requirements as technology incubators, 
Alter'Incub seeks to ensure that the businesses created are economically viable. A two-phased approach is used with jury selection at the end of phase one:

- Phase 1: 3-month "pre-incubation", evaluation phase of the project feasibility, individual support/ $360^{\circ}$ evaluation (external study)/collective meetings programme.

- Phase 2: 12-month incubation - customised support for projects with a favourable opinion from the jury, individual support/support to external expert assessment/collective meetings programme.

The individual support programme offers monthly appointments to monitor the project development as well as technical and methodological support, expert input on social innovation, legal issues and market feasibility, demonstration and proof of concept, finance and networking. Projects with the potential of creating at least two new jobs from the outset are supported at the end of Phase 2.

\section{The social economy in Grand Est as a pillar of regional development}

Grand Est is home to 15000 socially innovative businesses (associations, co-operatives, social enterprises), employing 200000 workers and providing EUR 4.1 billion in yearly salaries. Regional funding in 2018 amounted to just over EUR 1 million to support 405 social economy organisations. Focus is placed on social and labour market integration by targeting long-term unemployed people at risk of social exclusion. Organisations promote social insertion through economic activity, offering training and support.

By aligning strategies for the environment, training, skills and economic development, the Région Grand Est creates territorial alliances to develop the competitiveness and economic attractiveness of the region. An important instrument to implement the regional strategy for economic development, innovation and internationalisation (SRDEII) are the Offensive Growth and Employment Pacts (in French "POCE"). They facilitate a strong partnership for dialogue and action between the region and voluntary groups of municipalities. This territorial approach includes new innovative projects in the fields of social economy and social inclusiveness. Examples of local initiatives include recycling under the slogan "your waste becomes my product", new links between rural and urban zones by the means of a public school restoration project or the concept of an "inclusive city".

Source: OECD (2018f), PowerPoint Presentations for the Peer Learning in Regions in industrial transition Workshops: Inclusive Growth, 2223 October, Joensuu, Finland, Unpublished.

\section{Vertical and horizontal co-ordination}

Many inclusive growth initiatives require a co-ordinated approach to their design, financing and implementation. The challenge is to ensure that priorities align among the different actors - especially levels of government - and that responsibilities are clearly assigned and understood. The exact approach will differ for each region as local labour markets exhibit considerable diversity in terms of industrial structure and employment opportunities. An inclusive growth strategy is likely best designed with a placebased approach wherein structural policies aimed at social inclusion, such as housing and transport, are integrated with policies that can positively affect the region's productivity and growth, such as education, skills and connectivity.

Success depends not only on ensuring coherence and on building co-ordination; it also depends on actively engaging with a variety of stakeholders - from the private sector to the third sector - in order to identify needs and priorities, and ideally, co-design, co-produce and co-deliver services. While challenging, this is not impossible, and both Piemonte and Saxony offer examples of a co-ordinated strategy to support inclusive growth (Box 6.7). 


\section{Box 6.7. A co-ordinated approach to greater inclusiveness in Piemonte and Saxony}

\section{A strategy for inner areas in Piemonte}

Piemonte's "Strategy for Inner Areas" - embedded in Italy's National Strategy for Inner Areas - aims to address the economic and demographic decline of peripheral area by taking a co-ordinated approach to the provision of key public services, such as healthcare, education, transport/accessibility, and by basing development on local resources. The strategy is supported by two pillars: i) improving public services which will be funded by national resources; ii) targeted local development, that will be funded through different European Structural Investment Funds (specifically ERDF, EARDF and ESF). The initiative brings together the national, regional and local governments, as well as private actors for a bottom-up consultation process that assesses programmes and guides further development. Among the challenges are multi-level governance, co-ordination of actors and priorities, and leadership at the local level (i.e. the capacity of local communities to guide the local development process and build ownership of a common development vision among local stakeholders). An additional challenge is ensuring continuity in policy and funding. The strategy is just getting underway and given its complexity, results will require implementation past the current EU programming period (to 2020).

\section{Multi-level, multi-agency initiative to support youth employment in Saxony}

Saxony's "We Need All Talents" initiative aims to improve the school-education-occupation transition, prevent drop-out and youth unemployment, and help youth overcome personal crises. The initiative does not call for a new authority or agency, but rather focuses on an improved co-operation structure among existing relevant authorities and their assistance systems, in order to offer co-ordinated consultation and joint case management as one-stop-agencies. The Youth Employment Agency would combine: youth services associated with the Youth Welfare Office; employment support (for long-term unemployed) and case management associated with job centres; career guidance, training placement measures and employment agency services (for short-term unemployed); schools providing professional orientation and school social work. This is a good example of taking a well-being, systemic approach to addressing youth unemployment as a means to build greater inclusiveness in the region. Based on a 2018 agreement between the Free State of Saxony, the Association of Saxon Cities, the Saxon County Association and the Federal Employment Agency, it also highlights the importance of multi-stakeholder co-operation to support inclusiveness and promote well-being.

Sources: Piemonte (2018), "Peer Learning in Regions in industrial transition Workshops Prospective Initiative Template, Strategy for 'Inner Areas"', Prepared for the Peer Learning in Regions in Industrial Transition Workshop "Inclusive Growth", 28-29 June, 2018, Tällberg, Sweden, Unpublished; Saxony (2018), "Saxony", PowerPoint Presentation for the Peer Learning in Regions in Industrial Transition Workshop "Inclusive Growth", 28-29 June 2018, Tällberg, Sweden, Unpublished.

Policy outcomes, however, take time to see and require commitment and effort from all stakeholders. Ensuring sufficient time for consultation and, ideally, collaboration in programme design and delivery is critical. Strong and effective partnerships can take time to build but are also fundamental to policy acceptance and continuity, as well as weathering the changes and shifting priorities that can come with election cycles. 


\section{Key considerations and conclusions}

\section{Industrial transition is only successful when everyone benefits from sustained growth}

A focus on productivity growth is necessary by regions in industrial transition but may not be sufficient for achieving a fully successful transition. Unintended social consequences arising from transition, for example through job losses in old industries, need to be taken into account by policymakers. A range of policy measures is available to regions in industrial transition so they can ensure that those who may lose out from economic change are able to adapt to new economic conditions and begin breaking a cycle of disadvantage.

\section{Trade-offs between growth and inclusion will inevitably arise and need mitigation}

Further efforts are needed to deal with trade-offs when implementing policies for inclusive growth in regions in industrial transition. Some policies cannot be strictly classified as pro-inclusive growth. This is true of initiatives aimed at stimulating innovation and technological progress, for example. Such policies are fundamental to spur productivity growth but may put pressure on the relative demand for skilled workers through skill-biased technological change, thereby leaving the low-skilled workers behind. Policymakers in regions in industrial transition need to ensure that innovation and labour market policies are well co-ordinated in order to avoid widening skills and income gaps.

\section{Inclusive labour markets can yield widespread benefits when policies are appropriately designed}

Regions in industrial transition can face large differences in employment rates across socio-economic groups, with particularly low rates among youth, women, older people and low-skilled individuals. Policies that facilitate access to quality jobs simultaneously promote growth and reduce inequality. As a part of a policy programme for increasing job quality, measures to improve employment prospects include effective counselling, job-search assistance and temporary hiring subsidies for the low skilled. However, such active labour market policies represent a potential burden on regional government budgets and their effectiveness varies widely across programmes. This suggests that programme design is critical and that regions in industrial transition can learn a great deal from the experience of other regions that have gone through a similar experience.

\section{Successful transition means investing in places left behind}

Economic and social inequalities have a spatial dimension. Inequalities within regions result mainly from differences in growth rates and the policy response is to search for ways to unlock growth potential. Designing policies that target spatial inequalities requires that policymakers consider complementarities in their different objectives and the channels to fulfil these. Addressing income inequalities includes going beyond traditional transfers to households - targeting people - and should incorporate mechanisms aimed at ensuring equity in the provision of public goods and services - targeting places.

\section{Managing an inclusive transition requires embedding inclusiveness in policymaking}

Building more inclusive growth in regions in industrial transition rests on the potential to change or adjust how policies are designed and implemented. Concerns over the undue influence of vested interests, which may be associated with influential and traditionally dominant industries, need to be overcome through transparent policymaking, the inclusion of all relevant stakeholders and accountability. Engaging stakeholders through information sharing, consultation and participation, as well as active and clear communication, are fundamental to successful regional inclusive growth strategies. 


\section{References}

Ahlfeldt, G. and A. Feddersen (2018), "From periphery to core: Measuring agglomeration effects using high-speed rail”, Journal of Economic Geography, Vol. 18/2,1, pp. 355-390.

Ahrend, R. and A. Lembcke (2016), "Does It Pay to Live in Big(ger) Cities?: The Role of Agglomeration Benefits, Local Amenities, and Costs of Living", OECD Regional Development Working Papers, No. 2016/9, OECD Publishing, Paris, http://dx.doi.org/10.1787/e0490ba8-en.

Ahrend, R. et al. (2017), "What makes cities more productive? Agglomeration economies and the role of urban governance: Evidence from 5 OECD countries", OECD Productivity Working Papers, Vol. 2017/6, OECD Publishing, Paris.

Breemersch, K., J. Damijan and J. Konings (2017), "Labour Market Polarization in Advanced Countries: Impact of Global Value Chains, Technology, Import Competition from China and Labour Market Institutions", OECD Social, Employment and Migration Working Papers, No. 197, OECD Publishing, Paris, https://doi.org/10.1787/06804863-en.

Lundström, J. (2018), "Measuring Good Life in Southern Denmark: Using Well-being Indicators for Policy-Making", PowerPoint Presentation for the Peer Learning in Regions in Industrial Transition Workshop "Inclusive Growth", 28-29 June 2018, Tällberg, Sweden, Unpublished.

Martikainen, P. and T. Valkonen (1996), "Excess mortality of unemployed men and women during a period of rapidly increasing unemployment", The Lancet, Vol. 348/9032, pp. 909-912.

North Middle Sweden (2018), "North Middle Sweden", PowerPoint Presentation for the Peer Learning in Regions in Industrial Transition Workshop “Inclusive Growth”, 28-29 June 2018, Tällberg, Sweden, Unpublished.

OECD (2018a), OECD Employment Outlook 2018, OECD Publishing, Paris https://doi.org/10.1787/empl outlook-2018-en.

OECD (2018b), OECD Regions and Cities at a Glance 2018, OECD Publishing, Paris, https://doi.org/10.1787/reg cit glance-2018-en.

OECD (2018c), "OECD Experience on Pursuing Inclusive Growth in Regions in industrial transition", Scoping Paper for Peer Learning Workshop, Tällberg, 28-29 June, OECD, Paris, Unpublished.

OECD (2018d), OECD Regional Statistics (database), http://dx.doi.org/10.1787/region-data-en.

OECD (2018e), "Peer Learning in Regions in industrial transition Workshops: Inclusive Growth", Proceedings Paper for Peer Learning Workshop 5 "Inclusive Growth", OECD, Paris, Unpublished.

OECD (2018f), PowerPoint Presentations for the Peer Learning in Regions in industrial transition Workshops: Inclusive Growth, 22-23 October, Joensuu, Finland, Unpublished.

OECD (2017), The Pursuit of Gender Equality: An Uphill Battle, OECD Publishing, Paris https://doi.org/10.1787/9789264281318-en.

OECD (2015a), The Metropolitan Century: Understanding Urbanisation and its Consequences, OECD Publishing, Paris, https://doi.org/10.1787/9789264228733-en.

OECD (2015b), How's Life? 2015: Measuring Well-being, OECD Publishing, Paris, https://doi.org/10.1787/how life-2015-en.

OECD (2014), How's Life in Your Region?: Measuring Regional and Local Well-being for Policy Making, OECD Publishing, Paris, https://doi.org/10.1787/9789264217416-en.

Piemonte (2018), "Peer Learning in Regions in industrial transition Workshops Prospective Initiative Template, Strategy for 'Inner Areas'”, Prepared for the Peer Learning in Regions in Industrial Transition Workshop "Inclusive Growth", 28-29 June, 2018, Tällberg, Sweden, Unpublished

Saxony (2018), "Saxony", PowerPoint Presentation for the Peer Learning in Regions in Industrial Transition Workshop “Inclusive Growth”, 28-29 June 2018, Tällberg, Sweden, Unpublished. 
Strully, K.W. (2009), "Job loss and health in the US labor market”, Demography, Vol. 46/2, pp. 221-246. Veneri, P. and V. Ruiz (2016), "Urban-to-rural population growth linkages: Evidence from OECD TI3 regions", Journal of Regional Science, Vol. 56/1, pp. 3-24.

Wallonia (2018), "Peer Learning in Regions in industrial transition Workshops Good Practice Template", Self-employment Support Structures (SAACE), Prepared for the Peer Learning in Regions in Industrial Transition Workshop "Inclusive Growth", 28-29 June 2018, Tällberg, Sweden, Unpublished. 


\section{Annex 6.A. Overview of policy issues and responses in promoting inclusive growth}

Annex Table 6.A.1. Policy Issues, implementation mechanisms and rationales in promoting inclusive growth in regions in industrial transition

\begin{tabular}{|c|c|c|c|}
\hline Policy issue & Policy response & $\begin{array}{l}\text { Potential suite of implementation } \\
\text { mechanism }\end{array}$ & Rationale/additional benefits \\
\hline \multirow[t]{3}{*}{$\begin{array}{l}\text { Strengthening regional } \\
\text { well-being }\end{array}$} & \multirow{2}{*}{$\begin{array}{l}\text { Integrate vulnerable } \\
\text { populations into the labour } \\
\text { market }\end{array}$} & \multirow{2}{*}{$\begin{array}{l}\text { - Support disadvantaged groups } \\
\text { (long-term unemployed, women, } \\
\text { youth) through career guidance and } \\
\text { re-training schemes }\end{array}$} & $\begin{array}{l}\text { Generates inclusive employment } \\
\text { opportunities }\end{array}$ \\
\hline & & & Increases productivity \\
\hline & $\begin{array}{l}\text { Develop and implement a } \\
\text { regional-level well-being } \\
\text { framework }\end{array}$ & $\begin{array}{l}\text { - Development of regional measures } \\
\text { of material well-being and quality of } \\
\text { life } \\
\text { - Engaging in civil society and } \\
\text { academia to define well-being } \\
\text { measures }\end{array}$ & Greater well-being outcomes \\
\hline \multirow{3}{*}{$\begin{array}{l}\text { Addressing spatial } \\
\text { discrepancies and } \\
\text { territorial linkages }\end{array}$} & \multirow{2}{*}{$\begin{array}{l}\text { Encourage territorial } \\
\text { co-operation through rural- } \\
\text { urban partnerships }\end{array}$} & \multirow{2}{*}{$\begin{array}{l}\text { - Infrastructure (road networks, trains) } \\
\text { - Supply chains (e.g. agro-industry), } \\
\text { links between SMEs and universities } \\
\text { and/or research centres }\end{array}$} & $\begin{array}{l}\text { Utilises urban/rural complementarities } \\
\text { and supports regional development }\end{array}$ \\
\hline & & & $\begin{array}{l}\text { Extends the benefits of agglomeration } \\
\text { economies/increases GDP }\end{array}$ \\
\hline & $\begin{array}{l}\text { Ensure digital connectivity } \\
\text { and digital services in } \\
\text { remote regions }\end{array}$ & $\begin{array}{l}\text { - ICT investments, virtual delivery of } \\
\text { public services in rural areas }\end{array}$ & $\begin{array}{l}\text { Stimulates investments in digital } \\
\text { technologies }\end{array}$ \\
\hline \multirow{3}{*}{$\begin{array}{l}\text { Improving inclusive growth } \\
\text { governance }\end{array}$} & \multirow{2}{*}{$\begin{array}{l}\text { Build strategic partnerships } \\
\text { and stakeholder } \\
\text { engagement }\end{array}$} & \multirow{2}{*}{$\begin{array}{l}\text { - Multi-level partnerships, political } \\
\text { co-ordination committees, local } \\
\text { working groups, collaborative open } \\
\text { networks, platforms and agencies }\end{array}$} & Fosters stakeholder engagement \\
\hline & & & Increases efficiency \\
\hline & $\begin{array}{l}\text { Make inclusive growth an } \\
\text { explicit goal across levels } \\
\text { of government }\end{array}$ & $\begin{array}{l}\text { - Formal and non-formal co-operation } \\
\text { mechanisms, working groups, } \\
\text { guidelines }\end{array}$ & $\begin{array}{l}\text { Stimulates investments in green } \\
\text { technologies }\end{array}$ \\
\hline
\end{tabular}




\section{Annex A. Pilot Action on Regions in Industrial Transition: The peer-learning exercise}

As the first step of the European Commission's Pilot Action on Regions in Industrial Transition, throughout the course of 2018, the European Commission's DG REGIO and the OECD organised a series of peerlearning workshops. These workshops aimed to help regions undergoing industrial transition develop new approaches to revive their productivity and growth by considering new or different policy tools.

The first phase of the pilot action focused on the analysis of existing and proposed policy instruments and on identifying future challenges. Following a call for participation by the European Commission, ten regions and two countries participated in the peer-learning exercise: Cantabria (SP), Centre-Val de Loire (FR), East and North Finland (FI), Grand Est (FR), Greater Manchester (UK), Hauts-de-France (FR), North Middle Sweden (SE), Piemonte (IT), Saxony (DE), Wallonia (BE), and two countries, Lithuania and Slovenia. Many of the examples and insights in this report come from the discussions, findings and conclusions derived from the peer-learning workshops.

The peer-learning workshops were designed to generate dialogue and exchange among participants in order to better consider the distinct factors that can contribute to the next generation of regional innovation strategies. The workshops promoted mutual learning and sharing of best practices in policy design, implementation and monitoring. During the workshops, the participating regions and countries discussed among each other and with the EU and OECD lessons and policy conclusions that can be drawn on how to best address industrial transition.

The five topics discussed during the workshop series all represent specific obstacles to growth in regions facing industrial transition. The topics discussed included:

- Preparing for the jobs of the future: Building on existing industrial specialisations and workforce skills.

- Broadening and diffusing innovation: Exploring new ways to support education and capital investment.

- Transition to a climate-neutral economy: Ensuring the transition of regions to a low-carbon economy.

- Promoting entrepreneurship and mobilising the private sector: Promoting entrepreneurship and lifelong learning.

- Inclusive growth: Encouraging inclusive growth addressing socio-economic inequalities.

These topics are highly inter-connected and policymakers may face challenges aligning the diverse policy objectives they represent. Ensuring coherence in the overall policy mix, a functioning regional innovation system and appropriate governance structures were therefore critical factors that were discussed across all workshops.

The core group of workshop participants was composed of representatives from each region in charge of innovation-led regional development policies. In addition, participating regions extended the workshop invitation to regional experts on the respective workshop theme. Each workshop began with a session providing analytical insights from the OECD on the workshop theme, followed by an exchange of regional 
practices and experiences. A number of insights on how to address industrial transition were derived from undertaking a policy option canvas and a policy priority canvas in each workshop (Box A A.1).

\section{Box A A.1. Policy option canvas and policy priority canvas}

Each of the ten peer-learning workshops carried out in the context of the project was split into three sessions: i) setting the scene; ii) sharing regional experiences; and iii) a strategy workshop. The strategy session was an opportunity for all participants to map the current policy landscape for the workshop's respective policy theme and to discuss the effectiveness and impact of the existing policy instruments. The exercise took place in two stages, a policy option canvas and a policy priority canvas.

The policy option canvas provided insights into whether current instruments existing in each participating region were sufficient to address the policy challenge at stake (e.g. broadening innovation) and whether the partnerships in place had sufficient ability to make use of these type of instruments. To complete the policy priority canvas, the participating regions considered the impact of selected policy instruments on the chosen policy objectives as well as the degree to which the region can influence the design and/or implementation of the instrument.

The policy option canvas and policy priority canvas stimulated an important reflection process on how to better leverage existing policy instruments for industrial transition and brought a number of insights for participating regions. It also revealed differences in the regions' perceptions of how much influence regional governments should have on policies. 


\section{ORGANISATION FOR ECONOMIC CO-OPERATION AND DEVELOPMENT}

The OECD is a unique forum where governments work together to address the economic, social and environmental challenges of globalisation. The OECD is also at the forefront of efforts to understand and to help governments respond to new developments and concerns, such as corporate governance, the information economy and the challenges of an ageing population. The Organisation provides a setting where governments can compare policy experiences, seek answers to common problems, identify good practice and work to co-ordinate domestic and international policies.

The OECD member countries are: Australia, Austria, Belgium, Canada, Chile, the Czech Republic, Denmark, Estonia, Finland, France, Germany, Greece, Hungary, Iceland, Ireland, Israel, Italy, Japan, Korea, Latvia, Lithuania, Luxembourg, Mexico, the Netherlands, New Zealand, Norway, Poland, Portugal, the Slovak Republic, Slovenia, Spain, Sweden, Switzerland, Turkey, the United Kingdom and the United States. The European Union takes part in the work of the OECD.

OECD Publishing disseminates widely the results of the Organisation's statistics gathering and research on economic, social and environmental issues, as well as the conventions, guidelines and standards agreed by its members. 


\section{Regions in Industrial Transition}

\section{POLICIES FOR PEOPLE AND PLACES}

This report offers guidance on how to manage industrial transition and is directed towards all policymakers seeking to improve the "what" and "how" of policies that promote industrial change. It identifies how regions in industrial transition can become more competitive and more resilient in the context of major shifts brought about by globalisation, decarbonisation and ongoing technological change. It takes stock of discussions emanating from a series of peer-learning workshops jointly organised in 2018 by the European Commission and the OECD. The report presents a number of implementation tools that policymakers have at their disposal to activate regional innovation potential to help tackle these challenges and the often accompanying ones such as an unsuitable skills base, unemployment due to deindustrialisation, and limited investment opportunities.

Bringing together economic analysis and regional and country practice from the participating regions and countries on the topics of the future of work, entrepreneurship, innovation, transitioning to a climate-neutral economy and inclusive growth, the report identifies cross-cutting lessons to help policy-makers better design the next generation of smart specialisation and regional innovation strategies.

Consult this publication on line at https://doi.org/10.1787/c76ec2a1-en.

This work is published on the OECD iLibrary, which gathers all OECD books, periodicals and statistical databases. Visit www.oecd-ilibrary.org for more information.

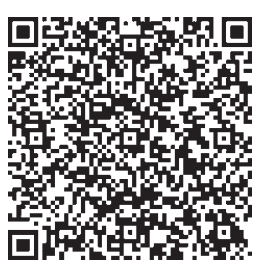

ISBN 978-92-64-80468-5
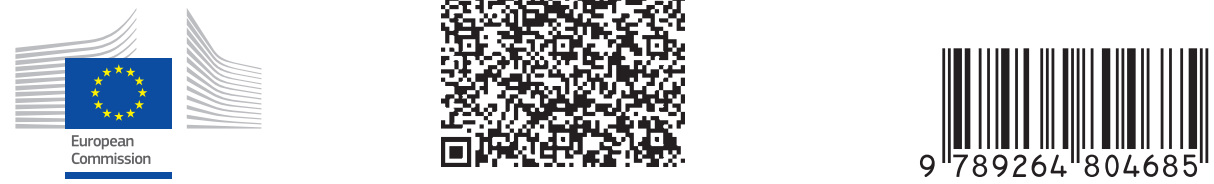